\title{
Pump and Fan Technology Characterization and R\&D Assessment
}

M. Guernsey, G. Chung, and W. Goetzler

October 2015 
(This page intentionally left blank) 


\section{NOTICE}

This report was prepared as an account of work sponsored by an agency of the United States Government. Neither the United States Government, nor any agency thereof, nor any of their employees, nor any of their contractors, subcontractors, or their employees, makes any warranty, express or implied, or assumes any legal liability or responsibility for the accuracy, completeness, or usefulness of any information, apparatus, product, or process disclosed, or represents that its use would not infringe privately owned rights. Reference herein to any specific commercial product, process, or service by trade name, trademark, manufacturer, or otherwise, does not necessarily constitute or imply its endorsement, recommendation, or favoring by the United States Government or any agency, contractor or subcontractor thereof. The views and opinions of authors expressed herein do not necessarily state or reflect those of the United States Government or any agency thereof.

Available electronically at www.osti.gov/home/ 


\title{
Preface
}

The Department of Energy's (DOE) Building Technology Office (BTO), a part of the Office of Energy Efficiency and Renewable Energy (EERE) engaged Navigant Consulting, Inc., (Navigant) to develop this report on energy efficiency opportunities and barriers for pumps and fans.

The initiatives identified in this report are Navigant's recommendations to DOE/BTO for pursuing in an effort to achieve DOE's energy efficiency goals. Inclusion in this report does not guarantee funding; water heating initiatives must be evaluated in the context of all potential activities that DOE/BTO could undertake to achieve their goals.

\section{Prepared for:}

U.S. Department of Energy

Office of Energy Efficiency and Renewable Energy

Building Technologies Office buildings.energy.gov

\section{Prepared by:}

Navigant Consulting, Inc.

77 South Bedford Street, Suite 400

Burlington, MA 01803

\author{
William Goetzler \\ Matt Guernsey \\ Greg Chung
}




\section{List of Acronyms}

\begin{tabular}{|c|c|}
\hline $\mathrm{A} / \mathrm{C}$ & Air-Conditioning \\
\hline $\mathrm{AC}$ & Alternating Current \\
\hline ACEEE & American Council for an Energy-Efficient Economy \\
\hline ACIM & Automatic Commercial Ice Maker \\
\hline AHU & Air Handling Unit \\
\hline BEP & Best Efficiency Point \\
\hline BI & Backward Inclined (centrifugal fan impeller) \\
\hline BLDC & Brushless DC Motors \\
\hline BMS & Building Management System \\
\hline BTO & Building Technologies Office (Department of Energy), DOE/BTO \\
\hline BVM & Beverage Vending Machine \\
\hline $\mathrm{CAC}$ & Central Air Conditioner \\
\hline $\mathrm{CAV}$ & Constant Air Volume \\
\hline $\mathrm{CCW}$ & Commercial Clothes Washer \\
\hline $\mathrm{CIF}$ & Commercial and Industrial Fans and Blowers - a DOE Rulemaking \\
\hline CIP & Commercial and Industrial Pumps - a DOE Rulemaking \\
\hline CRE & Commercial Refrigeration Equipment \\
\hline CUAC & Commercial Unitary Air Conditioning \\
\hline DOE & Department of Energy \\
\hline DOE/BTO & Department of Energy Building Technologies Office (part of EERE) \\
\hline $\mathrm{ECM}$ & Electronically Commutated Motor \\
\hline EIA & Energy Information Administration \\
\hline EPA & Environmental Protection Agency \\
\hline EERE & DOE's Office of Energy Efficiency and Renewable Energy \\
\hline EMS & Energy Management System \\
\hline EPCA & Energy Policy and Conservation Act of 2005 \\
\hline ESCC & End-Suction, Close-Coupled Pump \\
\hline ESFM & End-Suction, Frame-Mounted Pump \\
\hline $\mathrm{FC}$ & Forward Curved (centrifugal fan impeller) \\
\hline GHP & Geothermal Heat Pump (also known as ground-source heat pump, GSHP) \\
\hline HVAC & Heating, Ventilation, and Air-Conditioning \\
\hline HP & Heat Pump \\
\hline hp & horsepower \\
\hline HPWH & Heat Pump Water Heater \\
\hline IL & In-Line Pump \\
\hline LBNL & Lawrence Berkeley National Laboratory \\
\hline NOPR & Notice of Public Rulemaking \\
\hline PNNL & Pacific Northwest National Laboratory \\
\hline PTAC & Packaged Terminal Air Conditioner \\
\hline $\mathrm{R} \& \mathrm{D}$ & Research and Development \\
\hline RAC & Room Air Conditioner \\
\hline RSV & Radially Split, multi-stage Vertical in-line casing diffuser pump \\
\hline
\end{tabular}




\begin{tabular}{|ll|}
\hline SPVAC & Single Packaged Vertical Air Conditioner \\
\hline UEC & Unit Energy Consumption \\
\hline VAV & Variable Air Volume \\
\hline VSD & Variable Speed Drive \\
\hline VTS & Vertical Turbine Submersible pump \\
\hline WICF & Walk-in Coolers and Freezers \\
\hline
\end{tabular}




\section{Executive Summary}

The Building Technologies Office (BTO) within the Department of Energy's (DOE) Office of Energy Efficiency and Renewable Energy (EERE) works with researchers and industry to develop and deploy technologies that can substantially reduce energy consumption in residential and commercial buildings.

This report provides BTO and the research and development (R\&D) community with a technical and market analysis of pumps and fans as they pertain to commercial and residential buildings as well as key conclusions regarding the R\&D opportunities that can help achieve BTO's energy savings goals.

Our analysis found an annual technical savings potential of approximately 2.6 and 0.63 quads of primary energy for fans and pumps, respectively, assuming $100 \%$ adoption of best-in-class energy efficient technologies in the U.S. for the applicable installed base. We identified four $R \& D$ opportunity areas for fans and five R\&D opportunity areas for pumps that will help to achieve the identified savings potential, and therefore, BTO's energy savings goals. These key opportunities for R\&D are primarily focused on systems-level controls and technological improvements such as motors.

\section{Residential Building Summary}

In reviewing the existing equipment installed base, this study found that residential fans and pumps consume approximately 1.1 and 0.4 quads of primary energy, respectively, which is $7 \%$ of the total sector consumption (20.7 quads total). ${ }^{1}$ Fans are 3.5 times more common in residences in the U.S. (830 million in the U.S.), than pumps (240 million in the U.S.). Fans are common in most homes for use in HVAC, as well as being integrated into appliances (e.g., refrigerator or clothes dryer). Pump applications in residences are limited to just two appliances, dishwashers and clothes washers, and are only used in a small number of non-appliance applications in the U.S. The non-appliance pump applications, including wells, pools, hydronic space heating and domestic hot water recirculation, constitute less than 40 million total units.

${ }^{1}$ EIA. "Annual Energy Outlook 2014". Table A2. http://www.eia.gov/forecasts/aeo/ 
Figure ES-1 summarizes primary energy consumption for pumps and fans in the residential sector. $^{2}$
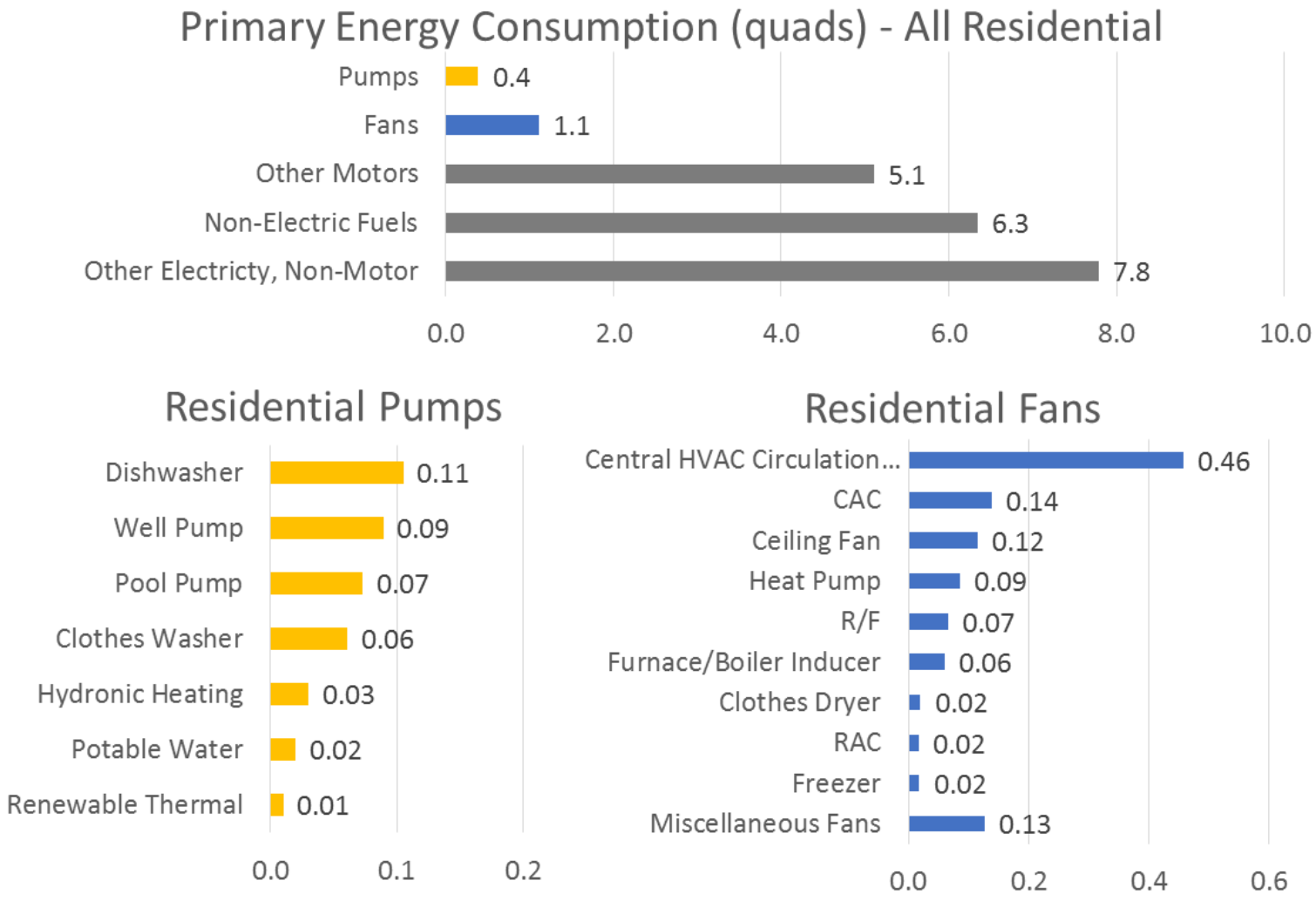

Figure ES-1: Residential Primary Energy Consumption Summary

Our analysis found an annual technical savings potential of $0.13(34 \%)$ and $0.9(81 \%)$ quads of primary energy for residential pumps and fans, respectively. This assumes $100 \%$ adoption of best-in-class energy efficient technologies in the U.S. for the applicable installed base. Figure ES-2 shows the savings potential breakdown by category for both pumps and fans.

The category of savings representing the largest opportunity in the residential sector is for motors and controls upgrades in fans. This comes from the upgrade to permanent magnet motors (e.g., electronically commutated motors, ECM) with advanced controls, representing 0.5 quads of primary energy savings. This category constitutes $50 \%$ of the total savings potential identified in this study for residences and 59\% of the savings potential identified for residential fans. Motors and controls improvements in pumps, by comparison, is only $12 \%$ of the total savings potential in this study for residences. However, pump motor and control improvements represent $85 \%$ of the savings potential in residential pumps, which highlights the fact that non-motor-based improvements are relatively significant for fans but not pumps.

\footnotetext{
${ }^{2}$ Assumes constant, nationwide site-to-primary energy conversion factor of 3.07 from the Energy Information Administration's Annual Energy Outlook 2014. http://www.eia.gov/forecasts/aeo/
} 

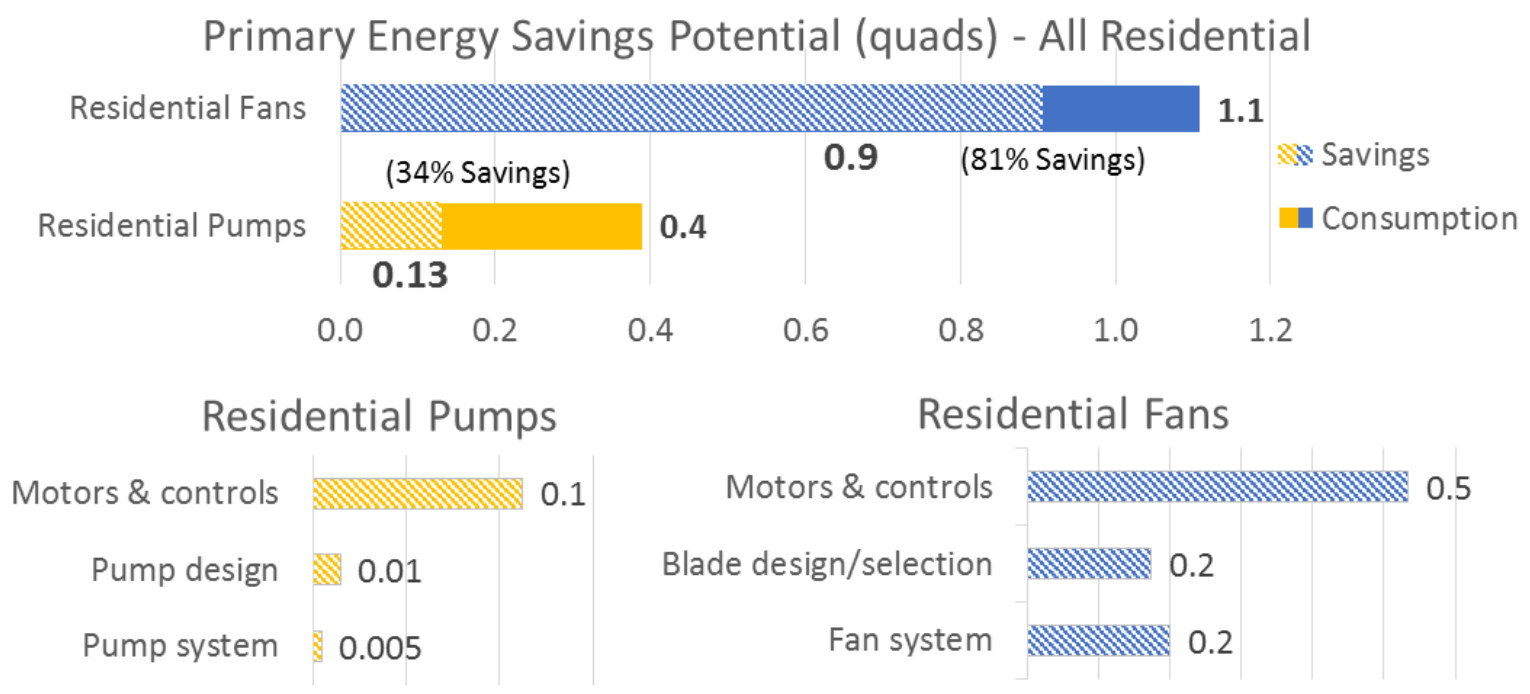

Figure ES-2: Residential Annual Primary Energy Technical Savings Potential (100\% Adoption)

\section{Commercial Building Summary}

In commercial buildings pumps and fans consume 0.63 and 2.4 quads of primary energy annually in the U.S., respectively, which is $8 \%$ of the sector total (17.8 quads total). ${ }^{3}$ Water pumping and HVAC pump applications are the largest end-use category of pumps $(0.53$ quads annually). Clean air ventilation dominates fan end-use consumption at 1.4 quads, more than 4 times greater than the next-largest end-use, commercial unitary air conditioner fans. In total, pumps and fans in HVAC applications consume 2.63 quads annually. Figure ES-3 summarizes primary energy consumption for pumps and fans in the commercial sector.

\footnotetext{
${ }^{3}$ EIA. "Annual Energy Outlook 2014". Tables A2. http://www.eia.gov/forecasts/aeo/
} 

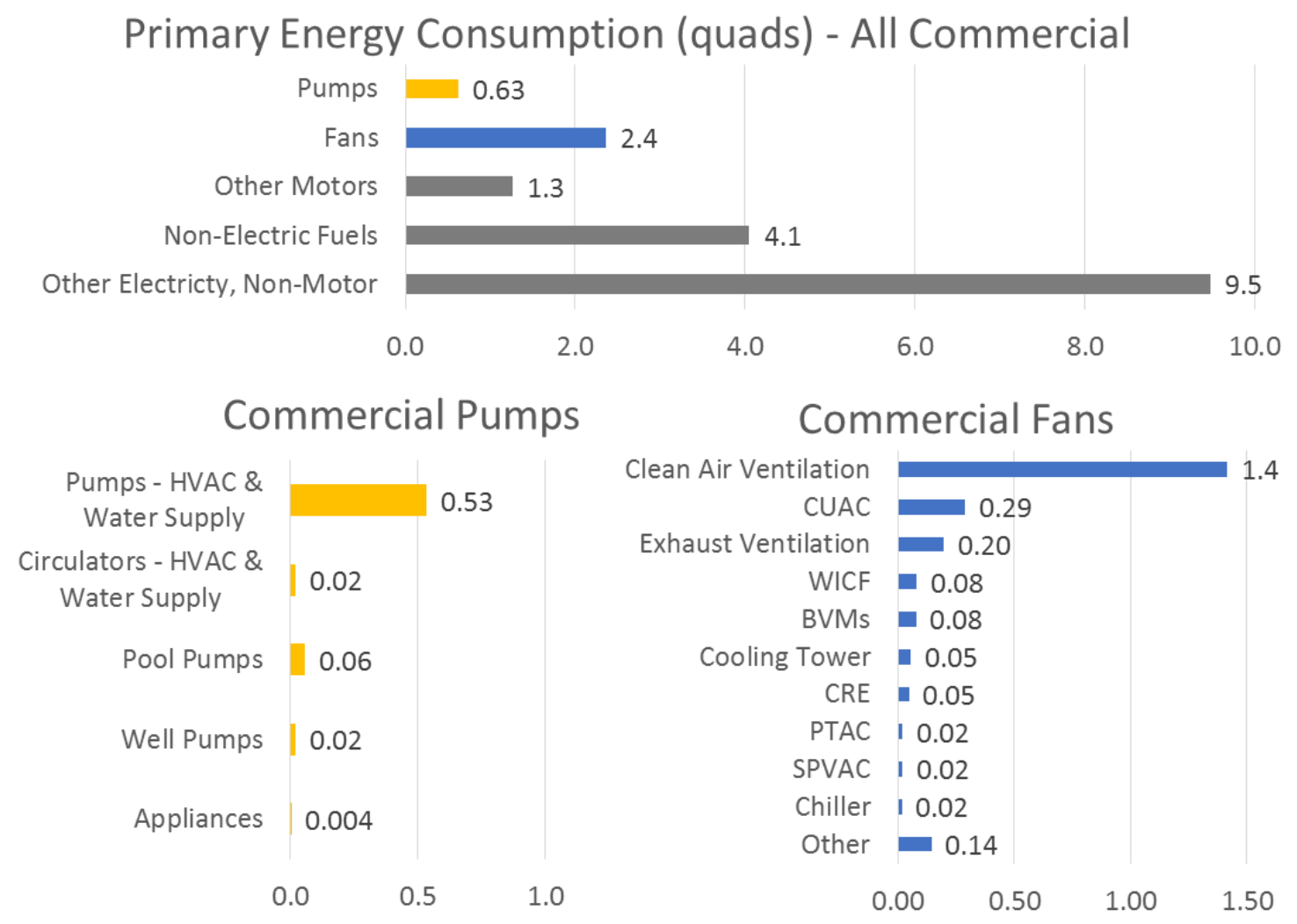

Figure ES-3: Commercial Primary Energy Consumption Summary

Our analysis identified an annual technical savings potential of $1.7(72 \%)$ and $0.5(75 \%)$ quads primary energy for commercial fans and pumps, respectively. This assumes $100 \%$ adoption of best-in-class energy efficient technologies in the U.S. for the applicable installed base. As with residential applications, fans in commercial applications provide substantially more savings opportunity than pumps. Again, this is due to a greater volume of equipment in the field, as well as greater savings across non-motor-related categories. Figure ES-4 shows a detailed summary of technical savings potential for commercial applications. 

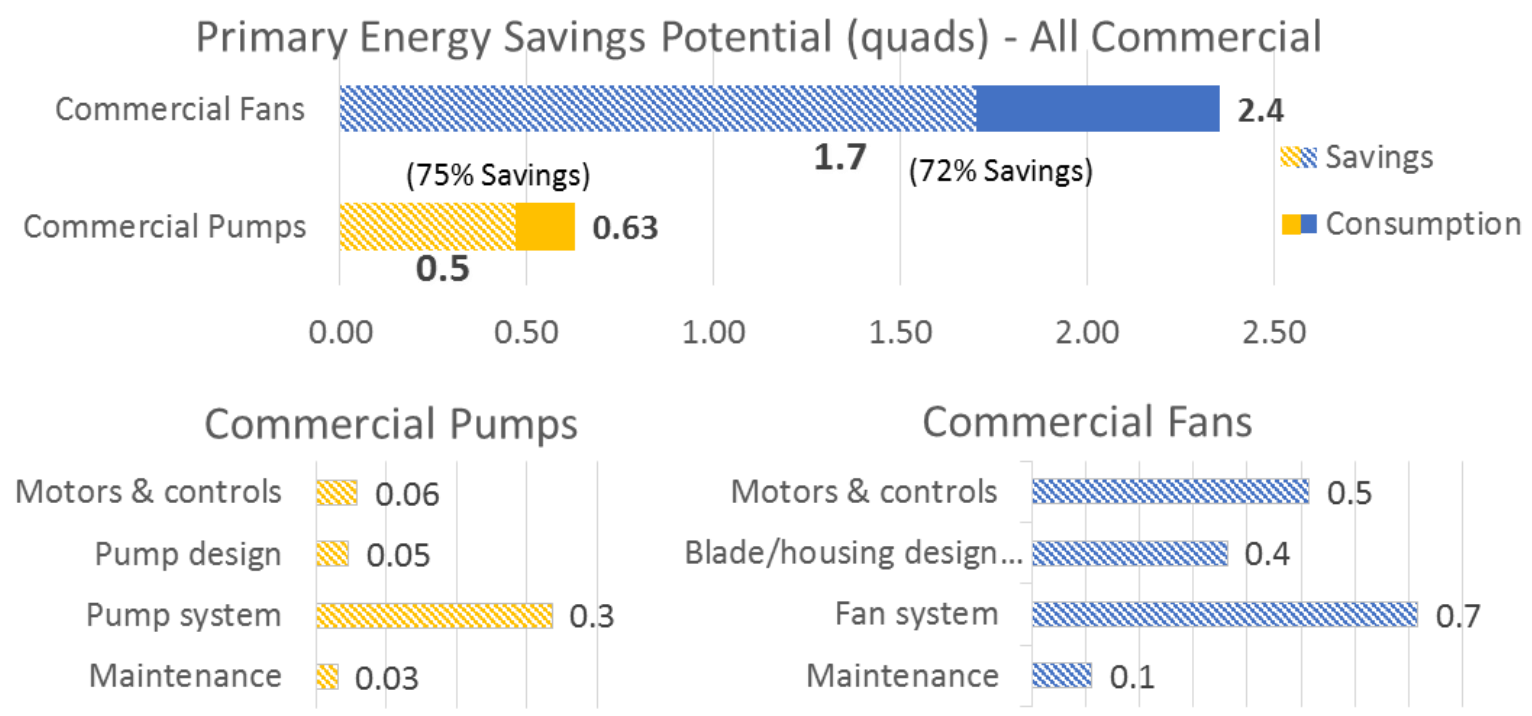

Figure ES-4: Commercial Annual Primary Energy Technical Savings Potential (100\% Adoption)

Variable speed pumping technologies dominate commercial pump savings potential; in this analysis we include variable pumping systems under the pump systems category, which can achieve 0.13 quads of savings ( $28 \%$ of commercial pump savings). Other system-related savings opportunities include improved pump sizing, pipe and component coatings to reduce frictional losses, and better piping configurations to reduce head loss. For pumps, the non-system-related savings categories all provide substantially smaller savings opportunities.

Commercial fans also achieve the majority of their savings through variable speed capabilities to better match system demand. Electronically commutated motors on light commercial applications (motors and controls category) and variable speed drives on larger commercial applications (included with variable air volume systems in the fan systems category) together contribute 0.5 quads of primary energy technical savings potential (30\% of commercial fan savings).

The savings potential we identified in this study, at more than $70 \%$ for both commercial fans and pumps (2.2 quads) and $81 \%$ and 33\% for residential fans and pumps, respectively (1.0 quads), combines all opportunities within the fan and pump systems to capture 3.2 quads of technical savings potential - a substantial opportunity by any measure. This includes a full spectrum of potential improvements, including better equipment sizing, optimized distribution geometries, lower friction piping/ducting, variable speed capabilities, optimized blades/impellers, lower friction bearings, and more. In summing up all opportunities in the entirety of the fan and pump systems, we acknowledge and capture the fact that no single technology or process can address building-system inefficiencies on its own. It is only by addressing the systems from a holistic perspective that the U.S. can achieve such substantial savings. 


\section{R\&D Opportunities}

We identified four R\&D opportunity areas for fans and five R\&D opportunity areas for pumps that will all help to achieve the identified savings potential, and therefore, BTO's energy savings goals. Table ES-1 summarizes each of these topic areas (in no particular order).

\section{Table ES-1: Research and Development Topic Areas}

\begin{tabular}{|c|c|c|}
\hline \multicolumn{2}{|l|}{ Category } & R\&D Opportunity Area \\
\hline & $\begin{array}{l}\text { Sensors \& } \\
\text { Controls (fan) }\end{array}$ & $\begin{array}{l}\text { Product-integrated occupancy sensors: Conduct building } \\
\text { simulations and field testing of built-in occupancy sensors on small- } \\
\text { zone based HVAC fans. Characterize costs and potential areas for } \\
\text { cost reductions. }\end{array}$ \\
\hline & $\begin{array}{l}\text { Aerodynamics } \\
\text { \& Hydraulic } \\
\text { Redesign } \\
\text { (fan/pump) }\end{array}$ & $\begin{array}{l}\text { Appliance-integrated fan improvements: Analyze and test } \\
\text { appliance-housed pump/fan improvements; identify manufacturing } \\
\text { barriers; recommend code updates and R\&D opportunities. }\end{array}$ \\
\hline & $\begin{array}{l}\text { Sensors \& } \\
\text { Controls (fan) }\end{array}$ & $\begin{array}{l}\text { Advanced sensors \& controls: Identify and evaluate advanced } \\
\text { sensor technologies and their commercialization status; research } \\
\text { adoption barriers; develop manufacturing processes to reduce cost } \\
\text { burden. }\end{array}$ \\
\hline & $\begin{array}{l}\text { System } \\
\text { Design (fan) }\end{array}$ & $\begin{array}{l}\text { Advanced duct sealing: investigate advanced duct sealing market } \\
\text { and determine barriers to widespread retrofit adoption. }\end{array}$ \\
\hline & $\begin{array}{l}\text { System } \\
\text { Design } \\
\text { (pump) }\end{array}$ & $\begin{array}{l}\text { Low-loss distribution components: Support cost-reducing efforts for } \\
\text { low-loss piping components; understand current market } \\
\text { opportunity for retrofit applications and new builds. }\end{array}$ \\
\hline & $\begin{array}{l}\text { Operations \& } \\
\text { Maintenance } \\
\text { (pump) }\end{array}$ & $\begin{array}{l}\text { Energy-optimized O\&M for pump systems: Research and identify } \\
\text { opportunities for connected pumps and integrating automated } \\
\text { pump system control into building management systems including } \\
\text { determination of key tools to help expand use of best practices. }\end{array}$ \\
\hline & $\begin{array}{l}\text { Sensors \& } \\
\text { Controls } \\
\text { (pump) }\end{array}$ & $\begin{array}{l}\text { Connected pool pumps: Conduct analysis and testing on connected } \\
\text { functionality for residential pool pumps to determine savings } \\
\text { potential from associated behavioral and operational changes. }\end{array}$ \\
\hline & $\begin{array}{l}\text { System } \\
\text { Design } \\
\text { (pump) }\end{array}$ & $\begin{array}{l}\text { Advanced bearings: Investigate innovative low friction bearings and } \\
\text { conduct research to reduce costs and to aid in miniaturization } \\
\text { efforts. }\end{array}$ \\
\hline
\end{tabular}

This study finds that big opportunities still remain for R\&D-based improvements to pumps and fans. Many of the component-level opportunities for energy savings, not discussed in this study, can be readily implemented with commercially-available technologies - this is the realm of BTO's residential and commercial building integration teams. Remaining R\&D opportunities for components are either incremental improvements, as opposed to step-wise improvements, or are not part of the fan/pump itself, but rather they are components that serve the broader distribution or building control systems, like low-head-loss piping components or improved sensors. 
The key opportunities for R\&D are increasingly focused on systems-level controls and technological improvements as Table ES-1, above, shows. Many relate to sensors, controls, and networked operation - topics that BTO covers in depth in their Sensors and Controls research program. Other key opportunities lie in motors improvements - detailed in the BTO Motors Report. This report ties together findings from these and other resources to help focus BTO's R\&D efforts and provide inputs to help determine the make-up of their R\&D portfolio. 


\section{Table of Contents}

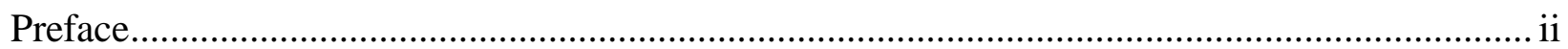

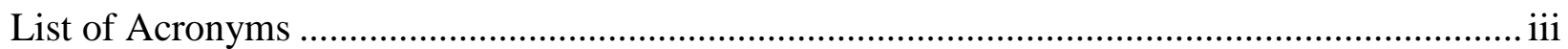

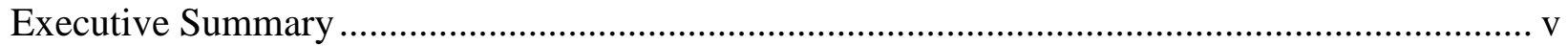

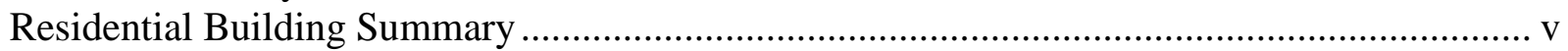

Commercial Building Summary .................................................................................... vii

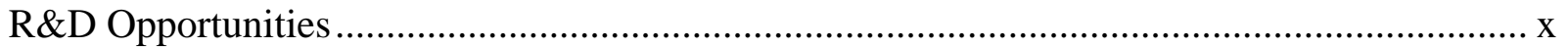

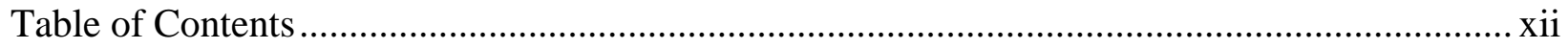

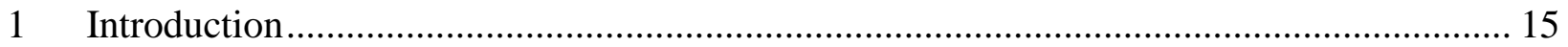

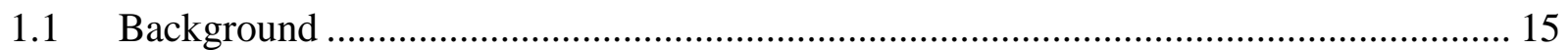

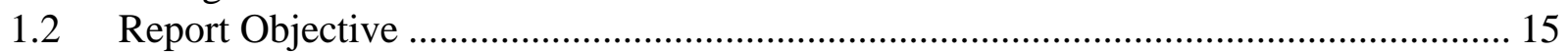

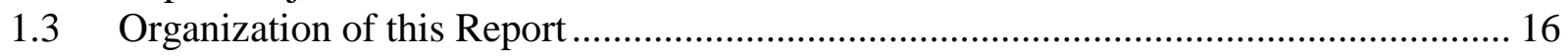

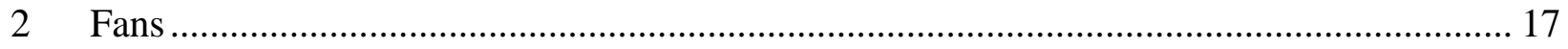

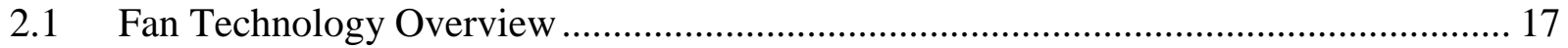

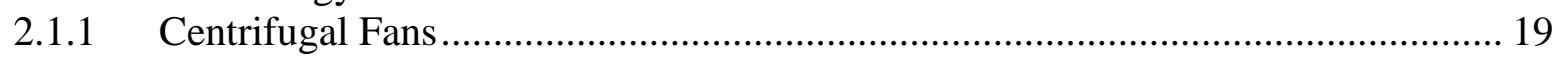

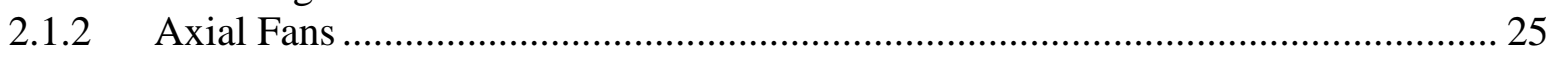

2.2 Residential Applications and Market Overview …………........................................ 31

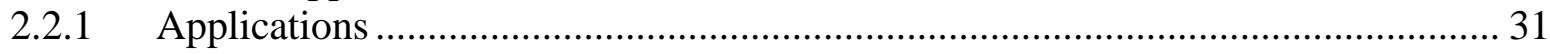

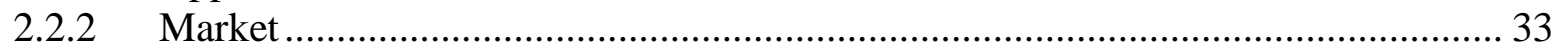

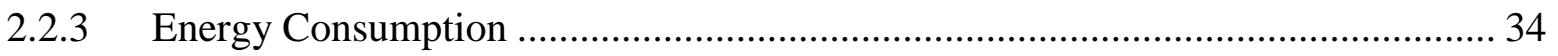

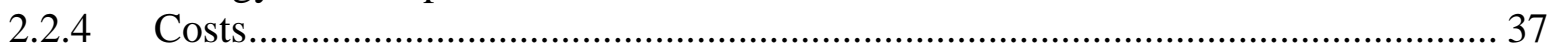

2.3 Commercial Applications and Market Overview....................................................... 38

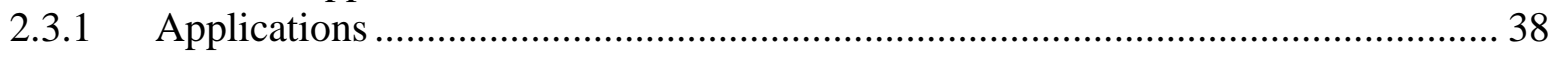

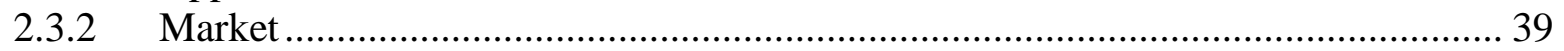

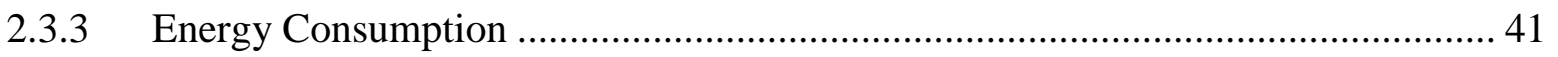

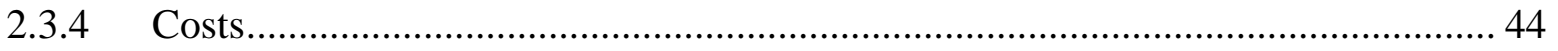

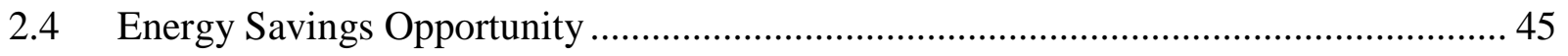

2.4.1 Energy Savings Summary ................................................................................... 45

2.4.2 Barriers and Challenges to Achieving Fan Energy Savings ................................. 46

2.4.3 Residential Energy Savings Opportunities ........................................................ 48

2.4.4 Commercial Energy Savings Opportunities........................................................ 52

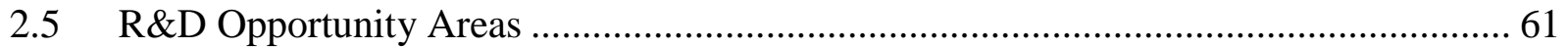

2.5.1 R\&D Initiative ID\#1: Product-Integrated Occupancy Sensors................................. 61

2.5.2 R\&D Initiative ID\#2: Appliance-Integrated Fan Improvements .............................. 62

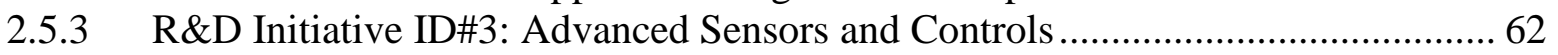

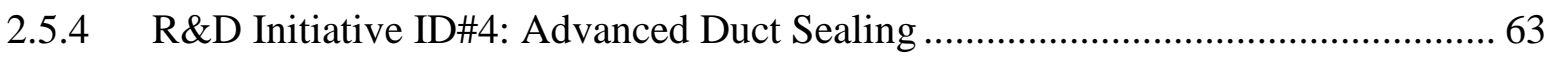

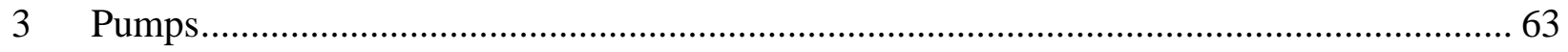

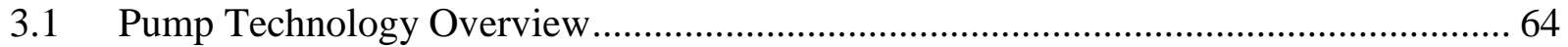

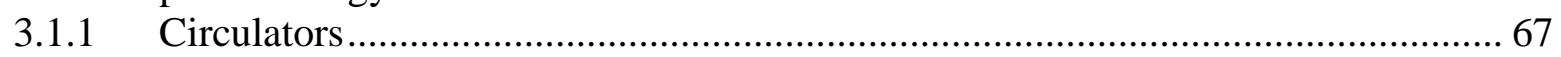

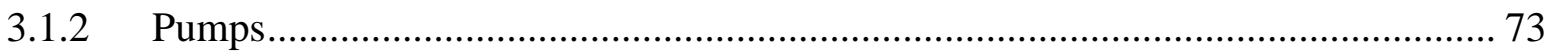

3.2 Residential Applications and Market Overview …………………........................... 79

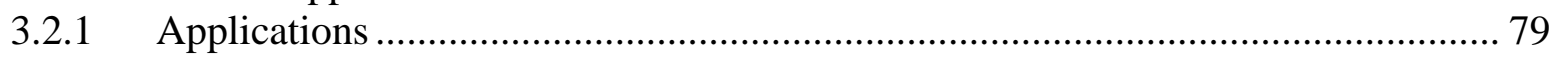

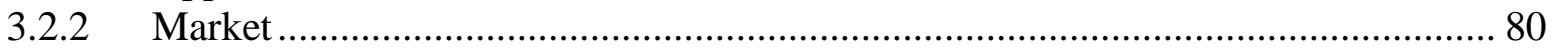

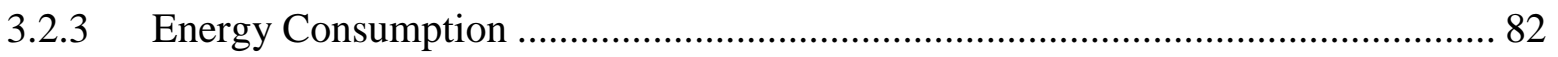

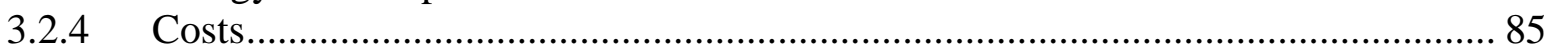

3.3 Commercial Applications and Market Overview....................................................... 85 


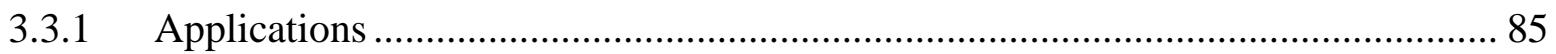

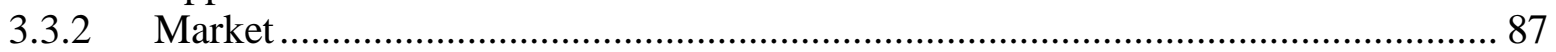

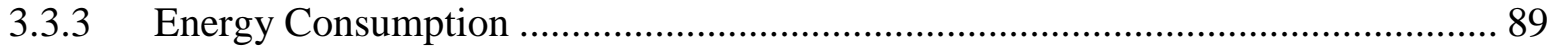

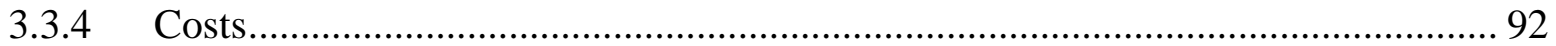

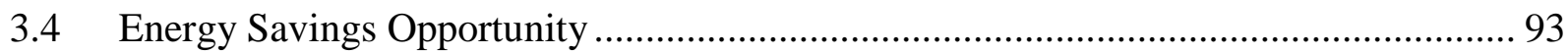

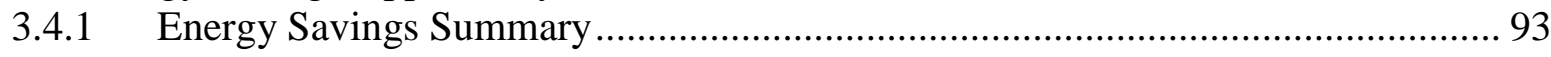

3.4.2 Barriers and Challenges to Achieving Pump Energy Savings ................................. 94

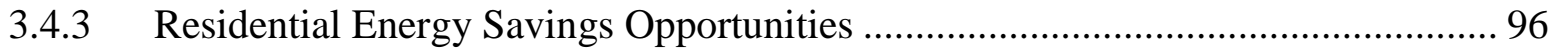

3.4.4 Commercial Energy Savings Opportunities..................................................... 99

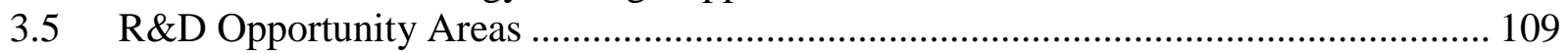

3.5.1 R\&D Topic ID\#1: Appliance-Integrated Pump Improvements............................ 110

3.5.2 R\&D Topic ID\#2: Low-Loss Piping and Pipe Components ................................. 110

3.5.3 R\&D Topic ID\#3: Energy Optimized O\&M for Pump Systems ............................ 111

3.5.4 R\&D Topic ID\#4: Connected Pool Pumps …………………………………....... 111

3.5.5 R\&D Topic ID\#5: Advanced Bearings ………….............................................. 112

4 Appendix A - Data Sources for Shipments and Installed Base ........................................ 113

5 Appendix B - Miscellaneous Residential Fans .............................................................. 116

$6 \quad$ Appendix C - Calculation Methodology ………....................................................... 117

7 Appendix D - Data Sources for Operating Hours and UEC …….................................. 119

8 Appendix E - Data Sources for Energy Savings Opportunities .......................................... 121

9 Appendix F - Motor Technology Overview....................................................................... 127

9.1 Single-Phase AC Induction Motors......................................................................... 127

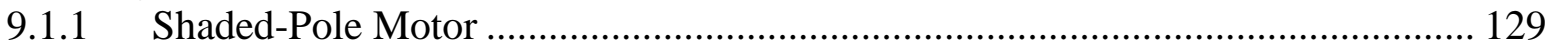

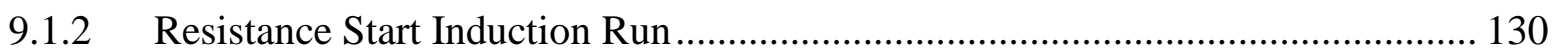

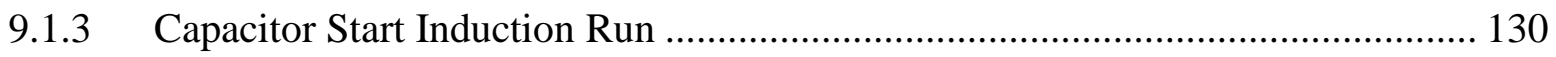

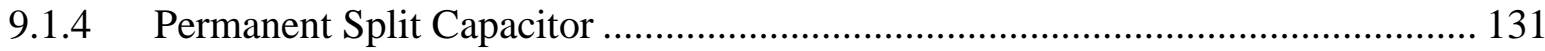

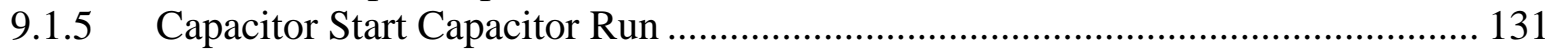

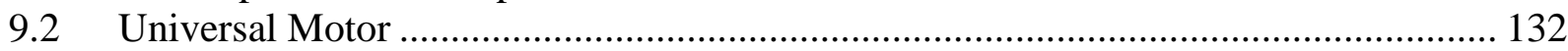

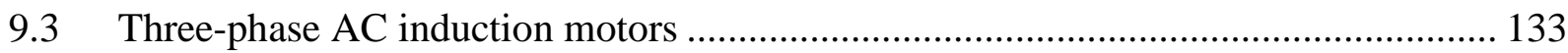

9.4 Advanced Motor Technologies and Controls.......................................................... 135

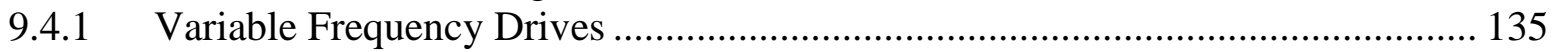

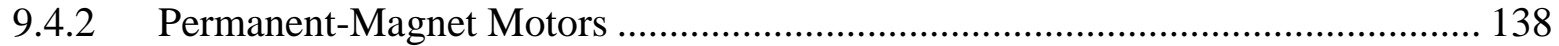

9.4.3 Electronically Commutated Motors (ECMs) with Integrated Controls ................ 139

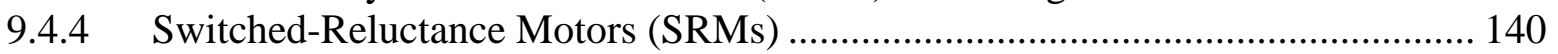

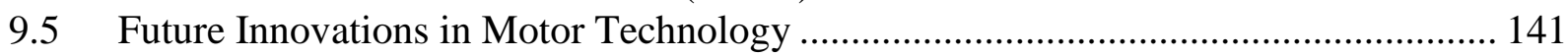

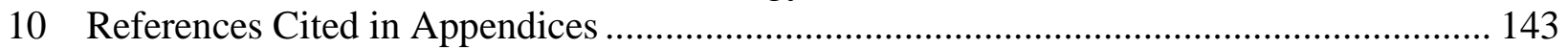


PUMP AND FAN TECHNOLOGY CHARACTERIZATION AND R\&D ASSESSMENT

(This page intentionally left blank) 


\section{Introduction}

\subsection{Background}

The Building Technologies Office (BTO) within the Department of Energy's (DOE) Office of Energy Efficiency and Renewable Energy (EERE) works with researchers and industry to develop and deploy technologies that can substantially reduce energy consumption in residential and commercial buildings. At the heart of their development work is a comprehensive research and development (R\&D) portfolio spread across many technologies and conducted by a combination of national laboratories and other firms.

To determine where best to focus their R\&D efforts within the building technology industry, BTO periodically analyzes technologies in depth. This research report on fans and pumps, and others like it, serve to determine priority areas for R\&D efforts based on relative contribution to nationwide energy consumption. Further the research determines where, within the various applications, the greatest achievable energy savings opportunities lie. Table 1-1 describes the general research process for this report.

Table 1-1: High-Level Research Process

\begin{tabular}{|c|c|c|}
\hline Step & Activity & Purpose/Outcome \\
\hline 1 & $\begin{array}{l}\text { Characterize energy consumption of specific } \\
\text { technologies/applications }\end{array}$ & $\begin{array}{l}\text { Provide comparison of energy consumption in a specific } \\
\text { focus area (e.g., fans) to other focus areas as well as } \\
\text { between sub-areas (e.g., HVAC blowers) }\end{array}$ \\
\hline 2 & $\begin{array}{l}\text { Characterize market dynamics for those } \\
\text { technologies, such as market shipments, installed } \\
\text { base, and turnover }\end{array}$ & $\begin{array}{l}\text { Determine the drivers/barriers that will help } \\
\text { encourage/inhibit deployment of energy efficient } \\
\text { technologies as well as the rate at which efficiency } \\
\text { improvements may be realized in the market }\end{array}$ \\
\hline 3 & $\begin{array}{l}\text { Characterize opportunities for providing energy } \\
\text { savings, including the total savings potential }\end{array}$ & $\begin{array}{l}\text { Understand magnitude of achievable savings if } \\
\text { efficiency improvements are deployed ( } 100 \% \text { adoption) }\end{array}$ \\
\hline 4 & $\begin{array}{l}\text { Identify R\&D opportunities where DOE and/or } \\
\text { industry could accelerate development and/or } \\
\text { deployment of energy efficient technologies }\end{array}$ & $\begin{array}{l}\text { Provide direction to R\&D portfolio management efforts } \\
\text { by characterizing specific } R \& D \text { opportunities. }\end{array}$ \\
\hline
\end{tabular}

This report follows this basic research process for pumps and fans (separately) in order to support DOE and industry R\&D efforts through the characterization and analysis of energy savings opportunities.

\subsection{Report Objective}

The objectives of this study are to:

- Characterize the state and type of pump and fan technologies used in residential and commercial appliances, equipment, and systems 
- Identify opportunities to reduce pump and fan energy consumption and the systems they comprise

This report provides BTO and the R\&D community with a technical and market analysis of pumps and fans as they pertain to commercial and residential buildings as well as key conclusions regarding the R\&D opportunities that can help achieve BTO's energy savings goals.

\subsection{Organization of this Report}

Chapter 2: Fans, discusses fan technologies (section 2.1) and characterizes the markets for fans by sector and application:

- Residential fans - Market analysis, energy use characterization, and costs (section 2.2)

- Commercial fans - Market analysis and energy use characterization (section 2.3)

- Fan energy savings opportunities for residential and commercial buildings (section 2.4)

Section 2.5 builds on the prior analyses, incorporating additional research on emerging technologies, to identify potential areas where R\&D efforts, through BTO or others, could boost efficiency of fans and fan systems.

Chapter 3: Pumps, mirrors chapter 2 and discusses pump technologies (section 3.1) and characterizes the pump market by sector and application:

- Residential pumps - Market analysis, energy use characterization, and costs (section 3.2)

- Commercial pumps - Market analysis and energy use characterization (section 3.3)

- Pump energy savings opportunities for residential and commercial buildings (section 3.4)

Section 3.5 builds on the prior analyses, incorporating additional research on emerging technologies, to identify potential areas where R\&D efforts, through BTO or others, could boost efficiency of pump and pump systems.

This report follows closely on the heels of BTO's “Energy Savings Potential and Opportunities for High-Efficiency Electric Motors in Residential and Commercial Equipment," (hereafter "BTO Motors Report") from December 2013. ${ }^{4}$ As such, it does not endeavor to re-evaluate the motor technologies, energy consumption, and energy savings opportunities in the motors used to drive fans and pumps. Instead, this report references the BTO Motors Report as appropriate and instead focuses on non-motor related energy efficiency improvements.

\footnotetext{
${ }^{4}$ Goetzler, W., Sutherland, T., Reis, C., "Energy Savings Potential and Opportunities for High-Efficiency Electric Motors in Residential and Commercial Equipment," Report to BTO, December 2013. http://energy.gov/sites/prod/files/2014/02/f8/Motor\%20Energy\%20Savings\%20Potential\%20Report\%202013-12-4.pdf
} 


\section{Fans}

\subsection{Fan Technology Overview}

Fans, consisting of multiple rotating blades powered by a motor, are used to move air in a variety of common residential and commercial applications. They are sold as part of a packed appliance (e.g., refrigerator) or building system (e.g., central heating and cooling) or independently (e.g., ceiling fan).

There are 2 basic types of fans: centrifugal fans and axial fans. The application dictates which type is preferable based on requirements for air flow, pressure increase, size and space restrictions, and overall cost. Typically, fan (and associated motor) selection is determined by the application or cost, while energy efficiency is a secondary driver. ${ }^{5}$ Figure 2-1 shows examples of both types of fans. Section 2.1.1 and 2.1.2 describe in detail the various sub-types of centrifugal and axial fans, respectively.
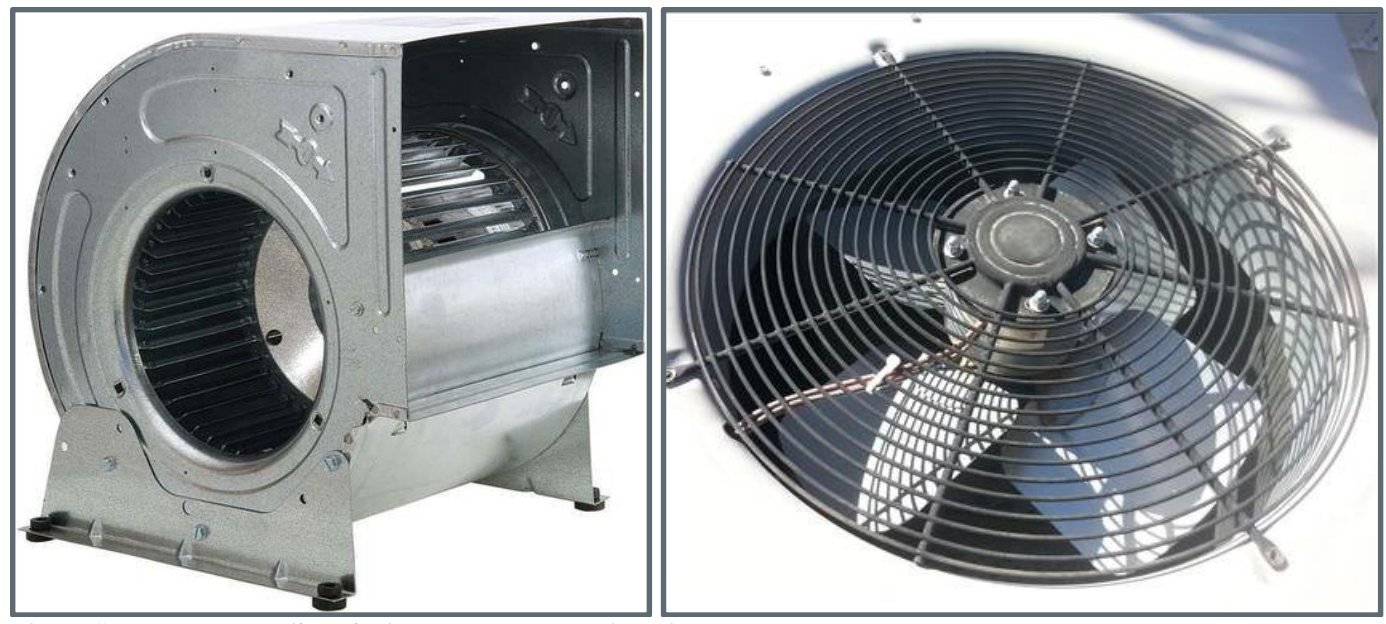

Photo Sources: www.directindustry.com; www.hvachowto.com

\section{Figure 2-1: Centrifugal air supply fan (left) and axial condenser fan (right)}

The DOE's Rulemaking for Commercial and Industrial Fans and Blowers (CIF) characterizes these fan types. ${ }^{6}$ This report does not describe the technology in depth, but does include them when estimating commercial fan energy consumption.

Fan performance curves detail an individual fan's delivered pressure, fan efficiency, and required power across its range of air flow. Figure 2-2 provides an example, with individual lines for pressure, efficiency, and power, all on a percentage-of-maximum air flow basis. The figure shows each line versus the "percent of free delivery," which is the conditions that exist when

\footnotetext{
5 "Energy Savings Potential and Opportunities for High-Efficiency Electric Motors in Residential and Commercial Equipment," prepared by Navigant Consulting Inc. for BTO, December 2013. http://www1.eere.energy.gov/library/viewdetails.aspx?productid=6746\&page $=2$

${ }^{6}$ The Energy Policy and Conservation Act of 2005 (EPCA), as amended, provides DOE with the statutory authority to set national energy conservation standards. The DOE has begun a rulemaking to establish energy conservation standards for Commercial and Industrial Fans and Blowers.

http://www1.eere.energy.gov/buildings/appliance_standards/rulemaking.aspx/ruleid/25
} 
there are no effective restrictions to air flow (no static pressure) at the fan's inlet or outlet. System designers will aim for the system to operate at, or close to, the best efficiency point (BEP), where the fan operates most effectively in terms of total efficiency (delivered pressure and airflow divided by power consumption) and maintenance considerations. Operating a fan at higher OR lower percent of free delivery will lower efficiency, increases equipment wear, and increases fan noise. Such performance curves are unique to each fan and are essential to understand when selecting a fan.

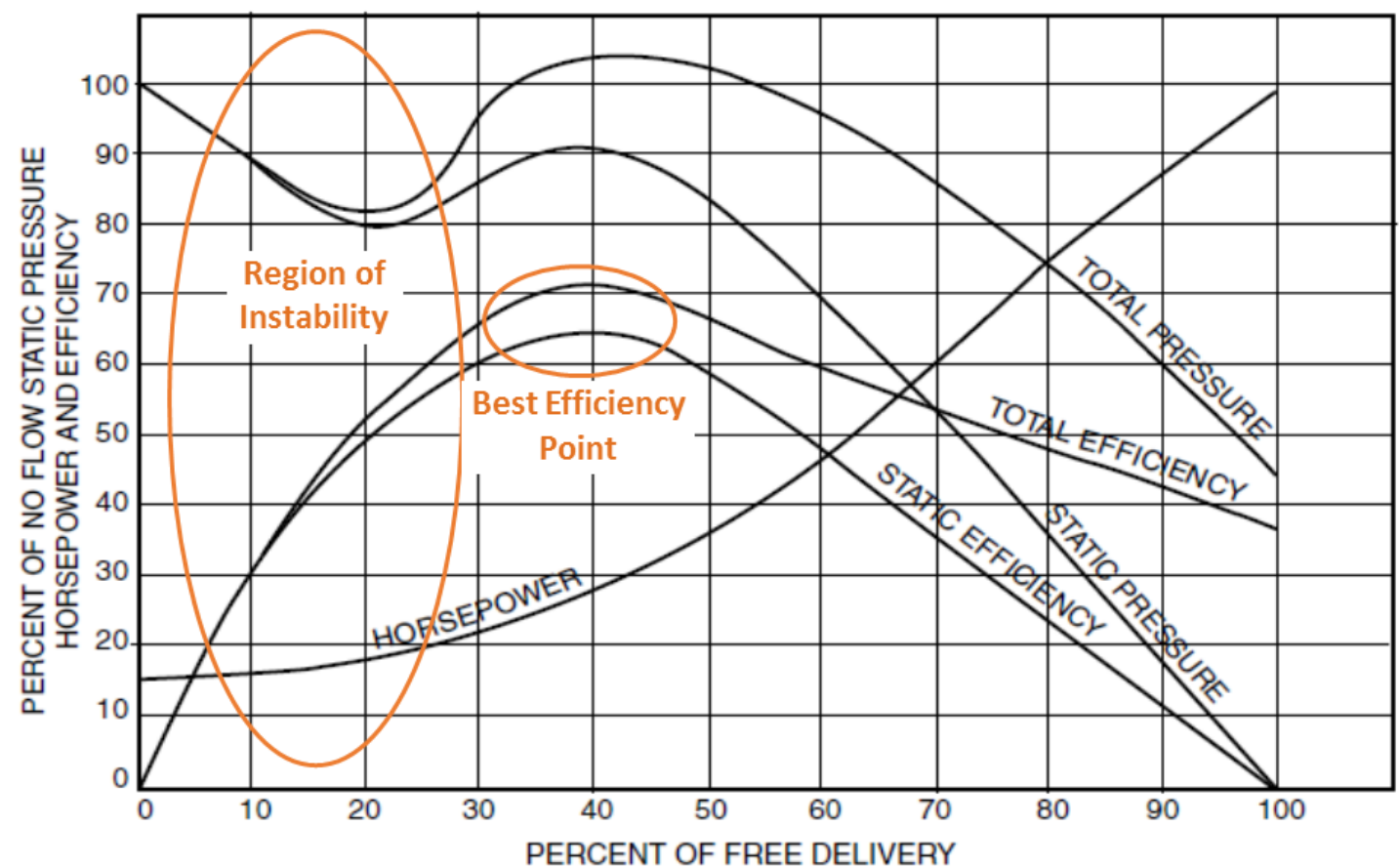

Graphic Source: Performance curve adapted from Twin City Fans - Fan Performance Characteristics of Centrifugal Fans ${ }^{7}$

\section{Figure 2-2: Example fan performance curve}

As Figure 2-2 shows, fans can have a region of instability. A fan operating in a region of instability can cause increased noise and vibration. Extended operation in this region can result in an unstable, pulsating airflow that will lead to impeller and structural damage to the fan and ductwork or other system components. Within the region of instability, stall occurs when the fan is providing flows that are too small for its intended design. A stalling fan indicates that the fan might have been improperly sized given the backpressure in the system. Stalled fans might also indicate a problem in the system, such as an obstruction that leads to airflow restriction.

Both centrifugal and axial fans can be driven directly, where the motor and fan assembly share the same drive shaft, or indirectly, where the motor drives the fan assembly via an intermediary link, typically a belt. Direct drives are simpler and require less maintenance. However, fan speed is limited to the possible speeds of the motor. Where a variable speed drive is available, directly

\footnotetext{
${ }^{7}$ Twin City Fan Companies, Ltd. "Fan Performance Characteristics of Centrifugal Fans.” Aerovent, 2000. http://www.tcf.com/docs/fan-engineering-letters/fan-performance-characteristics-of-centrifugal-fans---fe2400.pdf?Status=Master
} 
driven fans may be suitable. Indirect drives offers the flexibility to vary the fan speed compared to the motor speed by changing the gear ratio of the interconnecting belt.

Both fan types may be used for both "clean" and "dirty" airstreams (high moisture and/or particulate content), and in higher temperature applications. Figure 2-3 shows a summary of applications for each fan type

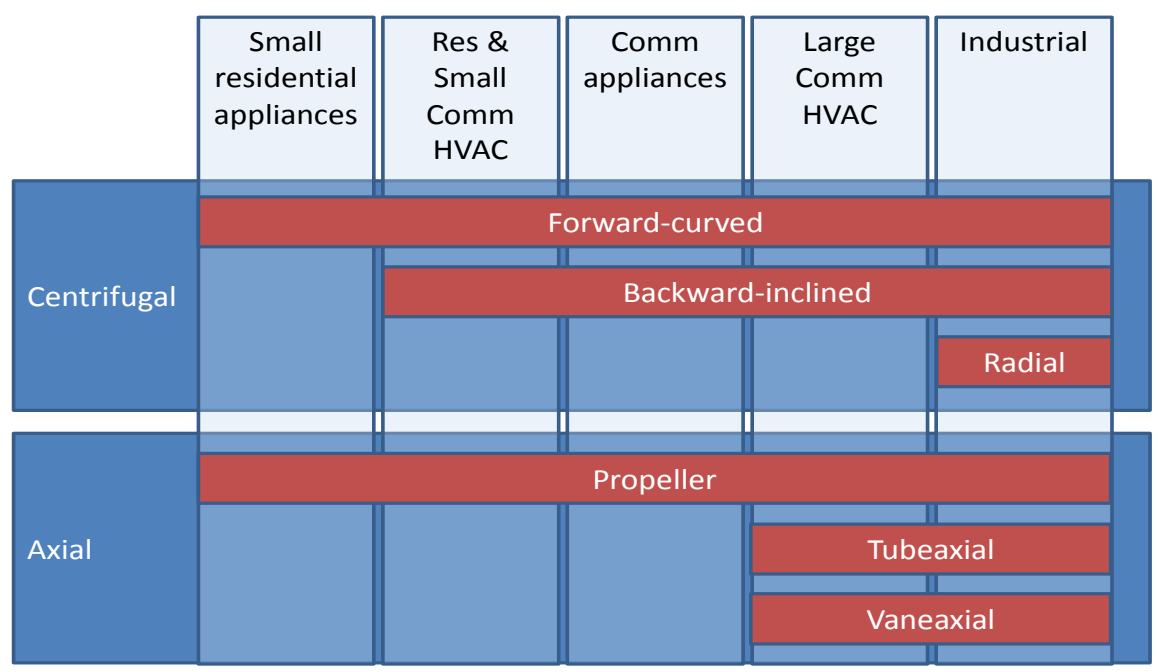

Figure 2-3: Fan applications by type

Beyond centrifugal and axial fans, manufacturers sell fans with other configurations, such as:

- Inline fans - A housed ${ }^{8}$ fan with a centrifugal impeller designed to be mounted between duct sections with air flowing in an axial direction at the fan inlet and outlet.

- Mixed-flow fans - A fan in which the fluid path through the impeller is between 20 and 70 degrees relative to the axis of rotation.

- Power roof ventilators - Powered roof ventilators can be axial or centrifugal fans within a weather-resistant housing and a base designed to fit over a roof or wall opening.

\subsubsection{Centrifugal Fans}

Centrifugal fans, often referred to as blowers or squirrel cage fans, draw air in through the center of a rotating impeller (or fan wheel) and accelerate it out to the blade tips. The air slows as it exits the impeller, converting the kinetic energy to an increase in static pressure at the discharge. Figure 2-4 shows an example impeller hub (left) and the direction of airflow in a cross sectioned hub (right).

${ }^{8} \mathrm{~A}$ fan housing is the casing within which the fan impeller spins. Please see Section 2.1.1 for further description. 


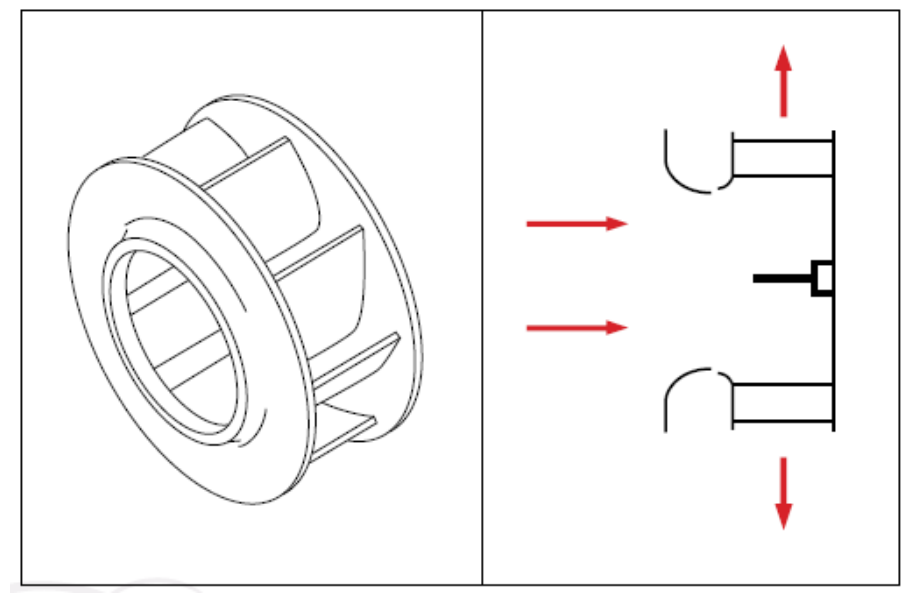

Graphic Source: AAON, Inc. ${ }^{9}$

Figure 2-4: Diagrams of a centrifugal fan

Centrifugal fans are capable of generating higher pressures than axial fans. Axial fans are typically limited to a specific ratio of 1.11 (discharge pressure divided by suction pressure), while centrifugal fans can provide specific ratios up to $1.20{ }^{10}$

The three types of centrifugal fans are classified by the shape and alignment of their fan blades relative to the direction of rotation: forward curved, backward inclined, and radial. Table 2-1 summarizes these fan types, their main applications, and operating characteristics. Forwardcurved fans offer a large variety of potential applications and can be found in a wide range of sizes. Backward-inclined centrifugal fans are typically more robust and more expensive, and thus are generally found in larger HVAC-specific applications. They also typically must be larger or driven at a higher speed to achieve similar air flows to a forward-curved fan. The three sub-types of backward-inclined fans (flat, curved, and airfoil) describe the type of blade shape within a backward-inclined configuration. Radial fans are typically larger, heavy-duty fans, used for industrial ventilation of dirty airstreams. The following subsections provide detail on each subtype.

Table 2-1: Summary of Centrifugal Fan Types

\begin{tabular}{|c|c|c|c|c|c|}
\hline & \multirow{2}{*}{ Forward-curved } & \multicolumn{3}{|c|}{ Backward-Inclined } & \multirow{2}{*}{ Radial } \\
\hline & & Flat & Curved & Airfoil & \\
\hline $\begin{array}{l}\text { Consumer } \\
\text { segment }\end{array}$ & - Residential & $\begin{array}{l}\text { - Residential \& } \\
\text { commercial }\end{array}$ & $\begin{array}{l}\text { - Residential \& } \\
\text { commercial }\end{array}$ & $\begin{array}{l}\text { - Residential \& } \\
\text { commercial }\end{array}$ & - Industrial \\
\hline $\begin{array}{l}\text { Volume \& } \\
\text { pressure }\end{array}$ & $\begin{array}{l}\text { - Low to high } \\
\text { volumes } \\
\text { - low pressure }\end{array}$ & $\begin{array}{l}\text { - Med to high } \\
\text { volumes } \\
\text { - Medium } \\
\text { pressure }\end{array}$ & $\begin{array}{l}\text { - Med to high } \\
\text { volumes } \\
\text { - Medium } \\
\text { pressure }\end{array}$ & $\begin{array}{l}\text { - High volume } \\
\text { - Medium } \\
\text { pressure }\end{array}$ & $\begin{array}{l}\text { - Low to } \\
\text { medium } \\
\text { volume } \\
\text { - High pressure }\end{array}$ \\
\hline Application & $\begin{array}{l}\text { - Res. HVAC (supply), } \\
\text { res. \& comm. } \\
\text { appliances }\end{array}$ & \multicolumn{3}{|c|}{$\begin{array}{l}\text { - Commercial clean air HVAC } \\
\text { - Forced-draft service } \\
\text { - Commercial appliances }\end{array}$} & $\begin{array}{l}\text { - Industrial } \\
\text { ventilation }\end{array}$ \\
\hline
\end{tabular}

\footnotetext{
${ }^{9}$ AAON, Inc. "Value in the Air". Accessed Feb 2015. https://www.aaon.com/Documents/Technical/ValueInTheAir_110106.pdf ${ }^{10}$ Energy Efficiency Guide for Industry in Asia. "Fans and Blowers." UNEP, 2006. http://www.energyefficiencyasia.org/docs/ee_modules/Chapter-Fans\%20and\%20Blowers.pdf
} 


\begin{tabular}{|c|c|c|c|c|c|}
\hline & \multirow{2}{*}{ Forward-curved } & \multicolumn{3}{|c|}{ Backward-Inclined } & \multirow{2}{*}{ Radial } \\
\hline & & Flat & Curved & Airfoil & \\
\hline $\begin{array}{l}\text { Operating } \\
\text { environment }\end{array}$ & $\begin{array}{l}\text { - Clean service; low } \\
\text { pressure }\end{array}$ & \multicolumn{3}{|c|}{ - Clean service } & $\begin{array}{ll}\text { - } & \text { High } \\
\text { particulate } \\
\text { airstreams }\end{array}$ \\
\hline Efficiency & • $60-65 \%$ & • $79-83 \%$ & & $\bullet>85 \%$ & - $69-79 \%$ \\
\hline Pros & $\begin{array}{l}\text { - Wide volume range } \\
\text { - Small size } \\
\text { - Light construction } \\
\text { - Quiet operation }\end{array}$ & \multicolumn{3}{|c|}{$\begin{array}{l}\text { - Sturdier construction for larger commercial use } \\
\text { - Generally more efficient } \\
\text { - Tolerant of changing fan system or building conditions } \\
\text { - Non-overloading; will not stall }\end{array}$} & $\begin{array}{l}\text { - Dirty air } \\
\text { streams }\end{array}$ \\
\hline Cons & $\begin{array}{l}\text { - Low efficiency } \\
\text { - Clean air only }\end{array}$ & \multicolumn{3}{|c|}{$\begin{array}{l}\text { - Clean air only } \\
\text { - More expensive } \\
\text { - Larger size, or faster speed needed to provide } \\
\text { equivalent airflow to a forward-curved fan }\end{array}$} & $\begin{array}{l}\text { - Low efficiency } \\
\text { - } \text { Higher noise }\end{array}$ \\
\hline \multicolumn{6}{|c|}{$\begin{array}{l}\text { Sources: } \\
\text { Energy Efficiency Guide for Industry in Asia. "Fans and Blowers." UNEP, 2006. http://www.energyefficiencyasia.org/docs/ee_modules/Chapter- } \\
\text { Fans\%20and\%20Blowers.pdf } \\
\text { DOE-EERE. “Improving Fan System Performance." Prepared by Lawrence Berkeley National Laboratory (LBNL) and Resource Dynamics Corp, } \\
\text { accessed Feb 2015. https://www1.eere.energy.gov/manufacturing/tech assistance/pdfs/fan sourcebook.pdf } \\
\text { Twin City Fan Companies, Ltd. "Fan Performance Characteristics of Centrifugal Fans." Aerovent, 2000. http://www.tcf.com/docs/fan-engineering- } \\
\text { letters/fan-performance-characteristics-of-centrifugal-fans---fe-2400.pdf?Status=Master }\end{array}$} \\
\hline
\end{tabular}

Housed fans are designed with a centrifugal impeller and a surrounding scroll casing, which is often known as the fan housing. The housing guides the air as it exits the impeller and directs it in the desired direction of outlet flow. Unhoused, or plenum fans, are fans without a fan housing, allowing air to discharge freely in all radial directions rather than controlling it with a housing. The plenum, which is the surrounding enclosure of the impeller, creates static pressure as the impeller discharges air into it. In general, unhoused fans are only used in larger commercial air handling or air supply applications. In the CIF rulemaking, DOE estimates that $43 \%$ of commercial centrifugal fan shipments are unhoused fans. Unhoused centrifugal fans are too large to be used in residential applications. ${ }^{11}$

Unlike housed fans, a plenum fan does not require a length of ductwork to allow adequate space for the outlet flow to develop a uniform profile. Unhoused fans can discharge uniform outlet flows directly from the plenum, which could allow for more flexibility in the building ducting.

Forward-curved fans are not suitable for unhoused fan applications because they are highly dependent on the housing for performance, and can become unstable. ${ }^{12}$ As such, smaller air supply applications which use forward-curved fan wheels would require fan housings. Typically, plenum fans have larger fan wheels and require higher operating speeds in order to reach the pressure and flow of a comparable housed fan. ${ }^{13}$

\footnotetext{
${ }^{11}$ DOE. NODA-LCC Spreadsheet from Commercial and Industrial Fans and Blowers Rulemaking. Accessed Feb 2015. http://www1.eere.energy.gov/buildings/appliance_standards/rulemaking.aspx/ruleid/25

12 AAON, Inc. "Value in the Air". Accessed Feb 2015. https://www.aaon.com/Documents/Technical/ValueInTheAir_110106.pdf

${ }^{13}$ Carrier Corp. “Application of Fans in Commercial HVAC Equipment”. Published May 2013.

dms.hvacpartners.com/docs/1001/public/0f/04-581070-01.pdf
} 


\subsubsection{Forward-curved}

Forward-curved (FC) fan blades curve in the direction of rotation and are commonly used in smaller, clean-air applications, but may also be applicable for a broad range of uses. The most common applications include heating, ventilation, and air conditioning (HVAC) for central circulation fans, room air conditioners (RAC), and other residential appliances. Figure 2-5 shows a diagram of forward-curved blades. Inlet air flows into the plane of the page and exits radially. Forward-curved geometry allows it to produce greater air velocities while rotating at lower speeds than other geometries, enabling lighter construction and greater numbers of blades other geometries.

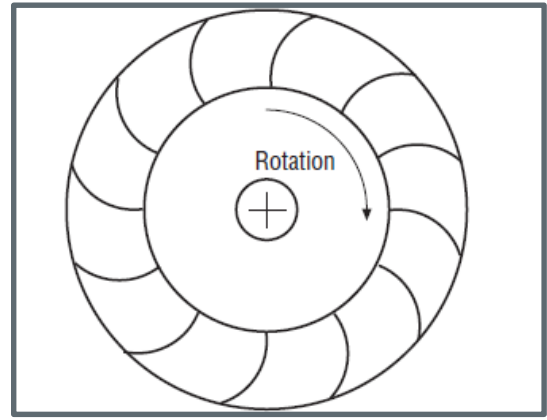

Graphic Source: DOE-EERE ${ }^{14}$

\section{Figure 2-5: Forward-curved fan type diagram}

While FC fans are typically energy inefficient relative to other centrifugal fan configurations, the many advantages of forward-curved fans allow it to be used extensively:

- Wide range of volumes - FC fans can be designed for low to high volume applications

- Small size - High volume output relative to the fan's small size makes them suitable for space constrained applications

- Light construction - Translates to lower cost construction, and in conjunction with the slow operation, translate to quiet operation

A downside of FC fans is a relatively low BEP efficiency of $60-65 \%{ }^{15}$. FC fans are limited to clean service applications as fan blades may be damaged due to light construction, and the curved fan blades could result in particulate accumulation.

FC fans can potentially overload the motor if the static pressure in the system decreases. Such a scenario may occur when the fan operates too far to the right of the BEP (see the fan performance curve in Figure 2-2, above). As the pressure drops, the fan's motor is required to provide increasing power, thus putting the motor at risk for overloading. Designers can design around overloading risks (as well as stall risks, see Figure 2-2, above).

FC fans have significant benefits (costs, air flow) but are sensitive to the operating conditions of the fan system. This makes them suitable for standard residential or commercial service, but unfit for some industrial processes.

\footnotetext{
${ }^{14}$ DOE-EERE. “Improving Fan System Performance.” Prepared by LBNL and Resource Dynamics Corp, accessed Feb 2015. https://www1.eere.energy.gov/manufacturing/tech_assistance/pdfs/fan_sourcebook.pdf

${ }^{15}$ Energy Efficiency Guide for Industry in Asia. "Fans and Blowers." UNEP, 2006. http://www.energyefficiencyasia.org/docs/ee_modules/Chapter-Fans\%20and\%20Blowers.pdf
} 


\subsubsection{Backward-inclined}

Backwards-inclined (BI) centrifugal fans are characterized by blades that tilt away from the direction of rotation. BI fans are commonly used in commercial and industrial HVAC systems, and also in some commercial appliances.

BI centrifugal fan geometry requires higher operational speeds than forward-curved fans to achieve desired pressure and airflow. To handle the increased tip speeds, manufacturers employ a sturdier, heavier blade construction. BI centrifugal fan impellers are also generally built with fewer fan blades than FC impellers. Due to the heavier construction, costs for a BI fan is typically more expensive than an equivalent FC fan. The higher operating speeds are desirable feature that enables direct drive connections with high speed motors ${ }^{16}$.

BI fans come in three variations based on blade shape: flat, curved, and airfoil. Figure 2-6 show each of these shapes. BI geometry allows the fan type to develop higher static pressure than FC fans, as the air leaves the impeller at a lower velocity.
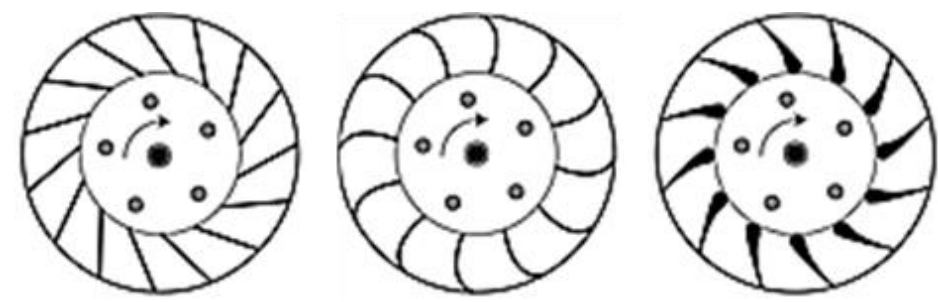

Graphic Source: $\mathrm{CIBSE}^{17}$

Figure 2-6: Backwards-inclined fan type diagrams (left to right: flat, curved, airfoil)

Flat-BI centrifugal fans have straight fan blades and are more robust than other backwardinclined fan types due to the simplicity of the flat blade geometry. Flat bladed designs are typically less than $80 \%$ efficient. ${ }^{18}$

Curved-BI fans have curved fan blades of uniform thickness. Curved-BI fans are generally more efficient than flat-BI fans, and can reach $80 \%$ efficiency or greater ${ }^{19}$, however, they are more prone to particulate build-up on the blades, therefore limiting use to clean-air applications. ${ }^{20}$

Airfoil-BI fans provide the highest efficiency of BI geometries due to their thin or hollow airfoil blades that enable lower rotating mass and provide higher pressure increases. However, because airfoil blades rely on the lift created by each blade, this fan type is highly susceptible to unstable operation because of stall. Loss of blade wall thickness can lead to cavity formation in the blades, which can severely interfere with fan performance.

\footnotetext{
16 Twin City Fan Companies, Ltd. "Fan Performance Characteristics of Centrifugal Fans.” Aerovent, 2000. http://www.tcf.com/docs/fan-engineering-letters/fan-performance-characteristics-of-centrifugal-fans---fe2400.pdf?Status=Master

${ }^{17}$ CIBSE. "Fans for ducted ventilation systems." CIBSE Journal, 2011. http://www.cibsejournal.com/cpd/2011-12/

${ }^{18}$ Energy Efficiency Guide for Industry in Asia. "Fans and Blowers." UNEP, 2006. http://www.energyefficiencyasia.org/docs/ee_modules/Chapter-Fans \%20and\%20Blowers.pdf

${ }^{19}$ Sources: 83\% (Energy Efficiency Guide for Industry in Asia)., 82\% (Twin City Fans), and 75-80\% (AAON)

${ }^{20}$ Energy Efficiency Guide for Industry in Asia. "Fans and Blowers." UNEP, 2006.

http://www.energyefficiencyasia.org/docs/ee_modules/Chapter-Fans\%20and\%20Blowers.pdf
} 
BI centrifugal fans are generally not suitable for particulate-laden air streams due to the low angle of impingement with the airstream. In curved or airfoil BI fans, the blade geometry promotes the accumulation of particles on the fan blades, which can create performance problems. Additionally, thin-walled airfoil fans, which depend greatly on aerodynamic performance for efficiency, are highly susceptible to erosion from particulates impinging along the blade surfaces. This makes curved or airfoil BI fans unsuitable for some "dirty" commercial applications, such as exhaust fans. Flat-BI fans can tolerate dirtier air streams and are less prone to dirt or particulate build-up.

Unlike FC fans, BI fans will not be overloaded as they near free-delivery, allowing them to be used in applications with changing static pressure. Figure 2-7 shows an example fan performance curve for a BI centrifugal fan. The horsepower required by the fan decreases when the flow rate increases past a certain point. As such, BI fans are ideally suited for systems in which pressures are either unknown of variable. Also, BI fans do not have a region of instability, allowing them to be used flexibly for a range of flow rates outside its BEP (although at a reduced efficiency).

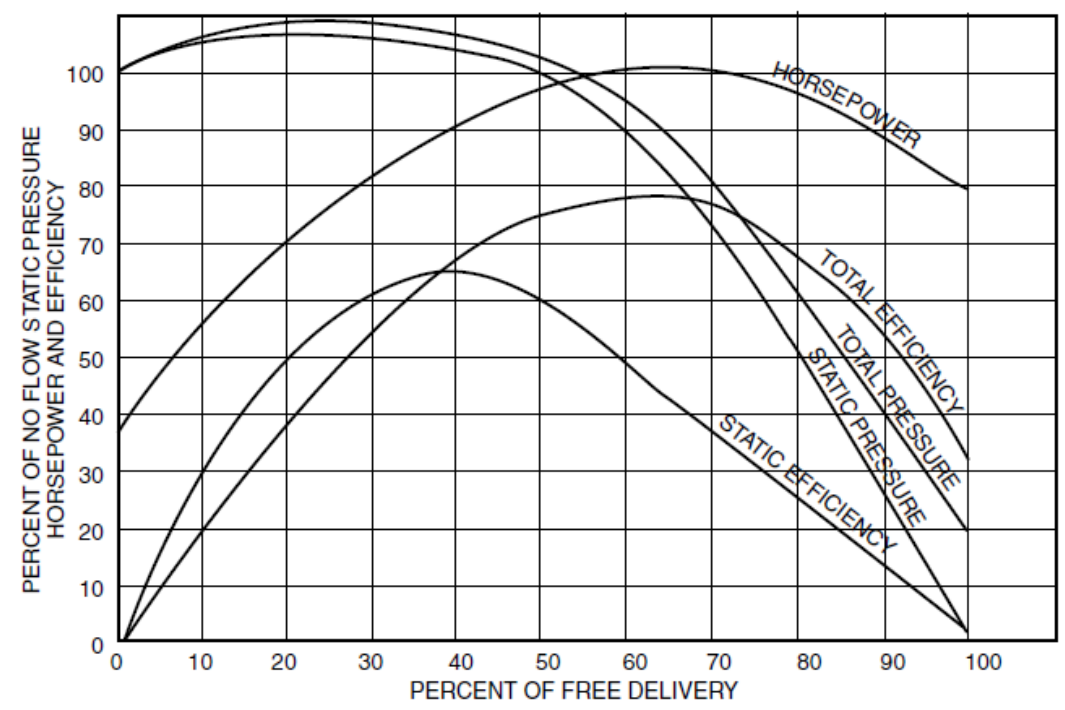

Graphic Source: Twin City Fans ${ }^{21}$

Figure 2-7: Example fan performance curve of a backwards-inclined fan

\subsubsection{Radial}

Radial blade centrifugal fans contain flat blades that extend radially inwards from the outer edge towards the center of the hub. Figure 2-8 shows a diagram of a radial centrifugal fan.

\footnotetext{
${ }^{21}$ Twin City Fan Companies, Ltd. "Fan Performance Characteristics of Centrifugal Fans.” Aerovent, 2000. http://www.tcf.com/docs/fan-engineering-letters/fan-performance-characteristics-of-centrifugal-fans---fe2400.pdf?Status=Master
} 


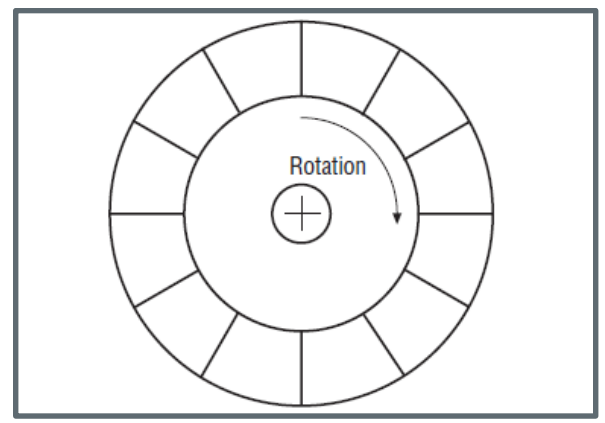

Graphic Source: DOE-EERE 22

\section{Figure 2-8: Radial fan types: radial (left) and radial tip (right)}

Radial fans are rugged in design, allowing them to handle a variety of "dirty" applications with fouled or particulate-filled airstreams. These fans are designed with larger clearances between blades, which allow the fan to operate at lower airflows and speeds without stalling.

Radial fans operate at high speeds, but typically serve low volume applications. They are less efficient than BI-fans, with peak efficiency between 70 and $80 \%{ }^{23}$. Radial fan designs are also louder than other fan types due to their impeller design and high operating speed.

Industrial applications typically use radial fans, especially where the airstreams are laden with suspended particulates or high moisture content, such as pulp and paper mills. This report, which focuses primarily on commercial and residential applications, will not specifically cover such industrial applications.

\subsubsection{Axial Fans}

Axial fans, as the name implies, move an airstream along the rotating axis of the fan. The air is pressurized by the aerodynamic lift generated by the fan blades, much like a propeller and an airplane wing. ${ }^{24}$ Figure 2-9 shows an example diagram of an axial fan. The number of blades and motor-to-fan coupling (i.e., direct versus indirect drive) varies by application and fan type.

\footnotetext{
22 DOE-EERE. “Improving Fan System Performance.” Prepared by LBNL and Resource Dynamics Corp, accessed Feb 2015. https://www1.eere.energy.gov/manufacturing/tech_assistance/pdfs/fan_sourcebook.pdf

${ }^{23}$ Energy Efficiency Guide for Industry in Asia. "Fans and Blowers." UNEP, 2006. http://www.energyefficiencyasia.org/docs/ee_modules/Chapter-Fans\%20and\%20Blowers.pdf

${ }^{24}$ DOE-EERE. “Improving Fan System Performance.” Prepared by LBNL and Resource Dynamics Corp, accessed Feb 2015. https://www1.eere.energy.gov/manufacturing/tech_assistance/pdfs/fan_sourcebook.pdf
} 


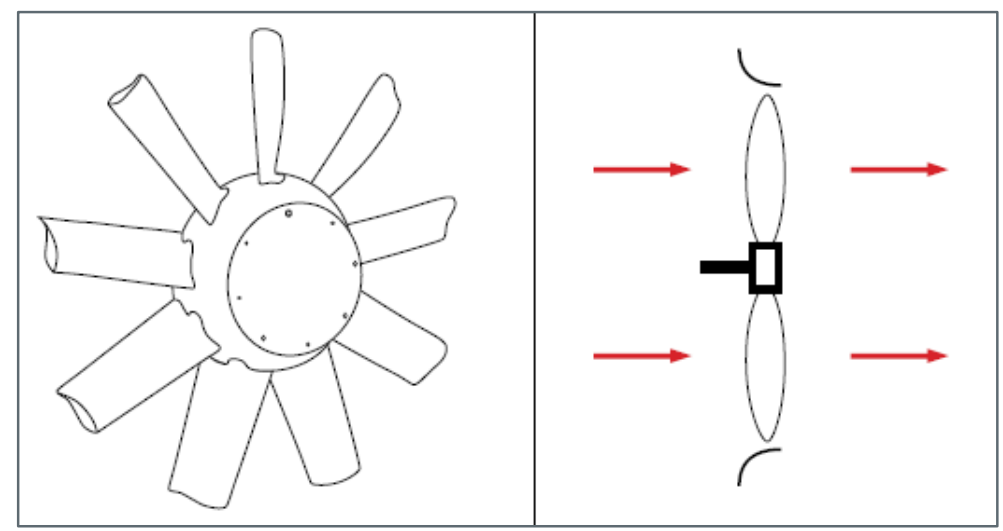

Graphic Source: AAON, Inc. ${ }^{25}$

\section{Figure 2-9: Diagrams of an axial fan}

Axial fans are commonly used for clean air applications that require high flow rates, such as condenser fans and ceiling fans. However, axial fans cannot generate high pressures, and thus are limited to low pressure applications with specific pressure ratios up to $1.11^{26}$ (see Section 2.1.1). Axial fans are cheaper and more compact than centrifugal fans for moving large amounts of air, and thus are preferred for high flow, low pressure applications.

Axial fans have less rotating mass but must rotate faster than centrifugal fans to achieve the same airflow. The high speed of rotation makes axial fans somewhat noisier than comparable centrifugal fans; however, this noise tends to be dominated by high frequencies, which tend to be easier to attenuate. ${ }^{27}$

Axial fans are commonly used in homes to circulate and ventilate indoor air (e.g., ceiling fans, window fans, exhaust fans), and to help with heat exchange for residential appliances (e.g., condenser fans for refrigerators and air conditioners). Axial fans in commercial buildings are used for air delivery, circulation, and exhausting applications. Some axial fans are designed to generate flow in reverse direction, which is helpful in certain ventilation applications.

Axial fans are at risk of stalling when delivering less airflow than that of the fan's best efficiency point. Performance of each fan, and the point of stall depends on the individual fan's characteristics. In the event of a flow blockage, axial fan motors also risk overloading when the required power rises as the fan moves away from its free delivery point.

Axial fans offer several different design variables depending on the required fan application:

- $\quad$ Fan speed - varying rotating speed, based on the fan drive connection (direct vs. indirect-drive) or based on variable speed drives, will change the resulting airflow through the fan

- Number of blades - more blades usually decreases air flow but increases pressure

\footnotetext{
${ }^{25}$ AAON, Inc. "Value in the Air". Accessed Feb 2015. https://www.aaon.com/Documents/Technical/ValueInTheAir_110106.pdf

${ }^{26}$ Energy Efficiency Guide for Industry in Asia. "Fans and Blowers." UNEP, 2006.

http://www.energyefficiencyasia.org/docs/ee_modules/Chapter-Fans\%20and\%20Blowers.pdf

${ }^{27}$ DOE-EERE. “Improving Fan System Performance.” Prepared by LBNL and Resource Dynamics Corp, accessed Feb 2015.

https://www1.eere.energy.gov/manufacturing/tech_assistance/pdfs/fan_sourcebook.pdf
} 
- Power curve - fans ideally are designed to exhibit a flat power curve to avoid overloading the motor in stall or if there is a flow restriction

- Hub-to-tip ratio - fans that have higher hub-to-tip ratios (outer hub diameter divided by propeller tip diameter) are able to deliver flows against higher back-pressures ${ }^{28}$

- Blade pitch angle - pitch angle affects airflow and fan performance - variable pitch blades can allow precision control of forward and even reverse airflow ${ }^{29}$

Axial fan sub types are classified by the housing, or the air flow improvements, around the propeller fan blades. Table 2-2 describes the three axial fan sub-types: propeller fans, tubeaxial fans, and vaneaxial fans. Propeller fans are typical axial fans that are used in a huge variety of residential and commercial applications. Tubeaxial and vaneaxial fans include air flow improvements that boost efficiency; they are not used in residential applications.

Table 2-2: Summary of Axial Fan Types

\begin{tabular}{|c|c|c|c|}
\hline & Propeller Fans & Tubeaxial Fans & Vaneaxial Fans \\
\hline Description & $\begin{array}{l}\text { - Multi-bladed rotating axial } \\
\text { fan }\end{array}$ & $\begin{array}{l}\text { Propeller fan placed } \\
\text { inside a cylinder for } \\
\text { better airflow }\end{array}$ & $\begin{array}{l}\text { Tubeaxial fan with outlet } \\
\text { vanes that further improve } \\
\text { airflow pattern }\end{array}$ \\
\hline $\begin{array}{l}\text { Consumer } \\
\text { segment }\end{array}$ & $\begin{array}{l}\text { - Residential, Commercial \& } \\
\text { Industrial }\end{array}$ & $\begin{array}{l}\text { - Commercial \& } \\
\text { Industrial }\end{array}$ & - Commercial \& Industrial \\
\hline $\begin{array}{l}\text { Volume and } \\
\text { pressure } \\
\text { characteristics }\end{array}$ & - High volume, low pressure & $\begin{array}{l}\text { - High volume, med } \\
\text { pressure }\end{array}$ & $\begin{array}{l}\text { - High volume, Medium to } \\
\text { high pressures }\end{array}$ \\
\hline Applications & $\begin{array}{l}\text { - } \text { Rooftop ventilation } \\
\text { - Exhaust fan for all sectors } \\
\text { - Condenser fan } \\
\text { - } \quad \text { "Free" fans for ventilation }\end{array}$ & $\begin{array}{l}\text { - Ducted HVAC } \\
\text { - Exhaust ducting }\end{array}$ & $\begin{array}{l}\text { - Induced-draft service for } \\
\text { boiler exhaust. }\end{array}$ \\
\hline $\begin{array}{l}\text { Operating } \\
\text { environment }\end{array}$ & - Clean; small airborne partic & late matter acceptable & \\
\hline Efficiency $^{1}$ & - $45-50 \%$ & - $67-72 \%$ & - $78-85 \%$ \\
\hline Pros & $\begin{array}{l}\text { - Cheap; simple } \\
\text { construction }\end{array}$ & $\begin{array}{l}\text { - Delivers higher } \\
\text { pressure } \\
\text { - Higher efficiency }\end{array}$ & $\begin{array}{l}\text { - Delivers highest pressure } \\
\text { - Highest efficiency } \\
\text { - Commonly use variable pitch } \\
\text { controls }\end{array}$ \\
\hline Cons & $\begin{array}{l}\text { - Can stall with } \\
\text { backpressure } \\
\text { - Low pressure application } \\
\text { only }\end{array}$ & $\begin{array}{l}\text { - Higher cost } \\
\text { - Typically ducted } \\
\text { applications only }\end{array}$ & $\begin{array}{l}\text { - High cost } \\
\text { - } \text { Primarily ducted applications } \\
\text { - Clean applications only }\end{array}$ \\
\hline \multicolumn{4}{|c|}{$\begin{array}{l}\text { Sources: } \\
\text { Energy Efficiency Guide for Industry in Asia. "Fans and Blowers." UNEP, } 2006 . \\
\text { http://www.energyefficiencyasia.org/docs/ee_modules/Chapter-Fans\%20and\%20Blowers.pdf }\end{array}$} \\
\hline
\end{tabular}

\footnotetext{
${ }^{28}$ Twin City Fan Companies, Ltd. "Fan Performance Characteristics of Axial Fans.” Aerovent, 2000.

http://www.tcf.com/docs/fan-engineering-letters/fan-performance-characteristics-of-axial-fans---fe-2300.pdf?Status=Master

${ }^{29}$ Monroe, R.C. "Consider Variable Pitch Fans." Hudson Products Corp, accessed Feb 2015.

http://www.hudsonproducts.com/products/tuflite/consider.pdf
} 


\subsubsection{Propeller}

The propeller fan is the most basic multi-bladed rotating axial fan with no additional features. They are used a large variety of applications, from small computer fans, to large commercialscale condenser fans. Compared to other fan types, propeller fans are inexpensive because of their simple construction. ${ }^{30}$ Figure 2-10 shows examples of propeller fans.
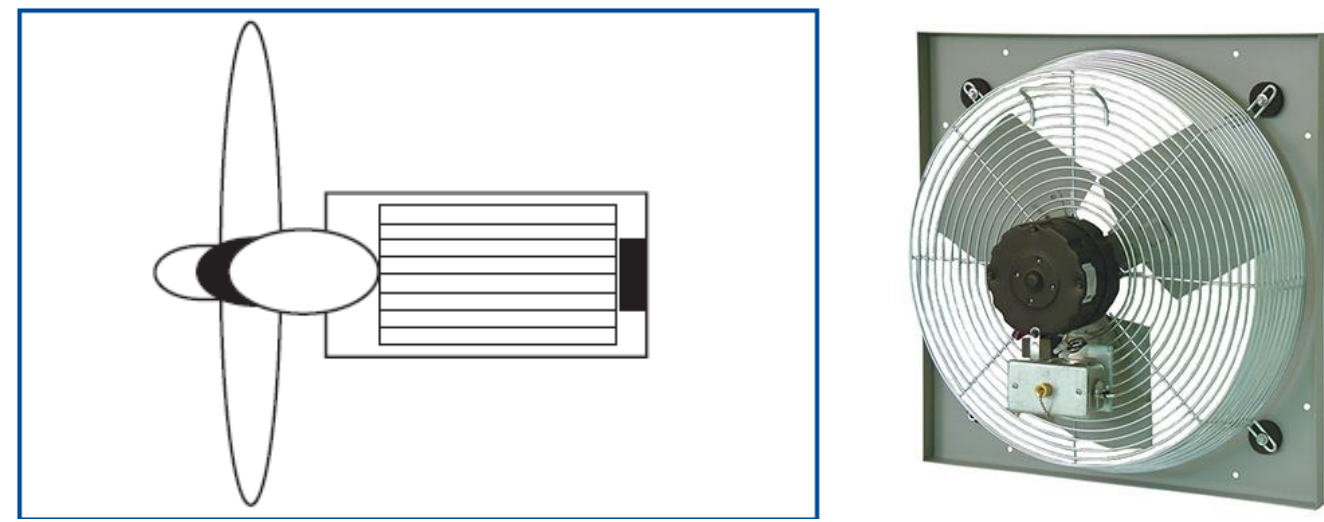

Graphic and Photo Source: DOE-EERE ${ }^{31}$; HVAC Solutions Direct ${ }^{32}$

Figure 2-10: Propeller fans; free fan (left) and panel fan (right)

Propeller fans have two general sub-categories:

- Free fans are free standing fans that circulate air in an unrestricted air space, such as ceiling fans, desk fans, and pedestal fans. They have simple designs are generally lower cost to manufacture; they are generally all direct drive.

- Panel/ring fans are ventilating fans that are embedded within a panel. Examples include window fans, bathroom exhaust fans, whole house fans, air conditioning condenser fans, etc. They may utilize direct and indirect drives.

Typical residential and commercial panel and ring fans use lightweight metal or plastic for both panels and impellers (refer to Figure 2-10). They have fewer, wider, and lighter blades for quieter operation. Though inexpensive, these fans tend to have limited operating conditions, and have the tendency to stall or overload if any flow passages are blocked. Fans used for commercial and/or industrial purposes have stronger, thinner fan blades and are designed for environments with more backpressure. ${ }^{33}$

\footnotetext{
${ }^{30}$ DOE-EERE. “Improving Fan System Performance.” Prepared by LBNL and Resource Dynamics Corp, accessed Feb 2015. https://www1.eere.energy.gov/manufacturing/tech assistance/pdfs/fan sourcebook.pdf

${ }^{31}$ DOE-EERE. “Improving Fan System Performance.” Prepared by LBNL and Resource Dynamics Corp, accessed Feb 2015. https://www1.eere.energy.gov/manufacturing/tech_assistance/pdfs/fan_sourcebook.pdf

${ }^{32}$ Continental Fan - Industrial Exhaust Fan. http://www.hvacsolutionsdirect.com/products/Commercial-Fans-Blowers/IndustrialWall-Exhaust-Fans-Wall-Exhaust-Fan-Shutters/Continental-Fan-PEF-SERIES-PANEL-MOUNTED-Industrial-Exhaust-Fan$\underline{\text { SKU147.html }}$

${ }^{33}$ Twin City Fan Companies, Ltd. "Fan Performance Characteristics of Axial Fans." Aerovent, 2000.

http://www.tcf.com/docs/fan-engineering-letters/fan-performance-characteristics-of-axial-fans---fe-2300.pdf?Status=Master
} 
Propeller fans tend to be noisy compared to other fans, reflecting their inefficient operation $(<50 \%)^{34}$. They operate best when operating close to free delivery - stall and overloading can happen when the fan is called on to provide greater static pressure (and less air flow)

\subsubsection{Tubeaxial}

A tubeaxial fan is essentially a propeller fan placed inside a cylinder. This housing controls the airflow around the fan and leads to improved airflow characteristics. While direct drive is possible, belt-driven configurations are more common so that they can be geared to run at 1,100 rpms. 2-, 4-, and 6- pole motors run at high operating speeds that are not suitable for tubeaxial fans without being geared down. ${ }^{35}$ Figure 2-11 shows examples of tubeaxial fans.
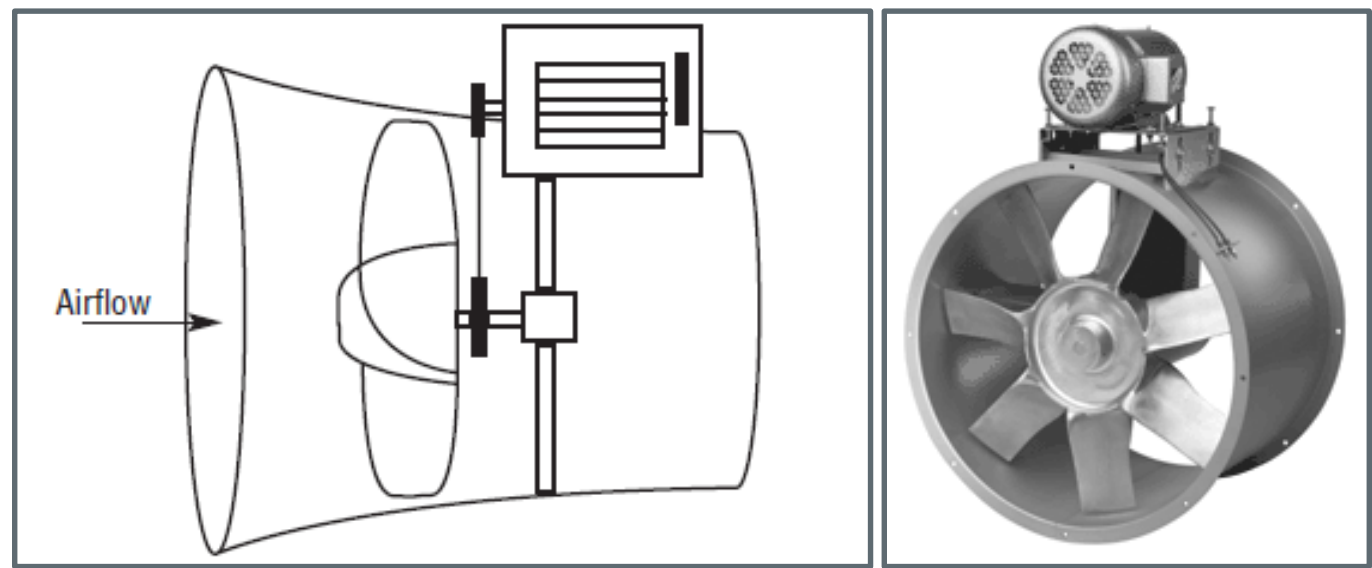

Graphic and Photo Sources: DOE-EERE ${ }^{36}$; Cincinnati Fan $^{37}$

\section{Figure 2-11: Tubeaxial fans}

Tubeaxial fans achieve higher airflow and deliver higher pressures than propeller fans because its strong construction allows for higher speeds and greater horsepower. With improved airflow due to the fan housing, tubeaxial fans are generally capable of achieving better efficiencies than propeller fans.

Tubeaxial fans are suited for medium-pressure, high airflow rate applications. They are typically used for ducted HVAC applications or for exhausting applications requiring higher pressures. Within a duct, tubeaxial fans may be mounted in series to increase delivery pressure. To increase airflow, they may also be mounted in parallel. ${ }^{38}$

\footnotetext{
${ }^{34}$ Energy Efficiency Guide for Industry in Asia. "Fans and Blowers." UNEP, 2006. http://www.energyefficiencyasia.org/docs/ee modules/Chapter-Fans\%20and\%20Blowers.pdf

${ }^{35}$ DOE-EERE. “Improving Fan System Performance.” Prepared by LBNL and Resource Dynamics Corp, accessed Feb 2015. https://www1.eere.energy.gov/manufacturing/tech_assistance/pdfs/fan_sourcebook.pdf

${ }^{36}$ DOE-EERE. “Improving Fan System Performance.” Prepared by LBNL and Resource Dynamics Corp, accessed Feb 2015. https://www1.eere.energy.gov/manufacturing/tech_assistance/pdfs/fan_sourcebook.pdf

${ }^{37}$ Sample tubeaxial fan from Cincinnati Fan. http://www.cincinnatifan.com/

${ }^{38}$ Twin City Fan Companies, Ltd. "Fan Performance Characteristics of Axial Fans." Aerovent, 2000.

http://www.tcf.com/docs/fan-engineering-letters/fan-performance-characteristics-of-axial-fans---fe-2300.pdf?Status=Master
} 
Despite their improvements over propeller fans, tubeaxial fans are more expensive due to the added airflow features and heavier construction. They also are still moderately noisy and provide relatively low energy efficiency $(65 \%) .{ }^{39}$

\subsubsection{Vaneaxial}

A vaneaxial fan is essentially a tubeaxial fan with outlet vanes that improve the airflow pattern, allowing the fan to develop higher pressures by harnessing the airstream's kinetic energy. ${ }^{40}$ These vanes, usually located downstream of the impeller, create a uniform outlet airflow and help remove any swirling imparted on the airstream. Vaneaxial fans are the most efficient of all axial fans (up to $85 \%$ if equipped with airfoil blades and small clearances). ${ }^{41}$ Like tubeaxial fans, vaneaxial fans tend to have a low rotating mass, which allows them to accelerate rapidly. This feature makes them a good fit for emergency ventilation applications where quick air removal or supply is required. ${ }^{42}$ Figure 2-12 displays a diagram and example of a vaneaxial fan.
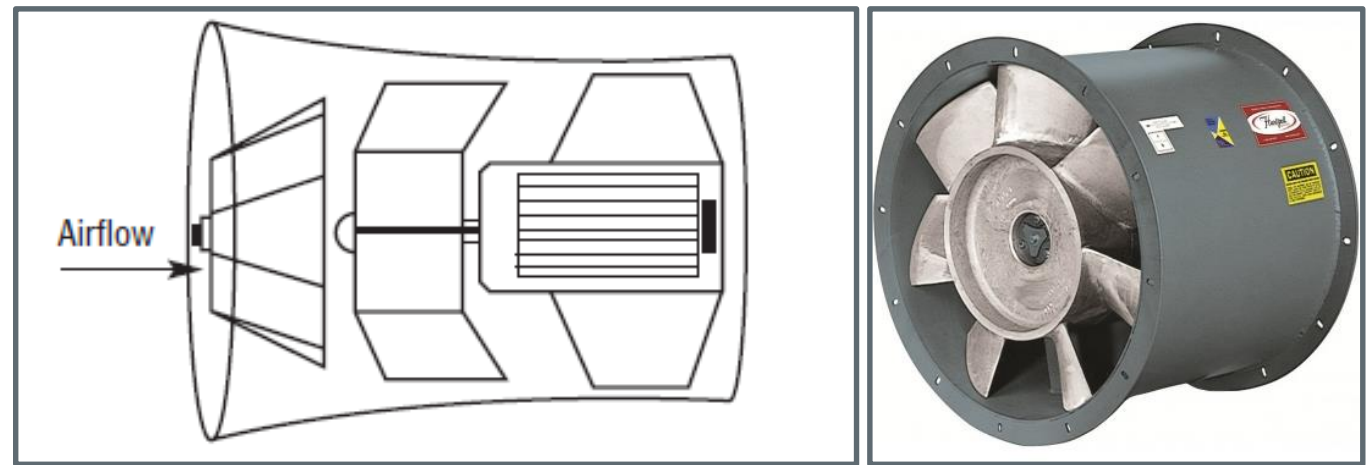

Graphic and Photo Sources: DOE-EERE ${ }^{43} ;$ Hartzell $^{44}$

\section{Figure 2-12: Vaneaxial fans}

The primary advantage of the outlet vanes is the ability of the fan to deliver air in medium- to high-pressure applications (up to $500 \mathrm{mmWC}^{45}$ ) that other axial fans would not be able to serve. Common applications include: induced draft service for boiler exhaust, ducted HVAC applications, and ducted industrial HVAC processes. For even higher pressure operation, multiple vaneaxial fans can be installed in series.

Vaneaxial fans are often equipped with variable-pitch blades, which can be adjusted to change the angle of attack to the incoming airstream. Variable-pitch blades can change the load on the

\footnotetext{
${ }^{39}$ Energy Efficiency Guide for Industry in Asia. "Fans and Blowers." UNEP, 2006. http://www.energyefficiencyasia.org/docs/ee_modules/Chapter-Fans\%20and\%20Blowers.pdf

${ }^{40}$ DOE-EERE. “Improving Fan System Performance.” Prepared by LBNL and Resource Dynamics Corp, accessed Feb 2015. https://www1.eere.energy.gov/manufacturing/tech_assistance/pdfs/fan_sourcebook.pdf

${ }^{41}$ Energy Efficiency Guide for Industry in Asia.

${ }^{42}$ DOE-EERE. “Improving Fan System Performance.” Prepared by LBNL and Resource Dynamics Corp, accessed Feb 2015. https://www1.eere.energy.gov/manufacturing/tech_assistance/pdfs/fan_sourcebook.pdf

${ }^{43}$ DOE-EERE. “Improving Fan System Performance.” Prepared by LBNL and Resource Dynamics Corp, accessed Feb 2015. https://www1.eere.energy.gov/manufacturing/tech_assistance/pdfs/fan_sourcebook.pdf

${ }^{44}$ Sample vaneaxial fan from Hartzell. www.hartzellairmovement.com

45 Energy Efficiency Guide for Industry in Asia. "Fans and Blowers." UNEP, 2006.

http://www.energyefficiencyasia.org/docs/ee_modules/Chapter-Fans\%20and\%20Blowers.pdf
} 
fan, providing an effective and efficient method of airflow control. Adjustments may be automated (during operation) or may be done manually as needed.

Despite the clear improvements in efficiency, vaneaxial fans, with their added vanes and potential variable pitch blades, are relatively expensive. They are also generally limited to cleanair applications, as buildup of contaminants or particulates on the vanes would decrease fan performance. ${ }^{46}$

\subsection{Residential Applications and Market Overview}

This section outlines the typical residential applications of fans and describes the current residential fan market in Section 2.2.1. Section 2.2.2 presents the energy consumption of these residential fan applications.

\subsubsection{Applications}

Fans play a significant role in residential HVAC, including indoor central circulation/supply fans, furnace and draft inducer fans, air conditioner and heat pump condenser fans, window and through-the-wall room air conditioners (RAC), ceiling fans, and pedestal/window fans. The report considers pedestal/window fans as a plug load with low overall usage and does not cover them in detail. ${ }^{47}$ Fans for residential applications, though they vary in type, size, and usage, are typically powered by a permanent split capacitor motor.

Circulation fans used in central HVAC products are the primary air supply fan for homes with central forced-air heating and/or cooling. They are centrifugal blower fans sized with sufficient capacity to both provide supply air throughout the home and also draw in return air through the return air vents. A typical home will have one circulation fan, which uses either forward-curved or backward-curved blades. For homes with combined heating and cooling systems (central HVAC), the circulation fan provides supply air to the home in both heating and cooling seasons. Circulation fans used in central HVAC products are considered in various DOE energy conservation standards rulemakings pursuant to EPCA.

Central air conditioners (CAC) and central heat pumps, in addition to an indoor circulation fan, require a fan for the outdoor condenser, which provides heat rejection to the environment (and for heat pumps, also draws heat in when in heating mode). Residential CACs or HPs typically use one axial fan per system. ${ }^{48}$

\footnotetext{
${ }^{46}$ Energy Efficiency Guide for Industry in Asia.

${ }^{47} \mathrm{EPCA}$, as amended, provides DOE with the statutory authority to set national energy conservation standards. As of 2014, furnace fans, central air conditioners and heat pumps, room air conditioners, furnaces, boilers, and ceiling fans are covered products DOE minimum efficiency standards. Pedestal fans or floor fans are not currently covered products under EPCA. Residential refrigerator/freezers and freezers are covered products under EPCA. With the exception of furnace fans and ceiling fans, efficiency standards do not explicitly cover fan energy consumption and efficiency, but regulates the energy consumption or efficiency of the entire product.

${ }^{48}$ EPCA does not cover CAC or HP supply blowers under the Furnace Fan energy conservation standards unless the CAC or HP is installed with a furnace. Supply blowers of central HVAC units (i.e., CACs or HPs) that are not installed with a residential furnace are covered by the Residential CAC and HP rulemaking.
} 
Residential furnaces and boilers use blowers to either provide supply air to sustain combustion (forced draft), or to provide exhaust for the combustion gases (induced draft). Furnaces and boilers that use fans are called "mechanical draft." Most residential furnaces sold today will have either an inducer fan or a forced draft fan. Higher efficiency residential boilers will have a mechanical draft fan to aid in exhaust of flue gases.

Window or through-wall RACs have a self-contained refrigeration cycle which is served by a single motor that powers an indoor blower and an outdoor axial condenser fan on the same shaft. RACs do not mix indoor and outdoor air streams; the indoor blower draws in and returns (conditioned) indoor air while the outdoor fan induces air circulation for the condenser on the outdoor side.

Ceiling fans are axial fans used for air circulation. Historically they were only used in warm weather to cool occupants. However, newer models can be reversed in heating months to create an updraft de-stratifies room air to bring warm air down from the ceiling. DOE is currently developing an energy conservation standard covering ceiling fans. Homes with ceiling fans tend to have multiple fans installed.

Residential refrigerator/freezers $(\mathrm{R} / \mathrm{F})$ use an axial evaporator fan to supply the refrigerated interior with cold air and an axial condenser fan to reject heat to the room. Residential freezers, however, do not always have two fans; we estimate that $50 \%$ of freezers only have an evaporator fan and rely on natural convection to remove heat from the condenser. ${ }^{49}$

Fans are also used within other household appliances to provide cooling and air circulation. For example clothes dryers require a fan for exhaust and dehumidifiers utilize a single fan to serve the condenser and evaporator.

This report does not cover in detail other miscellaneous fans used in homes. The energy use of these fans is typically not regulated and much less data is available. In general, they have one or more of the following characteristics: low yearly hours of usage, low power consumption, or low shipments and installed base. These miscellaneous fans include:

- Alternative residential ventilation:

- Whole house fan, used to draw hot indoor air out of the house and cooler outdoor air in through open windows during the evening/night

- Attic fan or powered attic ventilator used to exhaust hot attic air

- Residential exhaust fans

- Kitchen exhaust fan

- Bathroom exhaust fan

- Radon fan, operated continuously in homes (typically in basements) to prevent buildup of radon in the home

- Plug load fans - Window fans or pedestal fans

- Evaporative cooler blower (also known as a swamp cooler)

- Other residential appliances, such as heat pump water heater (HPWH) condenser fans and electronics cooling fans

\footnotetext{
49 "Energy Savings Potential and Opportunities for High-Efficiency Electric Motors in Residential and Commercial Equipment," prepared by Navigant Consulting Inc. for BTO, December 2013.

http://www1.eere.energy.gov/library/viewdetails.aspx?productid=6746\&page $=2$
} 


\subsubsection{Market}

The residential fan market is split between those fans sold direct to end users and those included as part of a larger appliance. Most fans are part of the latter group, and are sold as components (motor, fan blades, and controls) to manufacturers who assemble them into residential appliances. Aside from ceiling fans and various miscellaneous free fans (pedestal fans, window fans, and floor fans), complete fans, with motor, blades, and controls are typically not purchased by the end-user. Availability to residential users is typically limited to the purchase of replacement fan blades or motors.

Table 2-3 shows the estimated annual shipments and installed based for the key fan applications in the residential sector. See Appendix A - Data Sources for Shipments and Installed Base for sources and notes.

Table 2-3: Residential Fan Uses and Market Summary

\begin{tabular}{|c|c|c|c|c|}
\hline Applications & Fan Use & Typical Fan Type & $\begin{array}{l}\text { Est. Annual Shipments } \\
\text { (MM) }\end{array}$ & $\begin{array}{l}\text { Est. Installed } \\
\text { Base (MM) }\end{array}$ \\
\hline CAC & Condenser & Axial & 3.9 & 59.5 \\
\hline$C A C \& H P^{A}$ & $\begin{array}{l}\text { Circulation fan } \\
\text { (Evap) }\end{array}$ & Centrifugal & 2.0 & 10.9 \\
\hline Ceiling fan & Circulation & Axial & 17 & 84 \\
\hline Clothes Dryer & Exhaust & Centrifugal & 5.80 & 110 \\
\hline Dehumidifier & Evap \& Condenser & Axial & 1.17 & 15 \\
\hline Freezer & Condenser & Axial & 1.0 & 25 \\
\hline Freezer & Evaporator & Axial & 2.0 & 49 \\
\hline Furnace $^{A}$ & Circulation fan & Centrifugal & 2.63 & 59 \\
\hline Furnace \& Boiler & Inducer fan & Centrifugal & 2.68 & 59 \\
\hline Heat Pump & Condenser & Axial & 1.7 & 14.7 \\
\hline $\mathrm{RAC}^{\mathrm{B}}$ & Condenser & Axial & 7.5 & 29 \\
\hline $\mathrm{RAC}^{\mathrm{B}}$ & Supply fan & Centrifugal & 7.5 & 29 \\
\hline$R / F$ & Condenser & Axial & 8.6 & 144 \\
\hline $\mathrm{R} / \mathrm{F}$ & Evaporator & Axial & 8.6 & 144 \\
\hline \multicolumn{5}{|c|}{$\begin{array}{l}\text { Sources: See Appendix A - Data Sources for Shipments and Installed Base } \\
\text { A: Market data for residential central HVAC circulation fans are split into separate line items because they are differentiated by } \\
\text { DOE energy conservation standards. The Furnace Fan energy conservation standard covers indoor supply fans which are } \\
\text { installed with a furnace, including any standalone outdoor or indoor furnace, and CAC or HP unit installed with a furnace. EPCA } \\
\text { does not cover CAC or HP supply blowers under the Furnace Fan energy conservation standards unless the CAC or HP is } \\
\text { installed with a furnace. Circulation blowers of central HVAC units (i.e., CACs or HPs) with no installed furnace are covered } \\
\text { separately by the Residential CAC and HP rulemaking. } \\
\text { B: RACs typically run two fans on a single motor }\end{array}$} \\
\hline
\end{tabular}

Indoor central HVAC circulation fans are typically sold in a package with residential furnaces, central air conditioners, and heat pumps. Some major furnace manufacturers build their own circulation fans, but some purchase fans from a separate fan manufacturer. In the DOE Furnace Fan standards rulemaking, DOE assumes the manufacturer of the actual HVAC unit to be the manufacturer of the furnace fan. Circulation fans are also sold in A/C units, and feature the same 
fan technology as those sold in furnaces. Major residential furnace and A/C manufacturers include Carrier, Goodman, Trane, Lennox, Rheem, York, and Nordyne. ${ }^{50}$

Ceiling fans can be purchased by homeowners from various distributors. Major manufacturers include Hunter, Hampton Bay, Harbor Breeze, Casablanca, Westinghouse, Emerson, and Aloha Breeze. However, Hunter, Hampton Bay, and Harbor Breeze together constitute more than 45\% of the market for ceiling fans. Ceiling fans have a typical mean lifetime of 14 years. ${ }^{51}$

For residential appliance and HVAC applications such as RACs, CACs, HPs, dehumidifiers, and refrigeration appliances, the manufacturer of the appliance generally purchase or manufacture fan blades and motors separately. Large manufacturers may be able to cost-effectively manufacture the fan blades for their axial fan applications, but still often buy motors from a motor manufacturer. Depending on the complexity of the centrifugal blower, appliance manufactures might purchase or manufacture the blower wheel. While CACs and HPs have lower sales volumes than RACs, CAC's last much longer, (10 years for RAC versus 19 years for $\mathrm{CAC}^{52}$ ), thus the greater installed base of CACs.

Appendix B - Miscellaneous Residential Fans shows shipments and installed base estimates for select miscellaneous residential fans.

\subsubsection{Energy Consumption}

Fans account for $6 \%$ of all residential primary energy consumption. Figure 2-13 shows a breakdown of residential fan applications and their primary energy consumption.

\footnotetext{
${ }^{50}$ DOE. Technical Support Document - Residential Furnaces Fans Energy Conservation Standard, 2014. Accessed March 2015. http://www1.eere.energy.gov/buildings/appliance_standards/rulemaking.aspx/ruleid/41

${ }^{51}$ DOE. Preliminary Technical Support Document - Rulemaking for Ceiling Fans Energy Conservation Standards. Accessed Feb 2015. http://www1.eere.energy.gov/buildings/appliance_standards/rulemaking.aspx/ruleid/65

52 DOE. Technical Support Document - Residential Central Air Conditioning and Heat Pumps Energy Conservation Standard, 2011. Accessed Feb 2015. http://www1.eere.energy.gov/buildings/appliance_standards/product.aspx/productid/75.

DOE. Technical Support Document - Residential Room Air Conditioners Energy Conservation Standard, 2013. Accessed Feb 2015. http://www1.eere.energy.gov/buildings/appliance_standards/product.aspx/productid/41
} 


\section{Residential Primary Energy Breakdown}

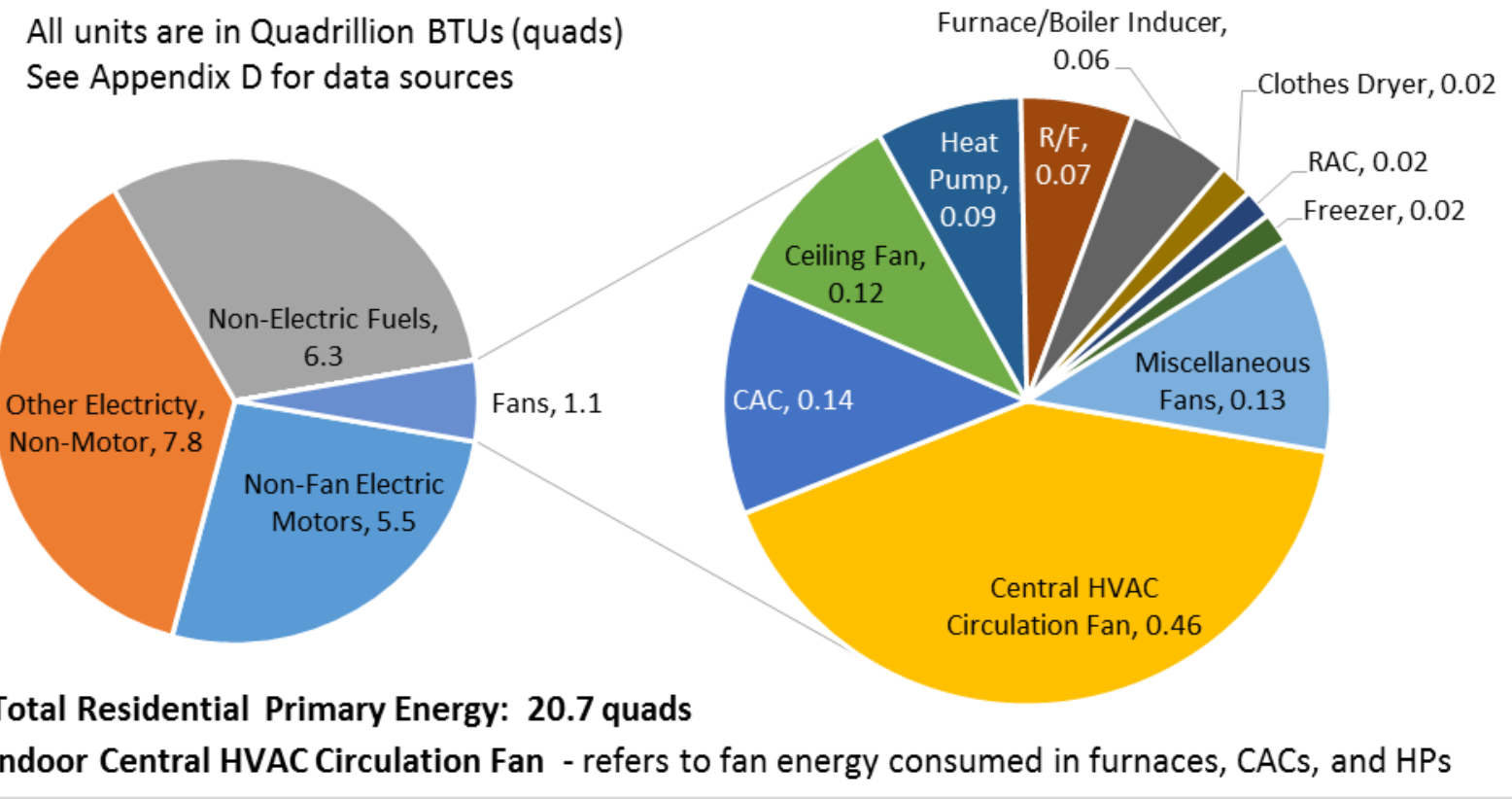

Figure 2-13: Residential fan primary energy consumption

Table 2-4 presents detailed data on the average annual operating hours, the average unit energy consumption (UEC), and the nationwide energy consumption of each fan. The site energy data reflects the total energy use for all fans of a given type installed in the United States. The primary energy (also known as source energy) consumption reflects the fuel (fossil or otherwise) used to serve the site energy needs. This accounts for losses in generation, transmission, and distribution. We assume a site-to-source conversation factor of 3.07. ${ }^{53}$ See Appendix C Calculation Methodology for relevant calculations of U.S. site and primary energy and Appendix D - Data Sources for Operating Hours and UEC for relevant sources.

Table 2-4: Residential Fan Energy Consumption for Selected Applications

\begin{tabular}{lccccc}
$\begin{array}{l}\text { Residential } \\
\text { Application }\end{array}$ & Fan Use & $\begin{array}{c}\text { Annual } \\
\text { Operating Hrs. }\end{array}$ & $\begin{array}{c}\text { Average UEC } \\
(\mathbf{k W h} / \mathbf{y r} \text { ) }\end{array}$ & $\begin{array}{c}\text { U.S. Site Energy } \\
\text { (TWh/yr.) }\end{array}$ & $\begin{array}{c}\text { U.S. Primary Energy } \\
\text { (Quads/yr., \%) }\end{array}$ \\
\hline CAC & Condenser & 1,000 & 220 & 13 & $0.14(12 \%)$ \\
\hline CAC and HPs ${ }^{A}$ & Circulation & 1,000 & 360 & 4.0 & $0.041(4 \%)$ \\
Ceiling fan & Circulation & 2,350 & 132 & 11 & $0.12(10 \%)$ \\
\hline Clothes Dryer & Exhaust & 283 & 20 & 1.9 & $0.020(2 \%)$ \\
Dehumidifier & Supply & 1,095 & 50 & 0.82 & $0.0086(1 \%)$ \\
\hline Freezer & Condenser & 3,000 & 24 & 0.58 & $0.0061(1 \%)$ \\
\hline Freezer & Evaporator & 3,000 & 24 & 1.2 & $0.012(1 \%)$ \\
\hline Furnace ${ }^{A}$ & Circulation & 1,870 & 678 & 40 & $0.42(37 \%)$ \\
Furnace and Boiler & Inducer & 650 & 98 & 5.8 & $0.061(5 \%)$ \\
\hline
\end{tabular}

${ }^{53}$ EIA. Annual Energy Outlook 2014. Accessed Feb 2015. http://www.eia.gov/forecasts/aeo/ 


\begin{tabular}{|c|c|c|c|c|c|}
\hline Heat Pump & Condenser & 1,000 & 560 & 8.2 & $0.086(8 \%)$ \\
\hline RAC & $\begin{array}{l}\text { Condenser \& } \\
\text { Supply }\end{array}$ & 750 & 60 & 1.6 & $0.017(2 \%)$ \\
\hline Refrigerator/Freezer & Condenser & 3,000 & 27 & 3.82 & $0.040(4 \%)$ \\
\hline Refrigerator/Freezer & Evaporator & 3,000 & 18 & 2.54 & $0.027(2 \%)$ \\
\hline \multirow[t]{2}{*}{ Miscellaneous Fans } & - & & & 12 & $0.13(11 \%)$ \\
\hline & & & & Total & $1.1(100 \%)$ \\
\hline \multicolumn{6}{|c|}{$\begin{array}{l}\text { Sources: See Appendix D - Data Sources for Operating Hours and UEC. } \\
\text { A: Furnace circulation fans and CAC circulation fans are the same technology but are classified differently in DOE energy } \\
\text { conservation standards. Please refer to Section } 2.2 .1 \text { for details. Note that available sources (and thus this study) do not } \\
\text { distinguish between CAC and HP supply fan operating hours, though HPs operate for heating and cooling, and CACs operate } \\
\text { only for cooling. }\end{array}$} \\
\hline
\end{tabular}

HVAC applications constitute $79 \%$ of the total fan primary energy consumption in the residential sector. Circulation fans for furnaces constitute $37 \%$ of total residential fan-related primary energy consumption and are the single largest fan load in the residential sector. This is due to high operating hours year round as well being one of the largest fans in a home, with motors between $0.5 \mathrm{hp}$ and $1 \mathrm{hp}$. The maximum consumption is usually associated with cooling operation.

Central air-conditioner and heat pump condenser fans also substantial contributors, consuming $20 \%$ of total fan-related residential annual energy consumption. The condenser fan within a CAC consumes about $10 \%$ of total electricity used by the system. They run on motors of with less than $0.5 \mathrm{hp}$ and are present in approximately $50 \%$ of residences. ${ }^{54}$ Indoor circulation fans for CACs and HPs account for $4 \%$ of total fan-related energy consumption. Ceiling fans, consuming $10 \%$ of total fan-related energy, typically use $1 / 3 \mathrm{hp}$ motors to drive the fan.

Remaining fan applications are those that built into home appliances, usually for vapor compression evaporators and condensers. These include (but are not limited to):

- Condenser and evaporator fans for refrigerator/freezers - $6 \%$ of residential primary energy consumption from fans; fan sizes are small, but usage hours are high and are present in virtually every home

- Condenser and evaporator fans for freezers - less significant at 2\%

- Draft fans for furnaces and boilers - 5\% total; usage is low (heating season only)

- Circulator fans for clothes dryers - constitute $2 \%$ of fan-energy consumption

We estimate that miscellaneous residential fans consume 0.13 quads, or about $11 \%$ of total fanrelated residential primary energy consumption. Miscellaneous fans include:

- Whole house fans - low penetration, but becoming more common among new building stock. Usage typically occurs in evenings and/or overnight when the outdoor temperature is cooler. While they remain a small overall consumer nationally, they could offer potential for energy savings if they are used instead of air conditioning

- Powered attic ventilators - minimal shipment and installed base data is publicly available; however, they are becoming decreasingly popular in most places as the

\footnotetext{
54 "Energy Savings Potential and Opportunities for High-Efficiency Electric Motors in Residential and Commercial Equipment," prepared by Navigant Consulting Inc. for BTO, December 2013.

http://www1.eere.energy.gov/library/viewdetails.aspx ?productid=6746\&page $=2$
} 
benefits in reducing HVAC load by active cooling of the attic have come under scrutiny. As a result, this report does not investigate the topic deeply.

- Home exhaust fans, such as bathroom exhaust fans and kitchen exhaust fans, are very prevalent in residential homes but are used very intermittently, thus we estimate they do not contribute significantly to total primary energy consumption $(<2 \%)$.

- Radon fans operate continuously, but have low unit energy consumption and low installed base. They are typically 40-200 watts. Radon fan energy consumption could increase in the future; as many as 7 million homes need radon mitigation systems (compared to a DOE-estimated current installed base of 600,000). ${ }^{55}$

- HPWHs fans and boiler inducer fans do not consume significant amounts of energy nationally due to low installed base in the residential sector; however, with the growth of the HPWH market, we expect these fans to make an increasing contribution to total fan energy nationwide in the coming years.

- Evaporative cooler blowers - low installed base, but potentially high usage and unit consumption. This report's estimates use are based on an Arthur D. Little study from 1999 for installed base and consumption estimates. ${ }^{56}$

- Computer and electronics fans are very low wattage $(<10 \mathrm{~W})$ and run intermittently, so we estimate a low overall consumption despite the large installed base.

\subsubsection{Costs}

Cost data for residential fans is very limited due to the fact that most residential fans are included as a component of a larger appliance. Replacement parts are available online for consumers and provide general guidance on costs. A brief review of prices for plastic evaporator and condenser fan blades for refrigerators ranging from $\$ 6$ to $\$ 22$. Refrigerator evaporator and condenser fan motors ran from $\$ 20-\$ 120$. As another data point, clothes dryer blower wheels can range from $\$ 22-\$ 45 .{ }^{57}$ We would expect similar ranges of prices for similar fans in other residential appliances. Since these prices are for replacements, it is not clear how they compare to fans in new products. Further, these costs do not include installation labor or cost of energy, so it would misleading to compare these data to lifecycle cost data for other fans.

Two fan applications have cost data available via DOE rulemaking activities: Furnace circulation fans and ceiling fans. Table 2-5 summarizes the cost data for these products.

\footnotetext{
55 EPA. “A Physician's Guide”. September 1993. http://www.epa.gov/radon/pubs/physic.html

56 "Opportunities for Energy Savings in Residential and Commercial Sectors with high-Efficiency Electric Motors." Prepared by Arthur D. Little, Inc. for DOE, 1999. http://www.totalenergycompany.com/pdf/Motor_Efficiency_DOE1999.pdf

${ }^{57}$ Based on 3/10/15 pricing for Frigidaire refrigerator and Kenmore clothes dryer replacement parts from http://www.appliancepartspros.com/
} 
Table 2-5: Residential Fan Costs - Furnace Circulation Fans and Ceiling Fans

\begin{tabular}{|c|c|c|c|c|}
\hline Application & Type & Size (hp) & $\begin{array}{c}\text { Average Purchase } \\
\text { Price }\end{array}$ & $\begin{array}{c}\text { Average } \\
\text { Lifecycle Cost }\end{array}$ \\
\hline $\begin{array}{l}\text { Furnace Circulation } \\
\text { Fan }{ }^{1}\end{array}$ & $\mathrm{FC} / \mathrm{BI}$ Centrifugal & $0.5-1$ & 290 & 2,400 \\
\hline Ceiling Fans ${ }^{2}$ & Axial Propeller & $1 / 3$ & 100 & 280 \\
\hline \multicolumn{5}{|c|}{$\begin{array}{l}\text { Sources: } \\
\text { 1. DOE. Technical Support Document - Residential Furnaces Fans Energy Conservation Standard, 2014. Accessed } \\
\text { March 2015. http://www1.eere.energy.gov/buildings/appliance standards/rulemaking.aspx/ruleid/41 } \\
\text { 2. DOE. Preliminary Technical Support Document - Rulemaking for Ceiling Fans Energy Conservation Standards. } \\
\text { Accessed Feb 2015. http://www1.eere.energy.gov/buildings/appliance standards/rulemaking.aspx/ruleid/65 }\end{array}$} \\
\hline
\end{tabular}

\subsection{Commercial Applications and Market Overview}

This section outlines the typical residential applications of fans and describes the current commercial fan market in Section 2.2.1. Section 2.2.2 presents the energy consumption of these commercial fan applications.

\subsubsection{Applications}

Clean air ventilation involves many different possible fan uses, including: air supply fans in air handling units, blowers in fan coil units, as well as other supplemental ventilation axial fans and blowers. Most common may be the air handler, whose purpose is to supply air throughout a commercial building. Supply air fans draw in outside or return air through hot or cold heat exchangers (containing hot/cold water from boiler/chiller systems), conditioning the air. The fans then force the conditioned air through the vents of the building, providing fresh air supply to the interior. Air handlers typically use one or more centrifugal fans, and may be housed or unhoused. They use forward or all variations of backward-curved blades.

Fan coil units provide space conditioning to individual rooms or spaces and are not connected to a central ducting system. They typically use centrifugal fans to blow air over a heat exchanger containing hot or cold water to condition the room air. They are available as packaged units from major HVAC manufacturers like Trane, Carrier or Johnson Controls.

Exhaust fans take return air from a building's HVAC system and exhaust it to the environment. Exhaust ventilation includes many different types of fans, including wall fans, rooftop ventilators, smoke or heat exhaust fans, and kitchen exhaust fans. For the commercial sector, DOE rulemaking considers axial panel fans and powered rooftop ventilators as the two fan types used in exhaust applications. Exhaust fans could be any either axial (panel propeller, tubeaxial, etc.) or centrifugal fans.

Single packaged vertical air conditioners (SPVAC) and packaged terminal air conditioners (PTACs) are space conditioning units found in hotels, as well as some apartments and office buildings. This report refers to SPVACs and PTACs as air conditioners due to the naming convention, but they also include heat pump models. Their indoor supply fans are typically centrifugal fans, while their outdoor condenser fans are typically axial propeller units. Unlike RACs, these units have separate motors powering each fan 
Commercial unitary air conditioners (CUAC, sometimes referred to as rooftop units, including heat pumps) are packaged space conditioning units which serve a variety of commercial applications. A CUAC typically utilizes a centrifugal indoor supply fan and an axial propeller outdoor condenser fan. The majority are belt driven, but higher efficiency ones are direct drive.

Chiller systems require fans for heat rejection either through an air-cooled condenser, or through a cooling tower for water-cooled chillers. Air-cooled chillers often use multiple axial propeller condenser fans, but the number varies depending on its size and configuration. Cooling tower fans utilize a large axial fan that circulates outdoor air through the cooling tower

Commercial refrigeration utilizes smaller fans. This category includes reach-ins (categorized as commercial refrigeration equipment, $\mathrm{CRE}$, in-line with DOE standard categorization), beverage vending machines (BVM), and walk-in coolers and freezers (WICF). Each of these applications uses two fans, one each for the evaporator and condenser; each fan is usually axial propeller type and connected to its own motor

Other miscellaneous commercial fan applications include:

- Mechanical draft in commercial furnaces and boilers to provide negative pressure (induced draft) or positive pressure (forced draft) for combustion

- Condenser fans for heat rejection in automatic commercial ice makers (ACIM) (typically very small axial propeller fans)

- Axial fans for cooling office equipment (computers, copiers, etc.)

- Blower in commercial clothes dryers to circulate drying air

- Vacuum cleaner fans

\subsubsection{Market}

Commercial fan manufacturers ship approximately 256,000 fans per year for clean air ventilation and approximately 125,000 fans per year for exhaust. ${ }^{58}$ Some of the primary manufacturers include: Twin City Fans, Greenheck, Loren Cook, New York Blower, Morrison Products, and Lau. The DOE CIF rulemaking found that the market is very distributed, with many fan manufacturers focusing on specific fan types. ${ }^{59}$ Table 2-6 lists commercial fans and their applications, along with estimated shipments and installed base.

Due to a lack of fan-coil-specific market and shipment information, fans in fan coil units are included in the Clean Air Ventilation category.

\footnotetext{
${ }^{58}$ DOE. National Impact Analysis - Rulemaking for Commercial and Industrial Fans and Blowers. Accessed Feb 2015. http://www1.eere.energy.gov/buildings/appliance_standards/rulemaking.aspx/ruleid/25.

In addition to considering centrifugal and axial fans, CIF also includes inline fans and mixed flow fans in Clean Air Ventilation applications. Powered roof ventilators (which may be centrifugal or axial fans) are included in Exhaust fan applications.

${ }^{59}$ Input from DOE subject matter expert.
} 
Table 2-6: Commercial Fan Uses and Market Summary

\begin{tabular}{|c|c|c|c|c|}
\hline Applications & Fan Use & Typical Fan Type & $\begin{array}{c}\text { Est. Annual } \\
\text { Shipments (1000s) }\end{array}$ & $\begin{array}{l}\text { Est. Installed Base } \\
\text { (MM) }\end{array}$ \\
\hline Clean Air Vent. & Supply \& circulation & Axial; Centrifugal & 260 & 4.0 \\
\hline Exhaust Vent. & Exhaust & Axial; Centrifugal & 120 & 2.0 \\
\hline PTACs & Indoor & Centrifugal & 500 & 5.0 \\
\hline PTACs & Outdoor & Axial & 500 & 5.0 \\
\hline SPVAC & Indoor & Centrifugal & 51 & 0.8 \\
\hline SPVAC & Outdoor & Axial & 51 & 0.8 \\
\hline CUAC & Small - Indoor & Centrifugal & 589 & 8.8 \\
\hline CUAC & Med - Indoor & Centrifugal & 169 & 2.5 \\
\hline CUAC & Lrg - Indoor & Centrifugal & 16 & 0.2 \\
\hline CUAC & Small - Outdoor & Axial & 589 & 8.8 \\
\hline CUAC & Med - Outdoor & Axial & 169 & 2.5 \\
\hline CUAC & Lrg - Outdoor & Axial & 16 & 0.2 \\
\hline Furnace & Draft Fan & Centrifugal & 616 & 9.2 \\
\hline Boiler & Draft Fan & Centrifugal & 32 & 0.9 \\
\hline Chillers & Air-cooled evaporator & Axial & 23 & 0.5 \\
\hline Cooling Tower & Outdoor Fan & Axial & 12 & 0.3 \\
\hline CRE & Condenser & Axial & 443 & 3.1 \\
\hline CRE & Evaporator & Axial & 443 & 3.1 \\
\hline BVMs & Condenser & Axial & 342 & 3.7 \\
\hline BVMs & Evaporator & Axial & 342 & 3.7 \\
\hline WICF & Condenser & Axial & 287 & 2.0 \\
\hline WICF & Evaporator & Axial & 287 & 2.0 \\
\hline ACIMs & Condenser & Axial & 162 & 2.0 \\
\hline
\end{tabular}

Manufacturers of packaged HVAC systems, such as CUACs, PTACs, and SPVACs usually buy fan components (motors and fan blades/wheels) separately and assemble them in-house. Little information is available on common fan blade or fan wheel suppliers. ${ }^{60}$ Heavy-duty, large axial fan blades (e.g., condenser fans) and blower wheels (e.g., supply fans) typically come from a major American fan manufacturer, while smaller (and often plastic) fan blades may be manufactured in-house or purchased from a low-cost, foreign manufacturer. CUAC manufacturers generally purchase the fan wheel and motor separately for indirect drive models, while they commonly purchase the whole assembly together for direct drive models. ${ }^{61}$

Fans used in commercial refrigeration, like BVM, WICF, CRE, and ACIM, are embedded as part of the appliance package. Replacement fans and motors may be available for businesses, however, the appliances are typically purchased with fans already installed. The manufacturers of the commercial appliances typically purchase the motors and fan blades (low-cost, low

\footnotetext{
${ }^{60}$ Manufacturing origin is not marked on fan blades/wheels, and so is typically unknown during DOE standards rulemaking.

${ }^{61}$ Input from DOE subject matter experts for PTACs and CUACs.
} 
efficiency injection molded plastic parts) separately, and likely not from the major fan manufacturers listed above.

\subsubsection{Energy Consumption}

Fans in commercial applications accounts for $13 \%$ of total commercial primary energy consumption. Fans account for $56 \%$ of the total motor energy consumption in the commercial sector. Figure 2-14 provides a breakdown of commercial fan applications and their associated primary energy consumption. See Appendix C - Calculation Methodology for a description of calculation methodology.

\section{Commercial Primary Energy Breakdown}

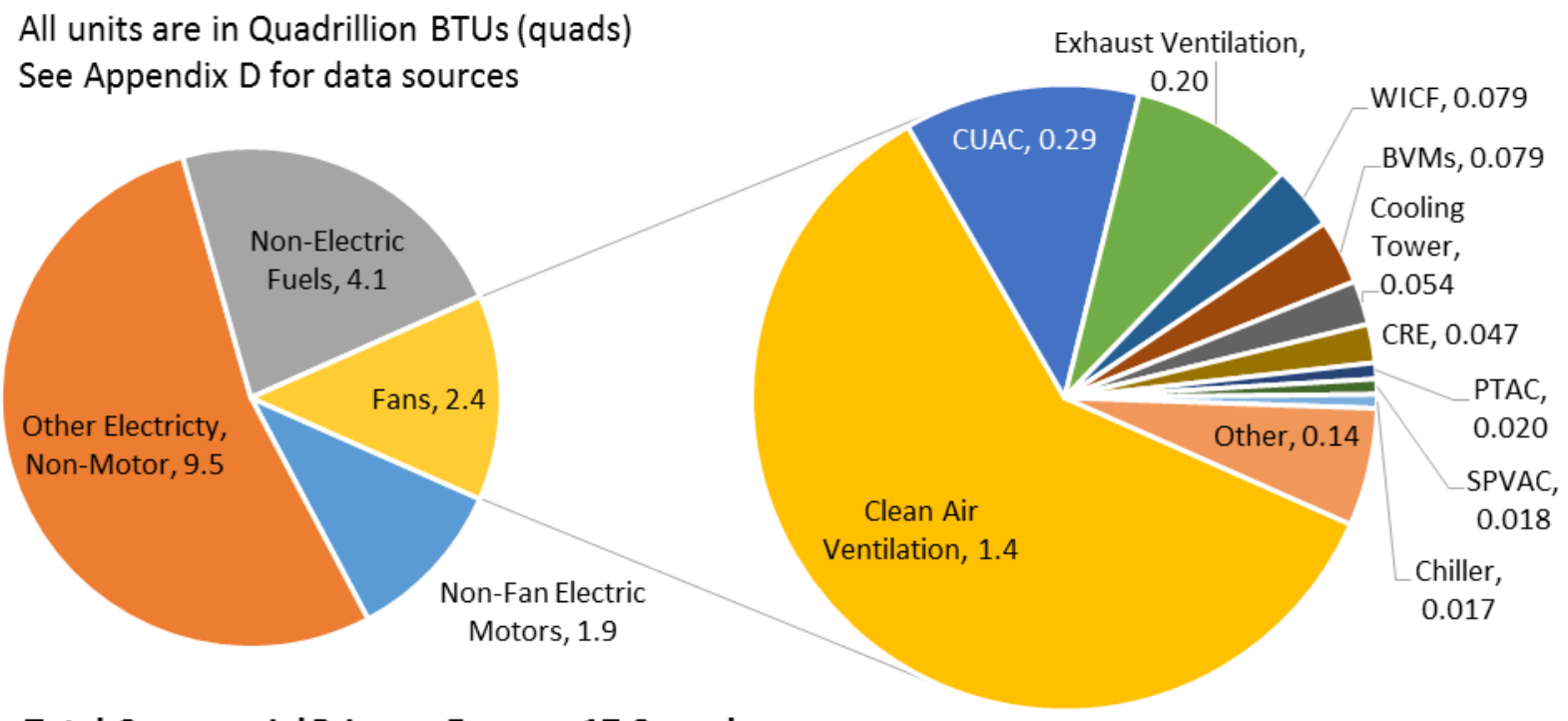

Total Commercial Primary Energy: 17.8 quads

Other: Boiler/furnace draft, ACIMs, and misc applications

Figure 2-14: Commercial fan primary energy consumption

Fans used for building ventilation and cooling account for over 2 quads, or $86 \%$ of commercial fan-related primary energy consumption. This includes ventilation fans (supply and exhaust), which together account for 1.6 quads (68\% of commercial fan-related primary energy), as well as packaged HVAC units like CUACs. Fans used in commercial refrigeration appliances, including CRE, BVM, and WICF account for $\sim 9 \%$. Miscellaneous fan applications, such as cooling fans in office equipment, commercial laundry, and furnace or boiler mechanical draft fans account for $5 \%$ of total fan-related consumption.

Table 2-7 presented detailed data on the average annual operating hours, the average unit energy consumption (UEC), and the nationwide energy consumption of each fan. 
Table 2-7: Commercial Fan Energy Consumption for Selected Applications

\begin{tabular}{|c|c|c|c|c|c|}
\hline $\begin{array}{l}\text { Commercial } \\
\text { Application }\end{array}$ & Fan Use & $\begin{array}{c}\text { Annual } \\
\text { Operating Hrs. }\end{array}$ & $\begin{array}{c}\text { Average UEC } \\
\text { (kWh/yr.) }\end{array}$ & $\begin{array}{l}\text { U.S. Site Energy } \\
\text { (TWh/yr.) }\end{array}$ & $\begin{array}{l}\text { U.S. Primary Energy } \\
\text { (Quads/yr., \%) }\end{array}$ \\
\hline Clean Air Vent. & $\begin{array}{l}\text { Supply \& } \\
\text { circulation }\end{array}$ & 6,700 & - & 140 & $1.4(60 \%)$ \\
\hline Exhaust Vent. & Exhaust & 6,200 & - & 19 & $0.20(8 \%)$ \\
\hline PTAC & Indoor & 3,600 & 230 & 1.1 & $0.012(0.5 \%)$ \\
\hline PTAC & Outdoor & 3,600 & 150 & 0.75 & $0.0079(0.3 \%)$ \\
\hline SPVAC & Indoor & 5,700 & 1,400 & 1.1 & $0.011(0.5 \%)$ \\
\hline SPVAC & Outdoor & 5,700 & 920 & 0.70 & $0.0074(0.3 \%)$ \\
\hline CUAC & Small - Indoor & 1,000 & 920 & 8.1 & $0.085(4 \%)$ \\
\hline CUAC & Med - Indoor & 1,200 & 1,800 & 4.5 & $0.047(2 \%)$ \\
\hline CUAC & Large - Indoor & 1,500 & 4,400 & 1.1 & $0.011(0.5 \%)$ \\
\hline CUAC & Small - Outdoor & 1,000 & 920 & 8.1 & $0.085(4 \%)$ \\
\hline CUAC & Med - Outdoor & 1,200 & 1,800 & 4.5 & $0.047(2 \%)$ \\
\hline CUAC & Large - Outdoor & 1,500 & 4,400 & 1.1 & $0.011(0.5 \%)$ \\
\hline Furnace & Draft Fan & 442 & 100 & 1.0 & $0.01(0.4 \%)$ \\
\hline Boiler & Draft Fan & 442 & 290 & 0.25 & $0.003(0.1 \%)$ \\
\hline Chiller & $\begin{array}{l}\text { Air-cooled } \\
\text { evaporator }\end{array}$ & 2,000 & 3,500 & 1.6 & $0.02(0.7 \%)$ \\
\hline Cooling Tower & Outdoor Fan & 2,400 & 20,000 & 5.1 & $0.054(2 \%)$ \\
\hline CRE & Condenser & 6,600 & 1,100 & 3.6 & $0.037(2 \%)$ \\
\hline CRE & Evaporator & 6,600 & 300 & 0.92 & $0.010(0.4 \%)$ \\
\hline BVM & Condenser & 8,760 & 1,500 & 5.7 & $0.060(3 \%)$ \\
\hline BVM & Evaporator & 8,760 & 490 & 1.8 & $0.019(1 \%)$ \\
\hline WICF & Condenser & 4,400 & 1,900 & 3.8 & $0.040(2 \%)$ \\
\hline WICF & Evaporator & 4,400 & 1,900 & 3.8 & $0.040(2 \%)$ \\
\hline ACIM & Condenser & 3,700 & 550 & 1.1 & $0.012(0.5 \%)$ \\
\hline \multirow[t]{2}{*}{ Misc. } & - & & - & 11 & $0.12(5 \%)$ \\
\hline & & & & Total: & $2.4(100 \%)$ \\
\hline
\end{tabular}

Clean air ventilation is the category of fan applications for delivering conditioned air to indoor spaces; it accounts for 1.4 quads, or $60 \%$ of total commercial fan-related primary energy consumption. The CIF rulemaking estimates that fans used for clean air applications can span from $<1 \mathrm{hp}$ to $>200 \mathrm{hp} .{ }^{62}$ (The larger end of fan sizes are generally housed or unhoused centrifugal fans.) The majority of centrifugal fans used for air handling supply for commercial buildings are between 3 and $35 \mathrm{hp}$. Axial fans, which can also be used as exhaust fans, are used for commercial clean air delivery with sizes typically $<10 \mathrm{hp}$. The CIF rulemaking estimates

\footnotetext{
${ }^{62}$ DOE. Life-cycle Costs Analysis - Rulemaking for Commercial and Industrial Fans and Blowers. Accessed Feb 2015. http://www1.eere.energy.gov/buildings/appliance_standards/rulemaking.aspx/ruleid/25.
} 
high annual usage (6,700 hours) though this may account for partial fan loading conditions where the fan runs at partial power. ${ }^{63}$

Commercial exhaust fans are typically smaller than clean air fans because they are not called on to supply pressure and flow throughout a building. Exhaust fans are made up mostly of axial panel fans and power roof ventilators which range in size up to $10 \mathrm{hp} .{ }^{64}$ The CIF rulemaking states that exhaust fans average 6,200 hours of use per year. ${ }^{65}$ An independent report quoted lower total usage, however we proceeded with the CIF rulemaking data because it was more current, and from based on a respected source. ${ }^{66}$

CUACs come in a range of sizes, and thus require fans which range significantly in power consumption. CUAC blowers range from $1.7-7.4 \mathrm{hp}$, while CUAC condenser fan range from $1 / 4$ to $1 \mathrm{hp} .{ }^{67} \mathrm{We}$ estimate that both fans use about $10 \%$ of the total unit electricity consumption of the CUAC unit. ${ }^{6}$ Combined, all CUAC indoor and outdoor fans consume approximately 0.3 quads, or $12 \%$ of total commercial fan-related primary energy

PTAC and SPVAC supply and condenser fans are relatively small: SPVACs range from 1/5 $3 / 4 \mathrm{hp}$ and PTACs range from 1/12 - 1/4 hp. SPVACs have one motor powering two indoor blowers (considered as one fan in this analysis). For both units, we estimate indoor fans consume $\sim 15 \%$ total unit energy consumption, and outdoor fans $\sim 10 \%$ of total unit energy consumption (rest attributed to the compressor).

As described in Section 2.2.2, many packaged HVAC units purchase motors and fan blades separately, before assembling and integrating them into the packaged unit. This practice, while cost effective, may yield lower overall fan efficiency as compared to fans which are sold preassembled. For example, a blower wheel may be paired with in-house housing which may not offer ideal airflow characteristics, while pre-assembled fan packages may offer housings which develop better flow. Please refer to Section 2.4 for more details on energy savings opportunities.

Chiller plant fans, including cooling tower fans and air-cooled chiller condenser fans, constitute $3 \%$ of commercial fan primary energy consumption. Chiller evaporator fans are between 2 and $10 \mathrm{hp}$ while cooling tower fan motors are between 5 and $25 \mathrm{hp}$. These fans run 2,000 and 2,400 hours per year for condenser fans and cooling tower fans, respectively. ${ }^{69}$

\footnotetext{
63 The DOE-ADL report (1999) finds significantly lower annual clean air ventilation usage rates (3000 hours) - Source: "Opportunities for Energy Savings in Residential and Commercial Sectors with high-Efficiency Electric Motors." Prepared by Arthur D. Little, Inc. for DOE, 1999. http://www.totalenergycompany.com/pdf/Motor Efficiency DOE1999.pdf.

${ }^{64}$ DOE. Life-cycle Costs Analysis - Rulemaking for Commercial and Industrial Fans and Blowers. Accessed Feb 2015. http://www1.eere.energy.gov/buildings/appliance_standards/rulemaking.aspx/ruleid/25.

${ }^{65}$ DOE. Life-cycle Costs Analysis - Rulemaking for Commercial and Industrial Fans and Blowers. Accessed Feb 2015. http://www1.eere.energy.gov/buildings/appliance standards/rulemaking.aspx/ruleid/25.

${ }^{66}$ DOE-ADL report (1999) estimates 5681 hours of annual usage. Source: "Opportunities for Energy Savings in Residential and Commercial Sectors with high-Efficiency Electric Motors.” Prepared by Arthur D. Little, Inc. for DOE, 1999. http://www.totalenergycompany.com/pdf/Motor_Efficiency_DOE1999.pdf.

${ }^{67}$ Input from DOE subject matter experts for CUACs, 2013.

68 "Energy Savings Potential and Opportunities for High-Efficiency Electric Motors in Residential and Commercial Equipment," prepared by Navigant Consulting Inc. for BTO, December 2013.

http://www1.eere.energy.gov/library/viewdetails.aspx? productid=6746\&page $=2$

69 "Opportunities for Energy Savings in Residential and Commercial Sectors with high-Efficiency Electric Motors." Prepared by Arthur D. Little, Inc. for DOE, 1999. http://www.totalenergycompany.com/pdf/Motor_Efficiency_DOE1999.pdf.
} 
Commercial refrigeration fans, account for $9 \%$ of total commercial fan-related primary energy. The fans used in these refrigeration appliances are generally very small; vary in usage. For example, ACIM fans use 6 to 15 watts. BVM fans run continuously, but the others cycle. ${ }^{70}$

We estimate fans used in other miscellaneous commercial applications such as office equipment cooling fans, commercial clothes dryer blowers, and vacuum cleaner fans consume approximately 0.12 quads, or $5 \%$ of fan-related primary energy consumption. ${ }^{71}$

\subsubsection{Costs}

As with residential fan applications, many commercial fans are sold as part of a piece of equipment and as a result, detailed cost data is not readily available on just the fan itself.

From DOE rulemaking activities, we aggregated costs for clean air ventilation fans (see Table 2-8) and for exhaust fans (see Table 2-9).

Table 2-8: Clean Air Ventilation Fan Costs

\begin{tabular}{|c|c|c|c|c|c|c|c|c|}
\hline \multirow{2}{*}{ Size (hp) } & \multicolumn{2}{|c|}{ Axial Unhoused } & \multicolumn{2}{|c|}{ Centrifugal Housed } & \multicolumn{2}{|c|}{ Centrifugal Unhoused } & \multicolumn{2}{|c|}{ Average } \\
\hline & $\begin{array}{c}\text { Purchase } \\
\text { Price }\end{array}$ & $\begin{array}{c}\text { Lifecycle } \\
\text { Cost }\end{array}$ & $\begin{array}{c}\text { Purchase } \\
\text { Price }\end{array}$ & $\begin{array}{l}\text { Lifecycle } \\
\text { Cost }\end{array}$ & $\begin{array}{c}\text { Purchase } \\
\text { Price }\end{array}$ & $\begin{array}{l}\text { Lifecycle } \\
\text { Cost }\end{array}$ & $\begin{array}{c}\text { Purchase } \\
\text { Price }\end{array}$ & $\begin{array}{c}\text { Lifecycle } \\
\text { Cost }\end{array}$ \\
\hline $0.1-1.00$ & $\$ 710$ & $\$ 7,000$ & $\$ 1,100$ & $\$ 7,500$ & $\$ 1,100$ & $\$ 9,100$ & 1,100 & 7,600 \\
\hline $1.00-1.80$ & 870 & 14,000 & 1,200 & 15,000 & 1,400 & 14,000 & 1,300 & 16,000 \\
\hline $1.80-3.25$ & 1,100 & 22,000 & 1,500 & 28,000 & 1,600 & 24,000 & 1,600 & 26,000 \\
\hline $3.25-5.85$ & 1,600 & 40,000 & 1,800 & 47,000 & 1,500 & 37,000 & 2,000 & 43,000 \\
\hline $5.85-10.54$ & 2,400 & 67,000 & 2,500 & 83,000 & 1,900 & 66,000 & 2,500 & 74,000 \\
\hline $10.54-18.98$ & 2,900 & 120,000 & 2,600 & 150,000 & 2,600 & 120,000 & 3,300 & 130,000 \\
\hline $18.98-34.20$ & & & 3,800 & 250,000 & 2,500 & 190,000 & 4,100 & 230,000 \\
\hline $34.20-61.62$ & & & 5,000 & 430,000 & 5,000 & 380,000 & 6,100 & 420,000 \\
\hline $61.62-111.01$ & & & 5,500 & 760,000 & 6,000 & 830,000 & 7,900 & 750,000 \\
\hline $111.01-200.0$ & & & 6,500 & $1,100,000$ & & & 6,500 & $1,100,000$ \\
\hline
\end{tabular}

\footnotetext{
70 "Energy Savings Potential and Opportunities for High-Efficiency Electric Motors in Residential and Commercial Equipment," prepared by Navigant Consulting Inc. for BTO, December 2013.

http://www1.eere.energy.gov/library/viewdetails.aspx?productid=6746\&page=2

${ }^{71}$ We estimate miscellaneous fan applications as $2.5 \%$ of total motor-related commercial energy consumption based on estimates for miscellaneous commercial motor consumption from the motor reports of 1999 and 2013. They associate $7 \%$ of commercial motor energy with miscellaneous motor applications. From the list of applications, we identified applications containing commercial fans (office equipment fans, dryers, vacuum cleaner fans). Based on our estimates, we associated $2.5 \%$ of commercial motor energy with these applications.

Sources:

"Opportunities for Energy Savings in Residential and Commercial Sectors with high-Efficiency Electric Motors." Prepared by Arthur D. Little, Inc. for DOE, 1999. http://www.totalenergycompany.com/pdf/Motor_Efficiency_DOE1999.pdf.

"Energy Savings Potential and Opportunities for High-Efficiency Electric Motors in Residential and Commercial Equipment," prepared by Navigant Consulting Inc. for BTO, December 2013.

http://www1.eere.energy.gov/library/viewdetails.aspx?productid=6746\&page $=2$
} 
Table 2-9: Exhaust Fan Costs

\begin{tabular}{|c|c|c|c|c|c|c|}
\hline \multirow[b]{2}{*}{ Size (hp) } & \multicolumn{2}{|c|}{ Axial Unhoused } & \multicolumn{2}{|c|}{ Powered Rooftop Ventilators } & \multicolumn{2}{|c|}{ Average } \\
\hline & $\begin{array}{c}\text { Purchase } \\
\text { Price }\end{array}$ & Lifecycle Cost & $\begin{array}{c}\text { Purchase } \\
\text { Price }\end{array}$ & Lifecycle Cost & $\begin{array}{c}\text { Purchase } \\
\text { Price }\end{array}$ & Lifecycle Cost \\
\hline $0.1-1.00$ & $\$ 710$ & $\$ 6,200$ & $\$ 920$ & $\$ 7,800$ & $\$ 810$ & $\$ 7,000$ \\
\hline $1.00-1.80$ & 870 & 13,000 & 1,400 & 16,000 & 1,100 & 15,000 \\
\hline $1.80-3.25$ & 1,100 & 20,000 & 2,100 & 25,000 & 1,600 & 23,000 \\
\hline $3.25-5.85$ & 1,600 & 37,000 & 2,900 & 42,000 & 2,300 & 40,000 \\
\hline $5.85-10.54$ & 2,400 & 63,000 & 3,900 & 67,000 & 3,100 & 65,000 \\
\hline $10.54-18.98$ & 2,900 & 98,000 & 7,300 & 110,000 & 5,100 & 110,000 \\
\hline
\end{tabular}

\subsection{Energy Savings Opportunity}

\subsubsection{Energy Savings Summary}

This report identifies savings opportunities for fans including improvements to motors and controls, fan blade or housing designs, and fan system designs.

Table 2-10 and Table 2-11 show a total of 2.6 quads of estimated annual primary energy technical savings potential for residential (0.9 quads) and commercial (1.7 quads) fans and fan systems, respectively. These estimates assume $100 \%$ adoption of each high-efficiency technology or other improvement. For each savings opportunity, we calculated national primary energy savings potential by estimating unit energy savings and potential suitability for the installed base of the relevant applications:

$$
\begin{aligned}
& \text { Energy savings potential }_{(\text {primary energy nationwide })} \\
& \qquad \begin{array}{l}
=\text { Energy consumption }_{(\text {primary energy in relevant applications })} \\
\times \text { Unit energy savings }_{(\%)} \times \text { Suitability }_{(\% \text { of all units installed })}
\end{array}
\end{aligned}
$$

We have attempted to eliminate duplicative potential savings in Table 2-10 and Table 2-11, and have noted such points of overlap in the following sections. For example, a building owner may address the need for varying fan airflow in a cooling tower by either installing a fan with variable speed drive, or installing a fan with variable pitch blades. Due to the interconnectedness of various savings opportunities, duplicative savings may still exist.

\section{Table 2-10: Residential Fan Technical Energy Savings Potential Summary (100\% adoption)}

\begin{tabular}{llc}
\hline Residential Savings Category & \multicolumn{1}{c}{ Description of Opportunities } & $\begin{array}{c}\text { Est. Annual U.S. Primary Energy Savings } \\
\text { Potential (quads) }\end{array}$ \\
\hline Fan motors and controls & $\begin{array}{l}\text { Advanced motors; smart controls; } \\
\text { airflow controls }\end{array}$ & 0.5 \\
\hline Blade design and selection & $\begin{array}{l}\text { Aerodynamic blade design; blade } \\
\text { selection }\end{array}$ & 0.2 \\
\hline
\end{tabular}




\section{Table 2-11: Commercial Fan Technical Energy Savings Potential Summary (100\% adoption)}

\begin{tabular}{llc}
\hline $\begin{array}{l}\text { Commercial Savings } \\
\text { Category }\end{array}$ & \multicolumn{1}{c}{ Description of Opportunities } & $\begin{array}{c}\text { Est. Annual U.S. Primary Energy } \\
\text { Savings Potential (quads) }\end{array}$ \\
\hline $\begin{array}{ll}\text { Fan motors and controls } \\
\text { Blade or housing design } \\
\text { and selection }\end{array}$ & $\begin{array}{l}\text { Advanced motors; variable speed drives } \\
\text { (VSD); smart controls; indirect drives }\end{array}$ & 0.5 \\
\hline Fan system & $\begin{array}{l}\text { Aerodynamic blade or housing design; } \\
\text { blade selection; variable pitch } \\
\text { Sizing; duct design; duct leakage; } \\
\text { Variable air volume (VAV) operation; } \\
\text { multiple fans; scheduling }\end{array}$ & 0.4 \\
\hline Maintenance & Ensure proper maintenance & 0.7 \\
\hline
\end{tabular}

This report includes potential energy savings for pump-specific motor and control improvements. These improvements include permanent magnet motors and variable speed drives (VSDs). See Appendix F - Motor Technology Overview for additional details on these technologies, and refer directly to the BTO Motors Report for citations and motors related data. ${ }^{72}$

\subsubsection{Barriers and Challenges to Achieving Fan Energy Savings}

Table 2-12 summarizes several barriers and challenges to achieving reducing energy consumption of fans and fan systems in the U.S.

Table 2-12: Summary of Barriers to Achieving Fan Energy Savings

\begin{tabular}{|c|c|c|c|}
\hline \multicolumn{2}{|l|}{ Category } & Barrier & Description \\
\hline & $\begin{array}{l}\text { System } \\
\text { Design }\end{array}$ & $\begin{array}{l}\text { System designers } \\
\text { motivated to } \\
\text { oversize fans }\end{array}$ & $\begin{array}{l}\text { - Conservative engineering practice leads designer to } \\
\text { specify fan system which exceeds system requirements } \\
\text { - Designers oversize fans due to uncertainties in system } \\
\text { specifications, fouling effects, or future capacity increases } \\
\text { - For designers, cost of over-specifying a fan is less than the } \\
\text { cost of inadequate system performance }\end{array}$ \\
\hline
\end{tabular}

\footnotetext{
72 "Energy Savings Potential and Opportunities for High-Efficiency Electric Motors in Residential and Commercial Equipment," prepared by Navigant Consulting Inc. for BTO, December 2013.

http://www1.eere.energy.gov/library/viewdetails.aspx?productid=6746\&page $=2$
} 


\begin{tabular}{|c|c|c|c|}
\hline Category & & Barrier & Description \\
\hline & $\begin{array}{l}\text { System } \\
\text { Design }\end{array}$ & $\begin{array}{l}\text { Poor system design } \\
\text { and controls }\end{array}$ & $\begin{array}{l}\text { - Designers may not consider designs that minimize static } \\
\text { pressure losses in the system or provide more energy } \\
\text { efficient performance (see "Split Incentives" barrier) } \\
\text { - Retrofit of a poorly designed system is costly and difficult }\end{array}$ \\
\hline & $\begin{array}{l}\text { System } \\
\text { Design }\end{array}$ & $\begin{array}{l}\text { Lack of training or } \\
\text { resistance to better } \\
\text { options }\end{array}$ & $\begin{array}{l}\text { Some building owners or facilities staff may lack training, } \\
\text { technical understanding, or otherwise hesitate to adopt } \\
\text { lower-energy options as retrofit options }{ }^{73}\end{array}$ \\
\hline & Fan Selection & $\begin{array}{l}\text { Space constraints } \\
\text { could limit efficient } \\
\text { options }\end{array}$ & $\begin{array}{l}\text { - Retrofits in existing buildings tend to be space-restricted, } \\
\text { as original installers typically select the smallest fans to } \\
\text { reduce first cost } \\
\text { - Some higher efficiency fans require more space for the } \\
\text { same airflow requirements }\end{array}$ \\
\hline & $\begin{array}{l}\text { Operations \& } \\
\text { Maintenance }\end{array}$ & $\begin{array}{l}\text { Poor installation or } \\
\text { maintenance } \\
\text { practices }\end{array}$ & $\begin{array}{l}\text { - Low cost parts \& poor design can result in inefficient } \\
\text { systems } \\
\text { - Maintenance is often overlooked due to time- or cost- } \\
\text { constraints }{ }^{74}\end{array}$ \\
\hline & $\begin{array}{l}\text { Operations \& } \\
\text { Maintenance }\end{array}$ & $\begin{array}{l}\text { Non-efficient } \\
\text { operation of fan } \\
\text { system }\end{array}$ & $\begin{array}{l}\text { - Maintaining efficient operating schedules requires } \\
\text { educated facilities staff including knowledge of the } \\
\text { technology and energy efficiency priorities }\end{array}$ \\
\hline & Costs & $\begin{array}{l}\text { Higher first costs for } \\
\text { efficient fans }\end{array}$ & $\begin{array}{l}\text { - High-efficiency fans and fan systems carry a high first-cost } \\
\text { premium over standard replacement options } \\
\text { - Lifecycle costs (including maintenance) are not commonly } \\
\text { considered during fan selection }\end{array}$ \\
\hline & Costs & $\begin{array}{l}\text { Poor fan efficiency in } \\
\text { appliances }\end{array}$ & $\begin{array}{l}\text { - Manufacturers of un-regulated appliances have little } \\
\text { motivation to use anything other than lowest-cost fans in } \\
\text { their appliances } \\
\text { - Appliance standards may not account for electricity } \\
\text { consumed by fans, thus do not motivate manufacturers to } \\
\text { improve fan efficiency }\end{array}$ \\
\hline & Costs & $\begin{array}{l}\text { Split incentives } \\
\text { prevent selection of } \\
\text { efficient options }\end{array}$ & $\begin{array}{l}\text { Building owners are not incentivized to save energy if the } \\
\text { building occupants pay energy bills; focused on low first } \\
\text { cost } \\
\text { - System designers only motivated to finish the design job } \\
\text { to customer specifications and not generally incentivized } \\
\text { to select an efficient system design or consider lifecycle } \\
\text { costs } \\
\text { - Fan system designers typically only motivated to push } \\
\text { high-efficiency equipment if customers are well educated } \\
\text { on the topic }\end{array}$ \\
\hline & $\begin{array}{l}\text { Sensors and } \\
\text { Controls }\end{array}$ & $\begin{array}{l}\text { Advanced occupancy } \\
\text { sensors and smart } \\
\text { controls options are } \\
\text { limited }\end{array}$ & $\begin{array}{l}\text { - Technology for advanced occupancy sensors, which can } \\
\text { count occupants and control ventilation rates, is not } \\
\text { currently available (though there are commercially } \\
\text { available products with basic occupancy sensors) }\end{array}$ \\
\hline
\end{tabular}

\footnotetext{
${ }^{73}$ Efficient fans may be larger, or a different type, or feature newer technology than baseline specification (BI vs. FC, plenum vs. housed fans for AHUs, lower RPM vs higher RPM, variable vs fixed speed). Similarly variable air volume systems may require several modifications to a constant air distribution system.

${ }^{74}$ Poor maintenance of fan (loose/damaged belt drive, fouled bearings, motor faults) and fan system (duct leaks/damage, clogged filters, poor system balancing) will increase system pressure and higher energy consumption
} 


\begin{tabular}{|c|c|c|c|}
\hline Category & & Barrier & Description \\
\hline & $\begin{array}{l}\text { Sensors and } \\
\text { Controls }\end{array}$ & $\begin{array}{l}\text { Resistance or } \\
\text { reluctance to adopt } \\
\text { smart controls }\end{array}$ & $\begin{array}{l}\text { - Sensor technology is new and relatively unproven in the } \\
\text { eyes of some engineers; skepticism may prevent adoption } \\
\text { - Smart HVAC controls may require a pre-existing building } \\
\text { (or home) management system to function effectively. }\end{array}$ \\
\hline & Aerodynamics & $\begin{array}{l}\text { Manufacturers of } \\
\text { small equipment } \\
\text { rarely consider } \\
\text { aerodynamic blade } \\
\text { designs }\end{array}$ & $\begin{array}{l}\text { - Higher cost of new design and potentially higher cost of } \\
\text { manufacture } \\
\text { - Manufacturers of fans used in residential applications or } \\
\text { integrated into appliances have little incentive for efficient } \\
\text { blades, where energy savings is a low priority (compared } \\
\text { to first cost) }\end{array}$ \\
\hline
\end{tabular}

Fan manufacturers face several challenges in implementing the efficient motors and blade design options described in Table 2-10 and Table 2-11.

As they are pushed by regulations to obtain higher fan efficiencies, fan manufacturers must use advanced motor and control systems, which are purchased parts and are outside of typical manufacturer core competencies. Adoption of efficient motors and sensors presents a challenge to manufacturers, who are unfamiliar with potential impacts on fan performance and on their supply chain.

To improve aerodynamic efficiency, fan manufacturers are typically comfortable with modifying blade designs for improved efficiency and performance; however, manufacturing fan blades using alternative, efficient materials could require significant investment into retooling and the development of new manufacturing processes.

Backwards-inclined centrifugal blades, while more efficient than forward-curved blades, must be larger and spin at a higher speed to deliver similar performance. Manufacturers of products containing integrated centrifugal fans will face challenges with geometric restrictions (e.g. larger fan enclosure, reduced size of other components), and motor restrictions (e.g. larger motor, higher power consumption) when selecting the backwards-inclined option.

\subsubsection{Residential Energy Savings Opportunities}

The subsections below provide findings for residential fan energy savings opportunities in three categories:

- Fan controls and drives

- Blade design and selection

- Fan system

\subsubsection{Fan Motors and Controls}

Table 2-13 displays potential savings opportunities in residential fan motors, controls, and drive systems and their technical savings potential. 
Table 2-13: Residential Fan Motors \& Controls Opportunities (Annual Technical Savings Potential)

\begin{tabular}{|c|c|c|c|c|}
\hline Residential Efficiency Options & Applications & $\begin{array}{l}\text { Est. Energy } \\
\text { Savings (\%) }\end{array}$ & $\begin{array}{c}\text { U.S. Primary } \\
\text { Energy Savings } \\
\text { Potential (quads) }\end{array}$ & $\begin{array}{l}\text { Est. First-Cost } \\
\text { Premium (\%) }\end{array}$ \\
\hline Brushless DC motors or ECMs & $\begin{array}{l}\text { All fans, including } \\
\text { those in appliances }\end{array}$ & $10-64 \%$ & 0.5 & Varies \\
\hline $\begin{array}{l}\text { Integrated smart controls; } \\
\text { occupancy sensor }\end{array}$ & Ceiling fans & $10 \%$ & 0.01 & High \\
\hline $\begin{array}{l}\text { Efficient control modes; } \\
\text { multi-stage }\end{array}$ & $\begin{array}{l}\text { Central HVAC } \\
\text { circulation fans }\end{array}$ & $10 \%$ & 0.04 & $68 \%$ \\
\hline \multicolumn{3}{|c|}{ Motors and Controls Sub-total } & $0.5^{\mathrm{A}}$ & \\
\hline \multicolumn{5}{|c|}{$\begin{array}{l}\text { Sources: See Appendix E - Data Sources for Energy Savings Opportunities } \\
\text { A: Does not sum due to rounding. }\end{array}$} \\
\hline
\end{tabular}

Brushless DC (BLDC), electronically commutated motors (ECMs), and other permanent magnet motors enable energy savings in all residential fan applications. Estimated energy savings vary depending on the usage and the baseline motor technology of each application. Similarly, firstcost premiums vary by each product (e.g. $22 \%$ first-cost premium for central HVAC circulation fans, 50\% first-cost premium for ceiling fans). Please refer to Appendix F-Motor Technology Overview, extracted from the BTO Motors Report, for detailed energy savings discussions of BLDC and ECMs for residential fan applications. ${ }^{75}$

Occupancy sensors in residential ceiling fans reduce runtime by turning on and off automatically. We estimate $10 \%$ fan energy savings is possible based on previous research. ${ }^{76}$ Sensors that additionally control ceiling fan lighting fixtures increases the savings. Ceiling fans with occupancy sensors are commercially available, though not common, with the option to connect to a home management system. ${ }^{77}$

Central HVAC circulation fans that already use BLDC motors can further save energy with more efficient controls, such as multi-staging modes. Typical circulation fans in the U.S. use a multispeed induction motor, providing usually a single airflow speed for each mode of operation (e.g. heating, cooling, ventilation modes). Multi-staged modes refers to the number of heating and cooling modes the fan can provide the home. Circulation fans can only utilize multi-staging if the heating or cooling equipment has the same multi-stage functions. At times of lower heating or cooling demand, multi-staged fans are able to reduce energy consumption by providing a correspondingly lower airflow to a lower stage of heating/cooling. ${ }^{78}$

\footnotetext{
75 "Energy Savings Potential and Opportunities for High-Efficiency Electric Motors in Residential and Commercial Equipment," prepared by Navigant Consulting Inc. for BTO, December 2013.

http://www1.eere.energy.gov/library/viewdetails.aspx?productid=6746\&page $=2$

76 "Energy Savings Potential and Research, Development, \& Demonstration opportunities for Residential Building Heating,

Ventilation, and Air Conditioning Systems. Prepared by Navigant for BTO, October 2012.

http://energy.gov/sites/prod/files/2014/09/f18/residential_hvac_research_opportunities.pdf

${ }_{77}$ Example commercial product can be found here: http://www.bigassfans.com/for-home/haiku/

Home energy management systems are a residential efficiency improvement that has the potential for significant energy savings.

We have not considered this technology improvement as it is a non-fan specific, though fans savings could be included.

${ }^{78}$ DOE. Technical Support Document - Residential Furnaces Fans Energy Conservation Standard, 2014. Accessed March 2015. http://www1.eere.energy.gov/buildings/appliance_standards/rulemaking.aspx/ruleid/41
} 


\subsubsection{Blade Design and Selection}

Table 2-14 summarizes potential savings opportunities in residential fan blade design and selection.

Table 2-14: Residential Fan Blade Design Opportunities (Annual Technical Savings Potential)

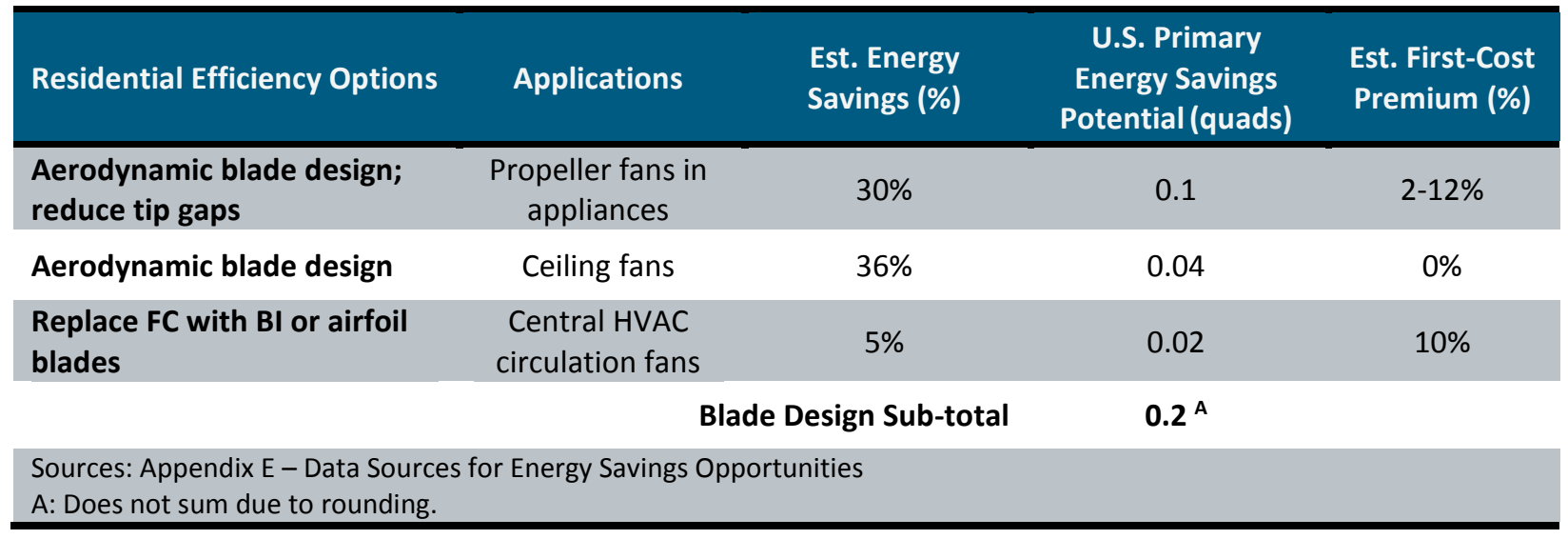

This report estimates a 30\% energy savings for aerodynamic blade design improvements in propeller fans that are integral to appliances, based on an analysis from the Fraunhofer Institute. The analysis found that by improving airflow entry characteristics around the hub, using 3D blade profiles, reducing gaps between blade tips and housings, and investigating rotor interactions with the fan casing could result in an increase efficiency by 15-20 percentage points. For this analysis, we estimated aerodynamic blade design raised the average efficiency of a propeller blade from $35 \%$ to $50 \%$, resulting in $30 \%$ energy savings for appliance propeller fans (ceiling fans excluded). ${ }^{79}$ We note that appliance buyers do not typically consider fan blade improvements in their buying decisions since fan energy consumption is not usually a consideration in the purchase of the appliance. Manufacturers look to reduce manufacturing costs of the integrated fan rather than increase fan efficiency, as they, in turn, are driven to reduce overall appliance cost by the customer.

We estimate $36 \%$ energy savings for airfoil blades, or other similar improvements to blade designs for ceiling fans. DOE, currently engaged in an Energy Conservation Standard rulemaking, estimates the design and implementation cost of better blades to be minimal. ${ }^{80}$ Until recently, residential ceiling fan efficiency (and efficacy of the blades) has not been a factor in customer buying decisions and manufacturers have typically used the lowest cost blade options. There are multiple ceiling fan manufacturers claiming to have efficient fan blade designs, though they are also usually paired with an advanced motor and drive system. ${ }^{81}$

The most energy efficient central HVAC circulation fan design options utilize backwardsinclined or backwards-curved blower wheels instead of the typical forward-curved blower

\footnotetext{
79 “Market Study for Improving Energy Efficiency for Fans" Prepared by Fraunhofer Inst. for SAVE Programme, July 2001. http://www.isi.fraunhofer.de/isi-wAssets/docs/x/de/publikationen/fans/fans-final-version.pdf

${ }^{80}$ DOE. Rulemaking for Ceiling Fans Energy Conservation Standards. Accessed Feb 2015. http://www1.eere.energy.gov/buildings/appliance_standards/rulemaking.aspx/ruleid/65

${ }^{81}$ Three examples: Sycamore http://www.sycamorefan.com/; Haiku http://www.bigassfans.com/for-home/haiku/; Aeratron fan http://aeratronaustralia.com.au/
} 
wheels. We estimate, from the Furnace Fans standards rulemaking analysis, approximately 5\% energy savings from switching blade configurations. ${ }^{82}$ Other sources have quoted an improvement of 6-10\% in static efficiency for backwards-curved fans between 500-1000 cubic feet per minute. ${ }^{83}$ DOE estimates $15-30 \%$ power reduction at peak speeds, but notes that backwards-inclined fan efficiency is more sensitive to airflow changes than forward-curved blades. $^{84}$

\subsubsection{Fan System}

Table 2-15 summarizes potential savings opportunities for residential fan systems, which includes not only the fan, but also the connected air delivery system.

\section{Table 2-15: Residential Fan System Opportunities (Annual Technical Savings Potential)}

\begin{tabular}{|c|c|c|c|c|}
\hline $\begin{array}{c}\text { Residential Savings } \\
\text { Opportunity }\end{array}$ & Applications & $\begin{array}{l}\text { Est. Energy Savings } \\
(\%)\end{array}$ & $\begin{array}{l}\text { U.S. Primary Energy } \\
\text { Savings Potential } \\
\text { (quads) }\end{array}$ & $\begin{array}{l}\text { Est. First-Cost } \\
\text { Premium (\%) }\end{array}$ \\
\hline $\begin{array}{l}\text { Design better airflow path } \\
\text { for upstream or } \\
\text { downstream components }\end{array}$ & $\begin{array}{l}\text { Central HVAC } \\
\text { circulation fans }\end{array}$ & $27 \%$ & 0.06 & varies \\
\hline \multirow[t]{2}{*}{ Minimize duct leakages } & $\begin{array}{l}\text { Central HVAC } \\
\text { circulation fans }\end{array}$ & $23 \%$ & 0.1 & varies \\
\hline & & Fan System Sub-total & $0.2^{A}$ & \\
\hline $\begin{array}{l}\text { Sources: See Appendix E - Dat } \\
\text { A: Does not sum due to roundi }\end{array}$ & $\begin{array}{l}\text { Sources for Ener } \\
\text { ng }\end{array}$ & ings Opportunities & & \\
\hline
\end{tabular}

Reducing static pressure experienced by the indoor circulation fan within HVAC equipment can increase fan efficiency and reduce energy usage. Manufacturers of residential furnaces and ACs typically install circulation fans in a cabinet that also houses other HVAC components such as heat exchange equipment and filters. The size of the cabinet and the geometry of the other upstream or downstream structures create static pressure for the fan to overcome. Manufacturers can reduce pressure losses by ensuring adequate airflow pathways around cabinet components. Homeowners can reduce static pressure in the HVAC system by regularly maintaining the supply fan, replacing filters, and ensuring the cabinet components are free of debris. According to a GE study, airflow restrictions reduce the efficiency for a standard furnace circulation fan from an estimated $12.5 \%$ to $9.1 \%$ (as well as affecting overall airflow). ${ }^{85}$ Correspondingly, using an improved cabinet design, we assume a $27 \%$ increase in estimated efficiency and energy savings.

\footnotetext{
82 DOE. Technical Support Document - Residential Furnaces Fans Energy Conservation Standard, 2014. Accessed March 2015. http://www1.eere.energy.gov/buildings/appliance_standards/rulemaking.aspx/ruleid/41

${ }^{83}$ GE Global Research.Wiegman, Herman. "Final Report for the Variable Speed Integrated Intelligent HVAC Blower.” 2003. www.osti.gov/scitech/servlets/purl/83501

${ }^{84}$ DOE. Technical Support Document - Residential Furnaces Fans Energy Conservation Standard, 2014. Accessed March 2015. http://www1.eere.energy.gov/buildings/appliance_standards/rulemaking.aspx/ruleid/41

${ }^{85}$ LBNL. Walker, Iain S. "Improving Air Handler Efficiency in Houses," Accessed: April 2015. http://aceee.org/files/proceedings/2004/data/papers/SS04_Panel1_Paper29.pdf

The source measured efficiency based on simulated airflow restrictions within the cabinet. This efficiency includes the efficiency of the furnace circulation fan motor and the efficiency of the fan blades. Overall efficiency is ratio of total fan work (pressure and flow generated by blades) to power input. We note that DOE measures furnace circulation fan effectiveness using FER (please see rulemaking for details - http://www1.eere.energy.gov/buildings/appliance_standards/rulemaking.aspx/ruleid/41)
} 
Residential duct leakages require the fan to work harder to provide the required ventilation and space conditioning. Alternatively, if the fan does not compensate for the duct leakage, the home will likely be inconsistently pressurized and conditioned. In the absence of residential-specific fan energy data for duct leaks, we assume a similar proportion of fan energy loss to that found in commercial buildings. Lawrence Berkeley National Labs (LBNL) found a 30\% increase in fan power for a commercial building with $10 \%$ duct leakage; from the energy consumption data, we estimate that sealing those leaks would yield $23 \%$ energy savings. ${ }^{86} \mathrm{We}$ assume the $10 \%$ leakage rate in the LBNL study is consistent with the average residential home leakage, and assume that duct sealing is applicable in all residences. ${ }^{87}$

\subsubsection{Commercial Energy Savings Opportunities}

The subsections below provide additional detail on the commercial fan savings opportunities in four categories:

- Fan controls and drives

- Blade or housing design and selection

- Fan system

- Maintenance

\subsubsection{Fan Motors and Controls}

Table 2-16 summarizes potential savings opportunities for commercial fan motors, controls, and drives.

Table 2-16: Commercial Fan Motors \& Controls Opportunities (Annual Technical Savings Potential)

\begin{tabular}{|c|c|c|c|c|}
\hline $\begin{array}{l}\text { Commercial } \\
\text { Efficiency Options }\end{array}$ & Applications & $\begin{array}{l}\text { Est. Energy } \\
\text { Savings (\%) }\end{array}$ & $\begin{array}{l}\text { U.S. Primary Energy } \\
\text { Savings Potential } \\
\text { (quads) }\end{array}$ & $\begin{array}{l}\text { Est. First-Cost } \\
\text { Premium (\%) }\end{array}$ \\
\hline $\begin{array}{l}\text { ECM or BLDC } \\
\text { motors }\end{array}$ & Outdoor fans - Packaged A/C units & $24 \%$ & 0.04 & varies \\
\hline $\begin{array}{l}\text { ECM or BLDC } \\
\text { motors }\end{array}$ & $\begin{array}{l}\text { Indoor fans - Packaged A/C units } \\
\text { (excluding CUAC); draft fans }\end{array}$ & $24 \%$ & 0.01 & varies \\
\hline $\begin{array}{l}\text { ECM or BLDC } \\
\text { motors }\end{array}$ & Exhaust Ventilation & $25 \%$ & 0.05 & varies \\
\hline $\begin{array}{l}\text { ECM or BLDC } \\
\text { motors }\end{array}$ & $\begin{array}{l}\text { Commercial Refrigeration (including } \\
\text { ACIM) }\end{array}$ & $60-70 \%$ & 0.1 & varies \\
\hline VSDs & Clean-air ventilation & \multicolumn{2}{|c|}{ Please refer to Section 2.4.4.3 } & varies \\
\hline VSDs & Indoor blower - CUAC & \multicolumn{2}{|c|}{ Please refer to Section 2.4.4.3 } & varies \\
\hline
\end{tabular}

\footnotetext{
${ }^{86}$ LBNL. Wray C.P. et al. "Duct Leakage Modeling in EnergyPlus and Analysis of Energy Savings from Implementing SAV with InCITe," March 2010. http://uc-ciee.org/downloads/DuctLkgModeling.Wray.pdf

${ }^{87}$ An average residential leakage rate of $10 \%$ was found in a study by Ecotope and University of Illinois for Puget sound (http://aceee.org/files/proceedings/2004/data/papers/SS04_Panel1_Paper14.pdf), though an ASHRAE study by M. Modera estimated 15-20\% leakage for flex-duct systems in Illinois (http://www.paltech.com.au/datasheets/Duct_Modera_ASHRAE_152.pdf)
} 


\begin{tabular}{|c|c|c|c|c|}
\hline $\begin{array}{l}\text { Commercial } \\
\text { Efficiency Options }\end{array}$ & Applications & $\begin{array}{l}\text { Est. Energy } \\
\text { Savings (\%) }\end{array}$ & $\begin{array}{l}\text { U.S. Primary Energy } \\
\text { Savings Potential } \\
\text { (quads) }\end{array}$ & $\begin{array}{l}\text { Est. First-Cost } \\
\text { Premium (\%) }\end{array}$ \\
\hline VSDs & Cooling tower fans & $40 \%$ & 0.02 & varies \\
\hline $\begin{array}{l}\text { Advanced } \\
\text { occupancy sensor } \\
\text { demand control } \\
\text { ventilation (DCV) }\end{array}$ & $\begin{array}{l}\text { Clean-air ventilation (terminal units, room } \\
\text { fan coil units); packaged } A / C \text { units } \\
\text { (excluding CUACs) }\end{array}$ & $20 \%$ & 0.1 & varies \\
\hline $\begin{array}{l}\text { Replace indirect } \\
\text { drive } w / \text { direct } \\
\text { drive }\end{array}$ & $\begin{array}{l}\text { Clean-air ventilation fans; CUAC indoor } \\
\text { blowers; Cooling tower fans }\end{array}$ & $5-15 \%$ & 0.08 & varies \\
\hline \multirow[t]{2}{*}{$\begin{array}{l}\text { Higher efficiency } \\
\text { indirect drives }\end{array}$} & $\begin{array}{l}\text { Clean-air ventilation fans; CUAC indoor } \\
\text { blowers; Cooling tower fans }\end{array}$ & $2-5 \%$ & 0.02 & varies \\
\hline & \multicolumn{2}{|c|}{ Motors and Controls Sub-total } & $0.5^{A}$ & \\
\hline \multicolumn{5}{|c|}{$\begin{array}{l}\text { Sources: See Appendix E - Data Sources for Energy Savings Opportunities } \\
\text { A: Does not sum due to rounding }\end{array}$} \\
\hline
\end{tabular}

Upgrading from induction motors to permanent magnet motors offers a significant energy savings opportunity for commercial fans. The upgrade opportunity is to use BLDCs or ECMs in place of commonly used permanent split capacitor motors for smaller commercial fan applications such as condenser fans and integrated appliance fans. We used energy savings estimates from the BTO Motors Report - please refer to this source for further details; Appendix F - Motor Technology Overview includes a discussion of these motor types, extracted from the BTO Motors Report. ${ }^{88}$

The BTO Motors Report estimated VSD energy savings of about $40 \%$ for indoor HVAC supply fans, and for cooling tower fans. VSDs can be installed on new equipment or retrofitted for larger 3-phase AC induction motors. Energy savings comes from the reduced power draw from part-load fan operation. For commercial indoor air supply VSDs (i.e. clean air ventilation and CUAC blowers), this analysis considers the energy savings in conjunction with variable air volume (VAV) systems, which Section 2.4.4.3 discusses in detail. The BTO Motors Report estimates that VSDs are common in new cooling tower fans shipped today - this report conservatively estimates the savings from upgrading the portion of the installed base currently without variable speed controls. ${ }^{89}$

Demand control ventilation (DCV) using infrared occupancy sensors could offer effective fan energy savings for terminal boxes (used in VAV systems to deliver air to each zone). ASHRAE 90.1-2010 standard mandates demand control ventilation for some large, high-occupancy spaces in new buildings. ${ }^{90}$ However, DCV retrofits with advanced occupancy sensors in existing

\footnotetext{
88 "Energy Savings Potential and Opportunities for High-Efficiency Electric Motors in Residential and Commercial Equipment," prepared by Navigant Consulting Inc. for BTO, December 2013.

http://www1.eere.energy.gov/library/viewdetails.aspx?productid=6746\&page=2

89 "Energy Savings Potential and Opportunities for High-Efficiency Electric Motors in Residential and Commercial Equipment," prepared by Navigant Consulting Inc. for BTO, December 2013.

http://www1.eere.energy.gov/library/viewdetails.aspx? productid $=6746 \&$ page $=2$

${ }^{90}$ Please refer to ASHRAE 90.1-2010 6.4.3.9 for details

(https://www.energycodes.gov/sites/default/files/documents/cn_demand_control_ventilation.pdf).
} 
buildings, particularly in offices and educational facilities already containing VAV systems, can offer attractive energy saving potential. For low-occupancy applications not covered by ASHRAE 90.1-2010 standards (e.g. small packaged HVAC applications), using occupancy sensor-based DCV may be a new area of potential savings if costs can be addressed. ${ }^{91}$

Advanced occupancy sensors and controls are able to count the number of people in a room or zone, and modulate ventilation air flow to meet the needs of the occupants. They are a current area of innovation and development, which could offer fan energy savings to a range of small and large HVAC applications.

Based on a Pacific Northwest National Laboratory (PNNL) study of fan coils used in an office setting, we estimate that common occupancy sensors can save approximately $10 \%$ of building fan energy, and advanced occupancy sensors and controls can save $30 \%$ of building fan energy. ${ }^{92}$ While the PNNL study focused on office space served by a VAV system, we approximate similar savings for zone-specific HVAC applications like fan coils, PTACs and SPVACs. We considered a potential upgrade of all small packaged HVAC units, and terminal box applications to advanced occupancy sensors.

Clean air ventilation fan systems such as air handling units and CUACs typically use indirect drives, which are less efficient than direct drives due to frictional losses in the belts or gears. ${ }^{93}$ Losses increase if the pulleys are not aligned or if the system is otherwise not properly designed. This report considers two improvements to existing belt drives: replacement with an improved indirect drive or replacement with a direct drive. Efficiency of the indirect drive depends on the type of belt or gear, but also depends on whether the fan unit undergoes regular maintenance. For fan units that use flat (or less efficient) belts, an improvement to synchronous (or "cogged") belts could yield slight efficiency improvements. ${ }^{94}$ A direct drive fan eliminates any losses in the drive system, but may only be practical for these applications if paired with a slower motor, or with a motor having a variable speed drive. ${ }^{95}$

\subsubsection{Blade or Housing Design and Selection}

Table 2-17 displays potential savings opportunities for improvements to commercial fan blade or housing designs.

\footnotetext{
${ }^{91}$ We note that CO2 sensors are most commonly used for DCV control of common areas, or high-occupancy zones.

92 PNNL. Zhang J. et al. "Energy Savings for Occupancy-Based Control of Variable-Air-Volume Systems.” January 2013. http://www.pnnl.gov/main/publications/external/technical_reports/PNNL-22072.pdf

${ }_{93}$ Indirect drives are belt or gear drives which connect the motor to the fan blades/impeller. Direct drives have a direct coupling between the motor and the blades.

${ }^{94}$ DOE-AMO. "Replace V-Belts with Notched or Synchronous Belt Drives," November, 2012. http://www1.eere.energy.gov/manufacturing/tech_assistance/pdfs/replace_vbelts_motor_systemts5.pdf

${ }_{95}$ We note that VSDs also experience losses of $<5 \%$ in the drive system.

Source: "Energy Savings Potential and Opportunities for High-Efficiency Electric Motors in Residential and Commercial Equipment," prepared by Navigant Consulting Inc. for BTO, December 2013.

http://www1.eere.energy.gov/library/viewdetails.aspx?productid=6746\&page $=2$
} 
Table 2-17: Commercial Fan Design Opportunities (Annual Technical Savings Potential)

\begin{tabular}{|c|c|c|c|c|}
\hline $\begin{array}{l}\text { Commercial Efficiency } \\
\text { Options }\end{array}$ & Applications & $\begin{array}{l}\text { Est. Energy } \\
\text { Savings (\%) }\end{array}$ & $\begin{array}{l}\text { U.S. Primary } \\
\text { Energy Savings } \\
\text { Potential (quads) }\end{array}$ & $\begin{array}{l}\text { Est. First-Cost } \\
\text { Premium (\%) }\end{array}$ \\
\hline $\begin{array}{l}\text { Aerodynamic blade design; } \\
\text { reduce tip gaps }\end{array}$ & $\begin{array}{l}\text { Propeller fans - HVAC } \\
\text { applications }\end{array}$ & $11 \%$ & 0.2 & $2-12 \%$ \\
\hline $\begin{array}{l}\text { Aerodynamic blade design; } \\
\text { reduce tip gaps }\end{array}$ & Propeller fans - appliances & $30 \%$ & 0.06 & $2-12 \%$ \\
\hline $\begin{array}{l}\text { Housing design; } \\
\text { Aerodynamic wheel/blade } \\
\text { design; reduce tip gaps }\end{array}$ & $\begin{array}{l}\text { Centrifugal fans - HVAC } \\
\text { supply fans }\end{array}$ & $7 \%$ & 0.1 & $7-12 \%$ \\
\hline Install variable pitch blades & $\begin{array}{l}\text { Larger axial fans - Clean-air } \\
\text { ventilation; cooling towers }\end{array}$ & $40 \%$ & 0.1 & varies \\
\hline \multirow[t]{2}{*}{$\begin{array}{l}\text { Replace FC with BI or airfoil } \\
\text { blades }\end{array}$} & $\begin{array}{l}\text { Centrifugal fans - small } \\
\text { HVAC supply fans (Small } \\
\text { CUAC, SPVAC, PTAC) }\end{array}$ & $19 \%$ & 0.01 & varies \\
\hline & & esign Sub-total & $0.4^{\mathrm{A}, \mathrm{B}}$ & \\
\hline \multicolumn{5}{|c|}{$\begin{array}{l}\text { Sources: Appendix E - Data Sources for Energy Savings Opportunities } \\
\text { A: Does not sum due to rounding } \\
\text { B: Variable pitch blades offer variable air flow control, similar to VSDs. We do not sum them as they may offer duplicative } \\
\text { savings with the VSD measure. }\end{array}$} \\
\hline
\end{tabular}

Most commercial fan applications can achieve increased efficiency by using aerodynamically optimized fan blades or housing designs. Some potential improvements described in the Fraunhofer report include using aerodynamic 3D blade profiles for simple propeller fan blades, reducing gaps between the blade tip and the housing to prevent secondary flow losses (in housed axial or centrifugal fans), and optimizing design of centrifugal fan housing to reduce flow nonuniformities. For centrifugal fans, fan wheel designs might also be improved by modifying the angle and pitch of the blade in a spiral, or equipping the wheels with blades with a changing profile along an axis parallel to the axis of rotation. ${ }^{96}$

Propeller fan blade design is currently an active area of innovation for HVAC applications, with multiple manufacturers offering energy efficient and/or noise-reducing designs (Figure 2-15). ${ }^{97}$ For HVAC propeller fans, we estimate a potential energy savings of $11 \%$ from an efficiency increase of 15 percentage points for blade improvements. ${ }^{98}$ Propeller fan blades used in commercial appliances are not designed for efficiency, and so can improve more through fan blade optimization than HVAC fans; we estimate an energy savings of 30\% for a similar 15 percentage point increase in average fan efficiency. For centrifugal HVAC supply and

\footnotetext{
${ }^{96}$ USPTO Patents: http://www.patentbuddy.com/Patent/20060051202, http://www.google.com/patents/US20090202352

${ }^{97}$ The following is a sampling of innovative blade designs, and is not meant to be representative of the entire market. http://www.multi-wing.net/evaporator-fans/; http://www.fridgewize.com/blog-posts/upgradeblade; http://spxcooling.com/parts/list/cooling/fans-and-drives; http://www.compositefantechnology.com/; http://www.ziehlabegg.com/us/

98 "Market Study for Improving Energy Efficiency for Fans” Prepared by Fraunhofer Inst. for SAVE Programme, July 2001. http://www.isi.fraunhofer.de/isi-wAssets/docs/x/de/publikationen/fans/fans-final-version.pdf
} 
ventilation fans, we estimate a 7\% energy savings, from an increase in average efficiency of 5\% for wheel and housing improvements. ${ }^{99}$
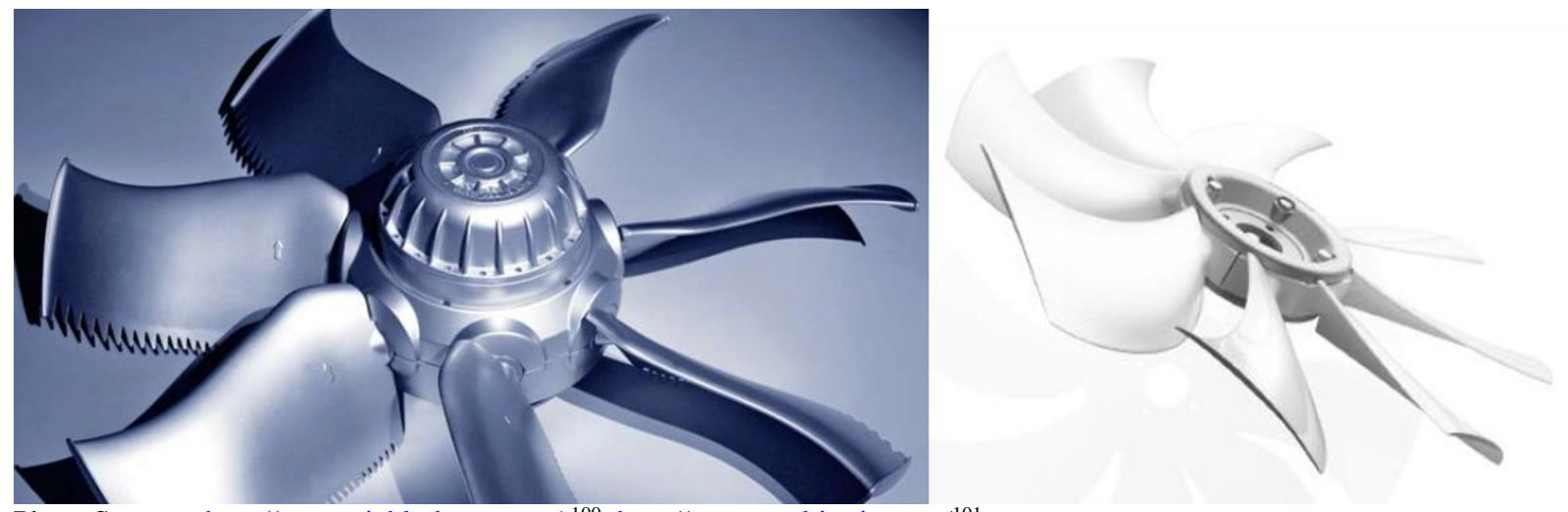

Photo Sources: http://www.ziehl-abegg.com/ ${ }^{100}$, http://www.multi-wing.net/ ${ }^{101}$

\section{Figure 2-15: Examples of commercial aerodynamic blade designs}

Large axial fan applications may use variable blade-pitch controls for systems with variable flow requirements. Automated variable pitch fans are able to change the fan blades' angle of attack, which changes the delivered airflow and pressure. Common applications for variable pitch controls are in vaneaxial fans and large propeller fans like cooling tower fans. Variable pitch fans offer an alternative flow control method to variable speed drives, while offering similar efficiencies at part load. ${ }^{102}$ There is overlapping energy savings potential between variable blade-pitch controls with VSD controls, as both technologies allow fans to provide variable air volume flows. However, the total U.S. technical energy savings potential for this technology is less than VSDs due to its limited applicability to cooling tower fans and ducted axial fan applications.

Similar to residential central HVAC circulation fans, smaller commercial HVAC supply fan impellers (e.g., small CUACs, and packaged air conditioners) may be forward-curved, which is typically less efficient than backwards-curved impellers. The installed base of larger HVAC supply fans (e.g., ventilation fans for AHUs) may also contain some forward-curved models. Forward curved fans are used typically because they are often cheaper, lighter, and more compact than backward-curved models - backwards-curved fans require a larger impeller to deliver the same amount of airflow. For these applications, we estimate a fan-related energy savings of approximately $20 \%$ from a theoretical upgrade from a $65 \%$ efficient FC blower wheel to an $80 \%$ efficient $\mathrm{BC}$ blower wheel. ${ }^{103} \mathrm{We}$ note that this is an estimate based on the efficiency

\footnotetext{
${ }^{99}$ Impeller wheel and housing innovations could improve forward-curved blowers but offer lower efficiency improvements to backwards-curved fans because they are relatively efficient. Centrifugal HVAC supply fans are an unknown mixture of forward and backward-curved fans.

Source: "Market Study for Improving Energy Efficiency for Fans" Prepared by Fraunhofer Inst. for SAVE Programme, July 2001. http://www.isi.fraunhofer.de/isi-wAssets/docs/x/de/publikationen/fans/fans-final-version.pdf

100 ZIEHL-ABEGG - FE2owlet Axial Fan. http://www.ziehl-abegg.com/us/fans-product-group-3.html?dtl=1\#jump_product61

${ }^{101}$ Multi-Wing - Sickle Series Fan Blades. http://www.multi-wing.net/pdfs/MWA\%20Sickle\%20Brochure.pdf

102 New Buildings Institute, Inc. "Variable Speed Drives." 2004. http://www.advancedbuildings.net/files/advancebuildings/Variable_Speed_Drives.pdf

${ }^{103}$ REHVA. Brelih, N. "How to improve energy efficiency of fans for air handling units." Accessed April 2015. http://www.rehva.eu/publications-and-resources/hvac-journal/2012/022012/how-to-improve-energy-efficiency-of-fans-for-airhandling-units
} 
of the wheel configuration and overall fan efficiency could vary depending on motor, drive, aerodynamic, or other fan-related losses.

\subsubsection{Fan System}

Table 2-18 describes quantified commercial fan system savings opportunities. We also include a discussion of other savings opportunities, for which we lack quantified data.

Table 2-18: Commercial Fan System Opportunities (Annual Technical Savings Potential)

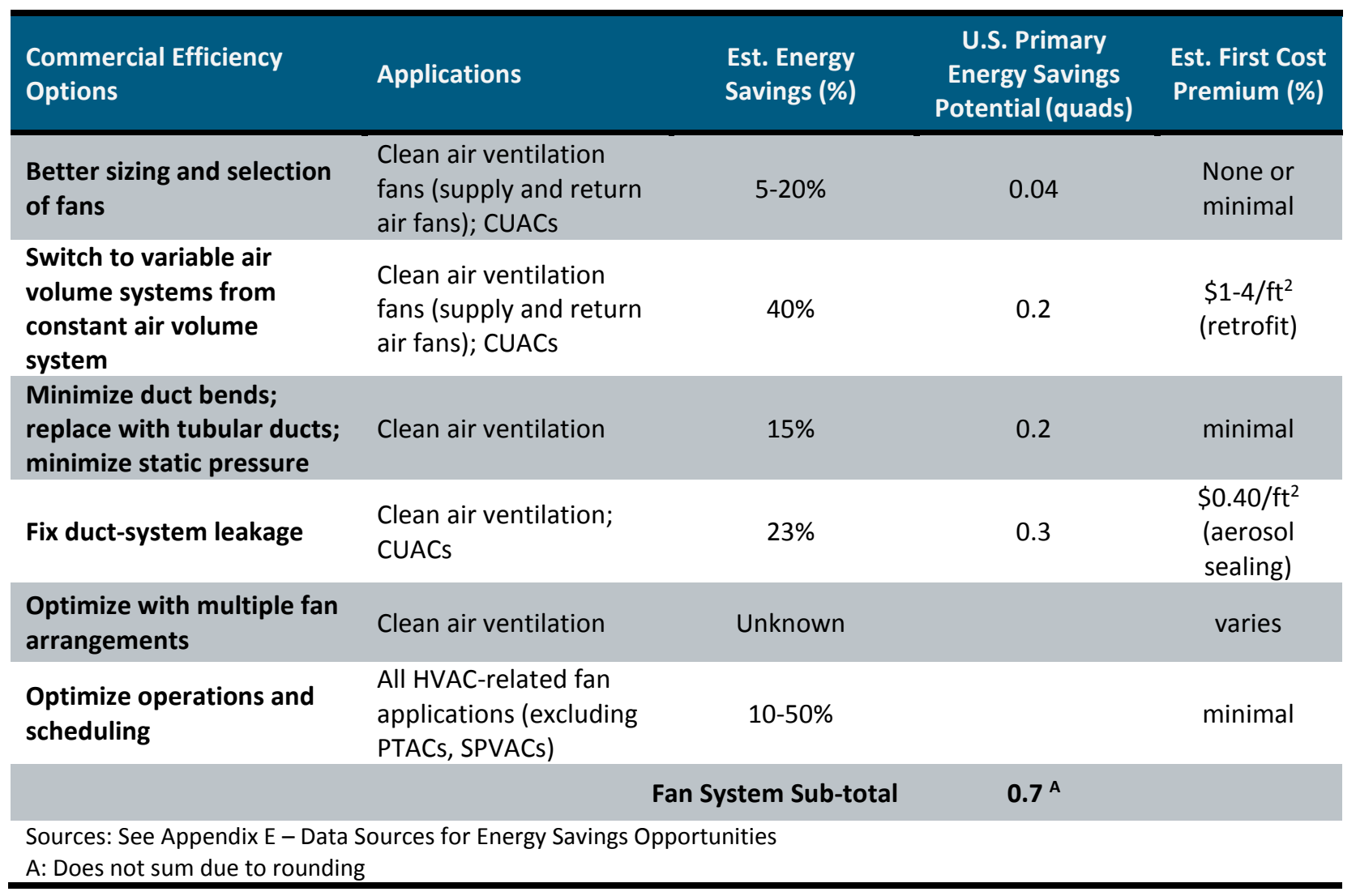

For HVAC fans, building engineers should select a fan size such that the fan operates optimally for specified airflow requirements. In practice, building engineers tend to oversize fans (or HVAC units, if packaged) to include a margin of safety for uncertainties in system design, future system expansion, or fouling effects over time. According to EPA, $60 \%$ of building fan systems are oversized. ${ }^{104}$ The Fraunhofer report estimated energy savings of 5-20\% for right-sizing fan systems. This yields approximately 0.2 quads of potential energy savings. The Air Movement and Control Association (AMCA) also estimates energy savings from fan system-related opportunities, like right-sizing, to be the majority of potential savings (see Figure 2-16).

Energy savings from rightsizing fans may be partially duplicative of VSD savings, as both opportunities enable higher fan efficiency by reducing airflow to more accurately match the building's needs. Rightsizing retrofits could save energy for existing constant air volume (CAV) HVAC systems, while VSDs would be used to convert CAV systems to VAV operation, if

${ }^{104}$ ENERGY STAR® Buildings Upgrade Manual, U.S. EPA Office of Air and Radiation, 62021 EPA 430-B-97-024D, July 1997 
feasible. VSDs will save energy for fans running at partial design speed regardless of whether the fan is rightsized. However, rightsizing for VAV systems could still be valuable, though we were not able to find data on the effect of rightsizing fans in VAVs. In order to avoid duplicative savings in this report, we estimated the savings potential of rightsizing fans to apply only to oversized fans used in CAV systems that cannot be otherwise be retrofitted with VAV. ${ }^{105}$

\section{Potential for Air System Savings}

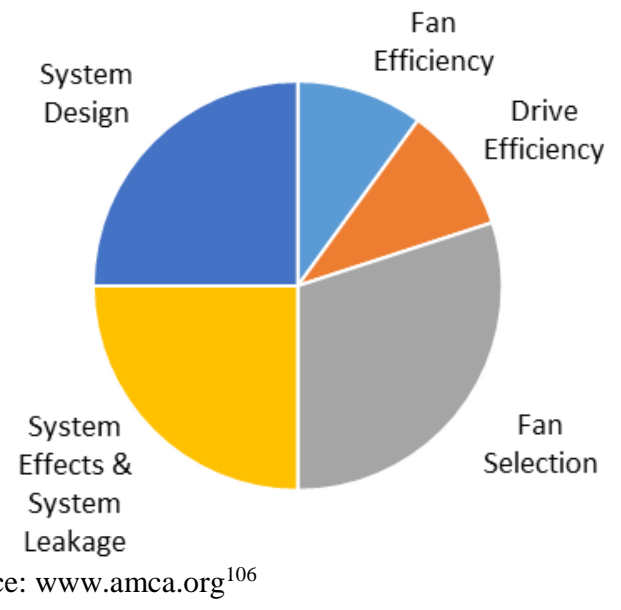

Graphic Source: www.amca.org 106

Figure 2-16: AMCA's estimated potential for air system savings

VAV systems can save fan energy compared to CAV systems due to the ability of the supply fan to reduce its speed (and hence power consumption). CAV systems in HVAC will typically have the supply fan running at a single speed, with generally no zonal control. VAV systems are able to provide variable airflows to various zones within the system; they are enabled by VSD controls in the air handling unit. In ASHRAE 90.1-2010, fan motors greater than 10 hp must either have a VSD or be otherwise able to provide variable airflows. ${ }^{107}$

Some CAV systems, which still exist in large numbers among the older commercial building stock, can be retrofitted to provide variable air flows. Though the retrofit opportunity varies by building application and age of the building, we assume that $40 \%$ of the commercial building stock can potentially be retrofitted with a VAV system. ${ }^{108}$ The BTO Motors Report estimates a

\footnotetext{
${ }^{105}$ We considered VAVs unsuitable if A) the building application did not require individual room control, or B) the building application does not have a changing occupancy or load. We estimate approx. 13\% suitability of rightsizing retrofits in the installed base.

${ }^{106}$ Reproduced from source: AMCA. “AMCA International's Opening Session.” 2015. http://www.amca.org/adovacy/documents/DOEFanEfficiencyProposal-AMCAAnnualMeetingRedux1-24-15.pdf

107 ASHRAE 90.1-2010 also allows fan motors $>10$ hp to be a vaneaxial fan with variable-pitch blades, or have a design wattage $\leq 30 \%$ at $50 \%$ air volume.

Source: Trane. Murphy K. W. et al. “ASHARE 90.1-2010 - The Evolution Continues.” 2008. http://www.gaccsouth.com/fileadmin/ahk_atlanta/Dokumente_Houston/2009/Praesentationen_Energieeffizienz_Konferenz/14_K evin_Murphy.pdf

$\overline{108}$ Estimate based on an energy-consumption-weighted average (for all commercial building applications) of $\%$ floor space already using VAVs. We found $52 \%$ of buildings using CAV systems (by weighting); of that we estimated $13 \%$ were unsuitable for VAV retrofit.

Source: PNNL. Zhang J. et al. "Energy Savings for Occupancy-Based Control of Variable-Air-Volume Systems.” January 2013. http://www.pnnl.gov/main/publications/external/technical_reports/PNNL-22072.pdf
} 
$40 \%$ fan energy savings with the implementation of a VSD; similarly, an EPA fan system upgrade report estimated 40-60\% potential fan energy savings by upgrading from VAC to VAV. ${ }^{109}$ We estimate a resulting fan energy savings of 0.2 quads. Building owners may also choose to retrofit existing VAV systems to function more efficiently by adding a suite of advanced sensors and controllers; building automation, and building management systems can also ensure efficient functioning of the VAV HVAC system.

A potential opportunity for reducing fan energy is to reduce the ducting losses by minimizing duct bends, right-sizing the ducts, removing flow obstructions, or otherwise reducing the static pressure drop in the fan system. Improved airflow patterns within the fan system also improve efficiency, which designers can achieve with airflow guide vanes at the fan inlet, outlet, or during duct bends. ${ }^{110}$ Airflow exiting the fan should be allowed to develop into a uniform profile before duct bends. Retrofits can focus on reducing system static pressure by removing excess dampers in the fan system and controlling airflow in more efficient ways (e.g. better sensors and variable controls on the supply fan). We assume that the majority of commercial buildings are not designed with consideration for optimal fan system airflow, and we believe this improvement is applicable to the majority of commercial HVAC systems. For new buildings, designers may be able to incorporate better ducting in the building design, but the same improvements may be restricted by space or geometrical constraints for a building retrofit.

Duct leakage results in extra energy consumption of the supply fan, which may experience a change in system static pressure and unbalancing of airflows in the system. The amount of duct leakage depends on both the size of the leak, but also on the fan supply pressure of the duct. Maintenance procedures, such as a duct tightness test to detect leaks, or installation of ducting with better seals and fittings can help commercial buildings avoid energy losses from leaks. Common sealing methods use duct, foil, or fiberglass tape to seal the ducts - other methods include using an aerosol spray to coat leaking ducts. Previous studies found eliminating leaks could translate to a fan power increase of 20-40\%; a model created by LBNL found a site fan energy consumption increase of $30 \%$ from a system with $10 \%$ leakage in both upstream and downstream ducting. Using the modelled energy consumption change, we estimate that sealing those same leaks would yield $23 \%$ energy savings. Using the same source, we estimate $75 \%$ of existing buildings can benefit from duct sealing. ${ }^{111}$

There are several other fan system-related savings opportunities for which energy savings is difficult to quantify (see following):

- Multiple fan arrangements

- Optimized schedules and controls

Large buildings with high ducting losses or highly variable ventilation requirements may benefit from using a multi-fan arrangement. In place of a large fan, a building can use multiple, smaller fans at different points in the duct network to boost airflow. Compared to a single-fan AHU, the multiple fan arrangement requires less initial air pressure, which could result in lower losses

\footnotetext{
109 EPA. "Stage Four Fan System Upgrades.” June 1998. http://www.fsec.ucf.edu/en/research/photovoltaics/vieo/audits/documents/FSEC-PV-OS-6-1998-1.pdf

${ }^{110}$ DOE-EERE. "Improving Fan System Performance," prepared by LBNL and Resource Dynamics Corp. April 2003. https://www1.eere.energy.gov/manufacturing/tech_assistance/pdfs/fan_sourcebook.pdf

${ }^{111}$ LBNL. Wray C.P. et al. "Duct Leakage Modeling in EnergyPlus and Analysis of Energy Savings from Implementing SAV with InCITe" March 2010. http://uc-ciee.org/downloads/DuctLkgModeling.Wray.pdf
} 
from air leakage, and offers better redundancy in the fan system. Smaller fans are less efficient individually (though this would depend on the specific performance of the selected fans), but could also offer better overall performance with less noise. We could not estimate any potential energy savings from multiple fan arrangements, due to lack of information and because savings would depend heavily on the building configuration.

The Fraunhofer study suggests that buildings can save fan energy by optimizing operating hours. Energy savings from runtime reductions depend on HVAC usage prior to and after optimizing, making them difficult to estimate for buildings nationwide. Examples of scheduling savings include turning the system off (or scaling back) when the building is typically unoccupied, and changing the schedule based on the time of year. Any potential scheduling energy savings would depend on the motivation of equipment and facility management to run HVAC efficiently. The Fraunhofer study estimated a wide range of potential energy savings (10-50\%).

Setting pressure and temperature setpoints for HVAC systems or zones to maximize energy efficiency could enhance the energy saving potential of a fan-related system within a building. For example, replacing a constant static pressure setpoint in a VAV system with a static pressure reset strategy (which modulates pressure setpoints according to lower loads) helps reduce supply fan consumption.

\subsubsection{Maintenance}

Table 2-19 summarizes the estimated maintenance-related fan savings.

Table 2-19: Commercial Fan Maintenance Opportunities (Annual Technical Savings Potential)

\begin{tabular}{llccc}
\hline Commercial Efficiency Options & Applications & $\begin{array}{l}\text { Est. Energy } \\
\text { Savings (\%) }\end{array}$ & $\begin{array}{r}\text { U.S. Primary Energy } \\
\text { Savings Potential (quads) }\end{array}$ & $\begin{array}{c}\text { Est. First Cost } \\
\text { Premium (\%) }\end{array}$ \\
\hline $\begin{array}{l}\text { Ensure proper maintenance } \\
\text { (belt drives, bearings, motors) }\end{array}$ & $\begin{array}{l}\text { All HVAC-related fan } \\
\text { applications }\end{array}$ & $5-20 \%$ & 0.1 \\
& & Sub-total & $\mathbf{0 . 1}$ \\
\hline Sources: See Appendix E - Data Sources for Energy Savings Opportunities & \\
\hline
\end{tabular}

Regular maintenance for fans and fan systems is essential for maintaining optimal operating efficiency. Common maintenance items for the fan include checking belts, bearings, and motor conditions. Maintenance to the fan system includes changing filters, system cleaning, and checking for duct leakage. Buildings often do not undergo regular system preventative maintenance due to time and budget constraints. Reactive maintenance is common practice typically, staff perform no maintenance work until a piece of equipment fails. However, performance degradation and increased energy consumption of the HVAC system will usually occur prior to equipment failure. 


\subsection{R\&D Opportunity Areas}

Through this study, Navigant has identified 4 potential R\&D topic areas that can help to address barriers to greater penetration of high efficiency fan technologies and overall energy savings in fan systems. Table 2-20 provides a non-prioritized list of these potential opportunities. It is not an exhaustive list, but rather a selection of topic areas that the authors of this study have deemed valuable in addressing key technological and market barriers.

\section{Table 2-20: Identified Fan R\&D Topic Areas}
ID Description
Category

Product-integrated occupancy sensors: Conduct building simulations

1 and field testing of built-in occupancy sensors on small-zone based HVAC fans. Characterize implementation costs and potential areas for cost reductions.

Appliance-integrated fan improvements: Analyze and test appliancehoused pump/fan improvements; identify manufacturing barriers;

2 recommend code updates and R\&D opportunities (same as Pump R\&D Initiative ID\#2).

Advanced sensors \& controls: Identify and evaluate advanced sensor

3 technologies and their commercialization status; research barriers to adoption; develop and understand manufacturing processes to aid commercial adoption.

4

Advanced duct sealing: investigate advanced duct sealing market and determine barriers to widespread retrofit adoption
Sensors \&

Controls
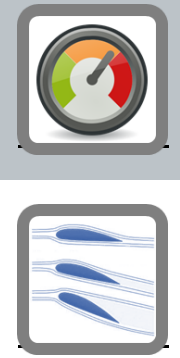

Aerodynamics

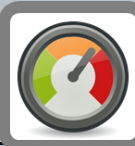

Sensors \& Controls

The following subsections describe each of the R\&D initiative in greater depth.

\subsubsection{R\&D Initiative ID\#1: Product-Integrated Occupancy Sensors}

Demand controlled ventilation (DCV) is standard for high-occupancy zones in new commercial buildings, but also offers potential energy savings in smaller spaces or lower-occupancy zones. Research on the feasibility of using occupancy sensors integrated into packaged fan/HVAC units can help identify specific opportunities for small-scale DCV. We have identified several residential (ceiling fans, portable air conditioners, and room air conditioners) and commercial (fan coil units, PTACs, and SPVACs) packaged ventilation units which may offer energy savings potential with DCV controls. We suggest performing research into equipping occupancy sensors in packaged HVAC units that typically rely on user controls, to evaluate the potential for energy savings.

To more accurately determine the amount of potential savings, we suggest conducting building simulations to model operating schedules of the various equipment in different residential and commercial applications. Prototyping sensor-integrated appliances and performing field trials would confirm the modeled energy savings and identify any reliability or usage concerns. 
Further research will help understand the costs needed to integrate the required sensors and controls into the different appliances, and to estimate any cost reductions necessary to enable cost-effectiveness.

Other areas for further investigation include:

- User satisfaction and perception with sensor-integrated appliances

- Actual usage of sensor-integrated appliance in field

\subsubsection{R\&D Initiative ID\#2: Appliance-Integrated Fan Improvements}

Generally, appliance manufacturers do not select efficient, appliance-integrated fans (and pumps) as they are driven to select the lowest cost option that meets the appliance's requirements. Manufacturers must prioritize the efficiency of each individual component to meet their product efficiency target. We estimate design improvements to appliance-integrated fans and pumps could save 0.2 quads of primary energy annually (see section 2.4.3.2, above). We propose research to characterize the potential impacts of improved design of fans and pumps, such as efficient aerodynamic blades, on product and manufacturing costs and on fan and system efficiency.

Understanding the potential increased product cost (if the fan/pump is a purchased part) or manufacturing cost (if the fan/pump is manufactured in-house) would be key to overcoming the financial barriers to any design improvement. Furthermore, to assess the feasibility of potential upgrades, it will be important to research how improving hydraulic or aerodynamic design would impact the manufacturing process of the pump/fan.

R\&D to characterize energy savings of improved designs can be conducted through modelling and field testing. We suggest, also, additional research to indicate any potential downstream impacts of improved appliance-integrated fan/pump designs, as well as any other impacts on appliance functionality.

Other areas for further investigation include:

- Secondary benefits to enhanced pump/fan design, such as noise reduction

- Regulatory benefits from more efficient designs, which may allow manufacturers to easily meet future appliance standards

\subsubsection{R\&D Initiative ID\#3: Advanced Sensors and Controls}

Advanced sensors and controls for HVAC, such as precision occupancy sensors that are able to distinguish the number of room occupants to control ventilation rates accordingly, offer significant energy saving benefits over scheduled HVAC controls. Sources also suggest that advanced occupancy sensors could offer savings over currently available occupancy sensors. We propose further assessment of advanced sensors while identifying activities to bring the most favorable technologies to market.

We suggest an assessment comparing the estimated energy savings, cost, and accuracy of all potential DCV sensor technologies. R\&D to understand the potential cost of any advanced sensor 
technology, and to identify processes that may lower this cost, can support commercialization of any favorable technologies.

Other areas for further investigation include:

- Current state of development and commercialization within the industry

- Impacts of enhanced DCV on equipment life, e.g., changes in equipment cycling and associated impact

\subsubsection{R\&D Initiative ID\#4: Advanced Duct Sealing}

The estimated impact of duct leakage on energy consumption is high and sources have found that a large percentage of residential and commercial buildings suffer from substantial duct leaks. Aerosol spray sealants have been commercially available for a decade. Research in this area should focus on conducting detailed market penetration analysis and understanding opportunities for improvements to technologies and processes.

We suggest a market study to assess the adoption of spray sealant technology with HVAC maintenance contractors, and to assess any barriers which are preventing greater market adoption. In support of the study, industry may benefit from analysis of current success of utility incentive programs for duct sealing in residential and commercial buildings. Discovery of any significant market or technological barriers could inform further research directions.

Other areas for further investigation include:

- Current installation practices and any potential building code compliance issues

- Best practices for installers of residential and commercial ducting

- Potential improvements to current duct sealing and insulation building codes 


\section{Pumps}

\subsection{Pump Technology Overview}

This report focuses on centrifugal rotodynamic pumps, which account for the vast majority of residential and commercial pump applications. Within industrial applications, rotodynamic pumps account for $70 \%$ of total sales, and $90 \%$ of total energy use. Additional pump types used in niche or non-building applications include: positive displacement, jet, liquid ring, and regenerative pumps. Positive displacement pumps represent a small part of the commercial and industrial pump market, often used for applications with viscous or shear-sensitive fluids. Residential and commercial sectors typically use pumps for clean water applications. For these applications, some positive displacement pumps can be used instead of rotodynamic pumps, but they are more expensive and typically have higher maintenance costs, making users more likely to choose rotodynamic pumps. ${ }^{112}$

Rotodynamic pumps operate by imparting kinetic energy from a spinning impeller to the working fluid. The pump converts this energy into pressure as the fluid exits the impeller and reaches the discharge. Centrifugal pumps, a subtype of rotodynamic pump, operate similarly to centrifugal fans: water enters the pump axially towards the center of the impeller, which then accelerates the fluid radially out and around the volute. Hereafter, we will only focus on centrifugal pumps, as they are most common in residential and commercial applications. Figure 3-1 shows a cross-section diagram of a typical centrifugal pump.

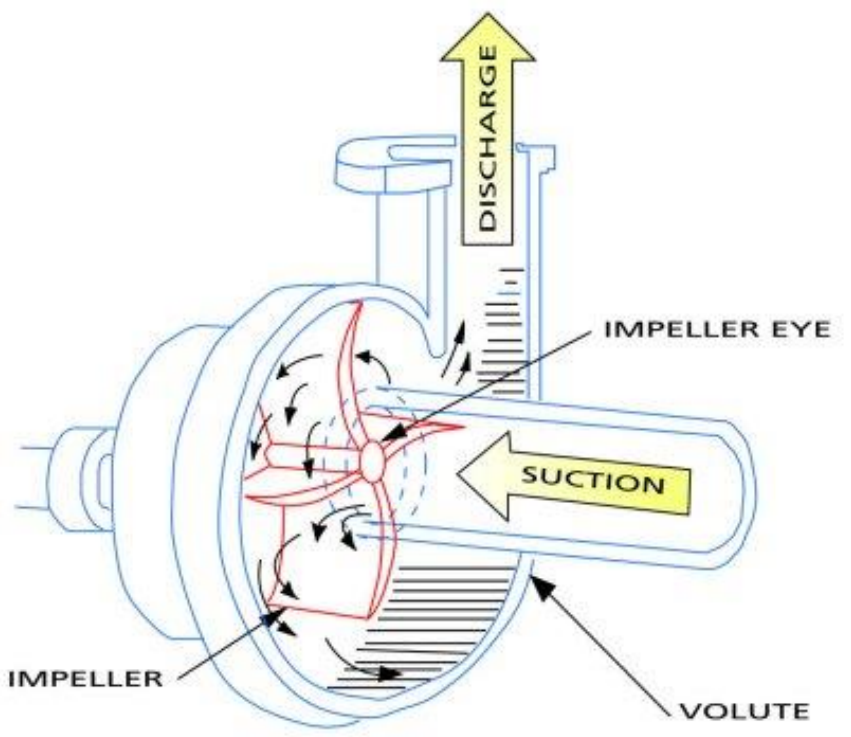

Photo Source: Pump Fundamentals ${ }^{113}$

Figure 3-1: Centrifugal pump schematic (Centrifugal, end-suction pump pictured)

\footnotetext{
${ }^{112}$ DOE. Framework Document - Rulemaking for Commercial and Industrial Pumps Energy Conservation Standards, Accessed Feb 2015. http://www1.eere.energy.gov/buildings/appliance standards/rulemaking.aspx/ruleid/14

${ }^{113}$ Pump Fundamentals. Accessed Feb 2015. http://www.pumpfundamentals.com/pump_glossary.htm
} 
For centrifugal pumps used in clean water applications, impeller vanes are typically backwardscurved (away from the direction of rotation). Unlike fans, vane curvature is not typically a variable design feature. Some alternative pumps types, such as wastewater and slurry pumps may offer radial/flat impeller vanes, which excel at passing solids and reduce clogging. Typically, clean water pumps greater than $5 \mathrm{hp}$. are fitted with induction motors (2- or 4-pole, which run at different speeds) to drive the impeller. Smaller pumps, $5 \mathrm{hp}$. or less, may utilize induction motors or be fitted with more efficient electronically commutated motors (ECM). ECMs provide variable speed capability and are typically more efficient than induction motors, but are limited to lower horsepower and are currently more expensive than induction motors. Variable speed drives may be added to most three-phase induction motors, small and large, and can provide significant potential energy savings benefits by reducing pump speed to match required load. However VSD are expensive and add significant first cost to the pump package.

Centrifugal pumps are capable of providing a range of pressures (commonly referred to as "head") and flow rates suitable for a wide suite of applications. Multistage centrifugal pumps, with multiple impellers in series, offer the option to serve high-head applications.

Pump selection is driven largely by the required water flow rate and pressure head. The typical selection process uses the following steps:

1. Determine target flow rate for the system - e.g., for a boiler hot water loop, this would be determined by the desired heat transfer, or temperature loss during circulation.

2. Determine target supply pressure and expected head loss in the piping system at the target flow rate - based on the frictional losses in the pipe, which is based on the geometry and restrictions, such as valves, in the system.

3. Identify suitable pumps using pump curves - equipment must work at the desired operating point (head and flow)

4. Select the best option - typically based on:

a. Pump efficiency at operating point; energy efficiency (control systems)

b. First cost, or future operating costs

c. Available floor space

d. Repair or maintenance factors

e. Future considerations (expansion of pumping system or degradation of pipes)

f. Safety factor

Multiple pumps may be installed for a given application in series and/or parallel to provide scalability, redundancy, or to provide the desired flow or pressure characteristics. Oversizing occurs frequently, reducing efficiency of the system, often as a result of designs that account for potential future expansion or degradation of pipe quality. In fixed speed pump applications, a throttling valve is used to reduce pump flow to the desired system characteristics. In variable speed pump applications, the pump speed may be decreased to reduce pump flow and head to the desired system flow.

Pump efficiency is related to the pump Specific Speed, the pump operating speed, and the flow rate of water. ${ }^{114}$ The Specific Speed is a dimensionless number characterizing the impeller type

\footnotetext{
${ }^{114}$ For more information about this relationship, please refer to Chapter 3, and Appendix 3.A in the CIP Rulemaking NOPR TSD and to Chapter 6 and 7 of Europump selection guide. (Sources on following page)
} 
and discharge characteristics of the pump. It relates rotational speed of the impeller, flow rate at BEP, and total developed head. Pumps with high flow and low head have high Specific Speed; pumps with low flow and high head have low Specific Speed. ${ }^{115}$ Pump operating speed is the rotational speed at which the impeller turns. Each pump is typically paired with an induction motor, thus potentially changing performance and efficiency if the pump is offered at different speeds (i.e. 2-pole vs 4-pole motors). DOE has proposed different standards for pumps at different speeds in the Commercial and Industrial Pump energy conservation standards rulemaking (CIP Rulemaking). ${ }^{116}$

It is only possible to compare pump efficiency by looking at a specific application and system conditions (head/flow required). Ideally the system operates as close to the BEP as possible (see Figure 3-2), but in reality, any change in system will lead to change in efficiency. Generally, incremental energy efficiency improvements associated with flow characteristics or impeller design is dwarfed by potential operational improvements by adding part-load controls using an ECM or VSD.

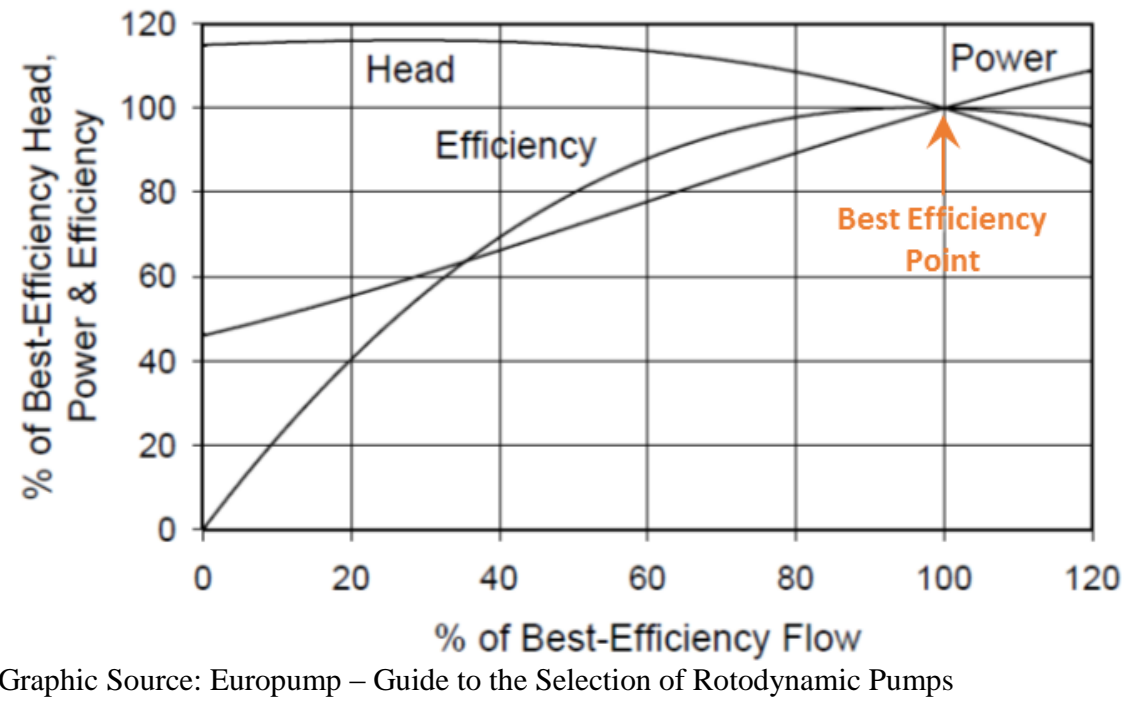

Figure 3-2: A sample pump performance curve

The pump industry refers to centrifugal pumps in two different broad categories based on the relative size and horsepower used by the pump, though this definition does not always provide a clear demarcation:

- "Pumps" are used in large applications; DOE considers pumps of 1-200 hp within the CIP rulemaking.

Sources:

DOE. NOPR- Rulemaking for Commercial and Industrial Pumps Energy Conservation Standards. Accessed Feb 2015. http://www1.eere.energy.gov/buildings/appliance standards/rulemaking.aspx/ruleid/14

Europump. "Guide to the Selection of Rotodynamic Pumps". 2008. http://europump.net/publications/guides-and-guidelines

${ }^{115}$ Budris, A.R. "Back To Basics: Pump Specific Speed and Suction Specific Speed." WaterWorld.com. Accessed Feb 2015. http://www.waterworld.com/articles/print/volume-25/issue-9/departments/pump-tips-techniques/back-to-basics-pump-specificspeed-and-suction-specific-speed.html

${ }^{116}$ DOE. NOPR- Rulemaking for Commercial and Industrial Pumps Energy Conservation Standards. Accessed Feb 2015. http://www1.eere.energy.gov/buildings/appliance_standards/rulemaking.aspx/ruleid/14 
- Circulators are smaller centrifugal pumps used to move water around in a closed loop, but generally are not called on to provide significant pressure head (only to overcome head loss during circulation). Circulators are essentially small pumps that operate in-line with the piping.

Sections 3.1.1 and 3.1.2 discuss circulators and pumps, respectively, in more detail. Figure 3-3 shows typical operating head and flow for pumps and circulators

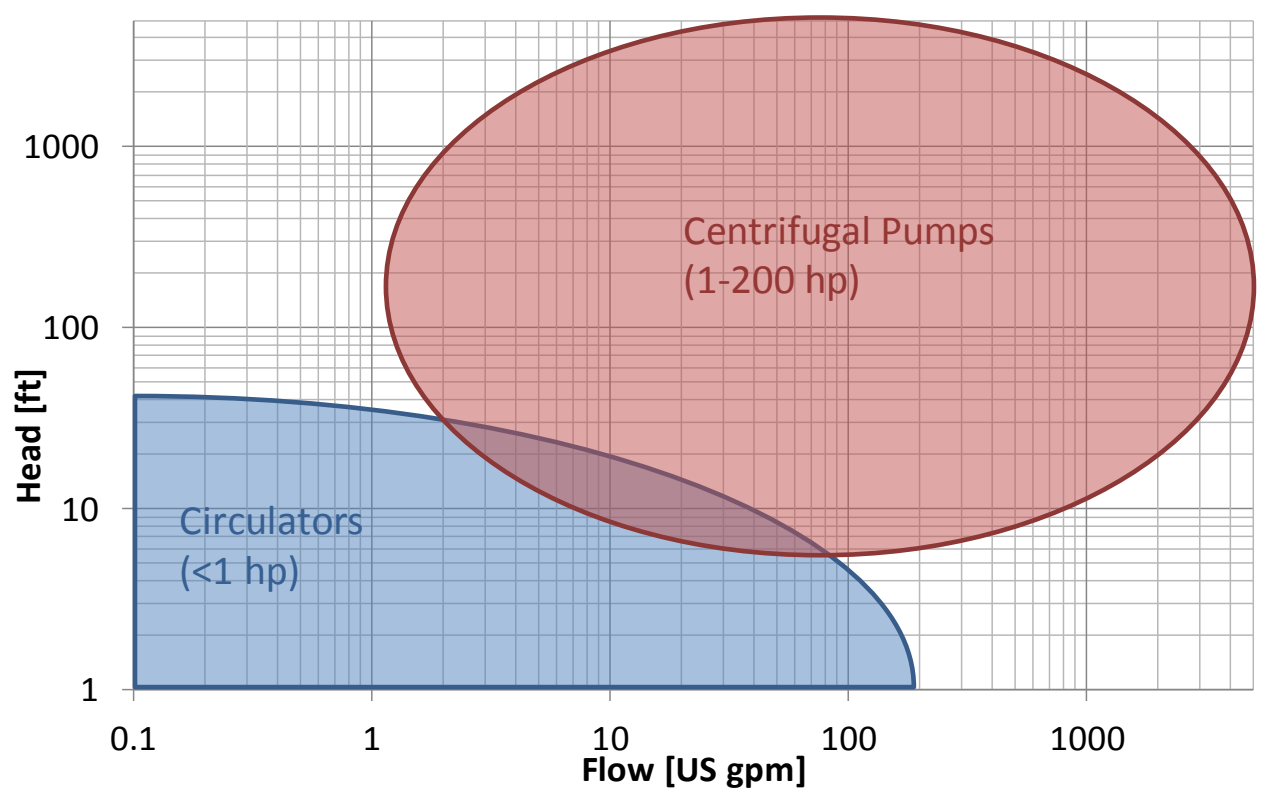

Graphic Source: Navigant Consulting, Inc.

Figure 3-3: Generalized pressure and flow provided by different centrifugal pump types ${ }^{117}$

\subsubsection{Circulators}

Circulator pumps (hereafter referred to as circulators) are horizontal, single-stage centrifugal pumps, with in-line pump housings. They typically operate in low head systems, and are generally quiet and vibration free while operating. Typical sizes range from $1 / 25 \mathrm{hp}$ to $\sim 1 \mathrm{hp}$. Figure 3-4 show an example of a circulator and an example application. DOE has proposed that circulators are covered as a type of pump under EPCA, but DOE has not established or proposed energy conservation standards for circulators.

\footnotetext{
${ }^{117}$ Input from DOE subject matter expert. 2015.
} 

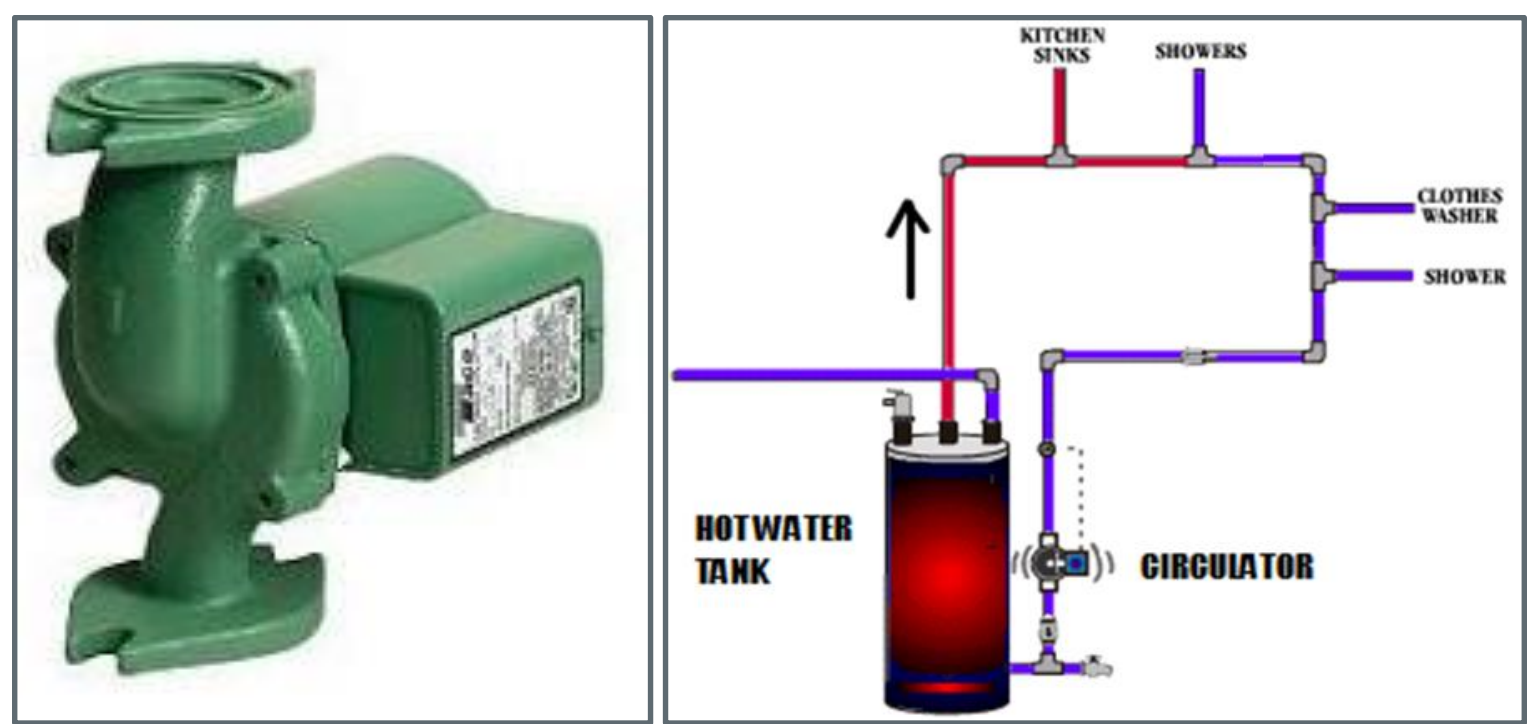

Photo Sources: www.pexuniverse.com ${ }^{118}$; www.plumbingsupply.com ${ }^{119}$

\section{Figure 3-4: Picture of a circulator, and a typical hot water loop with circulator}

There are three sub-types of circulators, though they all generally serve the same application and purpose. Two are close-coupled, meaning the pump and motor share one common shaft and the driver bearing(s) absorb all pump thrust loads (axial and radial), while one is flexibly-coupled, meaning the pump impeller connects to the motor using a coupler. Close-coupled circulators are generally more compact and lower cost than flexibly-coupled circulators.

In most cases, these sub-types are interchangeable; they have no distinctions in their applications or performance. Most circulators sold today are close-coupled, wet rotor circulators. Table 3-1 summarizes the differences and the following subsections describe them in greater detail.

\section{Table 3-1: Summary of Circulator Types}

\begin{tabular}{|c|c|c|c|}
\hline Attribute & $\begin{array}{l}\text { Close-coupled, } \\
\text { Wet rotor }\end{array}$ & $\begin{array}{l}\text { Close-coupled, } \\
\text { Horizontal in-line }\end{array}$ & Flexibly Coupled \\
\hline Consumer segment & \multicolumn{3}{|c|}{ - Residential, small commercial } \\
\hline $\begin{array}{l}\text { Volume \& pressure } \\
\text { characteristics }\end{array}$ & \multicolumn{3}{|l|}{ - Low pressure; low flow } \\
\hline Application & \multicolumn{3}{|c|}{$\begin{array}{l}\text { - Hydronic heating, Potable hot water circulation, Other (in-floor heating, heat recovery } \\
\text { units, water-source heat pumps, solar thermal, geothermal) }\end{array}$} \\
\hline Speed & $\begin{array}{l}\text { - Single \& multi-speed; } \\
\text { variable speed }\end{array}$ & - Single \& multi-speed & - Single \& multi-speed \\
\hline Lubrication & - System fluid & - Permanently lubricated & - Oil lubricated \\
\hline $\begin{array}{l}\text { Operating } \\
\text { environment }\end{array}$ & \multicolumn{3}{|l|}{ - Water } \\
\hline
\end{tabular}

\footnotetext{
118 PexUniverse.com. Example Taco circulator. Accessed Feb 2015. http://www.pexuniverse.com/content/taco-circulator-pumpdifferences

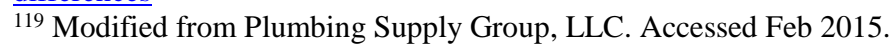

https://www.plumbingsupply.com/images/grundfos_recirculation_diagram.gif
} 


\begin{tabular}{|c|c|c|c|}
\hline Attribute & $\begin{array}{l}\text { Close-coupled, } \\
\text { Wet rotor }\end{array}$ & $\begin{array}{l}\text { Close-coupled, } \\
\text { Horizontal in-line }\end{array}$ & Flexibly Coupled \\
\hline Pros & $\begin{array}{l}\text { - No mechanical seal \& fewer } \\
\text { moving parts } \\
\text { - Rotor/stator are easily } \\
\text { replaceable parts }\end{array}$ & $\begin{array}{l}\text { - Motor/rotor not } \\
\text { affected by fluid } \\
\text { impurities }\end{array}$ & $\begin{array}{l}\text { - Can be repaired and/or } \\
\text { serviced } \\
\text { - Motor/rotor not affected by } \\
\text { fluid impurities }\end{array}$ \\
\hline Cons & $\begin{array}{l}\text { - Operation could be affected } \\
\text { by fluid impurities } \\
\text { - Limited size of motor }\end{array}$ & $\begin{array}{l}\text { - May require } \\
\text { maintenance (seal) }\end{array}$ & $\begin{array}{l}\text { - Louder operation } \\
\text { - Higher cost than close- } \\
\text { coupled }\end{array}$ \\
\hline
\end{tabular}

\subsubsection{Close-coupled, Wet Rotor}

A "wet rotor" means that the rotor shaft and bearings are constantly in contact with the water being circulated; thus the pump shaft is lubricated by the system fluid rather than oil. These are also sometimes referred to as "glandless" or "seal-less" circulators. Figure 3-5 shows a diagram of a typical wet-rotor circulator.

Wet rotors circulators do not require any mechanical seals between the pump side, which is exposed to liquid, and the rotor. Other circulator/pump types contain seals which keep the motor/rotor apart from the working fluid. The wet rotor motor is "canned," meaning that the copper windings are separated and located along the outer circumference of the motor casing. Circulator manufacturers typically design and/or manufacturer the wet-rotor motors, allowing manufacturers to reduce costs, and add additional control features. Comparatively, other circulator types will use an off-the-shelf motor, which circulator manufacturers would purchase from a motor manufacturer. 


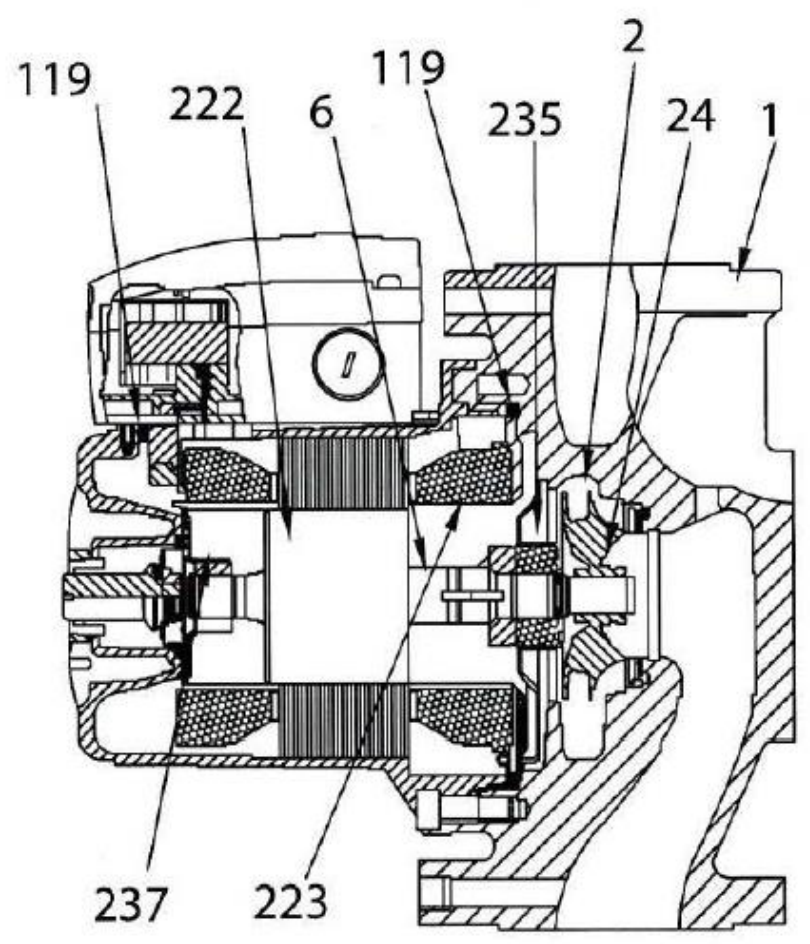

Graphic Source: Hydraulic Institute ${ }^{120}$

\section{Figure 3-5: Close-coupled, wet rotor circulator diagram}

Wet rotor circulators provide multiple advantages:

- Ubiquitous supply - They are primary type in use today and are readily available for all applications. Several major manufacturers only sell this type of circulator

- Fewer moving parts - They are easier and cheaper to manufacturer due to fewer moving parts than other circulator types. Further, they have no mechanical seals between the rotor and impeller.

- Easily replaced - If the motor fails, wet-rotor circulators are designed so that the motorimpeller assembly can be easily removed and replaced. Manufacturers offer replacement assemblies, allowing users to replace the part without needing to detach the circulator flanges from the piping

However, the two key downsides can be barriers in some applications:

- Impacted by fluid impurities - If the fluid is not free of impurities, they can build up at the bearing and cause pump failure.

- Limited motor size - wet rotor circulators are currently not available in the market with motors $>1 \mathrm{hp}$

\subsubsection{Close-coupled, Horizontal In-line}

Like wet-rotor designs, close-coupled, horizontal in-line circulators have a direct connection between impeller and motor, but maintain a sealed, dry rotor with sealed, permanently lubricated bearings. They maintain an air gap between the rotor and copper windings. Figure 3-6 shows a diagram of a close-coupled, horizontal in-line circulator.

\footnotetext{
${ }^{120}$ Hydraulic Institute. “American National Standard for Rotodynamic Centrifugal Pumps.” ANSI/HI 1.1-1.2-2014. 2014.
} 


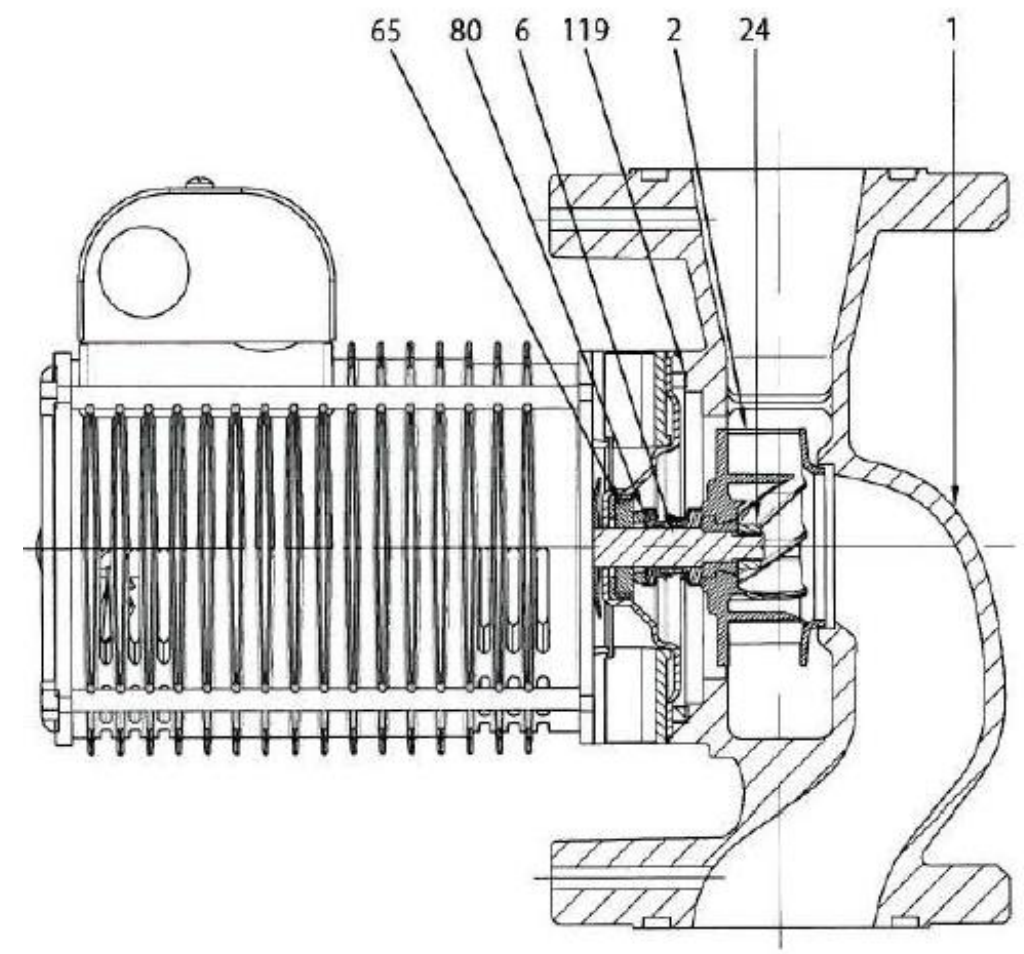

Graphic Source: Hydraulic Institute ${ }^{121}$

Figure 3-6: Close-coupled, Horizontal In-line circulator diagram and picture

Unlike wet rotor circulators, horizontal in-line circulators separate the working fluid from the motor with a seal, so the motor is not affected by impurities or fouling in the working fluid.

However, they also suffer from the following disadvantages:

- Limited serviceability - like all close-coupled pumps, it is inherently difficult to service, and the entire pump is typically replaced if a component fails. Unlike wet rotor circulators, horizontal in-line circulators, typically, are not designed for easy replacement of the motor-impeller assembly.

- Mechanical seal could fail- The addition of the mechanical seal between the working fluid and the motor adds to the design complexity and introduces an additional point of failure.

\subsubsection{Flexibly Coupled}

Flexibly coupled circulator pumps are the "original" circulator design and are essentially miniature in-line pumps. ${ }^{122}$ The pump and driver have separate shafts. The pump has an integral bearing housing to absorb all pump thrust loads. Driver is aligned and assembled directly to the pump unit, and the pump shaft is flexibly coupled to the drive shaft via a flexible element drive

${ }^{121}$ Hydraulic Institute. “American National Standard for Rotodynamic Centrifugal Pumps.” ANSI/HI 1.1-1.2-2014. 2014.

122 DOE. NOPR Technical Support Document (Section 3.1.2.3) - Rulemaking for Commercial and Industrial Pumps Energy Conservation Standards. Accessed Feb 2015.

http://www1.eere.energy.gov/buildings/appliance_standards/rulemaking.aspx/ruleid/14 
coupling. Given their similarities to larger in-line pumps (see section 3.1.2), the lines are blurred between when this stops being a circulator and becomes a "pump." For applications requiring circulators, there is typically no difference in performance between this type of circulator and the other types. Figure 3-7 shows an example and diagram of flexibly coupled circulators.

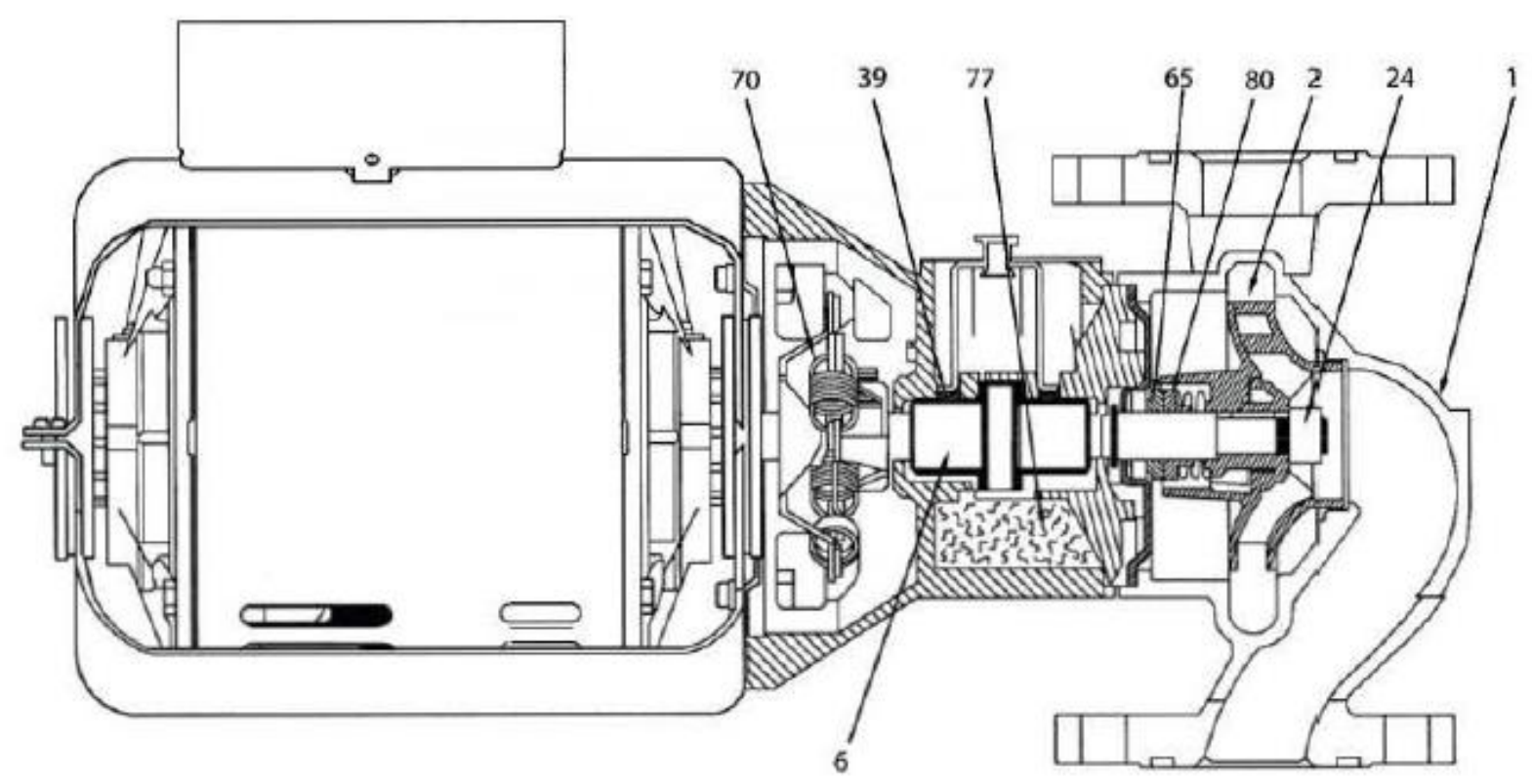

Graphic Source: Hydraulic Institute ${ }^{123}$

\section{Figure 3-7: Flexibly-coupled circulator diagram}

Flexible coupling has a couple key advantages over close-coupled circulators:

- Reduced forces on motor - Flexible coupling alignment between shafts reduces forces transmitted to the motor

- Can be maintained and/or serviced - Flex coupling means that access for maintenance is easier and component replacement (e.g., motor, impeller) is possible without discarding the whole pump

However, the mechanical seal may require maintenance and could fail. The flexible coupling can lead to extra noise during operation, and may also require service. Furthermore, due to the additional coupling, flexibly coupled circulators are likely to cost more than comparable closecoupled circulators.

${ }^{123}$ Hydraulic Institute. “American National Standard for Rotodynamic Centrifugal Pumps.” ANSI/HI 1.1-1.2-2014. 2014. 


\subsubsection{Pumps}

DOE has proposed energy conservation standards for certain pumps having power consumption greater than $1 \mathrm{hp}$ under the CIP standards rulemaking. ${ }^{124}$ Figure 3-8 shows an example of a typical centrifugal pump and a typical application.
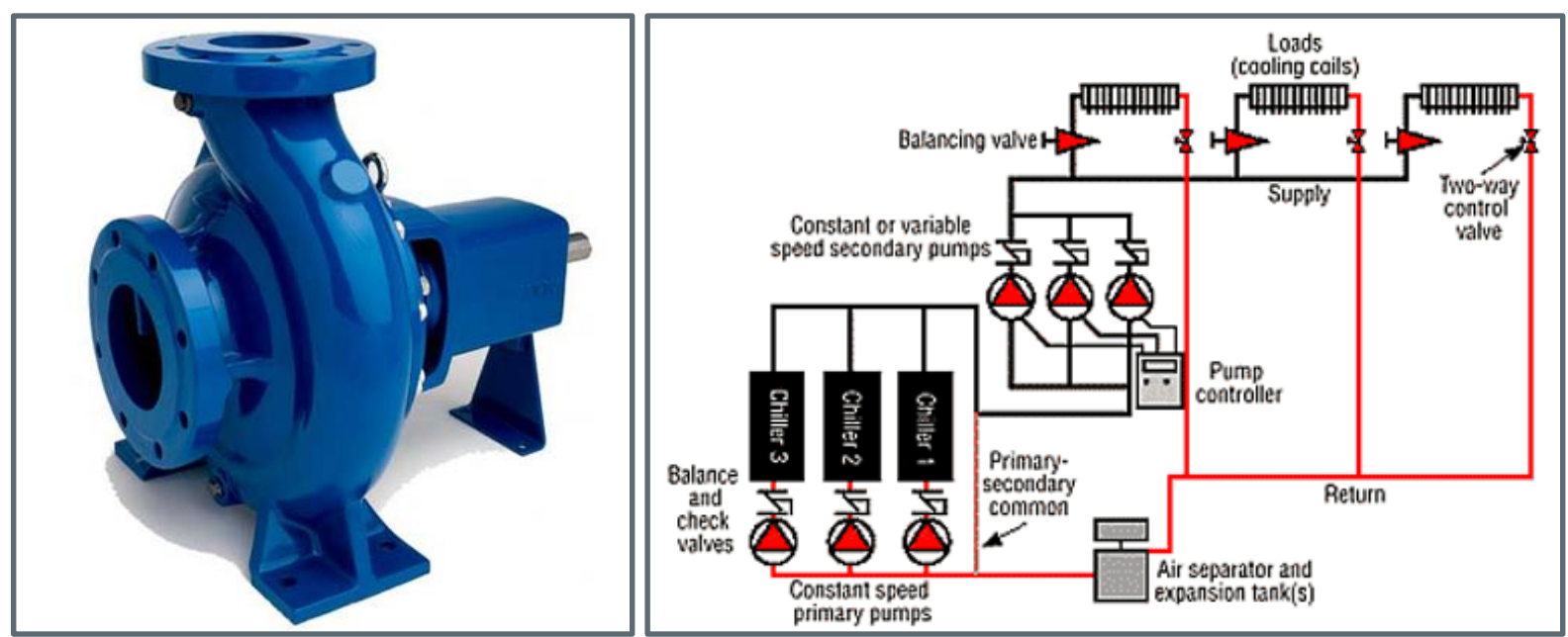

Photo Sources: www.apexpumps.com ${ }^{125}$; www.betterbricks.com ${ }^{126}$

\section{Figure 3-8: A centrifugal pump (left) and a typical cooling water loop schematic (right)}

This report covers five types of pumps: end-suction, close-coupled (ESCC); end-suction, framemounted (ESFM); in-line (IL); radially split, multi-stage, vertical, in-line, diffuser casing (RSV); and vertical turbine submersible (VTS). Pump types are generally defined by the physical arrangement of the pump, including layout of the impellers and motors, or how the pump is mounted. This report uses the pump types as described by the current DOE rulemaking for pumps. ${ }^{127}$ Pump selection is based on cost, maintenance, the layout of the pipes, how much space is available for the pumping system, other system considerations (safety factor, future expansion plans). Table 3-2 summarizes distinctions of each pump type.

\footnotetext{
${ }^{124}$ DOE. Rulemaking for Commercial and Industrial Pumps Energy Conservation Standards. Accessed Feb 2015. http://www1.eere.energy.gov/buildings/appliance_standards/rulemaking.aspx/ruleid/14

${ }^{125}$ Apex Pumps. Accessed Feb 2015. http://www.apexpumps.com/products.html

${ }^{126}$ BetterBricks - NEEA. Accessed Feb 2015. http://www.betterbricks.com/graphics/assets/images/Building_Ops/BOpEqSysWaterDistributionSystem_2W.png

127 DOE. Rulemaking for Commercial and Industrial Pumps Energy Conservation Standards. Accessed Feb 2015. http://www1.eere.energy.gov/buildings/appliance_standards/rulemaking.aspx/ruleid/14
} 
Table 3-2: Summary of Pump Types

\begin{tabular}{|c|c|c|c|c|c|}
\hline & $\begin{array}{l}\text { End-suction, close } \\
\text { coupled }\end{array}$ & $\begin{array}{l}\text { End-suction, } \\
\text { frame-mounted }\end{array}$ & $\begin{array}{l}\text { In-line (close or } \\
\text { flexibly coupled) }\end{array}$ & $\begin{array}{l}\text { Radially split, multi- } \\
\text { stage, vertical, in- } \\
\text { line, diffuser casing }\end{array}$ & $\begin{array}{l}\text { Vertical turbine } \\
\text { submersible }\end{array}$ \\
\hline Acronym & ESCC & ESFM & IL & RSV & VTS \\
\hline $\begin{array}{l}\text { Consumer } \\
\text { segment }\end{array}$ & \multicolumn{3}{|c|}{ - Multifamily residential \& commercial } & $\begin{array}{l}\text { - Multifamily } \\
\text { residential, } \\
\text { commercial \& } \\
\text { agriculture }\end{array}$ & $\begin{array}{l}\text { - Residential \& } \\
\text { agriculture }\end{array}$ \\
\hline $\begin{array}{l}\text { Volume \& } \\
\text { pressure } \\
\text { characteristics }\end{array}$ & \multicolumn{3}{|c|}{ - Low or med pressure, low to high flow } & $\begin{array}{l}\text { - High pressure, } \\
\text { medium-low flows }\end{array}$ & $\begin{array}{l}\text { - High pressure, } \\
\text { med-low flows }\end{array}$ \\
\hline Application & \multicolumn{3}{|c|}{$\begin{array}{l}\text { - Hydronic heating and chiller water circulation. } \\
\text { Pressure and circulation for potable/service water. }\end{array}$} & $\begin{array}{l}\text { - Pressure boost for } \\
\text { water distribution } \\
\text { - Agricultural small } \\
\text { scale irrigation. }\end{array}$ & - Well pumps. \\
\hline Pros & $\begin{array}{l}\text { Small and lower } \\
\text { cost than non- } \\
\text { close- coupled }\end{array}$ & $\begin{array}{l}\text { Easier servicing } \\
\text { due to flexible } \\
\text { coupling }\end{array}$ & $\begin{array}{l}\text { More compact } \\
\text { due to inline } \\
\text { configuration }\end{array}$ & $\begin{array}{l}\text { - Higher delivery } \\
\text { pressure for } \\
\text { pressure boosting }\end{array}$ & $\begin{array}{l}\text { - Submersible } \\
\text { - Capable of } \\
\text { delivering high } \\
\text { pressures }\end{array}$ \\
\hline Cons & $\begin{array}{l}\text { - Difficult to } \\
\text { service }\end{array}$ & $\begin{array}{l}\text { - Larger footprint } \\
\text { than close } \\
\text { coupled } \\
\text { - Higher cost } \\
\text { than ESCC }\end{array}$ & $\begin{array}{l}\text { More piping } \\
\text { losses due to } \\
\text { inline layout }\end{array}$ & $\begin{array}{l}\text { - Piping losses due to } \\
\text { tight fluid passages }\end{array}$ & $\begin{array}{l}\text { - Limited to well } \\
\text { pumping } \\
\text { applications } \\
\text { - Lower lifetime }\end{array}$ \\
\hline
\end{tabular}

Many of these pumps can be used interchangeably in any given application. Figure 3-9 shows the overlap in operating conditions (head and flow) for each pump type. ESCC, ESFM, IL tend to serve the same applications; for higher pressure/flow applications, a RSV pump might also be suitable. VTS serve well-pumping applications only, and while they overlap in terms of head and flow, they are not interchangeable. 


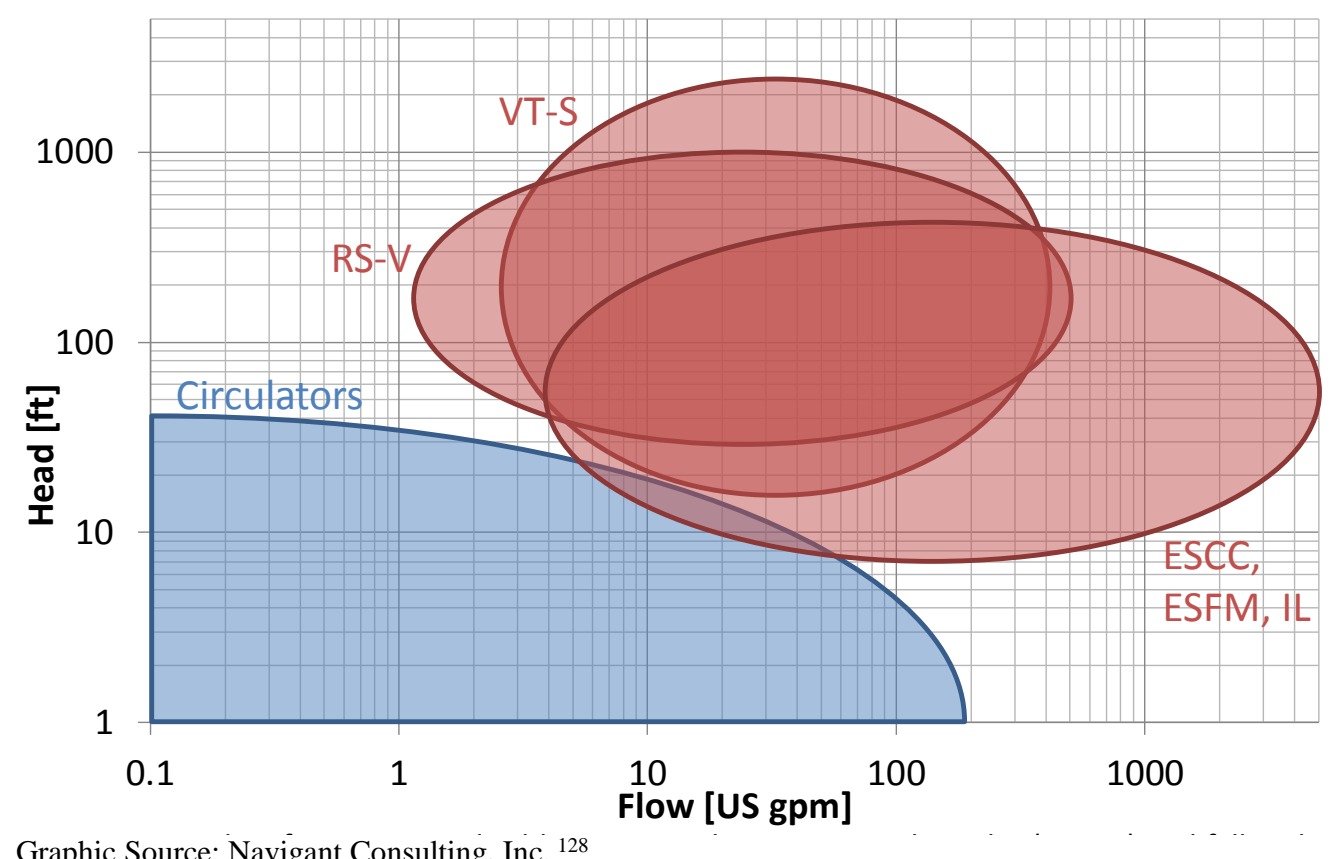

Figure 3-9: Generalized pressure and flow provided by different pump types

\subsubsection{End-suction, Close-coupled}

ESCC pumps are common, single-stage centrifugal pumps that pull water in along the same axis as the impeller, and outlet flow perpendicular to the axis of the impeller. Like other closecoupled pumps, the impeller shaft locks directly to the driver shaft, rather than using a flexible coupling. If any part of the driver fails, the entire motor and shaft assembly may need to be replaced. Close-coupling in this case allows these pumps to be smaller and to stand-alone without any kind of larger frame mounting, as is required for ESFM pumps. Figure 3-10 shows an example ESCC pump.

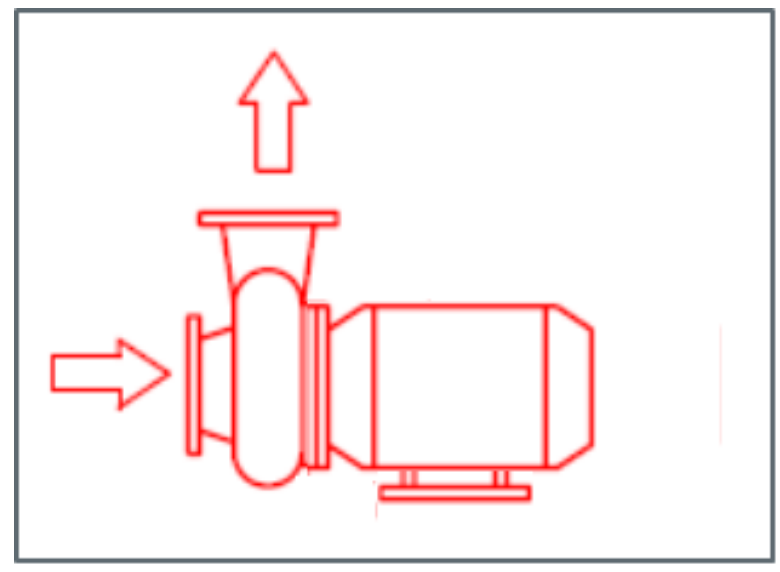

Graphic Source: Europump ${ }^{\mathbf{1 2 9}}$

Figure 3-10: End-suction, close-coupled pump diagram

${ }^{128}$ Created with input from DOE subject matter expert, and based on products offered by Grundfos and Taco. 2015
${ }^{129}$ Europump. "Guide to the Selection of Rotodynamic Pumps". 2008. http://europump.net/publications/guides-and-guidelines 
Because of the close-coupling, ESCCs are cheaper than flexibly coupled pumps. However, ESCCs are harder to service than flexible couple pumps, and thus typically need to be replaced upon failure. For ESCCs (and ESFMs), smaller pumps tend to be low cost/low efficiency. ESCC pumps tend to have flatter pump efficiency curves, which allows them to operate at or close to their best efficiency point for a range of flow conditions. ${ }^{130}$

\subsubsection{End-suction, Frame-mounted}

ESFM pumps are also common, single stage, centrifugal pumps that are used in a variety of building applications. ESFMs are similar in design and performance to ESCCs, however, ESFMs feature a flexible coupling between the drive shaft and the impeller. This design requires additional support for the various components, which the frame provides. Figure 3-11 shows an example diagram of an ESFM pump.

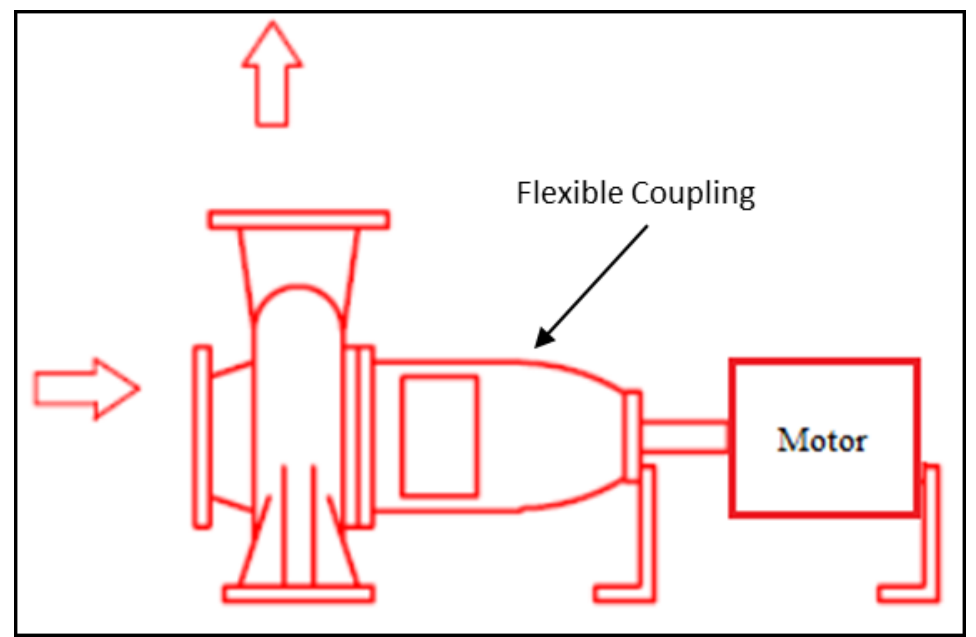

Graphic Source: Modified from Europump ${ }^{131}$

Figure 3-11: End-suction, frame-mounted pump diagram

The flexible coupling allows for greater range in operating load imbalances and allows the pump to be more easily serviced. Maintenance staff can remove the motor and impeller from the housing for servicing without disturbing the pipework. Frame mounting provides support to both the motor, shaft and the pump. Conversely, in ESCCs, the driver shaft must bear the entire weight of the motor in addition to the pump loads. Due to the addition of the flexible coupling, ESFMs are larger and bulkier than ESCCs.

\subsubsection{In-line}

IL pumps are identical to end-suction pumps, except that their housings redirect flow, such that the inlet is in-line with the outlet. Because of the in-line similarity to circulators, a circulator is often considered a scaled down version of an inline pump (though no wet-rotor options are

\footnotetext{
${ }^{130}$ Europump. "Guide to the Selection of Rotodynamic Pumps". 2008. http://europump.net/publications/guides-and-guidelines

${ }^{131}$ Europump. "Guide to the Selection of Rotodynamic Pumps". 2008. http://europump.net/publications/guides-and-guidelines
} 
available for IL pumps). This configuration offers convenience for system designers and generally reduces piping footprint.

IL pumps can be either close- or flex-coupled; larger IL pumps are typically flex-coupled while smaller pumps are close-coupled. IL pumps offer space benefits over ESCC and ESFM pumps, in that they can be used horizontally or vertically depending on the specific pump design and needs of the user. Figure 3-12 shows a diagram of an IL pump.

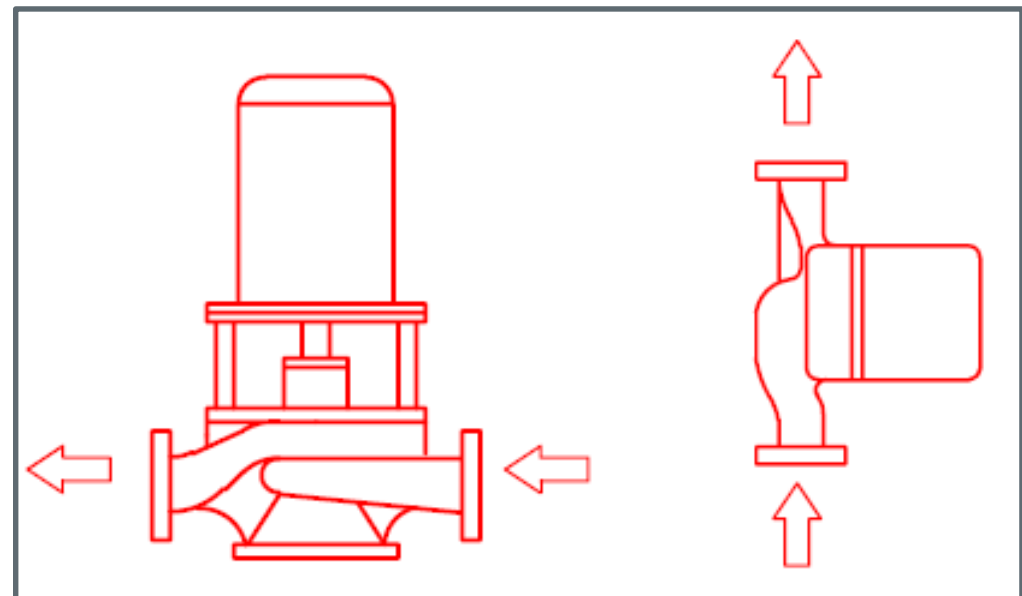

Graphic Source: Europump ${ }^{132}$

Figure 3-12: In-line pump diagram

Although pump efficiency is highly application dependent, inline pumps generally lose some efficiency due to the space-constrained arrangement of suction passages. However, an ESCC or ESFM may experience similar piping losses upstream from the pump in order to redirect flow in the desired direction.

\subsubsection{Radially split, multi-stage, vertical, in-line, diffuser casing}

RSV pumps are multistage pumps, containing multiple impellers to boost water to higher pressures than single-stage pumps can achieve (without the use of multiple pumps in series). The impellers are vertically stacked along the axis of the driver shaft; different numbers of impellers can be added or removed according to the desired delivery pressure. By serving high-pressure applications with a single pump, RSV systems can lower upfront costs and reduce maintenance costs. Figure 3-13 shows an example of an RSV pump.

132 Europump. "Guide to the Selection of Rotodynamic Pumps". 2008. http://europump.net/publications/guides-and-guidelines 


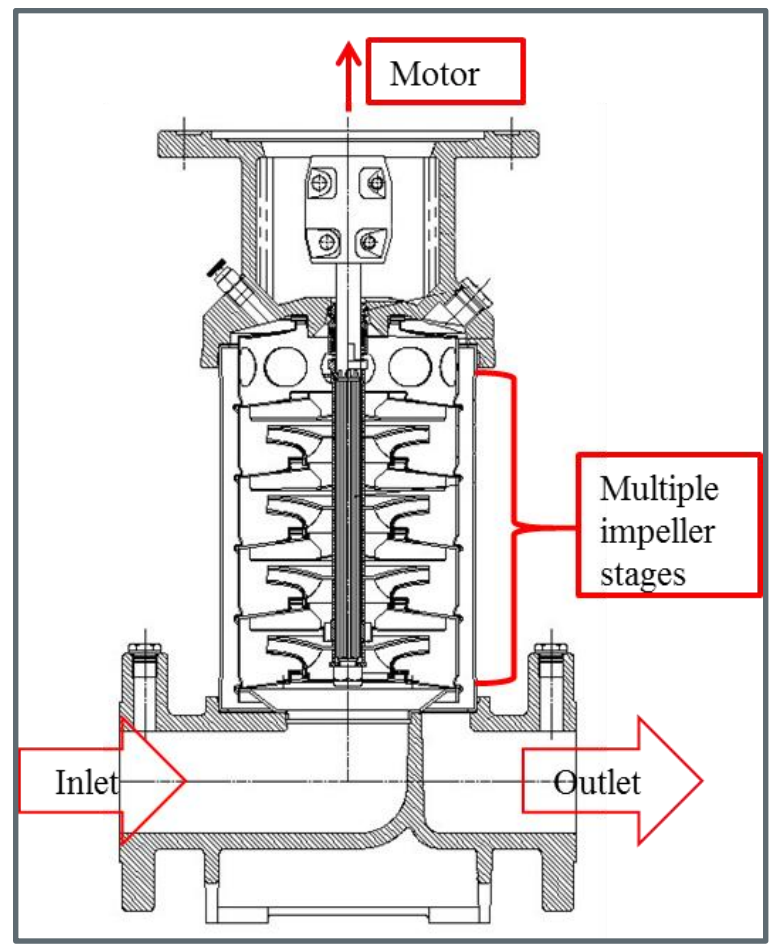

Graphic Source: Modified from Pentair ${ }^{133}$

Figure 3-13: Vertical multistage pump diagram

"Radial-split" indicates the method by which the pump can be taken apart for servicing. Radial split pumps offer easy access to the pump interior for ease of maintenance and modification. While efficiency remains application-dependent, RSV pumps might have lower efficiencies from tight hydraulic passages and relatively large drive shaft diameter. However, for high head applications, efficiency will be better than single stage pumps

Applications for RSV are similar to other pumps (heating, cooling, or potable water) but are most commonly used in tall buildings requiring high head to reach upper floors. Golf courses and small scale agricultural irrigation are also good applications for RSV pumps. RSV pumps are competitive with the other pump types during medium flow and medium pressure. In high pressure situations, there might not be any viable ESCC/ESFM competitors.

\subsubsection{Vertical turbine submersible}

Submersible vertical turbines (VTS) are single or multistage pumps, with vertically stacked impellers. The entire pump is designed to be submersible in order to be lowered down into a ground well (see Figure 3-14). Submersible motors are specialized and require waterproof casing around the motor, power supply lines, and other electrical components. Most VTS pumps depend on the surrounding water to carry about excess heat, and must function with adequate cooling water flow. ${ }^{134}$ Customers can select the diameter and the number of impellers of the pump depending on the depth and width of the ground well. The impellers are connected in series, allowing each subsequent stage to add to the delivered head.

\footnotetext{
${ }^{133}$ Pentair - VLR Vertical Multistage Centrifugal Pump. Accessed Feb 2015. http://pentairaes.com/pentair-nocchi-vlr-verticalmultistage-centrifugal-pumps.html

${ }^{134}$ Grundfos. Accessed Feb 2015. http://us.grundfos.com/products/find-product/submersible-motors.html\#literature
} 

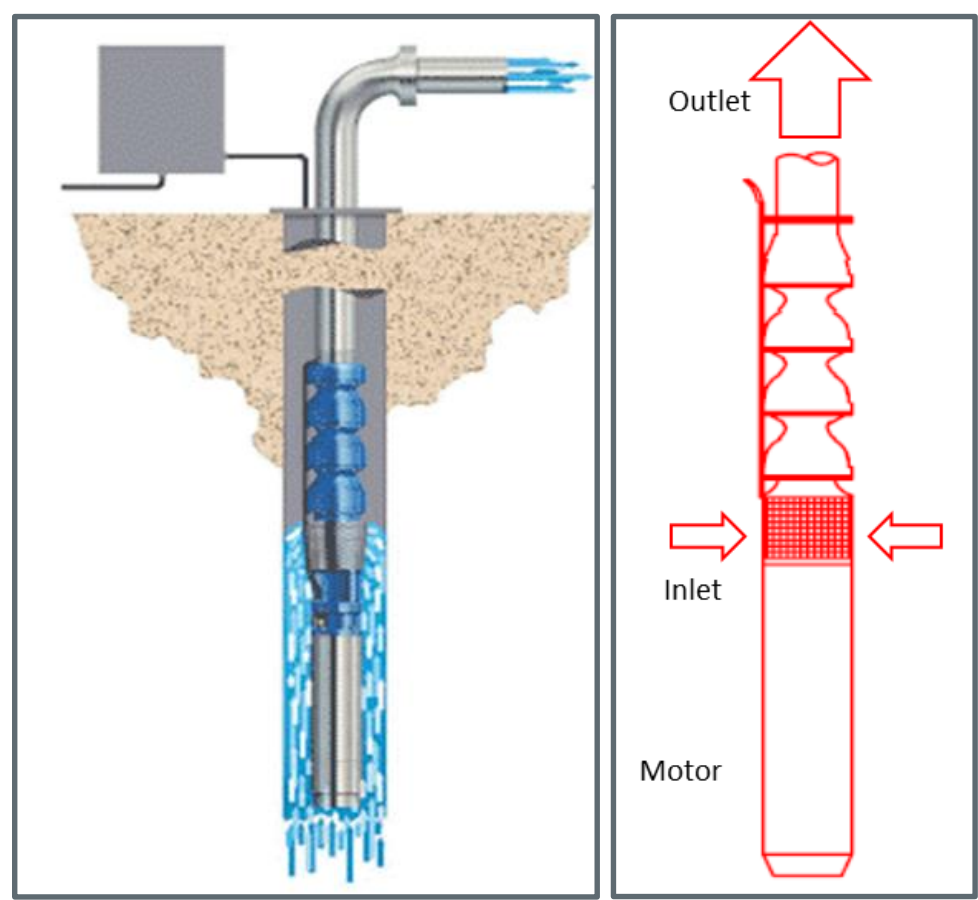

Photo and Graphic Sources: Geiger ${ }^{135}$; Europump - Guide to the Selection of Rotodynamic Pumps ${ }^{136}$

\section{Figure 3-14: VTS pump in operation (left) and pump diagram (right)}

Benefits and drawbacks of the multiple impeller design is similar to the RSV. VTS pumps could suffer from multiple points of failure that would result in water leaking into electrical components. As such, the average lifetime of a submersible pump is generally less than nonsubmersible pumps. ${ }^{137}$ VTS efficiency is reasonably good but a submersible motor is less efficient than conventional motor. Column pipe losses may be significant in deep wells but this is application dependent.

\subsection{Residential Applications and Market Overview}

This section outlines the typical use of pumps in residential applications and describes the current residential pump market in Section 3.2.1. Section 3.2.2 presents the energy consumption of these residential pump applications.

\subsubsection{Applications}

Hydronic heating is the primary stand-alone circulator application in the residential sector (excluding circulators built into appliances). Circulators are only used for hot water boilers, as steam boilers do not require circulators for heating. Geothermal heat pumps (GHP, also known as ground-source heat pumps) use circulators to circulate water through the in-ground loop field,

\footnotetext{
135 Geiger Pump \& Equipment. Accessed Feb 2015.

http://pumpshop.com.previewc28.carrierzone.com/G\%26LProductPics/TurbinePumps/SubExample3.gif

${ }^{136}$ Europump. "Guide to the Selection of Rotodynamic Pumps". 2008. http://europump.net/publications/guides-and-guidelines

${ }^{137}$ Refer to Section 3.2.2 for average lifetimes.
} 
but this constitutes only a small percentage of sales. Most solar thermal systems use circulators to move water between solar collectors and residential hot water tanks - they constitute an even smaller percentage of sales and installed base.

Some homes utilize pumps for domestic hot or cold water applications. Some large singlefamily homes (and multifamily buildings having a central water heater or boiler) have a hot water recirculation loop driven by a circulator, to ensure hot water is always available at the fixtures. The average single-family house does not need a recirculation loop; it is generally a luxury application.

For this report, we cover circulators of less than $1 / 4 \mathrm{hp}$, common in single-family and small multifamily buildings, within the residential discussion. We include larger circulators $(>1 / 4 \mathrm{hp})$, typical of large multifamily residential and commercial buildings, with commercial applications (see section 3.3.1).

Most domestic water supply pumping, typically provided by a municipal water system, is outside the scope of this report; however, homes that are not connected to such a system require a VTS well pump to provide a domestic water supply (historically, jet pumps have also been used for this purpose as well). The pumps are activated when the pressure within a pressurized well tank (partially filled with air) drops below a set-point. Pressure tanks are not generally intended to provide a large supply of water, but rather to ensure appropriate water pressure in the system and to avoid excessive short cycling of the pump when there are small draws at fixtures in the home. As the home uses the well water over the course of the day, the pump will run periodically to refill and re-pressurize the tank. ${ }^{138}$

Residential appliances such as dishwashers and clothes washers use small circulators to circulate and drain water. Dishwashers circulate water during wash cycles and drain water during and after wash cycles. Some models have separate pumps to perform these tasks, while some models use only a single pump. Clothes washers use a pump to drain water during and after wash cycles.

Residential pools utilize pumps to circulate pool water for cleaning. They are typically end suction pumps with a screen on the inlet to prevent ingestion of any debris. These may run intermittently or at constant part load - the usage varies by each pool owner's preferences and the amount of time per year that the pool is open.

Other miscellaneous residential pump applications include sump pumps, aquarium pumps, and hot tub/spa pumps. We have not attempted to characterize these pump options as they are applications with low energy consumption or intermittent usage.

\subsubsection{Market}

With the exceptions of pool pumps and well pumps, pumps used in single family homes are usually circulator pumps. Circulators are sold as a single package (impeller, motor and, if

\footnotetext{
${ }^{138}$ CATSWS. "Chapter 7: Groundwater and Well Design.” UC-Davis. Accessed Feb 2015. http://smallwatersystems.ucdavis.edu/Courses/WebCast/default files/Lecture\%207.pdf See source for additional discussion of residential water pumping system.
} 
present, controls) for various HVAC and potable water applications. Five major manufacturers dominate this market: Taco, Armstrong Limited, Grundfos, Wilo, Xylem (Bell \& Gossett).

Circulators serve a variety of residential and commercial HVAC applications. In total, circulator manufacturers ship 1.6 million units per year (excluding those inside appliances).

Approximately 1.55 million units are less than $1 / 4 \mathrm{hp}$ and, in this report, estimated suitable for single family residential use. An additional $\sim 88,000$ are between $1 / 4$ and $3 \mathrm{hp}$, which are suitable for commercial or large multi-family residential applications (covered in detail under commercial applications in section 3.3). ${ }^{139}$ Given a typical lifetime of $\sim 10$ years, we estimate an installed base of 15.5 million circulators in residential applications.

Wet-rotor circulators are the most common circulator type and their market share continues to grow. Moving forward, manufacturers have signaled that they may phase-out all other circulator types (i.e. Horizontal in-line, and Flexibly Coupled) as they begin to focus on more efficient ECM-driven models. ${ }^{140}$

Table 3-3 shows the estimated annual shipments and installed based for the key pump applications in the residential sector. See Appendix A - Data Sources for Shipments and Installed Base for sources and notes.

Table 3-3: Residential Pump Uses and Market Summary

\begin{tabular}{lcccc}
\hline \multicolumn{1}{c}{ Applications } & Pump Use & Pump Type & $\begin{array}{c}\text { Est. Annual } \\
\text { Shipments (MM) }\end{array}$ & $\begin{array}{c}\text { Est. Installed Base } \\
\text { (MM) }\end{array}$ \\
\hline Hydronic heating (boilers) & Circulation & Circulator & 1.11 & 11 \\
\hline Hot Water & Recirculation & Circulator & 0.34 & 3.4 \\
Well pump & Well water & VTS & 1.0 & 16 \\
\hline Dishwasher & Circulation \& Drain & Circulator & 5.69 & 95 \\
Clothes Washer & Drain & Circulator & 7.3 & 110 \\
\hline $\begin{array}{l}\text { Pool pump } \\
\text { Geothermal HP }\end{array}$ & Circulation & ESCC, ESFM & 0.67 & 5.36 \\
\hline Solar Thermal & Loop circulation & Circulator & 0.09 & 0.9 \\
Sources: See Appendix A-Data Sources for Shipments and Installed Base & 0.07 & 1 \\
\hline
\end{tabular}

$78 \%$ of all circulators sold are for hydronic heating circulation, while the remaining $22 \%$ are for potable water applications. ${ }^{141}$ While these numbers represent all circulator shipments (residential and commercial), we assume that this breakdown holds true for the residential sector since the majority of circulators are sold with motors $<1 / 4 \mathrm{hp}$, and are suitable for residential applications.

\footnotetext{
${ }^{139}$ DOE. "ASRAC Pumps Working Group Scope" - Slides from Commercial/Industrial Pumps Working Group. Accessed Feb 2015. http://www.regulations.gov/\#!documentDetail;D=EERE-2013-BT-NOC-0039-0037

${ }^{140}$ Input from DOE subject matter expert. 2015

${ }^{141}$ DOE. "ASRAC Pumps Working Group Scope" - Slides from Commercial/Industrial Pumps Working Group. Accessed Feb 2015. http://www.regulations.gov/\#!documentDetail;D=EERE-2013-BT-NOC-0039-0037
} 
Residential pool pumps have a typical lifetime of $\sim 10$ years. ${ }^{142}$ Major manufacturers include: Pentair Water Pool and Spa, Hayward, Jandy, Speck, and Waterway.

Well pumps are manufactured by a number of brands/companies, including: Byron Jackson (Flowserve), Grundfos (Grundfos), Goulds (ITT Goulds), Johnson (Sulzer), and Floway (Weir Group). They typically have a lifetime of $\sim 10$ years. ${ }^{143}$

Dishwashers use one or two pumps for water circulation and drainage. Data on the number of dishwashers using two pumps is not available; this report conservatively assumes 1 pump per dishwasher, though we believe this to be a low estimate. Dishwasher pump manufacturers include: Askoll, Hanning, Hanyu, Sung Shin, Bleckmann, Plaset, Copreci, and Welling. Residential clothes washers also integrate a small drain pump, which include pump manufacturers like Askoll and Hanning.

\subsubsection{Energy Consumption}

Pumps account for 0.4 Quads (2\%) of total residential primary energy consumption in the U.S. Figure 3-15 shows a breakdown of residential pump applications and their primary energy consumption. While homes use pumps for a variety of applications, the overall energy consumption for pumps is low compared to other electricity uses in residential homes. These data do not include the energy consumption of miscellaneous pump applications that this report does not characterize, such as sump pumps and aquarium pumps (see Section 3.2.1), due to low energy consumption and intermittent usage. See Appendix C - Calculation Methodology for a description of calculation methodology.

\footnotetext{
142 Environmental Protection Agency (EPA). "Pool and Sump Pumps; Residential Market and Industry Scoping Report." Prepared for ENERGY STAR. April 19, 2011.

${ }^{143}$ DOE. NOPR Technical Support Document - Rulemaking for Commercial and Industrial Pumps Energy Conservation Standards. Accessed Feb 2015. http://www1.eere.energy.gov/buildings/appliance_standards/rulemaking.aspx/ruleid/14
} 


\section{Residential Primary Energy Breakdown}

All units are in Quadrillion BTUs (quads)

See Appendix D for data sources

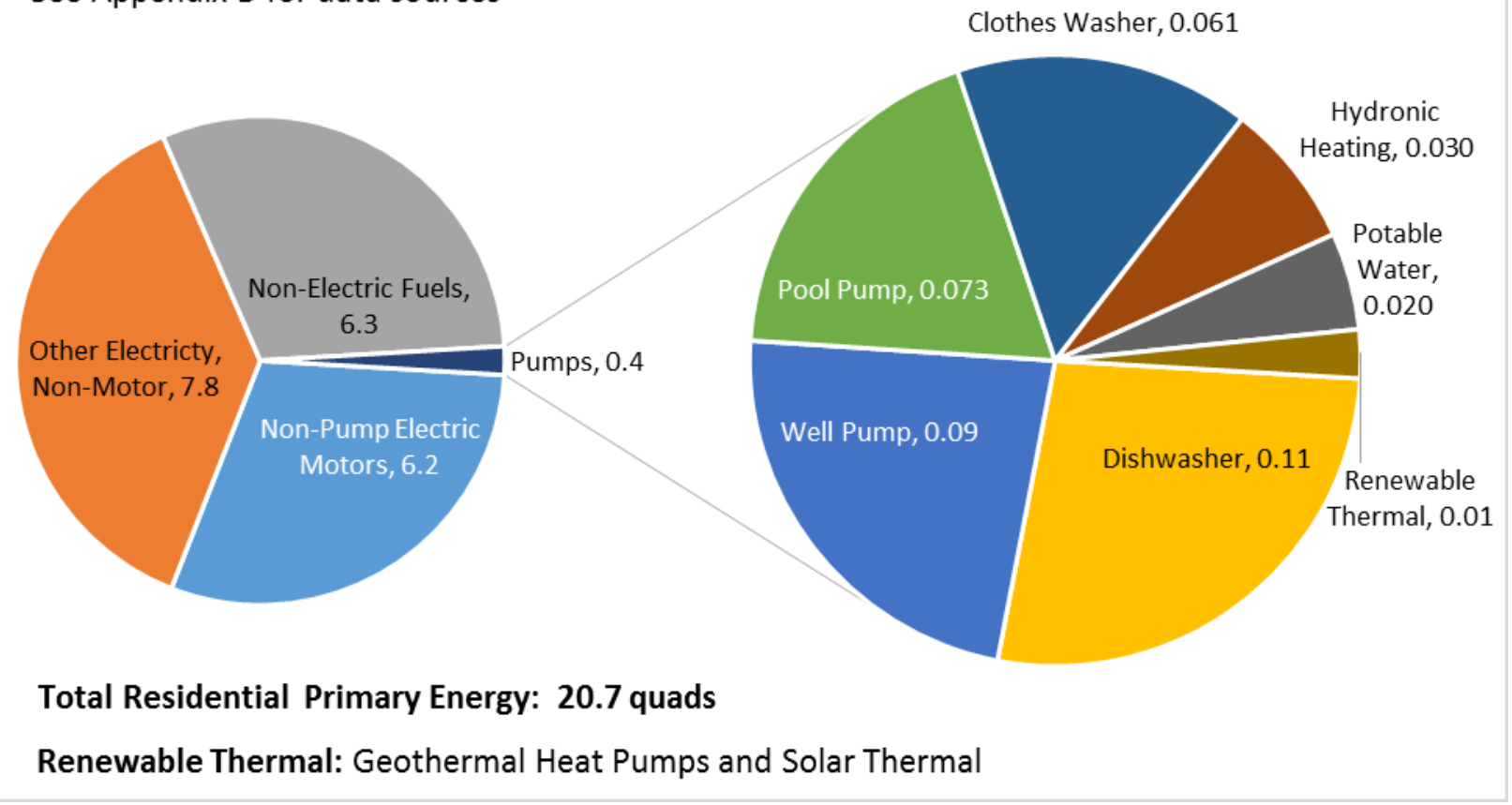

Figure 3-15: Residential pump primary energy consumption

Table 3-4 provides a detailed primary energy breakdown by pump applications, and provides average annual operating hours and the average unit energy consumption (UEC) of each pump.

Table 3-4: Residential Pump Energy Consumption for Selected Applications

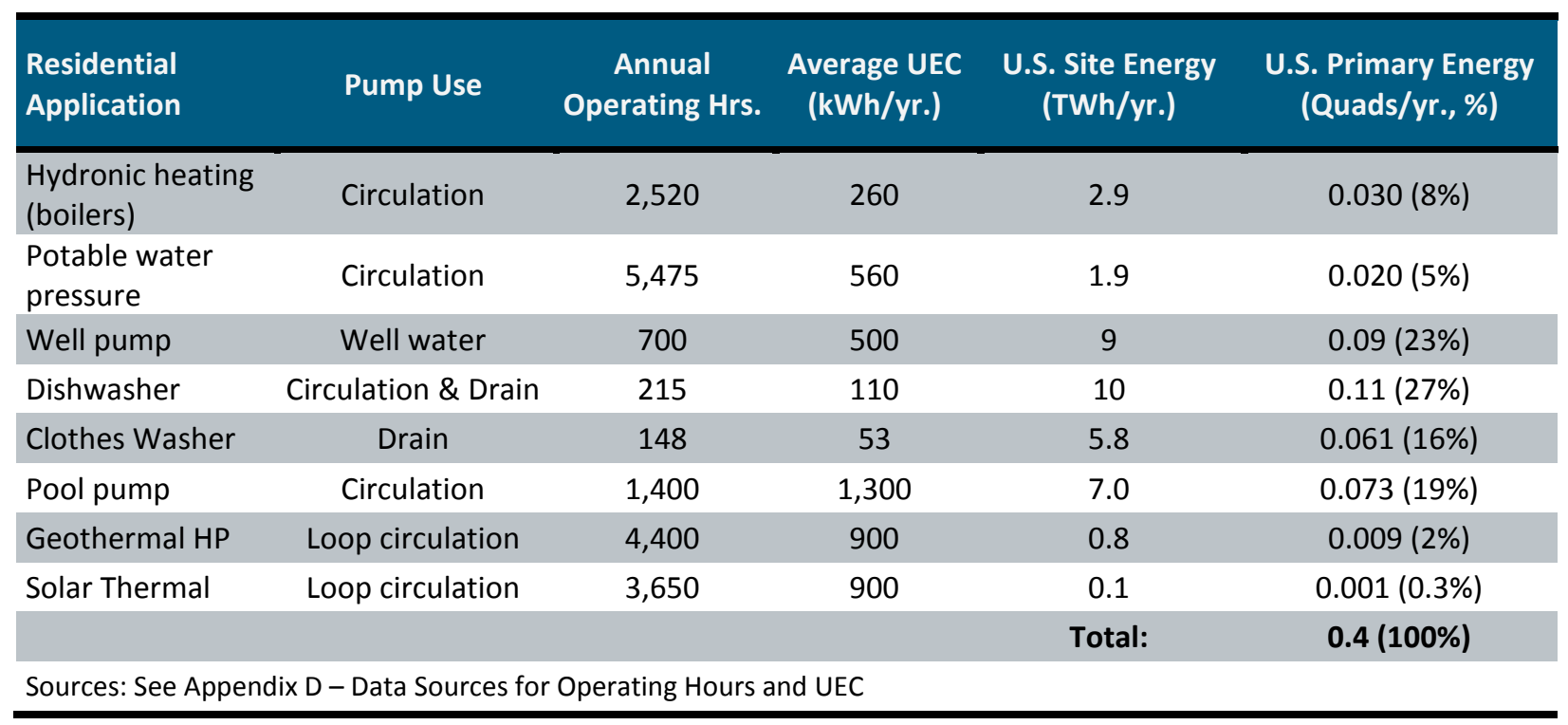

Dishwasher circulation and drain pumps together account for $27 \%$ of residential pump primary energy consumption. The drain pumps are typically 30-50 Watts, while circulation pumps may be larger, ranging from 45-100 Watts. The pumps have low operating hours and low overall 
energy consumption. The BTO Motors Report estimates that pumping energy accounts for approximately $15 \%$ of total dishwasher energy usage ${ }^{144}$

Clothes washer drain pumps range from 75-100 Watts, with typical draw during operation around 75 Watts. Like dishwasher pumps, clothes washer drain pumps have low average unit energy consumption (UEC), but a large installed base (110 MM installed units).

Pool pumps account for approximately $19 \%$ of total residential pump primary energy consumption. Residential pool pumps may be as large as $5 \mathrm{hp}$, but are generally in the 1-2 hp range. They run year-round in warm climates but are limited to warmer months in northern climates. Pumps continue to run in the off-season to keep the water in the pool from freezing, unless the pool has pipes that are properly winterized. We estimate that $30 \%$ of residential pools are winterized. ${ }^{145}$ From market studies and manufacturer's estimate, we estimate pumps run 4.2 hours a day during 5 months of swimming season. For non-winterized pools, we estimate that pumps will run 3.5 hours a day during the off-season. For winterized pools, we assume the pumps will not run during the off-season.

Well pumps consume $23 \%$ of total residential pump primary energy. They are one of the largest residential pumps, ranging from $1 / 2$ to $3 \mathrm{hp}$. We estimate $1 \mathrm{hp}$ as midrange for typically available models, operating 2 hours per day. ${ }^{146}$

Hydronic heating circulators and domestic hot water circulators are available for purchase individually by major circulator manufacturers (described in previous section) and are usually less than 1/4 hp. Based to DOE sources, this report estimates hydronic heating circulators operate for 2,520 hours annually and domestic hot water circulators operate for 5,475 hours annually. ${ }^{147}$ Both applications have low overall impact on national energy consumption due to a low installed base for either application within the residential sector. Energy consumption of these pump applications is more significant in the commercial sector (see section 3.3.3).

We estimate circulators for GHP loop-fields are, on average, $1 / 4 \mathrm{hp}$ pump for a 4 tons system. ${ }^{148}$ Year-round operation of GHP for both heating and cooling leads to high annual operating hours. However, the low GHP installed base makes the total consumed energy insignificant compared to other pump applications. The pump usage of a given system varies widely since GHP pumps are not integrated with the heat pump itself and are not typically accounted for when looking at

\footnotetext{
144 "Energy Savings Potential and Opportunities for High-Efficiency Electric Motors in Residential and Commercial Equipment," prepared by Navigant Consulting Inc. for BTO, December 2013. http://www1.eere.energy.gov/library/viewdetails.aspx?productid=6746\&page=2

${ }^{145}$ EPA. "Pool and Sump Pumps; Residential Market and Industry Scoping Report." Prepared for Energy Star. April 19, 2011. From market report, $50 \%$ of installed base are in 4 states (CA, FL, TX, AZ). We assume that these pools are not winterized. We also assume an additional $20 \%$ are in similar warm-weather states (thus pools are not winterized).

146 Town of Smyrna, DE. “Appliance Usage Calculator.” Accessed Feb 2015. http://www.smyrna.delaware.gov/DocumentCenter/Home/View/1284

${ }^{147}$ In Table 2-4, we estimate that boiler inducer fans run for 650 hours/yr. (full load hours). It is unclear what underlying assumptions go into the 2500 hour estimate for circulators in hydronic heating applications and why these values differ so dramatically. While in many applications the circulator will run constantly, or nearly so, we do not have data to determine the extent to which this is the case. Accordingly, we report the data as reported to us from our sources. Source: DOE. "ASRAC Pumps Working Group Scope" - Slides from Commercial/Industrial Pumps Working Group. Accessed Feb 2015. http://www.regulations.gov/\#!documentDetail;D=EERE-2013-BT-NOC-0039-0037

${ }^{148}$ Kavanaugh, S. "Less Pumping means Cooler Ground Loops.” For ASHRAE Journal, July 2011. https://www.ashrae.org/File\%20Library/docLib/Journal\%20Documents/2011\%20July/026-035_kavanaugh.pdf
} 
system efficiency. Pump sizing and selection is done by a system designer/installer and anecdotal evidence suggests that practices vary widely, leading to many pumps that are run inefficiently.

\subsubsection{Costs}

Many residential pumps are available for direct purchase by customers, including pumps for potable water and hydronic heating, well pumps, and pool pumps. Table 3-5 summarizes costs for these applications. Cost data are not available for pumps that are typically sold as part of an appliance (e.g., dishwasher). These products are available for replacement purchase online, which may provide insight into relative costs. However, costs can vary widely as the assembly that the manufacturer may sell is not always consistent between manufacturers.

Table 3-5: Available Residential Pump Costs

\begin{tabular}{|c|c|c|c|c|}
\hline Application & Type & Size (hp) & $\begin{array}{c}\text { Average Purchase } \\
\text { Price }\end{array}$ & $\begin{array}{c}\text { Average Lifecycle } \\
\text { Cost }^{4}\end{array}$ \\
\hline Hydronic Circulation ${ }^{1}$ & Circulator & $1 / 25$ & $\$ 88$ & $\$ 410$ \\
\hline Hydronic Circulation ${ }^{1}$ & Circulator & $1 / 6$ & $\$ 280$ & $\$ 600$ \\
\hline Domestic Hot Water ${ }^{1}$ & Circulator (Bronze) & $1 / 25$ & $\$ 180$ & $\$ 880$ \\
\hline Well pump ${ }^{2}$ & VTS & 1 & $\$ 430$ & $\$ 980$ \\
\hline Pool pump ${ }^{3}$ & ESCC/ESFM & $1 / 2-5$ & $\$ 600$ & $\$ 1,900$ \\
\hline \multicolumn{5}{|c|}{$\begin{array}{l}\text { Sources: } \\
\text { 1. Navigant market research; average of online retailer price for each size/application (Mfrs: Wilo, Grundfos, Taco). } \\
\text { 2. Navigant market research; average of online retailer price for } 1 \mathrm{hp} \text { well pumps (Mfrs: Flotec, Franklin, Red Lion) } \\
\text { 3. EPA. "Pool and Sump Pumps; Residential Market and Industry Scoping Report." Prepared for Energy Star. April 19, } 2011 . \\
\text { 4. Average UEC*average lifetime*price for electricity. Used national average for } 2014, \$ 0.125 / k W h \\
\text { Source: Energy Information Administration (EIA). “Average Retail Price of Electricity to Ultimate Customers - Table 5.3." } \\
\text { Accessed March 2015. http://www.eia.gov/electricity/monthly/epm table grapher.cfm?t=epmt } 53\end{array}$} \\
\hline
\end{tabular}

\subsection{Commercial Applications and Market Overview}

This section outlines the typical use of pumps in commercial and multifamily residential applications and describes the current pump market in Section 3.4.1. Section 3.4.2 presents the energy consumption of these residential fan applications.

\subsubsection{Applications}

Commercial pumps are primarily used in HVAC and potable water applications. Depending on the size and requirements of the building, a large (1/4 hp - $3 \mathrm{hp}$ ) circulator, ESCC, ESFM, IL, or RSV pump may be used. For tall buildings, specialized high-head pumps like RSV type pumps are typically the most suitable to provide sufficient water pressure for the upper floors.

In HVAC, commercial buildings need pumps for circulating water for:

- Boilers - Pumps circulate the hot water to fan coil units or other heating equipment. They must provide enough head to overcome the head losses in the piping and enough 
flow to ensure the building is adequately heated. One or more boilers may connect to one or more pumps depending on the building's needs.

- Chillers - Much like boiler hot water loops, pumps circulate water throughout chilled water loops to connect with air handling units, fan coil units or other cooling equipment. Similar to boilers, one system may include one or more chillers and one or more pumps.

- Cooling water - Water-cooled chillers require a cooling water loop to reject heat to the environment via a cooling tower.

- Geothermal heat pumps - Similar to residential GHPs, pumps power the in-ground loop field. Depending on the size of the heat pump and ground loop, a circulator or a pump might be selected.

In high-rise commercial and multi-family residential buildings, pumps or circulators boost domestic water supply pressures when head from the municipal water system is insufficient to serve the upper floors. Some tall buildings use storage tanks on floors throughout the building to hold potable water, in which case pumps serve to fill and pressurize the tanks. Buildings may use multiple pumps in series or in parallel for these purposes. Some configurations use pumps on multiple floors, providing the additional boost in pressure only at that height in the building when it is required. ${ }^{149}$ These approaches help reduce the necessary pressure and flow delivered by each boosting pump, and can reduce overall pump usage.

Commercial pool pumps in public or hotel pools aid in pool cleaning. These pumps draw water through a filter to remove any debris and allow the water to be treated with chemicals before delivering it back into the pool. Typically they use end-suction pumps of varying sizes. Large public pools may use a single pump or multiple smaller pumps in parallel to fulfil the required water recirculation rate and provide redundancy.

Commercial buildings without connections to municipal water systems require well pumps to provide potable water. Much like residential applications, commercial buildings use submersible (VTS) pumps, but with higher horsepower to provide higher flow rates. Such applications are typically limited to rural areas beyond the reach of municipal distribution systems.

Some commercial appliances like ACIMs, and commercial clothes washers (CCWs) use circulators to provide water circulation and/or draining. A batch ACIM circulates water from a sump, through a water distributor and over the evaporator plate. The water freezes on the evaporator plate, and the resulting ice is emptied into a storage container. For these batch ice makers, the circulator works intermittently, generally only during the freeze cycle. Continuoustype commercial ice makers do not use circulators, and typically drains any excess water that does not freeze. They typically use one circulator per plate, but the size and number of pumps (and evaporator plate) may vary for larger equipment. CCWs, similar to residential washers, use a small circulator to drain water during and after the wash cycle.

We estimate the energy consumption from any other miscellaneous pumping applications in commercial buildings to be small.

\footnotetext{
${ }^{149}$ Brickey, M., Larson, P.E., Sanchez, J. "How Potable Water Rises to the Top of Skyscrapers." Plumbing Standards Magazine, Oct-Dec 2005. http://www.asseplumbing.org/Articles/Water/How\%20Potable\%20Water\%20Rises\%20to\%20the\%20Top\%20of\%20Skyscrapers-\%200ctoDec05.pdf
} 


\subsubsection{Market}

DOE has obtained industry estimates for shipments of different pump types through the CIP standards rulemaking. Table 3-6 shows pump shipments by type; the "all sectors" column includes commercial, industrial, agricultural, and municipal pumps, and excludes circulators. The portion of pumps sold to the commercial sector is 51\% for ESCC/ESFM/IL pumps and $13 \%$ for VTS pumps. ${ }^{150}$ No data is available on the portion of RSV pumps sold for commercial applications, so we have assumed $51 \%$.

\section{Table 3-6: Pump Shipments by Type (2012)}

\begin{tabular}{|c|c|c|c|}
\hline & Pump Type & All Sectors ${ }^{a}$ & Commercial b \\
\hline ESCC & & 171,456 & 87,443 \\
\hline ESFI & & 44,042 & 22,461 \\
\hline IL & & 50,424 & 25,716 \\
\hline RSV & & 49,975 & 25,487 \\
\hline VTS & & 104,406 & 13,573 \\
\hline Tota & & 420,303 & 174,680 \\
\hline \multicolumn{4}{|c|}{$\begin{array}{l}\text { a. DOE. NOPR Technical Support Document (Figure 3-13)-Rulemaking for Commercial and } \\
\text { Industrial Pumps Energy Conservation Standards. Accessed Feb } 2015 \text {. } \\
\text { http://www1.eere.energy.gov/buildings/appliance_standards/rulemaking.aspx/ruleid/14 } \\
\text { b. Scaled by \% of commercial shipments. } \\
\text { DOE. NOPR Technical Support Document (Table } 8.2 .3 \text { ) - Rulemaking for Commercial and } \\
\text { Industrial Pumps Energy Conservation Standards. Accessed Feb } 2015 \text {. } \\
\text { http://www1.eere.energy.gov/buildings/appliance_standards/rulemaking.aspx/ruleid/14 }\end{array}$} \\
\hline
\end{tabular}

Pump life varies by application and pump type and may range from 10 to 24 years. ${ }^{151} \mathrm{We}$ estimate an average lifetime of 14 years for ESCC, ESFM and IL pumps. ${ }^{152}$ VTS have a shorter average lifetime of 10.5 years. ${ }^{153}$

Table 3-7 shows the estimated annual shipments and installed based for the key pump applications in the commercial sector. The "HVAC and water supply" category includes hot and cold water loops for HVAC, chiller cooling tower loops, GHP loop fields, hot water recirculation, and potable water supply. See Appendix A - Data Sources for Shipments and Installed Base for sources and notes.

\footnotetext{
${ }^{150}$ DOE. NOPR Technical Support Document (Table 8.2.3) - Rulemaking for Commercial and Industrial Pumps Energy Conservation Standards. Accessed Feb 2015. http://www1.eere.energy.gov/buildings/appliance_standards/rulemaking.aspx/ruleid/14

${ }^{151}$ DOE. NOPR Technical Support Document (Table 8.2.3) - Rulemaking for Commercial and Industrial Pumps Energy Conservation Standards. Accessed Feb 2015. http://www1.eere.energy.gov/buildings/appliance_standards/rulemaking.aspx/ruleid/14

152 Averaged by the 3 pump types from Pumps NOPR TSD. ESCC and IL pumps are typically more "disposable" since it's difficult to repair the pumps. ESFM pumps can be serviced and are more expensive upfront, so they are not replaced as quickly. ${ }^{153}$ DOE. NOPR Technical Support Document (Table 8.2.3) - Rulemaking for Commercial and Industrial Pumps Energy Conservation Standards. Accessed Feb 2015. http://www1.eere.energy.gov/buildings/appliance_standards/rulemaking.aspx/ruleid/14
} 
Table 3-7: Commercial Pump Uses and Market Summary

\begin{tabular}{|c|c|c|c|c|}
\hline Applications & Pump Use & Pump Type & $\begin{array}{l}\text { Est. Annual } \\
\text { Shipments } \\
\text { (thousands) }\end{array}$ & $\begin{array}{c}\text { Est. } \\
\text { Installed } \\
\text { Base (MM) }\end{array}$ \\
\hline Pumps - HVAC \& Water Supply & $\begin{array}{c}\text { Circulation; Water } \\
\text { pressure boost }\end{array}$ & ESCC, ESFM, IL, RSV & 161 & 2.25 \\
\hline $\begin{array}{l}\text { Circulators - HVAC \& Water } \\
\text { Supply }\end{array}$ & Circulation & Circulators & 88 & 0.88 \\
\hline Pool Pumps & Circulation & ESCC/ESFM & 31 & 0.31 \\
\hline Well Pumps & Well pumping & VTS & 14 & 0.14 \\
\hline Commercial Ice Makers & Circulation & Circulator & 136 & 1.70 \\
\hline Commercial Clothes Washers & Drain & Circulator & 206 & 1.93 \\
\hline
\end{tabular}

Installed base and shipment data cannot be broken down into the individual applications within the HVAC and water supply category because of the overlap in pump types. Little data is available that would help determine what systems the individual shipments would serve. This report estimates installed base using the pump shipments and average lifetime of the pump types. $^{154}$

According to the DOE and the Hydraulic Institute, there are approximately 450 pump manufacturers serving the US market. Ten companies represent 60 percent to 70 percent of the total U.S. pumps market: Grundfos, Sulzer, Weir Group, KSB, Xylem, Flowserve, Ebara, Pentair, Roper Industries, and ITT Goulds. ${ }^{155}$ The industry has seen substantial consolidation in the past 25 years. These 10 companies comprise approximately 70 brands, nearly all of which were formerly independent firms. Table 3-8 shows a breakdown of the top manufactures and the pumps they manufacture. Pump manufacturers, with the exception of Grundfos, do not typically make their own motors (unlike wet-rotor circulator manufacturers).

Table 3-8: Top 10 Pump Suppliers with Pump Types

\begin{tabular}{|c|c|c|c|c|c|}
\hline Parent Company & Brand/Operating Unit & ESCC & ESFM & AS/RS & VT/S \\
\hline Ebara & Ebara & $x$ & & & \\
\hline Flowserve & Byron Jackson & & & & $x$ \\
\hline Flowserve & Flowserve & & $x$ & $x$ & \\
\hline Flowserve & IDP & & $x$ & $x$ & \\
\hline Grundfos & Grundfos & $x$ & $x$ & $x$ & $x$ \\
\hline Grundfos & PACO & $x$ & $x$ & & \\
\hline Grundfos & Peerless & $x$ & $x$ & & $x$ \\
\hline ITT Goulds & $A C$ & & & & \\
\hline ITT Goulds & Goulds & $x$ & $x$ & $x$ & $x$ \\
\hline KSB & KSB & & $x$ & $x$ & \\
\hline Pentair & Aurora & $x$ & $x$ & & \\
\hline
\end{tabular}

\footnotetext{
${ }^{154}$ DOE. NOPR Technical Support Document (Ch. 3) - Rulemaking for Commercial and Industrial Pumps Energy Conservation Standards. Accessed Feb 2015.http://www1.eere.energy.gov/buildings/appliance_standards/rulemaking.aspx/ruleid/14

${ }^{155}$ DOE. NOPR Technical Support Document (Ch. 3) - Rulemaking for Commercial and Industrial Pumps Energy Conservation Standards. Accessed Feb 2015.http://www1.eere.energy.gov/buildings/appliance_standards/rulemaking.aspx/ruleid/14
} 


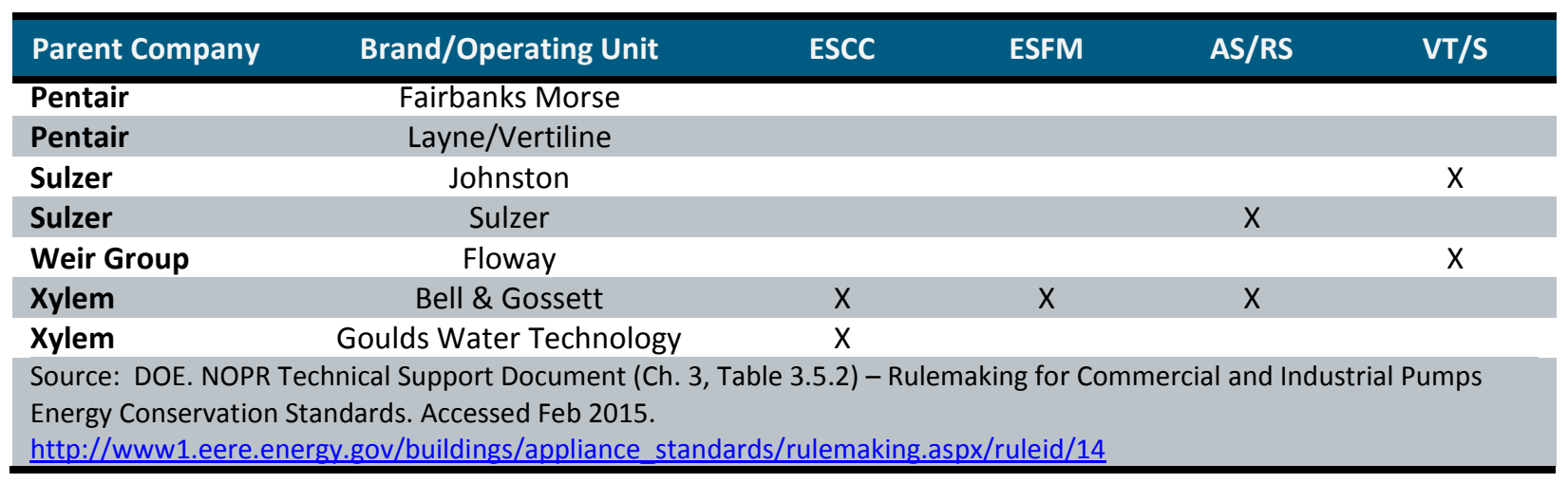

For commercial HVAC and domestic hot water circulation applications (similar to larger pumps), this report estimates an installed base of 0.9 million circulators. ${ }^{156}$ These circulators, with power greater than $1 / 4 \mathrm{hp}$, are larger than those used for residential applications. They are manufactured by five primary companies: Taco, Armstrong Limited, Grundfos, Wilo, Xylem (Bell \& Gossett).

We estimate small circulator pumps used in appliances like ACIMs and commercial clothes washers have a combined installed base of 3.6 million. These circulators are much smaller than other commercial circulators and are more akin to residential circulators. Major manufacturers of ACIM pumps include: Hartell and Morrill. Major manufacturers of commercial clothes washer pumps include: Askoll and Hanning. ${ }^{157}$

\subsubsection{Energy Consumption}

Pumps account for 0.6 Quads (4\%) of total commercial primary energy consumption. Figure 3-16 shows a breakdown of commercial pump applications and their primary energy consumption. We estimate that energy consumption from any other miscellaneous pumping applications is insignificant. See Appendix C - Calculation Methodology for a description of calculation methodology.

\footnotetext{
156 DOE. "ASRAC Pumps Working Group Scope" - Slides from Commercial/Industrial Pumps Working Group. Accessed Feb 2015. http://www.regulations.gov/\#!documentDetail;D=EERE-2013-BT-NOC-0039-0037

${ }^{157}$ Input from DOE subject matter experts for ACIMs and CCWs. 2015.
} 


\section{Commercial Primary Energy Breakdown}

All units are in Quadrillion BTUs (quads)

See Appendix $D$ for data sources
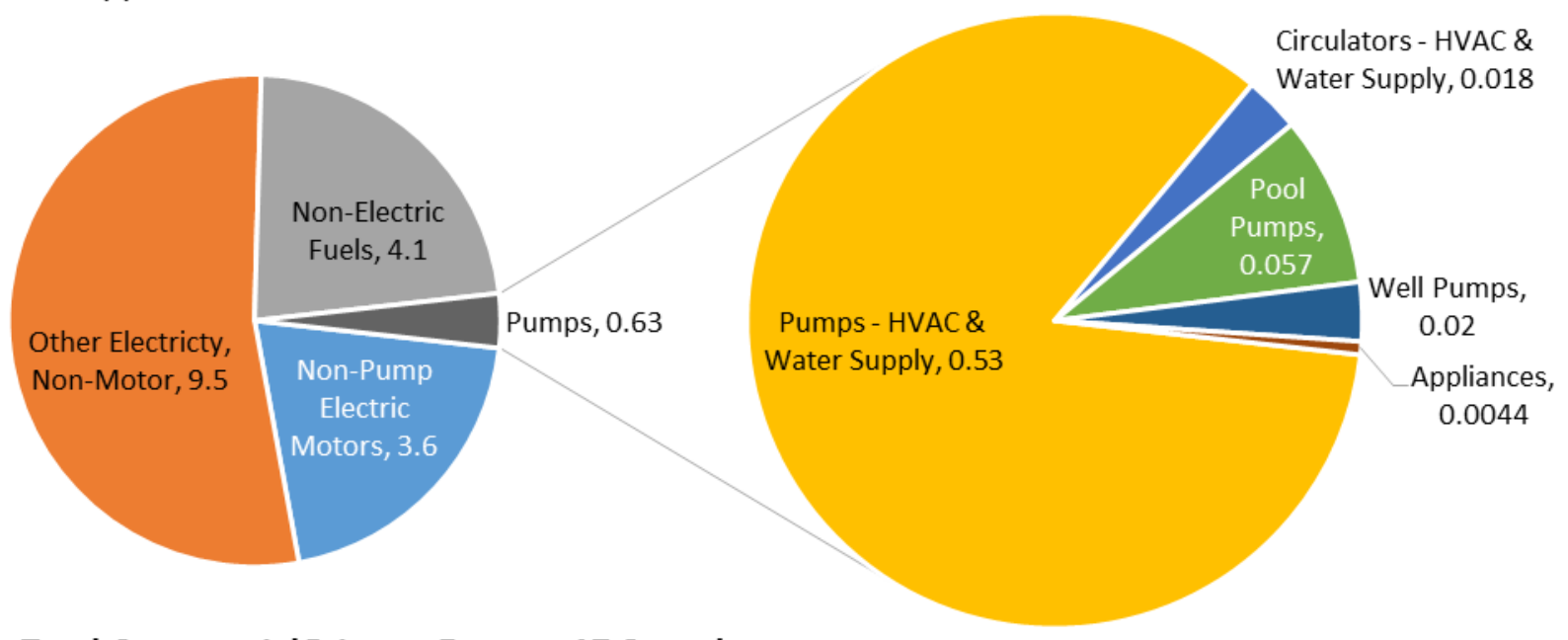

Total Commercial Primary Energy: 17.8 quads

Appliances: ACIMs and CCWs

Commercial HVAC and Water Supply Applications: Chilled water loop, chiller cooling tower loop, boiler heating loop, potable water, GSHP

Figure 3-16: Commercial pumps primary energy consumption

Table 3-9 provides a breakdown of energy use by commercial pump applications, and provides average annual operating hours and the average unit energy consumption (UEC) of each pump. The "HVAC and water supply" category includes hot and cold water loops for HVAC, chiller cooling tower loops, GHP loop fields, hot water recirculation, and potable water supply.

Table 3-9: Commercial Pump Energy Consumption for Selected Applications

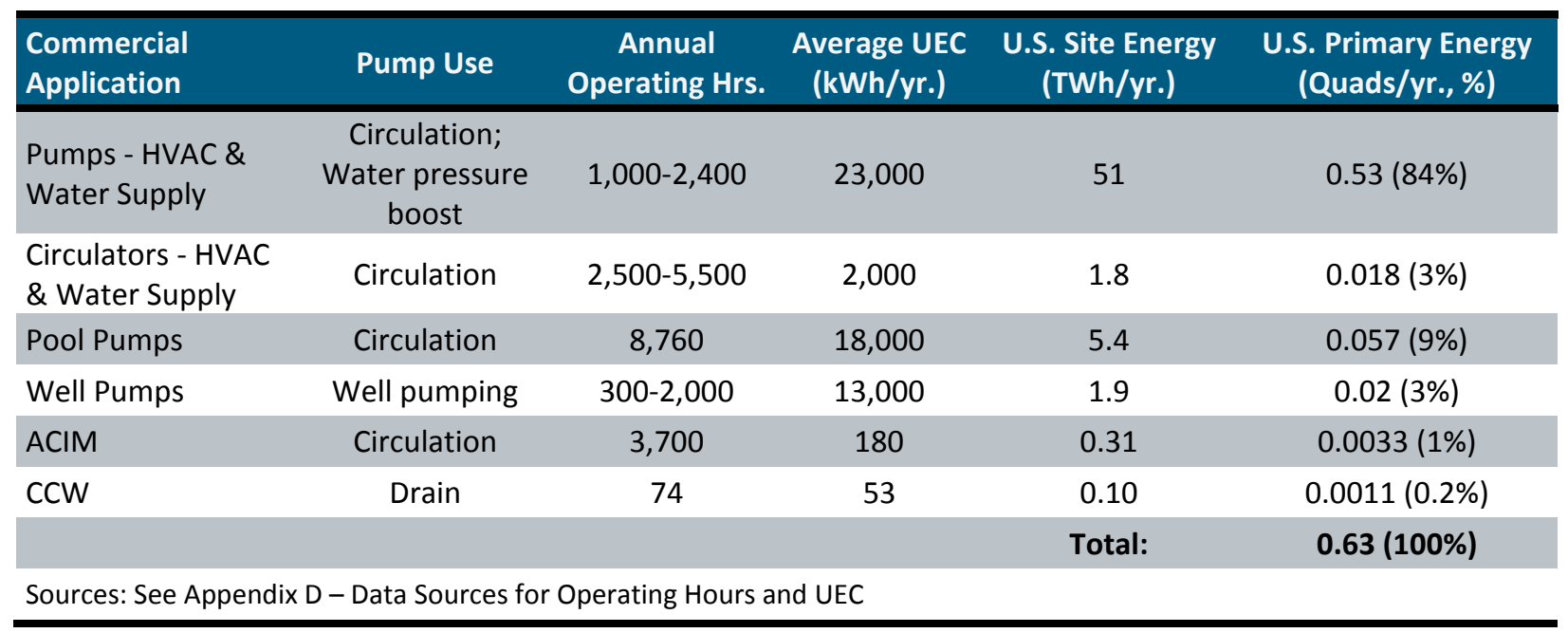


We estimate that pumps and circulators used for HVAC and potable water applications account for 0.55 quads, or $87 \%$ of total pump-related commercial primary energy consumption. This includes pumps greater than $1 \mathrm{hp}$ (based on DOE commercial/industrial pumps rulemakings definitions) and circulators between $1 / 4$ and 3 HP. The estimated operating hours are based on average operating hours of the building systems served by the pumps and circulators:

- Pump hours based on commercial building-system operating hours ${ }^{158}$

$\circ \quad$ Chiller/boiler $=2000$ hours

$\circ$ Cooling tower $=2400$ hours

- Pressure Boost $=1000$ hours

- Circulator hours based on multi-family residential building-system operating hours ${ }^{159}$

$\circ$ Boiler/hydronic heating $=2500$ hours

○ Hot water recirculation $=5500$ hours

The unit energy consumption for HVAC and water supply pumps was estimated largely independent of application due to lack of available information. The average UEC for pumps is a shipment-weighted average from the DOE rulemaking. ${ }^{160}$

Commercial pool pumps typically range in size between 1 and $5 \mathrm{hp}$. This report assumed a 2.7 hp average pump and one pump per pool. However, depending on the pool size and volume of water in the pool, engineers may specify multiple pumps. Building code in many states mandates that pool pumps operate continuously ton maintain cleanliness. ${ }^{161}$

Commercial well pumps consume an estimated 0.02 quads (3\%) of commercial pump-related primary energy consumption. These are VTS pumps and they range in size depending on the building's requirements. According to the CIP standards rulemaking, we estimate well pumps are used between 300 and 2000 hours of operation per year. ${ }^{162}$

Pumps used in commercial appliances (ACIMs and commercial clothes washers) and pumps used for commercial geothermal heat pumps represent a combined $1 \%$ of commercial pumprelated energy consumption. ACIM pumps are typically very small circulators, between 6 and 12 watts. Altogether, pumps account for a very small percentage of the total ACIM electricity draw, with shaft power rated between 1-3\% of the total electricity draw of the ACIM. CCWs have similar pumps as residential clothes washers, which use between 75-100 Watts. These drains are run for an estimated 15 minutes at the end of each wash cycle, thus yearly usage hours are very

\footnotetext{
${ }^{158}$ Chiller/Boiler, Cooling tower - Source: DOE-ADL “Opportunities for Energy Savings in Residential and Commercial Sectors with high-Efficiency Electric Motors.” Prepared by Arthur D. Little, Inc. for DOE, 1999.

http://www.totalenergycompany.com/pdf/Motor_Efficiency_DOE1999.pdf.

Pressure boost - Source: DOE. NOPR Technical Support Document (Table 7.2.3) - Rulemaking for Commercial and Industrial Pumps Energy Conservation Standards. Accessed Feb 2015.

http://www1.eere.energy.gov/buildings/appliance_standards/rulemaking.aspx/ruleid/14

${ }^{159}$ DOE. "ASRAC Pumps Working Group Scope" - Slides from Commercial/Industrial Pumps Working Group. Accessed Feb 2015. http://www.regulations.gov/\#!documentDetail;D=EERE-2013-BT-NOC-0039-0037

${ }^{160}$ DOE. NOPR Technical Support Document (Ch. 9 and 10) - Rulemaking for Commercial and Industrial Pumps Energy Conservation Standards. Accessed Feb 2015.

http://www1.eere.energy.gov/buildings/appliance_standards/rulemaking.aspx/ruleid/14

${ }^{161}$ Spectra Light. "Eco Pool Pump." Accessed March 2015. http://www.spectralightuv.com/eco-pool-pump.html

162300-2000 hrs. a year is for irrigation, which may or may not be similar to well pumping; however the median $1000 \mathrm{hrs}$. is similar to that of residential well pumps.

Source: DOE - NOPR Technical Support Document (Table 7.2.3) - Rulemaking for Commercial and Industrial Pumps Energy Conservation Standards
} 
low. For both of these commercial appliances, the primary energy consumption is low due to low power and low usage. ${ }^{163}$

\subsubsection{Costs}

The DOE has well characterized cost data for most commercial building applications. Table 3-10 summarizes purchase price and lifecycle cost data for pump types included in DOE's CIP standards rulemaking. This rulemaking covers pumps from 1 to $200 \mathrm{hp}$, which, at the higher end, overlaps substantially with non-building applications. Prices listed in Table 3-10 do not include the price of the pump motor.

Table 3-10: HVAC and Water Supply Pump Prices and Costs

\begin{tabular}{|c|c|c|c|c|c|c|c|c|}
\hline \multirow[b]{2}{*}{ Size (hp) } & \multicolumn{2}{|c|}{ ESCC } & \multicolumn{2}{|c|}{ ESFM } & \multicolumn{2}{|c|}{ IL } & \multicolumn{2}{|c|}{ Average } \\
\hline & $\begin{array}{c}\text { Purchase } \\
\text { Price }\end{array}$ & $\begin{array}{l}\text { Lifecycle } \\
\text { Cost }\end{array}$ & $\begin{array}{c}\text { Purchase } \\
\text { Price }\end{array}$ & $\begin{array}{c}\text { Lifecycle } \\
\text { Cost }\end{array}$ & $\begin{array}{c}\text { Purchase } \\
\text { Price }\end{array}$ & $\begin{array}{l}\text { Lifecycle } \\
\text { Cost }\end{array}$ & $\begin{array}{c}\text { Purchase } \\
\text { Price }\end{array}$ & $\begin{array}{c}\text { Lifecycle } \\
\text { Cost }\end{array}$ \\
\hline $1-1.79$ & $\$ 1,200$ & $\$ 3,900$ & $\$ 1,200$ & $\$ 5,900$ & $\$ 1,300$ & $\$ 3,900$ & $\$ 1,200$ & $\$ 4,600$ \\
\hline $1.8-3.24$ & 1,100 & 5,700 & 1,200 & 8,500 & 1,500 & 6,500 & 1,300 & 6,900 \\
\hline $3.25-5.84$ & 1,200 & 9,100 & 1,300 & 14,000 & 1,700 & 11,000 & 1,400 & 11,000 \\
\hline $5.85-10.53$ & 1,600 & 15,000 & 1,500 & 23,000 & 1,900 & 18,000 & 1,700 & 19,000 \\
\hline $10.54-18.97$ & 1,600 & 26,000 & 1,600 & 40,000 & 2,100 & 30,000 & 1,800 & 32,000 \\
\hline $18.98-34.19$ & 1,800 & 44,000 & 1,700 & 63,000 & 2,600 & 54,000 & 2,000 & 53,000 \\
\hline $34.2-61.61$ & 2,300 & 77,000 & 1,800 & 110,000 & 2,400 & 75,000 & 2,200 & 86,000 \\
\hline $61.62-111$ & 2,500 & 130,000 & 2,100 & 190,000 & 3,400 & 130,000 & 2,700 & 150,000 \\
\hline $111.01-200$ & 3,100 & 220,000 & 2,800 & 350,000 & 5,100 & 270,000 & 3,700 & 280,000 \\
\hline
\end{tabular}

Table 3-11 summarizes cost data from the same CIP standards rulemaking for submersible well pumps (VTS). Cost data on the smaller pumps included in commercial appliances (e.g., ice makers) is not readily available.

Table 3-11: Well Pump (VTS) Prices and Costs

\begin{tabular}{lcc}
\hline & \multicolumn{2}{c}{ VTS } \\
\cline { 2 - 3 } Size $(\mathbf{h p})$ & Purchase Price & Lifecycle Cost \\
\hline $1.8-3.24$ & $\$ 380$ & $\$ 3,600$ \\
$3.25-5.84$ & $\$ 590$ & $\$ 6,800$ \\
$5.85-10.53$ & $\$ 1,300$ & $\$ 16,000$ \\
$10.54-18.97$ & $\$ 1,400$ & $\$ 23,000$ \\
$18.98-34.19$ & $\$ 1,600$ & $\$ 41,000$ \\
$34.2-61.61$ & $\$ 1,700$ & $\$ 53,000$ \\
Source: DOE. NOPR - LCC Spreadsheet - Rulemaking for Commercial and Industrial Pumps \\
Energy Conservation Standards. Accessed Mar 2015.
\end{tabular}

${ }^{163}$ Input from DOE subject matter experts on ACIMs and CCWs. 2015. 


\subsection{Energy Savings Opportunity}

\subsubsection{Energy Savings Summary}

Pump industry experts generally consider pump technology to be mature, thus pump innovations tend to be incremental. However, energy savings opportunities are still available in pumping systems when we consider improvements to pump motors, pump controls, and distribution systems. In the following sections, we describe energy savings opportunities for residential and commercial pumps that focus on potential improvements in pump motors and controls, pump design, pumping systems and, for commercial pumps, pump maintenance.

We have attempted to eliminate duplicative potential savings in Table 3-12 and Table 313 , and have noted such points of overlap in the following sections. Due to the interconnectedness of various savings opportunities, duplicative savings may still exist.

Table 3-12 and Table 3-13 show a total of 0.6 quads of estimated annual primary energy technical savings potential for residential ( 0.1 quads) and commercial ( 0.5 quads) pumps and pump systems, respectively. These estimates assume 100\% adoption of each high-efficiency technology or other improvement. We do not sum all savings potential from each opportunity, as some address the same problem (e.g. pump oversizing). For each savings opportunity, we calculated national primary energy savings potential by estimating unit energy savings and potential suitability for the installed base of the relevant applications:

$$
\begin{aligned}
& \text { Energy savings potential (primary energy nationwide) } \\
& \text { = Energy consumption (primary energy in relevant applications) } \\
& \times \text { Unit energy saving }_{(\%)} \times \text { Suitability }_{(\% \text { of all units installed })}
\end{aligned}
$$

We have attempted to eliminate duplicative potential savings in Table 3-12 and Table 3-13, and have noted such points of overlap in the following sections. Due to the interconnectedness of various savings opportunities, duplicative savings may still exist.

Table 3-12: Residential Pump Technical Energy Savings Potential Summary (100\% adoption)

\begin{tabular}{llc}
\hline $\begin{array}{l}\text { Residential Savings } \\
\text { Category }\end{array}$ & Description of Opportunities & $\begin{array}{c}\text { Est. Annual U.S. Primary } \\
\text { Energy Savings Potential } \\
\text { (quads) }\end{array}$ \\
\hline $\begin{array}{l}\text { Pump motors and } \\
\text { controls }\end{array}$ & ECM; VSD; "Smart" controls & 0.1 \\
\hline $\begin{array}{l}\text { Pump design } \\
\text { Pump system }\end{array}$ & Hydraulic redesign & 0.01 \\
\hline A: Savings do not sum due to rounding. & Total Residential & $\mathbf{0 . 1}$ (34\% savings) \\
\hline
\end{tabular}


Table 3-13: Commercial Pump Technical Energy Savings Potential Summary (100\% adoption)

\begin{tabular}{|c|c|c|}
\hline $\begin{array}{l}\text { Commercial } \\
\text { Savings Category }\end{array}$ & Description of Opportunities & $\begin{array}{l}\text { Est. Annual U.S. Primary Energy } \\
\text { Savings Potential (quads) }\end{array}$ \\
\hline $\begin{array}{l}\text { Pump motors and } \\
\text { controls }\end{array}$ & ECMs; VSDs; "Smart" controls & 0.1 \\
\hline Pump design & $\begin{array}{l}\text { Hydraulic redesign; Smoother surfaces; Lower } \\
\text { friction bearings }\end{array}$ & 0.05 \\
\hline Pump system & $\begin{array}{l}\text { Variable flow system (VSDs required); better pump } \\
\text { sizing; better piping configurations; pipe } \\
\text { linings/coatings }\end{array}$ & 0.3 \\
\hline \multirow[t]{2}{*}{ Maintenance } & Better maintenance practices & 0.03 \\
\hline & Total Commercial & $0.5^{A}$ (75\% savings) \\
\hline
\end{tabular}

This report includes potential energy savings for pump-specific motor and control improvements such as ECMs and VSDs. See Appendix F - Motor Technology Overview for additional details on these technologies, and refer directly to the BTO Motors Report for citations and motors related data. ${ }^{164}$

\subsubsection{Barriers and Challenges to Achieving Pump Energy Savings}

Table 3-14 summarizes several barriers and challenges to reducing energy consumption in the U.S. from pumps and pump systems.

\section{Table 3-14: Summary of Barriers and Challenges Facing Pump Efficiency Improvements}

\begin{tabular}{|c|c|c|c|}
\hline Category & & Barrier & Description \\
\hline & $\begin{array}{l}\text { Hydraulic } \\
\text { Design }\end{array}$ & $\begin{array}{l}\text { Manufacturers } \\
\text { not motivated } \\
\text { to improve } \\
\text { hydraulic design }\end{array}$ & $\begin{array}{l}\text { - Hydraulic design improvements (both designing and } \\
\text { manufacturing) is costly compared to value added } \\
\text { - Hydraulic design improvements yield small energy savings }(<5 \%)\end{array}$ \\
\hline & System Design & $\begin{array}{l}\text { System } \\
\text { designers } \\
\text { motivated to } \\
\text { over-size pumps }\end{array}$ & $\begin{array}{l}\text { - Systems designers \& contractors do not want to get a "callback" } \\
\text { from customers due to poor performance and therefore tend to } \\
\text { err on the side of over-performance, regardless of energy use } \\
\text { (cost of over-specifying a pump is less than the cost of } \\
\text { inadequate performance) } \\
\text { - Commercial system designers commonly oversize equipment to } \\
\text { account for future demand requirements, pipe-fouling frictional } \\
\text { losses, and due to uncertainty of actual system head loss during } \\
\text { building design }\end{array}$ \\
\hline
\end{tabular}

164 "Energy Savings Potential and Opportunities for High-Efficiency Electric Motors in Residential and Commercial Equipment," prepared by Navigant Consulting Inc. for BTO, December 2013.

http://www1.eere.energy.gov/library/viewdetails.aspx?productid=6746\&page $=2$ 


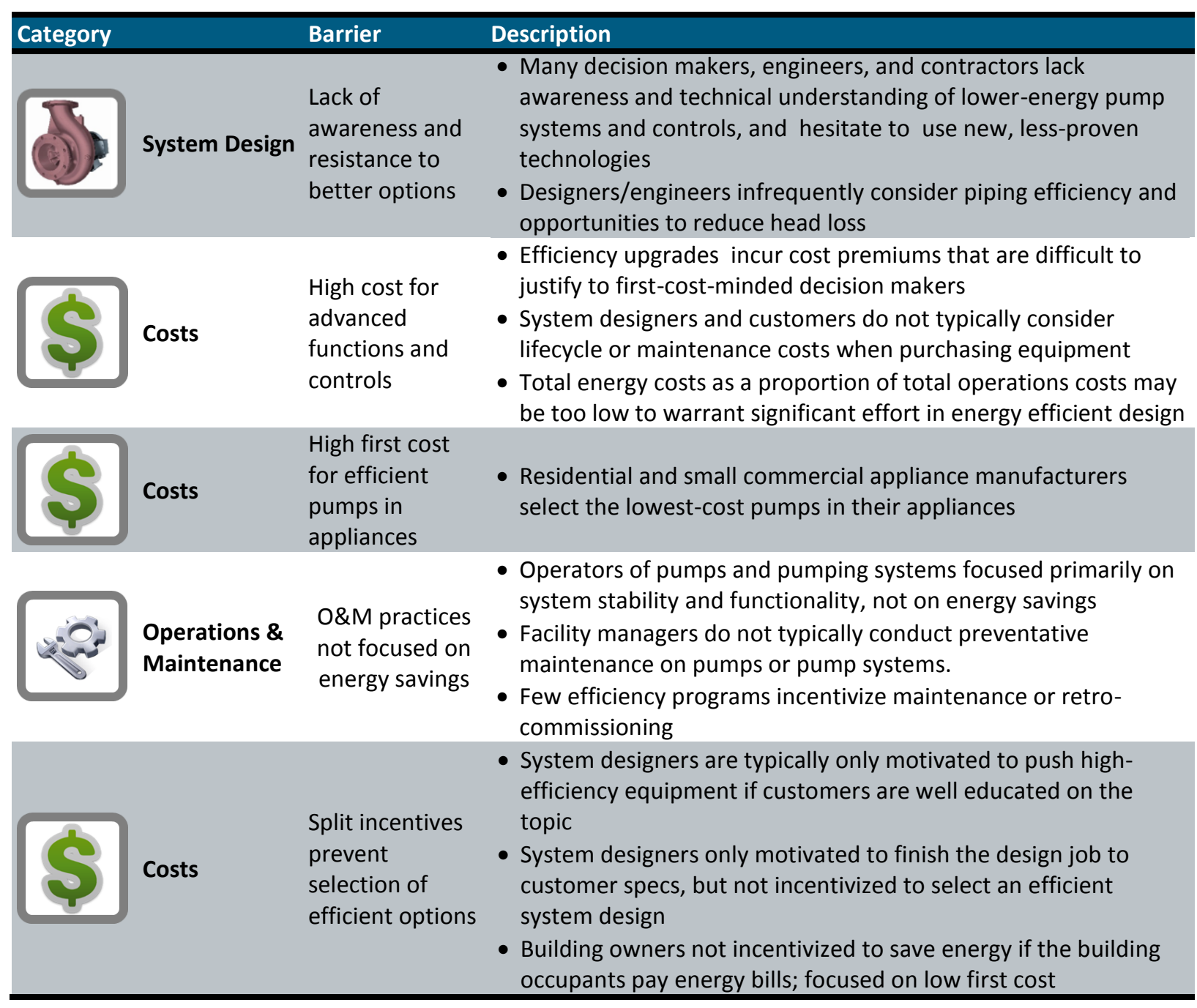

Pump manufacturers currently face challenges implementing higher efficiency pump design options described in the "Pump motors and controls" and "Pump design" categories of Table 3-12 and Table 3-13.

Circulator manufacturers currently manufacture wet rotor PSC motors in-house, while purchasing expensive ECMs at low volumes for high efficiency circulators. To remain cost competitive as ECM circulator sales increase, circulator manufacturers must either a) partner with an ECM manufacturer capable of selling low cost ECMs at a high volume, or b) switch their PSC motor production lines to manufacture ECMs. For the latter, the significant upfront investment required presents a financial challenge to many U.S. circulator manufacturers.

Pump manufacturers can achieve higher efficiency via smoother impeller surfaces by switching casting methods, from sand casting to investment or die casting. Potential new methods of casting are a technical challenge, as die casting can only cast bronze impellers and investment casting is not suitable for cast iron parts. Manufacturers can also coat impellers and/or casings to achieve smoother surfaces, but face a barrier to adoption because the industry has not yet agreed on the reliability of coatings. 


\subsubsection{Residential Energy Savings Opportunities}

The following subsections discuss residential pump energy savings opportunities in:

- Pump controls

- Pump design

- Pumping system

\subsubsection{Pump Motors and Controls}

Table 3-15 summarizes potential savings opportunities for residential pump controls and drives.

Table 3-15: Residential Pump Motors and Controls Savings Opportunities (Annual Savings)

\begin{tabular}{|c|c|c|c|c|}
\hline $\begin{array}{l}\text { Residential Savings } \\
\text { Opportunity }\end{array}$ & Applications & $\begin{array}{l}\text { Est. Energy } \\
\text { Savings (\%) }\end{array}$ & $\begin{array}{c}\text { U.S. Primary Energy } \\
\text { Savings Potential (quads) }\end{array}$ & $\begin{array}{l}\text { Est. First-Cost } \\
\text { Premium (\%) }\end{array}$ \\
\hline ECMs & $\begin{array}{l}\text { All non-appliance } \\
\text { circulators }\end{array}$ & $40 \%$ & 0.02 & $177 \%$ \\
\hline ECMs & Dishwashers & $10 \%$ & 0.01 & - \\
\hline $\begin{array}{l}\text { "Connected" functionality; } \\
\text { interface w/home energy } \\
\text { management device }\end{array}$ & Pool pumps & Unknown & & \\
\hline VSDs & Pool pumps & $82 \%$ & 0.06 & $275 \%$ \\
\hline $\begin{array}{l}\text { "Smart" controls; auto- } \\
\text { adapting controls (uses } \\
\text { ECMs) }{ }^{3}\end{array}$ & Hydronic heating & $70 \%-90 \%$ & 0.02 & $50-250 \%$ \\
\hline \multicolumn{3}{|c|}{ Motors and Controls Sub-total } & $0.1^{A}$ & \\
\hline
\end{tabular}

Advanced motors (i.e., ECMs or other permanent magnet motors) and advanced controls (e.g., VSDs, or "smart" controls) can achieve 0.1 quads of energy savings for residential pumping applications. For circulator applications using wet-rotor circulators, such as hot water circulation or hydronic heating, most manufacturers now offer circulators with ECMs and variable speed control. However, manufacturers still use permanent split capacitor (PSC) motors for their flexibly coupled or permanently lubricated ("horizontal in-line") product lines, as well as some wet-rotor product lines. ${ }^{165}$ Major circulator manufacturers also offer smart controls, typical paired with ECMs, which feature auto-adapting speed regulation for hydronic heating flow based on room temperature measurements and settings. ${ }^{166}$

\footnotetext{
${ }^{165}$ DOE subject matter expert. Nov 2014.

${ }^{166}$ Permanent magnet motors typically include integrated variable load controls, or are packaged with variable speed drives, allowing them to function at high efficiency through a range of speeds. ECMs, a subset of permanent magnet motors, refer to low horsepower brushless DC motors with integrated variable speed controls, often sought as efficient replacements to PSC induction motors. For more motor technology information, please refer to Appendix E.

Source: "Energy Savings Potential and Opportunities for High-Efficiency Electric Motors in Residential and Commercial Equipment," prepared by Navigant Consulting Inc. for BTO, December 2013.

http://www1.eere.energy.gov/library/viewdetails.aspx?productid=6746\&page $=2$
} 
ECMs are a primary energy saving opportunity for appliance-integrated pumps. Of the two appliance-integrated pump applications we evaluated (dishwashers and clothes washers), only dishwashers benefit from variable speed control, which helps optimize energy use during the wash cycle. ${ }^{167}$ Residential clothes washer drain pumps only drain at discrete times in the wash cycle and therefore work optimally in an on-off manner. As a result, clothes washers do not benefit from the variable speed controls available with ECMs, but would still benefit from the increased motor efficiency. ${ }^{168}$ Depending on the baseline efficiency of the integrated pump, there could be a large variance in potential unit energy savings. For a standard PSC motor baseline, an ECM can provide $10-20 \%$ improvement in efficiency.

Low-speed operation of pool pumps offer the single largest potential energy savings for residential pumps. Pool pumps can operate at significantly reduced pump speed (but for a longer time), with no effect on pool cleanliness. Because pump power is proportional to the cube of the shaft speed, a drop in motor speed by a factor of 2 , for example, will reduce the power draw by a factor of 8. ${ }^{169}$ Low-speed operation is typically enabled with ECMs and multi- or variable-speed controls (as opposed to a single-speed solution) because running a pool cleaner/vacuum typically requires twice the flow rate needed for prolonged filtration. Variable speed pumps are commercially available and rated by ENERGY STAR, and multi/variable-speed pumps are currently mandated by several states (including California and Florida). Despite this, an EPA study shows that of the current installed base of pool pumps, the vast majority are single-speed (96\% as of 2011, though the installed base could have changed significantly since that time). The overall energy savings varies based on the pump usage defined by the pool owner; the previously mentioned study has found energy savings of up $82 \%{ }^{170}$

Variable-speed pool pumps can be complimented with a connection to a home energy management system (i.e. "connected" pool pumps); homeowners can use the system to monitor and control the usage characteristics of the pump. Homeowners with remote access to their pumps could focus on implementing energy saving behavior, such as ensuring the pump runs at low speed and it is not left running longer than necessary. By running the pump during off-peak times, connected pool pumps could also net cost savings for homeowners on time-of-use rates. ${ }^{171}$ While not saving site energy, this saves primary energy by reducing peak loads, and shifting the pumping load to times when utilities operate more efficient baseload generation. Since this technology depends primarily on user behavior to achieve savings and since no testing has been done to broadly validate energy savings, we assume no primary energy savings.

167 "Energy Savings Potential and Opportunities for High-Efficiency Electric Motors in Residential and Commercial Equipment," prepared by Navigant Consulting Inc. for BTO, December 2013.

http://www1.eere.energy.gov/library/viewdetails.aspx?productid=6746\&page=2

${ }^{168}$ We do not include motors savings for residential clothes washer pumps. They were not analyzed in BTO Motors Report because they were not a significant consumer of electricity compared to other motors in the residential clothes washer.

${ }_{169} \frac{P_{1}}{P_{2}}=\left(\frac{N_{1}}{N_{2}}\right)^{3}$, where $\mathrm{P}$ is power and $\mathrm{N}$ is shaft speed. Thus any reduction to shaft speed results in a cubed reduction to power. Thus a pump running at reduced speed but over a longer time will consume less total electricity than a pump running at full speed for a shorter time.

${ }^{170}$ Environmental Protection Agency (EPA). "Pool and Sump Pumps; Residential Market and Industry Scoping Report." Prepared for ENERGY STAR. April 19, 2011.

171 Time-of-use rate plans change the price of energy according to the cost of producing energy at the time of use. Utilities charge lower prices during off-peak hours, as demand is low and can be served with lower-cost energy sources. These plans offer a financial incentive for users to shift usage away from peak times. 


\subsubsection{Pump Design}

Table 3-16 estimates the opportunity for energy savings by improving pump design in residential pumps and circulators.

Table 3-16: Residential Pump Design Savings Opportunities (Annual Savings)

\begin{tabular}{|c|c|c|c|c|}
\hline $\begin{array}{l}\text { Residential Savings } \\
\text { Opportunity }\end{array}$ & Applications & $\begin{array}{l}\text { Est. Energy } \\
\text { Savings (\%) }\end{array}$ & $\begin{array}{l}\text { U.S. Primary Energy Savings } \\
\text { Potential (quads) }\end{array}$ & $\begin{array}{l}\text { Est. First-Cost } \\
\text { Premium (\%) }\end{array}$ \\
\hline Hydraulic redesign & $\begin{array}{l}\text { Non-appliance circulators; } \\
\text { pool pumps; well pumps }\end{array}$ & $4 \%$ & 0.008 & $21 \%$ \\
\hline Hydraulic redesign & Appliances & $4 \%$ & 0.007 & \\
\hline \multicolumn{3}{|c|}{ Pump Design Sub-total } & $0.01^{A}$ & \\
\hline \multicolumn{5}{|c|}{$\begin{array}{l}\text { Sources: See Appendix E - Data Sources for Energy Savings Opportunities } \\
\text { A: Does not sum due to rounding }\end{array}$} \\
\hline
\end{tabular}

Designing pumps for better hydraulic performance is a viable option for larger, non-appliance residential pumps, such as pool pumps, well pumps and circulators used in HVAC or water supply applications. Hydraulic redesign can include better impeller design, tighter pump clearances, and/or reduced frictional losses in pump seals. Better hydraulic designs are achieved through a combination of historically-identified best practices and modern computer-aided design and analysis methods. ${ }^{172}$ Hydraulic redesign can be both a one-time investment for the manufacturer to build new casting dies, as well as an ongoing higher expense to maintain tolerances in manufacturing and bolster associated quality control measures. As we have no specific source for energy savings for hydraulic redesign of residential pumps, we assumed an overall efficiency improvement equal to the improvement for commercial pumps of $4 \%$.

For appliance-integrated pumps, optimizing hydraulic performance is not typically a viable design option. Manufacturers do not typically employ optimized designs for appliance pumps due to the highly competitive nature of this market, which drives manufacturers to specify lowest-cost components. Further, the energy consumption of the pump represents a fraction of the total energy consumption of the appliance. In the absence of well-documented data, we estimate potential energy savings to be equal to that possible for commercial pumps (4\% potential energy savings). ${ }^{173}$ Hydraulic redesign can also offer noise reductions for household appliances, which does provide brand value, especially for premium products. ${ }^{174}$

\subsubsection{Pumping System}

Table 3-17 summarizes the opportunity for energy savings by improving pump design in residential pumps and circulators.

\footnotetext{
${ }^{172}$ DOE-TSD, Section 3.6.1.5. Rulemaking for Commercial and Industrial Pumps Energy Conservation Standards. Accessed Feb 2015. http://www1.eere.energy.gov/buildings/appliance_standards/rulemaking.aspx/ruleid/14

173 TSD. DOE. Rulemaking for Commercial and Industrial Pumps Energy Conservation Standards. Accessed Feb 2015. http://www1.eere.energy.gov/buildings/appliance_standards/rulemaking.aspx/ruleid/14

${ }^{174}$ Johnson Electric. “Custom Low Noise and Energy Efficient Pump Platforms for Dishwashers.” Accessed Mar 2015. http://www.johnsonelectric.com/en/features/dishwasher-combo-pump.html
} 
Table 3-17: Residential Pump System Opportunities (Annual Technical Savings Potential)

\begin{tabular}{llclc}
\hline $\begin{array}{l}\text { Residential Savings } \\
\text { Opportunity }\end{array}$ & Applications & $\begin{array}{c}\text { Est. Energy Savings } \\
\text { (\%) }\end{array}$ & $\begin{array}{c}\text { U.S. Primary Energy } \\
\text { Savings Potential (quads) }\end{array}$ & $\begin{array}{c}\text { Est. First-Cost } \\
\text { Premium (\%) }\end{array}$ \\
\hline Better pump sizing & $\begin{array}{l}\text { Non-appliance } \\
\text { circulators }\end{array}$ & $20 \%$ & 0.005 & None \\
\hline & Pump System Sub-Total & $\mathbf{0 . 0 0 5}$ \\
\hline
\end{tabular}

In residential HVAC and water supply applications, contractors/installers frequently install circulators that are oversized. Contractors will oversize to ensure the circulator serves the home's needs with an additional factor of safety to avoid getting called back to the home with complaints of poor performance. In some cases, the circulator might have multiple speed options, but contractors will set it on the highest speed to avoid performance issues. ${ }^{175}$ Financial incentives for contractors/installers do not motivate them to ensure efficient functioning of the pump, but rather to ensure that the homeowner will not request future non-paying service. Remedies to circulator oversizing focus on introducing energy efficient practices among retailers, installers/contractors, and homeowners; there would be minimal effect on first costs of circulators.

We estimate "rightsizing" (either a smaller, performance-appropriate circulator, or using a lower speed setting on existing circulator) can save $20 \%$ energy on average. ${ }^{176} \mathrm{We}$ have no reliable sources regarding the applicability of this measure to the installed circulator base. We assumed limited $40 \%$ applicability, as most circulators sold are $1 / 25 \mathrm{hp}$, which is the smallest model commonly offered by circulator manufacturers.

\subsubsection{Commercial Energy Savings Opportunities}

The following subsections discuss commercial pump energy savings opportunities in:

- Pump controls

- Pump design

- Pumping system improvements

- Maintenance

\subsubsection{Pump Motors and Controls}

Table 3-18 estimate the opportunity for energy savings by improving commercial pump motors and controls. For more technical details on motor and variable speed drive improvements, please refer to the BTO Motors Report.

\footnotetext{
175 DOE subject matter expert. Nov 2014.

176 Based on energy savings from commercial pump oversizing. Source: EEP. "14 energy-efficiency improvement opportunities in pumping systems," Electrical Engineering Portal. October 2014. http://electrical-engineering-portal.com/14-energy-efficiencyimprovement-opportunities-in-pumping-systems
} 
Table 3-18: Commercial Pump Motors and Controls Opportunities (Annual Technical Savings Potential)

\begin{tabular}{|c|c|c|c|c|}
\hline $\begin{array}{l}\text { Commercial Savings } \\
\text { Opportunity }\end{array}$ & Applications & $\begin{array}{l}\text { Est. Energy } \\
\text { Savings (\%) }\end{array}$ & $\begin{array}{l}\text { U.S. Primary Energy } \\
\text { Savings Potential (quads) }\end{array}$ & $\begin{array}{l}\text { Est. First-Cost } \\
\text { Premium (\%) }\end{array}$ \\
\hline $\begin{array}{l}\text { NEMA Premium Motor } \\
\text { (3 phase AC) }\end{array}$ & $\begin{array}{l}\text { Pumps for HVAC \& water } \\
\text { supply; well pumps }\end{array}$ & $3 \%$ & 0.02 & \\
\hline ECMs & $\begin{array}{l}\text { Circulators for HVAC \& } \\
\text { water supply }\end{array}$ & $20 \%$ & 0.004 & $177 \%$ \\
\hline ECMs & ACIM & $71 \%$ & 0.002 & \\
\hline VSDs & $\begin{array}{l}\text { Pumps for HVAC \& water } \\
\text { supply }\end{array}$ & \multicolumn{2}{|c|}{ See Section 3.4.4.3 } & \\
\hline VSDs & Pool Pumps & $41 \%$ & 0.02 & $275 \%$ \\
\hline $\begin{array}{l}\text { "Smart" controls; auto- } \\
\text { adapting controls (uses } \\
\text { ECMs) }\end{array}$ & $\begin{array}{l}\text { Circulators for HVAC \& } \\
\text { Water Supply }\end{array}$ & $70 \%-90 \%$ & 0.01 & $50-250 \%$ \\
\hline \multirow[t]{2}{*}{$\begin{array}{l}\text { "Connected" } \\
\text { functionality - interface } \\
\text { with building energy } \\
\text { management device }\end{array}$} & $\begin{array}{l}\text { Pumps and circulators } \\
\text { for HVAC \& water } \\
\text { supply; Well pumps }\end{array}$ & Unknown & & \\
\hline & Motors and C & itrols Sub-total & $0.1^{A, B}$ & \\
\hline \multicolumn{5}{|c|}{$\begin{array}{l}\text { Sources: See Appendix E - Data Sources for Energy Savings Opportunities } \\
\text { A: Does not sum due to rounding. } \\
\text { B: VSD energy savings for HVAC and water supply pumps are considered duplicative of opportunities identified in the Pumping } \\
\text { System. Please refer to Section 3.4.4.3 for details. }\end{array}$} \\
\hline
\end{tabular}

Upgrading commercial pump motors and controls offer 0.1 quads of potential energy savings. ECMs, at this time, are not readily available for the motor sizes (larger than $3 \mathrm{hp}$ ) needed in large commercial pumping applications. We note that larger power ECMs are becoming available in larger pumps, but are still rare in the U.S. market. For larger pump applications, it is more cost effective to upgrade AC motors with a VSD and obtain energy savings from part load performance. Permanent magnet motors offer greater efficiency $(+10 \%)$ at peak performance, but may not be as favorable as VSDs at part load. ${ }^{177}$ We do not consider ECM upgrades for commercial pumping applications. Commercial building owners can upgrade existing HVAC and water supply pumps to more efficient, NEMA premium, 3-phase AC induction motors, which are widely available. However, the incremental efficiency improvement is only on the order of 3\% (primary energy), though this improvement can be applied to most of the installed base. ${ }^{178}$ A commercial motor minimum efficiency standard may be created to ensure new pumps contain NEMA-premium motors.

For commercial HVAC circulators from $1 / 4$ to $3 \mathrm{hp}$, the unit energy savings potential from ECMs and "smart" variable speed controls (based on individual room settings and temperature)

\footnotetext{
${ }^{177}$ DOE subject matter expert, 2015.

178 "Energy Savings Potential and Opportunities for High-Efficiency Electric Motors in Residential and Commercial Equipment," prepared by Navigant Consulting Inc. for BTO, December 2013.

http://www1.eere.energy.gov/library/viewdetails.aspx?productid=6746\&page $=2$
} 
is $20 \%$ and $70-90 \%$, respectively. ${ }^{179}$ Despite these unit savings, overall national primary energy impact is limited to approximately 0.014 quads due to the limited commercial circulator installed base. Similarly, upgrades to higher efficiency motors for commercial appliances yield low overall savings due to low total energy consumption. ${ }^{180}$

For commercial HVAC and water supply pumps, the largest potential primary energy savings come from using variable speed drives that enable commercial pumps to provide varying flow and pressure depending on system demands. A VSD allows the pump to operate closer to its best possible efficiency at the desired system flow and pressure. VSD technology enables variable flow HVAC systems, and, as a retrofit, the removal of inefficient flow controls in constant flow systems. Barriers to VSD retrofits for pumps include high equipment cost, high installation cost, and special requirements for locating the control box. Please refer to Section 3.4.4.3 for further discussion of VSD improvements in pumping systems.

Similar to residential pool pumps, commercial pool pumps could benefit from operation at lower speeds to save energy. For commercial pumps, this means the use of a VSD on an AC induction motor (for larger pumps) or an ECM with variable speed control (for smaller pumps). We estimate a lower degree of savings than for residential applications because commercial pool pumps require more water circulation due to higher usage and higher cleaning requirements. This would typically require pumps to operate closer to full speed, minimizing energy savings. For water circulation/purification during off-peak times, a reduced pump speed can still save an estimated $41 \%$ of unit energy. ${ }^{181}$

"Connected" functionality ties pumps to a building management system or energy management system (BMS/EMS); generally, the technology requires electronic pump control systems and the ability to network with BMS/EMS (Figure 3-17). Several commercial vendors currently offer this functionality. ${ }^{182} \mathrm{New}$ buildings could integrate pumping systems in a larger BMS/EMS, which may also control HVAC and water supply pressure in addition to lighting, and other building equipment. Connected retrofit opportunities require an existing BMS/EMS for control and communication; retrofit opportunities are most feasible if HVAC operations are already controlled.

\footnotetext{
${ }^{179}$ BuildingGreen.com. "High-Efficiency, Variable-Speed Pumps from Wilo and Grundfos.” September 2010. https://www2.buildinggreen.com/article/high-efficiency-variable-speed-pumps-wilo-and-grundfos

${ }^{180}$ Commercial clothes washer pumps were not analyzed in the BTO Motors Report. We estimate that due to low total primary energy consumption, pump energy savings will be insignificant.

${ }^{181}$ Environmental Protection Agency (EPA). "Pool and Sump Pumps; Residential Market and Industry Scoping Report."

Prepared for ENERGY STAR. April 19, 2011.

182 Examples of connected pump systems: KSB. http://www.ksb.com/ksben/Products and Services/Automation/Process Control/10736/leittechnik.html; Taco. http://www.taco-hvac.com/products/iworx_building_management_monitoring_and_control_system/index.html
} 


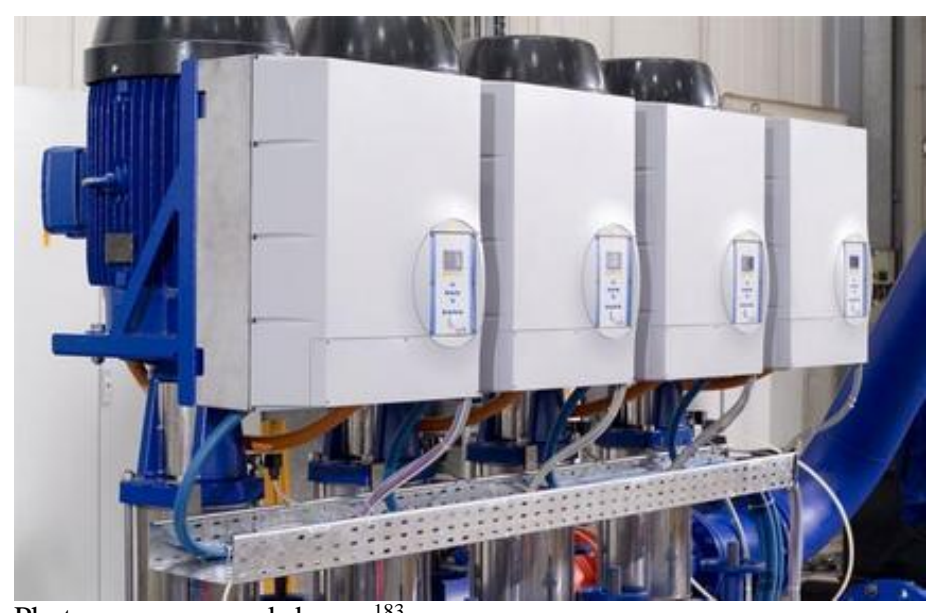

Photo source: www.ksb.com ${ }^{183}$

\section{Figure 3-17: Connection of variable speed pumping system to BMS}

Connected functionality in a commercial building could result in energy savings by optimizing pumping strategy to meet building demand. For example, the controller might determine the efficiency of the various pumping system components and select the optimum pumping strategy to save the most energy. For a multi-pump system, it may dispatch pumps according to pump or system efficiencies based on room, zone, or building needs. ${ }^{184}$ From lack of data and diversity of potential strategies, we have not been able to quantify potential energy savings opportunities.

\subsubsection{Pump Design}

Table 3-19 estimates the opportunity for energy savings by improving commercial pump design.

\section{Table 3-19: Commercial Pump Design Opportunities (Annual Technical Savings Potential)}

\begin{tabular}{|c|c|c|c|c|}
\hline $\begin{array}{l}\text { Commercial Savings } \\
\text { Opportunity }\end{array}$ & Applications & $\begin{array}{l}\text { Est. Energy } \\
\text { Savings (\%) }\end{array}$ & $\begin{array}{c}\text { U.S. Primary Energy } \\
\text { Savings Potential (quads) }\end{array}$ & $\begin{array}{l}\text { Est. First-Cost } \\
\text { Premium (\%) }\end{array}$ \\
\hline Hydraulic redesign & $\begin{array}{l}\text { All non-appliance } \\
\text { pumps }\end{array}$ & $4 \%$ & 0.03 & $21 \%$ \\
\hline Smoother pump surfaces & $\begin{array}{l}\text { All non-appliance } \\
\text { pumps }\end{array}$ & $0.1 \%$ & 0.001 & High \\
\hline $\begin{array}{l}\text { Lower friction bearings } \\
\text { (including magnetic bearings) }\end{array}$ & $\begin{array}{l}\text { Pumps - HVAC \& } \\
\text { Water Supply }\end{array}$ & $3.5 \%$ & 0.02 & High \\
\hline \multirow[t]{2}{*}{ Impeller trimming } & $\begin{array}{l}\text { Pumps - HVAC \& } \\
\text { Water Supply }\end{array}$ & $5 \%-10 \%$ & 0.01 & None \\
\hline & & $\begin{array}{l}\text { Pump Design } \\
\text { Sub-total }\end{array}$ & $0.05^{A, B}$ & \\
\hline \multicolumn{5}{|c|}{$\begin{array}{l}\text { Sources: See Appendix E - Data Sources for Energy Savings Opportunities } \\
\text { A: Does not sum due to rounding. } \\
\text { B: Impeller trimming deemed as a duplicative energy savings opportunity to "Better pump sizing selection" and "Variable speed } \\
\text { drives" opportunities. Not included in this Sub-total. }\end{array}$} \\
\hline
\end{tabular}

\footnotetext{
${ }^{183}$ KSB - PumpDrive. http://www.ksb.com/linkableblob/ksb-en/10744-1495/galleryMediumLsTn/PumpDrive_45KWgalleryMediumLsTn.jpg

${ }^{184}$ Energy Manager Today. “80\% of Electricity Used by Water Systems is from Pumping, Says Motors@Work.” March 2015. http://www.energymanagertoday.com/80-electricity-used-water-systems-pumping-says-motorswork-0109958/
} 
Hydraulic redesign is a general term that relates to enhancing pump performance by improving the design of the wetted components within the pump. Improvements include:

- Efficient design of impeller geometry, and/or volute/casing geometry

- Tighter clearances, and reduction of other volumetric losses (which result in backflow losses)

- Better seals to reduce frictional losses

- Any other mechanical design which improves fluid flow paths through the pump

DOE focuses on hydraulic redesign as the primary option for efficiency improvements in the CIP standards rulemaking. ${ }^{185}$ DOE considers pumps as a mature technology; those features that the CIP rulemaking defines as the highest possible efficiency from hydraulic redesign are already commercially available. Baseline pumps, which are still common in the market, however, can gain $4 \%$ energy savings by implementing this improvement. The CIP standards rulemaking is limited to commercial pumps sold individually from pump manufacturers, and does not include pumps included in commercial appliances. ${ }^{186}$

Using smoother pump surfaces is a potential improvement opportunity which could result in energy savings due to lower frictional losses through the wetted components of a pump. This enhancement includes using low-friction surface coatings on various wetted components, and using better manufacturing processes to produce smoother wetted components. Low-friction coatings can be applied to new pumps at the factory, but can also be field-applied for existing pumps. Pump coatings have properties such as hydrophobicity, self-leveling (to fill pits or surface non-uniformities), and hydraulic smoothness, which help ensure a smooth surface finish and reduce frictional losses in pump components. ${ }^{187}$ DOE has stated coatings are more typically used for sanitary, corrosion-resistant, or other damage resistant properties rather than efficiency improvements. ${ }^{188}$ Corrosion- or damage-resistance does not directly impact as-new efficiency, but could affect the efficiency of the pump over its lifecycle. ${ }^{189}$ A study retrofitting old pumps with polymeric coatings has showed a $12 \%$ decrease in electricity consumption - this indicates a coating that resists fouling could maintain higher efficiency over time, as compared to uncoated pumps. ${ }^{190}$

In the CIP standards rulemaking, DOE reviewed data regarding smoother pump surfaces in the NOPR Technical Support Document and found that at common design points for commercial pumps, smoother surface finishes yield insignificant energy savings for new pumps. ${ }^{191}$ While

\footnotetext{
185 DOE. Rulemaking for Commercial and Industrial Pumps Energy Conservation Standards. Accessed Feb 2015. http://www1.eere.energy.gov/buildings/appliance_standards/rulemaking.aspx/ruleid/14

${ }^{186}$ Hydraulic design is not a consideration for these pumps and no data is known about potential hydraulic design savings regarding pumps integrated into commercial appliances.

${ }^{187}$ Power Engineering. Oharriz, O. “Coatings Can Improve Submersible Pump Efficiency.” August 2009. http://rumfordgroup.com/pumps/assets/PDF/en/articles/ARTICLE-SubmersiblePumps.pdf

${ }^{188}$ DOE-TSD. Rulemaking for Commercial and Industrial Pumps Energy Conservation Standards. Accessed Feb 2015. http://www1.eere.energy.gov/buildings/appliance_standards/rulemaking.aspx/ruleid/14

${ }^{189}$ Due to lack of data, we have not attempted to characterize energy savings from retrofits of degraded pumps.

${ }^{190}$ Water World. Xia, W. "Polymer Coating of Pumps Boost Efficiency, Performance.” Accessed Mar 2015. http://www.belzona.com/pumps/assets/pdf/en/articles/ARTICLE-WaterWorldReprint.pdf

${ }^{191}$ DOE-TSD Ch. 3. Rulemaking for Commercial and Industrial Pumps Energy Conservation Standards. Accessed Feb 2015. http://www1.eere.energy.gov/buildings/appliance_standards/rulemaking.aspx/ruleid/14
} 
other sources provide ranges of energy savings of between 2 and $15 \%$ for new pumps, this analysis uses the CIP standards rulemaking estimate of $0.1 \%$ energy savings. ${ }^{192}$

Low-friction bearings can significantly reduce the frictional losses in the pump bearing (Figure 3-18). Such bearings feature new materials (e.g. silicon nitride, ceramic coated bearings), or improved designs that reduce weight and/or change surface topography. Magnetic bearings, for example, reduce friction by creating an air gap between the rotating shaft and the bearing using electro-magnets and an advanced controls system. Magnetic bearings have negligible friction and no need for lubrication; the control system is typically bulky and expensive, which limits potential applications. ${ }^{193}$ Low-friction bearings are currently used in high-speed applications or other application-specific cases, where the initial cost is justified by high frictional energy savings. Cost reductions in the control system could make these feasible to a wider range of applications. ${ }^{194}$

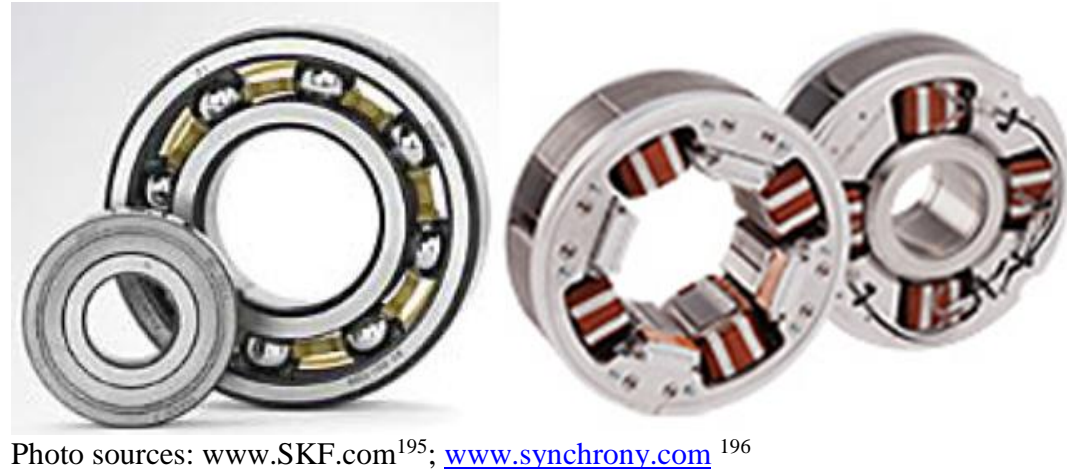

\section{Figure 3-18: Low-friction, energy efficient bearings (left), and Magnetic bearings (right)}

Impeller trimming is a retrofit opportunity used specifically for oversized pumps without variable speed drives. If the current pump provides too much head or flow at its intended design speed, pump owners can reduce the impeller diameter by physically trimming it, or by replacing it with a smaller impeller. Trimming shifts the pump curve, providing delivery of less flow and head without changing motor speed. Impeller trimming lowers the maximum efficiency of the pump by adding clearances between the impeller and casing, increasing backflow - thus, trimming would not save as much energy as a properly sized pump. The amount of energy

\footnotetext{
192 Power Engineering. Oharriz, O. “Coatings Can Improve Submersible Pump Efficiency.” August 2009. http://rumfordgroup.com/pumps/assets/PDF/en/articles/ARTICLE-SubmersiblePumps.pdf Water World. Xia, W. "Polymer Coating of Pumps Boost Efficiency, Performance.” Accessed Mar 2015. http://www.belzona.com/pumps/assets/pdf/en/articles/ARTICLE-WaterWorldReprint.pdf

${ }^{193}$ Miniaturization of magnetic bearing controls could make it possible for these bearings to be used more widely for industrial purposes. Source: NY Times. Eisenberg, A. "Bearings That Pack a Punch (and Their Own Controls).” January 2010. http://www.nytimes.com/2010/01/03/business/03novel.html?_r=0

${ }^{194}$ WaterWorld. Budris, A. “Activated Magnetic Bearing Potential for Centrifugal Pumps.” Accessed Mar 2015. http://www.waterworld.com/articles/print/volume-26/issue-3/departments/pump-tips-techniques/activated-magnetic.html

195 SKF Energy Efficient Bearings. http://www.skf.com/binary/12-154513/100955\%20Bearings\%20in\%20centrifugal\%20pumps tcm 12-154513.pdf

196 Synchrony- NovaGlide Magnetic Bearings. http://www.synchrony.com/products/magnetic-bearings/
} 
savings depends on the original sizing of the impeller and the trimmed diameter. Literature from multiple sources shows that $5-10 \%$ energy savings is possible. ${ }^{197}$

Impeller trimming is duplicative with "rightsizing" of commercial pumps; correctly sized pumps should not be trimmed (please refer to Section 3.4.4.3 for details on oversized pumps). Thus, we consider impeller trimming as a separate retrofit opportunity, but do not count it towards total potential energy savings. As a retrofit opportunity, impeller trimming duplicates the efficiency gained by using improved motor and variable speed drive systems to provide lower pressure or flow rates. Compared to VSDs, trimming is a more cost effective retrofit option, but it does not allow the pump to operate at variable speeds. Trimming reduces the maximum efficiency of the pump by increasing the impeller-housing clearance. ${ }^{198}$ For pumps that operate in constant conditions, impeller trimming may be a more cost-effective efficiency improvement to VSDs. In constant flow systems that cannot be retrofitted to become variable flow, impeller trimming or rightsizing are efficient options; savings may not be duplicative with VSDs in these cases.

\subsubsection{Pumping System}

Table 3-20 estimates the opportunity for energy savings by improving commercial pump system design. In general, pump owners cannot realize significant pumping system energy savings from reduced losses in the system unless the pump can efficiently reduce the delivered pressure head at the required flow (and thus, power consumed). For example, in a retrofit situation, reducing piping losses may allow a single speed pump to provide less head, but unless it is equipped with a VSD or the impeller is trimmed, the pump will not provide less head without increasing flow and moving away from the point of best efficiency (assuming it was originally sized at BEP).

Table 3-20: Commercial Pump System Opportunities (Annual Technical Savings Potential)

\begin{tabular}{|c|c|c|c|c|}
\hline $\begin{array}{l}\text { Commercial Savings } \\
\text { Opportunity }\end{array}$ & Applications & $\begin{array}{l}\text { Est. Energy } \\
\text { Savings (\%) }\end{array}$ & $\begin{array}{l}\text { U.S. Primary Energy } \\
\text { Savings Potential } \\
\text { (quads) }\end{array}$ & $\begin{array}{l}\text { Est. First-Cost Premium } \\
(\%)\end{array}$ \\
\hline $\begin{array}{l}\text { Variable flow system } \\
\text { (with VSDs) }\end{array}$ & $\begin{array}{l}\text { Pumps and circulators for } \\
\text { HVAC \& Water Supply }\end{array}$ & $40 \%$ & 0.1 & High \\
\hline Better pump sizing & $\begin{array}{l}\text { All non-appliance pump } \\
\text { applications }\end{array}$ & $20 \%$ & 0.08 & $\begin{array}{l}\text { None (for new); same as } \\
\text { replacement (for } \\
\text { retrofit) }\end{array}$ \\
\hline $\begin{array}{l}\text { Better piping } \\
\text { configurations (e.g., } \\
\text { size, efficient fittings) }\end{array}$ & $\begin{array}{l}\text { All non-appliance pump } \\
\text { applications }\end{array}$ & $20 \%$ & 0.09 & $\begin{array}{l}\text { Depends on length of } \\
\text { piping }\end{array}$ \\
\hline Pipe linings/coatings & $\begin{array}{l}\text { Pumps and circulators for } \\
\text { HVAC \& Water Supply }\end{array}$ & $15 \%$ & 0.04 & $\begin{array}{l}50 \% \text { less expensive than } \\
\text { pipe replacements }\end{array}$ \\
\hline \multicolumn{3}{|c|}{ Pump System Sub-total } & $0.3^{A}$ & \\
\hline \multicolumn{5}{|c|}{ Sources: See Appendix E - Data Sources for Energy Savings Opportunities } \\
\hline
\end{tabular}

\footnotetext{
${ }^{197}$ KSB. “Impeller trimming.” Accessed Mar 2015. http://www.ksb.com/fluidfuture-en/pumps-and-valves/impeller-trimming/; Savar, M. et al.. "Improving centrifugal pump efficiency by impeller trimming," Abstract - Desalination. 2009. http://www.sciencedirect.com/science/article/pii/S0011916409008388

${ }^{198}$ Pumps \& Systems. Nelik, L. "Variable Speed or Impeller Trim?” 2010. http://www.pumpsandsystems.com/topics/pumps/pumps/variable-speed-or-impeller-trim
} 
Variable flow pumping systems are common for large HVAC designs in new buildings; ASHRAE 90.1-2010 code requires VSDs on pumps greater than $5 \mathrm{hp}$. However, constant flow systems have been standard practice until recently.

Constant flow systems use pumps operating at constant speed circulating cooling or heating water regardless of building loads, thus wasting pumping energy by circulating water at full power in non-full-load conditions. Constant flow systems also use three-way valves to allow bypass of individual heating or cooling coils when space conditioning is unneeded. ${ }^{199}$ Three-way valves are necessary for proper function of a constant flow system, and should be replaced by two-way valves in a variable flow system.

Variable flow systems use pumps equipped with VSDs, which modulate flow according to building HVAC demands. ${ }^{200}$ Figure 3-19 shows an illustrative diagram of constant and variable flow pumping systems.

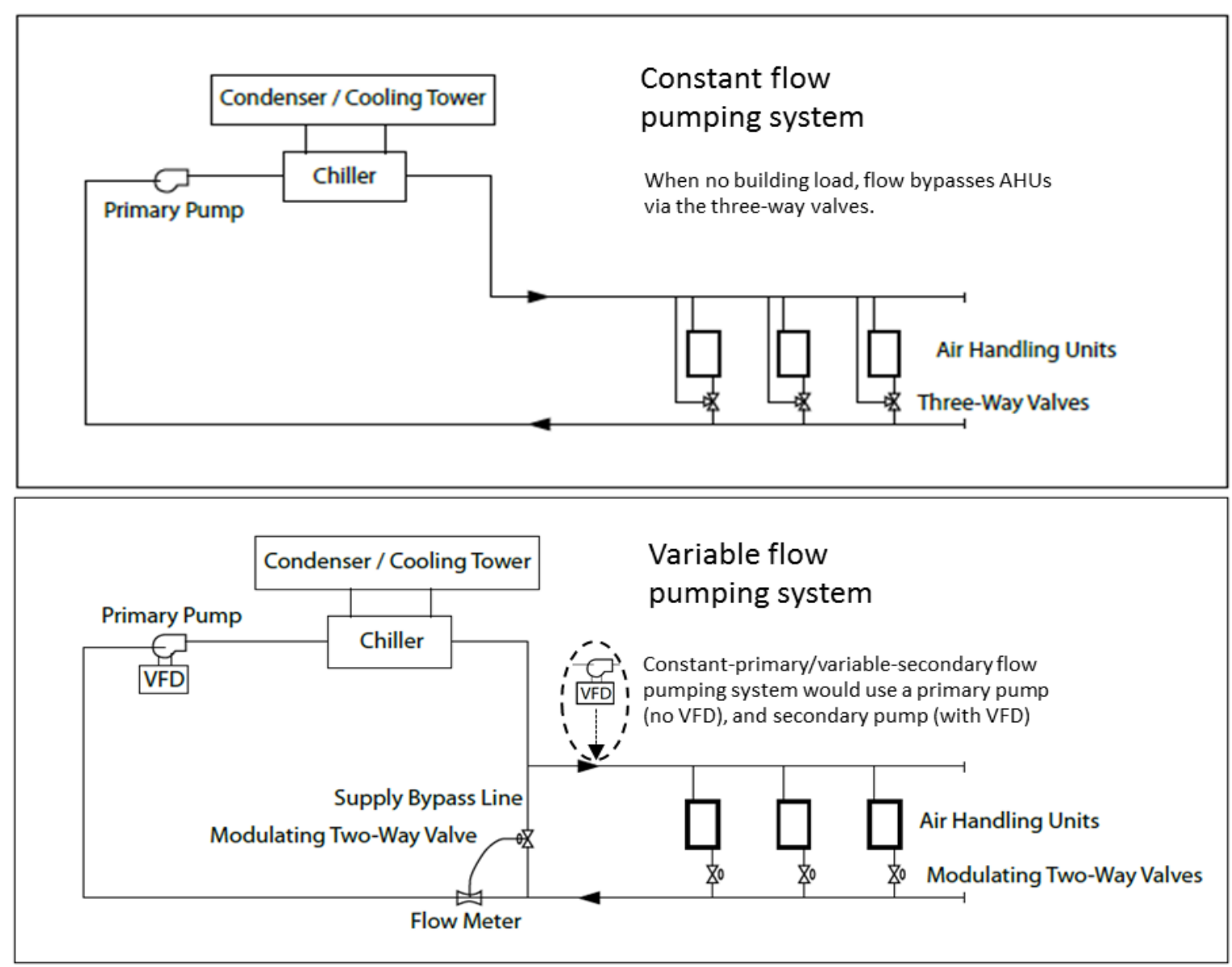

Graphic Source: Modified from AAON. ${ }^{201}$

\section{Figure 3-19: Example of constant and variable flow pumping systems}

\footnotetext{
199 Armstrong white paper. T. Egan. "Conversion From Constant Flow System to Variable Flow” Accessed Mar 2015. http://armstrongfluidtechnology.com/en/resources-and-tools/education-and-training/white-papers/white-papers

200 We do not distinguish between variable-primary and constant-primary, variable-secondary systems. Both configurations are considered as improvements over constant-flow pumping systems.

${ }^{201}$ Adapted by Navigant from AAON. https://www.aaon.com/Documents/Technical/VariableFlow_110411.pdf
} 
The energy savings opportunity focuses on retrofit of older buildings that continue to use constant flow pumping systems and inefficient flow controls. Elimination of constant flow pumping systems for HVAC (e.g. chillers and boilers), and the three-way valves associated with such systems, yield energy savings that depend on each building's current operation. We estimate potential energy savings of $40 \%$ of installing a variable flow system, compared to a constant flow system. ${ }^{202}$ We estimated potential applicability of this retrofit opportunity based on practical feasibility of system retrofit, while accounting for systems already using variable flow. In general, building owners will find the first costs of a variable flow system retrofit high compared to a simple replacement of constant flow components; however, they could find that existing utility incentives for VSDs and variable flow systems would make the retrofit financially attractive.

Building engineers and designers frequently select oversized pumps, designing with a safety factor to ensure adequate pump demand for the future, but rarely considering the efficiency ramifications. Section 3.4.3.3 (Residential Pumping Systems), discusses contractor and designer incentives for oversizing pumps. In commercial applications, this issue is further exacerbated by designers and installers who may further oversize pumps to account for possible corrosion in the pump or in the pipes, which results in increased pumping requirements from frictional losses. Pump systems often use throttling valves to reduce the amount of flow of an oversized pump, driving the pump away from its optimal performance and towards significantly lower efficiency; proper sizing can eliminate the need for any flow throttling. We estimate that "rightsizing" retrofits of oversized pumps can result in $20 \%$ potential energy savings, but is dependent upon the specific characteristics of the building's installed pumping system.

Improved piping configurations include larger pipes and/or advanced fittings to reduce frictional losses. System designers should attempt to evaluate pumping costs for different pipe diameters (see Figure 3-20), and select the one which results in the lowest lifecycle cost. Designers must also balance space availability and the impact of reduced water velocity for the pumping application (e.g. heating water system designs should consider heat lost while pumping), which may require smaller pipes. We estimate between 15-20\% energy savings from larger pipes, and sweep elbows that utilize a higher radius turn. ${ }^{203}$ Building designers typically do not design piping networks with pumping efficiency as a major consideration, indicating that potential opportunities for piping network retrofits may be high. However, improving piping configurations may not be possible in existing buildings with space constraints or piping that is inaccessible without major construction. Building owners may also find the cost of piping and/or fitting replacement cost prohibitive. New buildings could benefit the most in designing for better piping configurations, as long as new pumps are properly sized.

\footnotetext{
${ }^{202}$ Armstrong white paper. B. Ross. "Pumping Systems - Low Hanging Fruit in Saving Energy" Accessed Mar 2015. http://armstrongfluidtechnology.com/en/resources-and-tools/education-and-training/white-papers/white-papers ${ }^{203}$ Wider 90 degree radius than "hard" 90 degree elbow. Source: PG\&E. "Draft Report Residential Swimming Pools." Feb 2007. Larger pipes yield 20\% savings: Source: Water Research Foundation. "Strategies to Save Energy during the Pumping Process." Accessed Mar 2015. http://www.waterrf.org/knowledge/energy-management/FactSheets/EnergyMgt-EEPumping-FactSheet.pdf
} 


\section{Annual Water Pumping Cost for 1000 Feet of Pipe of Different Sizes}

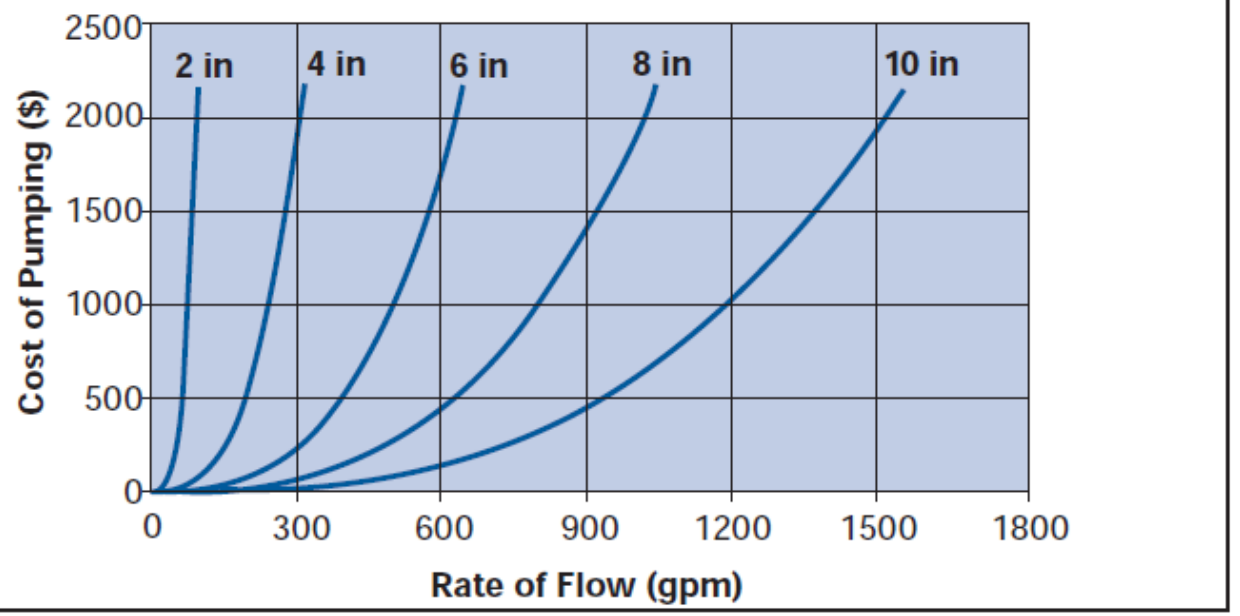

Based on $1000 \mathrm{ft}$. for clean iron and steel pipes (schedule 40 ) for pumping $70^{\circ} \mathrm{F}$ water. Electricity rate$0.05 \$ / \mathrm{kWh}$ and 8,760 operating hours annually. Combined pump and motor efficiency $-70 \%$.

Graphic Source: DOE - Office of Industrial Technologies 204

Figure 3-20: Sample pumping costs for different pipe sizes

Building owners can use pipe linings and coatings to stop pinhole leaks and improve the fluid flow characteristics within the network. For old piping, building owners can use a pipe lining retrofit, which involves coating the inside of the pipes with a corrosion-resistant epoxy, to extend pipe life and enhance pump system efficiency by reducing frictional head loss. In new buildings, system designers can install lined pipes to reap the benefits for the entire product life.

Additionally, designers may be less likely to oversize pumps if they know the piping network is corrosion-resistant. Linings cost approximately $50 \%$ of the amount needed to completely replace the piping. ${ }^{205}$ Literature suggests $40 \%$ reduction in frictional losses, though total savings depends on the length and width of piping, as well as the pump specified to deliver pressure and flow. ${ }^{206}$ We estimate the energy savings would be similar to piping configuration improvements (approximately 15\% energy savings) and are applicable only to piping systems in need of retrofit. ${ }^{207}$

\subsubsection{Maintenance}

Table 3-21 estimates the opportunity for energy savings by improving commercial maintenance practices.

\footnotetext{
${ }^{204}$ DOE-Office of Industrial Technologies. "Reduce Pumping Costs through optimum Pipe Sizing,” Dec 1999. http://www1.eere.energy.gov/manufacturing/tech assistance/pdfs/motor1.pdf

${ }^{205}$ Nu Flow. "Epoxy Lining." Accessed Mar 2015. http://www.nuflowtech.com/Products/EPOXYLINING.aspx

${ }^{206}$ DOE-Office of Industrial Technologies. "Reduce Pumping Costs through optimum Pipe Sizing,” Dec 1999. http://www1.eere.energy.gov/manufacturing/tech_assistance/pdfs/motor1.pdf

${ }^{207}$ It is possible to have epoxy-coatings for new pipes. In this case, there may be less energy savings from reducing frictional losses. However, coatings in new pipes may offer corrosion-resistance, and ensure more efficient water flow over the lifetime of the pipe.
} 
Table 3-21: Commercial Pump Maintenance Opportunities (Annual Technical Savings Potential)

\begin{tabular}{l|cccc}
\hline $\begin{array}{l}\text { Commercial Savings } \\
\text { Opportunity }\end{array}$ & Applications & $\begin{array}{l}\text { Est. Energy } \\
\text { Savings (\%) }\end{array}$ & $\begin{array}{r}\text { U.S. Primary Energy } \\
\text { Savings Potential (quads) }\end{array}$ & $\begin{array}{c}\text { Est. First-Cost } \\
\text { Premium (\%) }\end{array}$ \\
\hline $\begin{array}{l}\text { Correction of common } \\
\text { pumping problems }\end{array}$ & $\begin{array}{l}\text { All non-appliance } \\
\text { pumps }\end{array}$ & $\begin{array}{l}2 \%-15 \% \\
\text { Maintenance Sub-total }\end{array}$ & 0.03 & None \\
\hline
\end{tabular}

Pumping problems can occur from poor design or improper system operation. Common pumping problems include:

- Leaking in valves, joints or pipes

- Cavitation within the pump ${ }^{208}$

- Sealing issues

Unless the owner properly maintains the pump, pumping problems can result in severe performance losses and early degradation of pump components. Maintenance activities include replacement of worn impellers, and regular inspection and replacement of seals, bearings, and lubrication. ${ }^{209}$ We estimate that $50 \%$ of currently installed pumps require some kind of pump maintenance, which in turn can yield energy savings of $2-15 \% .^{210}$

\subsection{R\&D Opportunity Areas}

Through this study, Navigant has identified five potential R\&D topic areas that can help to address barriers to greater penetration of high efficiency pump technologies and overall energy savings in pump systems. Table 3-22 provides a non-prioritized list of these potential opportunities. It is not an exhaustive list, but rather a selection of topic areas that the authors of this study have deemed valuable in addressing key technological and market barriers.

\footnotetext{
${ }^{208}$ Cavitation - if static pressure in the pump drops below vapor pressure of the pumping liquid, the liquid vaporizes into tiny bubbles. As the bubbles return to liquid state, they create high-velocity water jets into the surrounding pump surfaces. This may damage the impeller and pump surfaces, and result in wear to bearings and seals.

${ }^{209}$ EEP. "14 energy-efficiency improvement opportunities in pumping systems". October 2014. http://electrical-engineeringportal.com/14-energy-efficiency-improvement-opportunities-in-pumping-systems

${ }^{210}$ Multiple sources.

Savings of 2-7\% - Source: EEP. "14 energy-efficiency improvement opportunities in pumping systems". October 2014.

http://electrical-engineering-portal.com/14-energy-efficiency-improvement-opportunities-in-pumping-systems

Savings of 10-15\% - Source: AEAT. "Study on improving the Energy Efficiency of Pumps". Feb 2001.

http://www.watergymex.org/Watergy\%20Toolkit/resources/53_Improving\%20Energy\%20Efficiency\%20of\%20Pumps.pdf
} 
Table 3-22: Identified Pump R\&D Topic Areas

ID Description

Category

Appliance-integrated pump improvements: Analyze and test

1 appliance-housed pump and fan improvements; identify manufacturing barriers; recommend code updates and R\&D opportunities (same as Fan R\&D Opportunity ID\#2).

Hydraulic

Design

Low-loss distribution components: Support cost-reducing efforts for

2 low-loss piping components; understand current market opportunity for retrofit applications and new builds.

Energy-optimized O\&M for pump systems: Research and identify

3 opportunities for connected pumps and integrating automated pump system control into building management systems including determination of key tools to help expand use of best practices.

Connected pool pumps: Conduct analysis and testing on connected

4 functionality for residential pool pumps to determine savings potential from associated behavioral and operational changes.

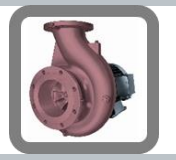

System Design

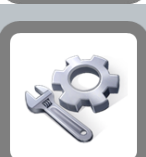

Operations \& Maintenance

5

Advanced bearings: Investigate innovative low friction bearings and conduct research to reduce costs and to aid in miniaturization efforts.

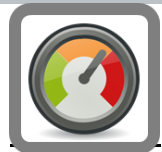

Sensors \& Controls

The following subsections describe each of the R\&D opportunities in greater depth.

\subsubsection{R\&D Topic ID\#1: Appliance-Integrated Pump Improvements}

Please see discussion of this initiative in Section 2.5.2 for R\&D Initiative ID\#2.

\subsubsection{R\&D Topic ID\#2: Low-Loss Piping and Pipe Components}

Recent developments in low-loss pipe linings and low-loss components has opened up additional opportunities for reducing frictional losses in pump systems. While the specific methods may differ for new piping versus retrofitting of older system, the benefits for both include increased efficiency, energy savings, and reduced pipe degradation over time leading to extended pipe life. In older buildings, corrosion can lead to reduced system efficiency. Complete replacement of the piping typically requires major renovations to access all the piping, and is rarely cost effective unless the building has historical value. Pipe lining and replacement of valves and other restrictive components can be cost-effective retrofit solutions by avoiding the need for complete system replacement. Research into cost reduction methods for these technologies, including factory-based solutions and field installation-based solutions, will help to enable greater penetration, both new and retrofit applications.

Other areas for further investigation include:

- Level of awareness of this technology among designers/installers

- System designer opinions and concerns (if any) regarding pipe linings, and other low-loss piping or piping components

- Suitability of use for new builds; potential for lining use in new pipe networks 


\subsubsection{R\&D Topic ID\#3: Energy Optimized O\&M for Pump Systems}

Commercial pump controls, setpoints, and schedules can be more efficiently managed by a building management system than manually by a facility manager, who may be responsible for many systems and buildings. However, without oversight by an engaged operator, even an advanced building management system will operate inefficiently, for example, by mismatching operating schedule to actual usage hours. A key unknown factor to research is to determine what barriers (e.g. technical, user-related, etc.) exist for facility managers that, if addressed, would increase usage of automated control systems and ensure better energy savings outcomes for those controlled systems. R\&D opportunities could address these key subject areas:

- Optimal control strategies of multiple pumps and the pumping system to lower energy consumption and reduce lifecycle costs

- Hardware and software tools (e.g., real-time energy monitoring systems) that can help facility managers to more easily identify incorrect operation and address issues rapidly with confidence

- Level of control and data monitoring necessary for easy management of pump systems (e.g., energy consumption of entire HVAC system, on/off pump status, pump energy consumption, etc.)

The areas lacking in knowledge include data on the current state of integration of variable speed pumps into building systems, the energy savings achieved by this integration, and remaining barriers to increased adoption of integrated pumps with automated controls. Energy savings operations rely heavily on an understanding of facility manager behaviors and is likely to vary across the commercial sector. We expect that greater insights into these factors will provide greater direction for how to pursue development of specific technologies.

Other areas for further investigation include:

- Study of current pump user (or facility manager) behaviors, over different applications in the commercial sector

- Benefits of enhanced fault and failure management, including value for users (providing greater insight into faults and providing system-specific maintenance alerts instead of schedule based), and value to manufacturers (providing insights into failure modes)

\subsubsection{R\&D Topic ID\#4: Connected Pool Pumps}

As "smart," or connected operation of appliances and equipment becomes more common, it is unclear what energy savings would be achievable for pool pumps, the single largest standalone pump opportunity in the residential sector. Research into using smart controls for pool pumps and into options for connecting pump operation/controls to home energy management systems would provide insight into the achievable savings. Research would focus on how the pump would be operated or instrumented to help save energy, and would need to consider behavioral impacts of homeowners.

Connected pool pumps that allow external applications or devices to access and control the pump may be viable candidates for price-sensitive load shifting operation or automated demand 
response program participation. For homeowners on time-of-use pricing tariffs, shifting loads to off-peak periods would bring down operating costs and accelerate the payback for highefficiency equipment. Participation in a demand response program would expand the value by helping utilities or system operators to manage grid demand. In both cases, R\&D opportunities would focus on understanding any primary energy savings potential (comparing baseload generation to less efficient peaking generation) achieved through peak shifting and demand response participation.

Research will be required to understand how remote access by a user will change usage patterns (including the impact of software algorithms). Remote access enables intimate monitoring of pump speed, throughput, and could enable sensing of pool filtration efficacy to determine appropriate shutoff times. However, the achievable energy savings from these features depends on how users operate the system. Field studies to determine actual savings would be required to fully understand the market value of this product.

Other areas for further investigation include:

- Benefits of pump fault detection, on energy savings, and on equipment maintenance costs

- Different methods a connected pump can monitor pump usage with respect to maintenance schedules

- Manufacturer value from collection of failure data towards understanding failure modes

\subsubsection{R\&D Topic ID\#5: Advanced Bearings}

Low-friction bearings help reduce frictional losses of the rotating pump shaft and is an active area of innovation. Advanced bearing concepts feature alternative bearing materials (e.g. silicon nitride, ceramic coated bearings) or radically different bearing designs (e.g. magnetic). Advanced bearings may be able to achieve up to 5\% savings, and may help reduce maintenance requirements (e.g. no lubrication needed in magnetic bearings). Currently, these advanced bearings are limited to specialized applications (e.g. large applications, high speed, clean-room, etc.) due to substantial cost premiums relative to typical bearings. R\&D efforts should focus on:

- Cost reduction of advanced bearings via advanced manufacturing methods - Cost reductions would enable broader adoption in high-volume equipment. New materials may be one pathway to achieve this. For magnetic bearings in particular, the control systems add a new and large cost not required for traditional bearings. Investigation of these costs is needed to determine what opportunities may exist for cost reduction.

- Miniaturization - Manufacturers target many of these advanced bearings for larger, industrial applications where size and space are not major concerns. Further investigation is required to explore options for miniaturize magnetic or other advanced bearings, and how that may impact cost. Research would be exploratory in nature to identify the potential specific focus areas for further development.

Other areas for further investigation include:

- Understanding the market viability of advanced, industrial bearings in commercial pumps

- Maximum first-cost of bearings for cost effectiveness of premium products.

- Reliability of advanced bearings in commercial applications 


\section{Appendix A - Data Sources for Shipments and Installed Base}

Table 4-1: Data Sources for Residential Fan Shipments and Installed Base

\begin{tabular}{|c|c|c|c|c|c|}
\hline \multirow{2}{*}{$\begin{array}{l}\text { Residential } \\
\text { Fan }\end{array}$} & \multirow{2}{*}{ Fan Use } & \multicolumn{2}{|c|}{ Estimated Annual Shipments } & \multicolumn{2}{|r|}{ Estimated Installed Base } \\
\hline & & Millions & Sources/Notes & Millions & Sources/Notes \\
\hline CAC & Condenser & 3.9 & $\begin{array}{c}\text { Appliance magazine, } 2013 \text { (via } \\
\text { BTO Motors Report) }\end{array}$ & 59.5 & TSD (DOE, 2011c) \\
\hline CAC and HPs & Circulation & 2.0 & $\begin{array}{l}\text { TSD (DOE, 2014); TSD (DOE, } \\
\text { 2011c) }\end{array}$ & 10.9 & TSD (DOE, 2014); RECS (EIA, 2009) \\
\hline Ceiling fan & Circulation & 17.0 & $\begin{array}{c}\text { Appliance magazine, } 2013 \text { (via } \\
\text { BTO Motors Report) }\end{array}$ & 83.8 & $\begin{array}{c}\text { Framework (DOE, 2013) (via BTO } \\
\text { Motors Report) }\end{array}$ \\
\hline Clothes Dryer & Exhaust & 5.8 & $\begin{array}{c}\text { Appliance magazine, } 2013 \text { (via } \\
\text { BTO Motors Report) }\end{array}$ & 110.0 & TSD (DOE, 2011b) \\
\hline Dehumidifier & Circulation & 1.2 & $\begin{array}{c}\text { Appliance magazine, } 2013 \text { (via } \\
\text { BTO Motors Report) }\end{array}$ & 15.0 & Pre-analysis TSD (DOE, 2014g) \\
\hline Freezer & Condenser & 1.0 & $\begin{array}{c}\text { Appliance magazine, } 2013 \text { (via } \\
\text { BTO Motors Report) }\end{array}$ & 24.7 & TSD (DOE, 2011d) \\
\hline Freezer & Evaporator & 2.0 & $\begin{array}{c}\text { Appliance magazine, } 2013 \text { (via } \\
\text { BTO Motors Report) }\end{array}$ & 49.4 & TSD (DOE, 2011d) \\
\hline Furnace & Circulation & 2.6 & TSD (DOE, 2014a) & 58.7 & TSD (DOE, 2014a) \\
\hline $\begin{array}{l}\text { Furnace and } \\
\text { Boiler }\end{array}$ & Inducer & 2.7 & $\begin{array}{c}\text { Based on TSD (DOE, 2007); } \\
\text { NODA-TSD (DOE, 2014i) }\end{array}$ & 59.5 & $\begin{array}{c}\text { Based on TSD (DOE, 2007); } \\
\text { NODA-TSD (DOE, 2014i) }\end{array}$ \\
\hline Heat Pump & Condenser & 1.7 & $\begin{array}{c}\text { Appliance magazine, } 2013 \text { (via } \\
\text { BTO Motors Report) }\end{array}$ & 14.7 & TSD (DOE, 2011c) \\
\hline RAC & Condenser & 7.5 & $\begin{array}{c}\text { Appliance magazine, } 2013 \text { (via } \\
\text { BTO Motors Report) }\end{array}$ & 28.7 & TSD (DOE, 2011b) \\
\hline RAC & Circulation & 7.5 & $\begin{array}{c}\text { Appliance magazine, } 2013 \text { (via } \\
\text { BTO Motors Report) }\end{array}$ & 28.7 & TSD (DOE, 2011b) \\
\hline $\begin{array}{l}\text { Refrigerator/Fr } \\
\text { eezer }\end{array}$ & Condenser & 8.6 & $\begin{array}{c}\text { Appliance magazine, } 2013 \text { (via } \\
\text { BTO Motors Report) }\end{array}$ & 143.5 & TSD (DOE, 2011b) \\
\hline $\begin{array}{l}\text { Refrigerator/Fr } \\
\text { eezer }\end{array}$ & Evaporator & 8.6 & $\begin{array}{c}\text { Appliance magazine, } 2013 \text { (via } \\
\text { BTO Motors Report) }\end{array}$ & 143.5 & TSD (DOE, 2011b) \\
\hline
\end{tabular}

Table 4-2: Data Sources for Commercial Fan Shipments and Installed Base

\begin{tabular}{|c|c|c|c|c|c|}
\hline \multirow{2}{*}{$\begin{array}{l}\text { Commercial } \\
\text { Fan }\end{array}$} & \multirow[b]{2}{*}{ Fan Use } & \multicolumn{2}{|c|}{ Estimated Annual Shipments } & \multicolumn{2}{|c|}{ Estimated Installed Base } \\
\hline & & Thousands & Sources/Notes & Millions & Sources/Notes \\
\hline $\begin{array}{l}\text { Clean Air } \\
\text { Ventilation }\end{array}$ & $\begin{array}{l}\text { Supply \& } \\
\text { circulation }\end{array}$ & 260 & LCC/NIA (DOE, 2015b) & 4 & LCC/NIA (DOE, 2015b) \\
\hline $\begin{array}{l}\text { Exhaust } \\
\text { Ventilation }\end{array}$ & Exhaust & 120 & LCC/NIA (DOE, 2015b) & 2 & LCC/NIA (DOE, 2015b) \\
\hline PTAC & Indoor & 500 & $\begin{array}{c}\text { TSD (DOE, 2012c) (via BTO } \\
\text { Motors Report) }\end{array}$ & 5.0 & (BTO Motors Report, 2013) \\
\hline PTAC & Outdoor & 500 & $\begin{array}{c}\text { TSD (DOE, 2012c) (via BTO } \\
\text { Motors Report) }\end{array}$ & 5.0 & (BTO Motors Report, 2013) \\
\hline SPVAC & Indoor & 51 & $\begin{array}{c}\text { TSD (DOE, 2009a) (via BTO } \\
\text { Motors Report) }\end{array}$ & 0.8 & (BTO Motors Report, 2013) \\
\hline SPVAC & Outdoor & 51 & $\begin{array}{c}\text { TSD (DOE, 2009a) (via BTO } \\
\text { Motors Report) }\end{array}$ & 0.8 & (BTO Motors Report, 2013) \\
\hline CUAC & Small - Indoor & 589 & $\begin{array}{c}\text { TSD (DOE, 2012e) (via BTO } \\
\text { Motors Report) }\end{array}$ & 8.8 & (BTO Motors Report, 2013) \\
\hline CUAC & Med - Indoor & 169 & $\begin{array}{c}\text { TSD (DOE, 2012e) (via BTO } \\
\text { Motors Report) }\end{array}$ & 2.5 & (BTO Motors Report, 2013) \\
\hline
\end{tabular}




\begin{tabular}{|c|c|c|c|c|c|}
\hline \multirow{2}{*}{$\begin{array}{l}\text { Commercial } \\
\text { Fan }\end{array}$} & \multirow[b]{2}{*}{ Fan Use } & \multicolumn{2}{|c|}{ Estimated Annual Shipments } & \multicolumn{2}{|c|}{ Estimated Installed Base } \\
\hline & & Thousands & Sources/Notes & Millions & Sources/Notes \\
\hline CUAC & Lrg. - Indoor & 16 & $\begin{array}{c}\text { TSD (DOE, 2012e) (via BTO } \\
\text { Motors Report) }\end{array}$ & 0.2 & (BTO Motors Report, 2013) \\
\hline CUAC & $\begin{array}{l}\text { Small - } \\
\text { Outdoor }\end{array}$ & 589 & $\begin{array}{c}\text { TSD (DOE, 2012e) (via BTO } \\
\text { Motors Report) }\end{array}$ & 8.8 & (BTO Motors Report, 2013) \\
\hline CUAC & $\begin{array}{l}\text { Med - } \\
\text { Outdoor }\end{array}$ & 169 & $\begin{array}{l}\text { TSD (DOE, 2012e) (via BTO } \\
\text { Motors Report) }\end{array}$ & 2.5 & (BTO Motors Report, 2013) \\
\hline CUAC & Lrg. - Outdoor & 16 & $\begin{array}{c}\text { TSD (DOE, 2012e) (via BTO } \\
\text { Motors Report) }\end{array}$ & 0.2 & (BTO Motors Report, 2013) \\
\hline Furnace & Draft & 616 & $\begin{array}{l}\text { TSD (DOE, 2015a); TSD } \\
\text { (DOE, 2012e) }\end{array}$ & 9.2 & $\begin{array}{c}\text { TSD (DOE, 2015a); TSD (DOE, } \\
\text { 2012e) }\end{array}$ \\
\hline Boiler & Draft & 32 & $\begin{array}{c}\text { Pre-Analysis TSD (DOE, } \\
2014 b)\end{array}$ & 0.9 & Pre-Analysis TSD (DOE, 2014b) \\
\hline Chiller & $\begin{array}{l}\text { Air-cooled } \\
\text { evaporator }\end{array}$ & 23 & $\begin{array}{l}\text { Adjusted from USCB } \\
\text { Average 2009, } 2010 \text { (via } \\
\text { BTO Motors Report) }\end{array}$ & 0.5 & $\begin{array}{l}\text { Adjusted from (BTO Motors } \\
\text { Report, 2013) }\end{array}$ \\
\hline Cooling Tower & Outdoor & 12 & Report (DOE-ADL, 1999) & 0.3 & (BTO Motors Report, 2013) \\
\hline CRE & Condenser & 443 & $\begin{array}{c}\text { (Appliance, 2012) (via BTO } \\
\text { Motors Report) }\end{array}$ & 3.1 & (BTO Motors Report, 2013) \\
\hline CRE & Evaporator & 443 & $\begin{array}{c}\text { (Appliance, 2012) (via BTO } \\
\text { Motors Report) }\end{array}$ & 3.1 & (BTO Motors Report, 2013) \\
\hline BVM & Condenser & 342 & $\begin{array}{c}\text { TSD (DOE, 2009b) (via BTO } \\
\text { Motors Report) }\end{array}$ & 3.7 & (BTO Motors Report, 2013) \\
\hline BVM & Evaporator & 342 & $\begin{array}{l}\text { TSD (DOE, 2009b) (via BTO } \\
\text { Motors Report) }\end{array}$ & 3.7 & (BTO Motors Report, 2013) \\
\hline WICF & Condenser & 287 & $\begin{array}{c}\text { TSD (DOE, 2010) (via BTO } \\
\text { Motors Report) }\end{array}$ & 2.0 & (BTO Motors Report, 2013) \\
\hline WICF & Evaporator & 287 & $\begin{array}{l}\text { TSD (DOE, 2010) (via BTO } \\
\text { Motors Report) }\end{array}$ & 2.0 & (BTO Motors Report, 2013) \\
\hline ACIM & Condenser & 162 & $\begin{array}{c}\text { TSD (DOE, 2012a) (via BTO } \\
\text { Motors Report) }\end{array}$ & 2.0 & (BTO Motors Report, 2013) \\
\hline
\end{tabular}

Table 4-3: Data Sources for Residential Pump Shipments and Installed Base

\begin{tabular}{|c|c|c|c|c|c|}
\hline \multirow{2}{*}{$\begin{array}{l}\text { Residential } \\
\text { Pump }\end{array}$} & \multirow{2}{*}{ Pump Use } & \multicolumn{2}{|c|}{ Estimated Annual Shipments } & \multicolumn{2}{|c|}{ Estimated Installed Base } \\
\hline & & Millions & Sources/Notes & Millions & Sources/Notes \\
\hline $\begin{array}{l}\text { Hydronic } \\
\text { heating (boilers) }\end{array}$ & Circulation & 1.11 & $\begin{array}{l}\text { Presentation (ASRAC Pumps } \\
\text { Working Group, 2015) }\end{array}$ & 11 & $\begin{array}{l}\text { Presentation (ASRAC Pumps } \\
\text { Working Group, 2015) }\end{array}$ \\
\hline $\begin{array}{l}\text { Potable water } \\
\text { pressure }\end{array}$ & Circulation & 0.34 & $\begin{array}{l}\text { Presentation (ASRAC Pumps } \\
\text { Working Group, 2015) }\end{array}$ & 3.4 & $\begin{array}{l}\text { Presentation (ASRAC Pumps } \\
\text { Working Group, 2015) }\end{array}$ \\
\hline Well pump & Well water & 1.0 & (USCB, 2008) & 16 & $\begin{array}{l}\text { Estimated based on product } \\
\text { shipments and lifetime }\end{array}$ \\
\hline Dishwasher & $\begin{array}{l}\text { Circulation } \\
\text { and Drain }\end{array}$ & 5.69 & $\begin{array}{l}\text { Appliance magazine, } 2013 \\
\text { (via BTO Motors Report) }\end{array}$ & 95 & TSD (DOE, 2012d) \\
\hline Clothes Washer & Drain & 7.3 & $\begin{array}{l}\text { Appliance magazine, } 2013 \\
\text { (via BTO Motors Report) }\end{array}$ & 109 & (BTO Motors Report, 2013) \\
\hline Pool pump & Circulation & 0.67 & (EPA, 2011) & 5.36 & (EPA, 2011) \\
\hline Geothermal HP & $\begin{array}{l}\text { Loop } \\
\text { circulation }\end{array}$ & 0.09 & (Navigant Research, 2013) & 0.9 & $\begin{array}{l}\text { Estimated based on product } \\
\text { shipments and lifetime }\end{array}$ \\
\hline
\end{tabular}


Table 4-4: Data Sources for Commercial Pump Shipments and Installed Base

\begin{tabular}{|c|c|c|c|c|c|}
\hline \multirow{2}{*}{ Commercial Pump } & \multirow{2}{*}{ Pump Use } & \multicolumn{2}{|c|}{ Estimated Annual Shipments } & \multicolumn{2}{|c|}{ Estimated Installed Base } \\
\hline & & Thousands & Sources/Notes & Millions & Sources/Notes \\
\hline $\begin{array}{l}\text { Pumps - HVAC \& } \\
\text { Water Supply }\end{array}$ & $\begin{array}{l}\text { Circulation; } \\
\text { Water } \\
\text { pressure boost }\end{array}$ & 161 & NOPR TSD (DOE, 2014c) & 2.25 & $\begin{array}{l}\text { Estimated based on product } \\
\text { shipments and lifetime }\end{array}$ \\
\hline $\begin{array}{l}\text { Circulators - HVAC \& } \\
\text { Water Supply }\end{array}$ & Circulation & 88 & $\begin{array}{l}\text { Presentation (ASRAC } \\
\text { Pumps Working Group, } \\
\text { 2015) }\end{array}$ & 0.88 & $\begin{array}{l}\text { Estimated based on product } \\
\text { shipments and lifetime }\end{array}$ \\
\hline Pool Pumps & Circulation & 31 & (APSP, 2013) & 0.31 & $\begin{array}{l}\text { Estimated based on product } \\
\text { shipments and lifetime }\end{array}$ \\
\hline Well Pumps & Well pumping & 14 & NOPR TSD (DOE, 2014c) & 0.14 & $\begin{array}{l}\text { Estimated based on product } \\
\text { shipments and lifetime }\end{array}$ \\
\hline $\begin{array}{l}\text { Automated } \\
\text { Commercial Ice } \\
\text { Makers }\end{array}$ & Circulation & 136 & TSD (DOE, 2012a) & 1.70 & $\begin{array}{l}\text { Estimated based on product } \\
\text { shipments and lifetime }\end{array}$ \\
\hline $\begin{array}{l}\text { Commercial Clothes } \\
\text { Washers }\end{array}$ & Drain & 206 & TSD (DOE, 2014e) & 1.93 & $\begin{array}{l}\text { Estimated based on product } \\
\text { shipments and lifetime }\end{array}$ \\
\hline $\begin{array}{l}\text { Pumps - HVAC \& } \\
\text { Water Supply }\end{array}$ & $\begin{array}{l}\text { Circulation; } \\
\text { Water } \\
\text { pressure boost }\end{array}$ & 161 & NOPR TSD (DOE, 2014c) & 2.25 & $\begin{array}{l}\text { Estimated based on product } \\
\text { shipments and lifetime }\end{array}$ \\
\hline
\end{tabular}




\section{Appendix B - Miscellaneous Residential Fans}

Table 5-1: Data and Sources for Miscellaneous Residential Fan Shipments and Installed Base

\begin{tabular}{|c|c|c|c|}
\hline $\begin{array}{l}\text { Misc. Residential Fan } \\
\text { Application }\end{array}$ & $\begin{array}{l}\text { Estimated Annual } \\
\text { Shipments }(1,000 s)\end{array}$ & $\begin{array}{l}\text { Est. Installed Base } \\
\text { (Millions) }\end{array}$ & Notes \\
\hline HPWH Condenser Fan & 43 & 0.3 & $\begin{array}{l}\text { All units assumed to be ENERGY STAR. Estimated } \\
\text { using (EPA, 2013) }\end{array}$ \\
\hline Boiler Inducer Fan & 44 & 0.8 & DOE SME estimate \\
\hline Whole House Fan & & 6.6 & Estimate based on (PG\&E, 2004a); (RASS, 2009) \\
\hline Kitchen Exhaust Fan & 7700 & 82.5 & Estimate based on (PG\&E, 2004b) \\
\hline Bathroom Exhaust Fan & 3300 & 39 & Estimate based on (PG\&E, 2004b) \\
\hline Attic Fan & & 3.6 & Estimated nationally \\
\hline Radon Fan & & 0.6 & Estimated by DOE-BTO \\
\hline Window Fan & & 55 & Report (DOE-ADL, 1999) \\
\hline Evaporative Cooler Blower & & 4 & Report (DOE-ADL, 1999) \\
\hline PC/Electronics Cooling & & 41 & Report (DOE-ADL, 1999) \\
\hline Other misc. & & 0 & Report (DOE-ADL, 1999) \\
\hline
\end{tabular}




\section{Appendix C - Calculation Methodology}

This appendix describes our general methodology to estimates data for the following tables: Table 2-3: Residential Fan Uses and Market Summary Table 2-4: Residential Fan Energy Consumption for Selected Applications Table 2-6: Commercial Fan Uses and Market Summary Table 2-7: Commercial Fan Energy Consumption for Selected Applications Table 2-13 through to Table 2-19: Residential and Commercial Fan Savings Opportunities Table 3-3: Residential Pump Uses and Market Summary Table 3-4: Residential Pump Energy Consumption for Selected Applications Table 3-7: Commercial Pump Uses and Market Summary Table 3-9: Commercial Pump Energy Consumption for Selected Applications Table 3-15 through to Table 3-21: Residential and Commercial Pump Savings Opportunities

\section{Market Data}

Annual shipment data for pump and fan applications either originate directly from the cited sources, or are interpolated or adapted from data in the cited sources. For some equipment covered by DOE rulemakings without direct correlation between shipment data and specific applications, we relied on DOE subject matter experts to help estimate the appropriate shipments.

Notable exceptions to this shipment data methodology are geothermal heat pumps and residential well pumps, where we could find no direct data or SMEs. For residential well pumps, we estimated shipments by dividing the installed base by the average product lifetime. For geothermal heat pumps, we estimated pump shipments by dividing total shipment tonnage by the average size of a residential geothermal heat pump.

Installed base of pumps and fans for different applications were estimated in three ways. Where possible, we used data directly, or adapted data from the cited source. In the absence of directly cited data, we calculated installed base by summing historical shipments (by year) over the average lifetime of the pump or fan. If historical shipments were not available, we estimated installed base by multiplying current annual shipments with the average lifetime of the pump/fan.

\section{Energy Consumption Data}

Average annual operating hours for different pump and fan applications are obtained directly from cited sources, or adapted from the cited source. For pumps and fans with a DOE rulemaking source, we typically estimated operating hours for products at the baseline efficiency level. If operating hours were not directly provided in the DOE source, we performed an average of operating hours, weighted by product shipments of different equipment classes. If operating hours for product-integrated pumps and fans are not provided in DOE rulemaking documentation, we acquired DOE SME input to estimate average operating hours.

We could not find an appropriate source for operating hours of residential solar thermal heat pumps, so we assumed average operation of 10 hours a day. For commercial pool pumps, we assumed constant operation as described by government mandate in the cited source. 
Average unit energy consumption, similar to operating hours, were calculated from cited source where available, and weighted by shipments of different equipment classes or product types (if a DOE rulemaking source was used). For pump and fan UECs for appliance-integrated equipment, we estimated UEC as a percentage of the average product energy consumption using DOE SME input. In the absence of DOE rulemaking sources, we estimated UEC from average annual hours of operation, and the average rated wattage of the pump/fan.

For each application, we calculated annual site energy consumption as the product of average annual operating hours and average annual UEC. We calculated national primary energy consumption by multiplying site energy consumption with a site-to-source conversion factor and appropriate unit conversion. The site-to-source conversion was calculated from data from Annual Energy Outlook, 2014. ${ }^{211}$

\section{Energy Savings Opportunity Estimates}

Estimated energy savings represent the percent energy savings of the opportunity, either generally (representing all applications), or of a single unit (unit energy savings) which are then calculated for all applicable units. These estimates were either directly quoted from the cited source, adapted from cited source, or adapted from multiple sources. Where there was a range of possible energy savings, the average of all estimates was used to calculate estimated energy savings. Potential applications for each energy savings opportunity were judged based on descriptions of the opportunity in the cited source and other supporting literature.

National primary energy savings was calculated as follows:

$$
\begin{aligned}
& \text { Energy savings potential } \\
& \quad=\text { Enerimary energy nationwide }) \\
& \times \text { Unit energy saving }_{(\%)} \times \text { Suitability }{ }_{(\% \text { of all units installed })}
\end{aligned}
$$

The "energy consumption" term was calculated in previous sections, representing the average total energy consumption of pumps or fans in relevant applications. The estimated suitability was a percentage representing the proportion of the current installed base to which the savings opportunity was deemed applicable. These estimates were made based on current market penetration of the savings opportunity, and, when available, input from research sources and DOE subject matter experts. Further work to refine these estimates may be valuable for some savings opportunities with limited applicable data.

Estimated first cost premium of energy savings opportunities are directly estimated or adapted from the cited sources, where available.

${ }^{211}$ EIA. Annual Energy Outlook 2014. Accessed Feb 2015. http://www.eia.gov/forecasts/aeo/ 


\section{Appendix D - Data Sources for Operating Hours and UEC}

Table 7-1: Data Sources for Residential Fan Operating Hours and UEC

\begin{tabular}{|c|c|c|c|c|c|}
\hline \multirow{2}{*}{$\begin{array}{l}\text { Residential } \\
\text { Fan }\end{array}$} & \multirow{2}{*}{ Fan Use } & \multicolumn{2}{|c|}{ Annual Operating Hours } & \multicolumn{2}{|r|}{ Average UEC } \\
\hline & & Hours & Sources/Notes & kWh/yr. & Sources/Notes \\
\hline CACs & Condenser & 1,000 & TSD (DOE, 2011c) & 220 & TSD (DOE, 2011c) \\
\hline CAC and HPs & Circulation & 1,000 & TSD (DOE, 2011c) & 360 & TSD (DOE, 2014a) \\
\hline Ceiling fans & Circulation & 2,350 & Pre-analysis TSD (DOE, 2014f) & 132 & Pre-analysis TSD (DOE, 2014f) \\
\hline Clothes Dryers & Exhaust & 283 & TSD (DOE, 2011b) & 20 & TSD (DOE, 2011b) \\
\hline Dehumidifiers & $\begin{array}{l}\text { Condenser \& } \\
\text { Supply fan }\end{array}$ & 1,095 & Pre-analysis TSD (DOE, 2014g) & 40 & Pre-analysis TSD (DOE, 2014g) \\
\hline Freezers & Condenser & 3,000 & TSD (DOE, 2011d) & 24 & TSD (DOE, 2011d) \\
\hline Freezers & Evaporator & 3,000 & TSD (DOE, 2011d) & 24 & TSD (DOE, 2011d) \\
\hline Furnace Fans & Supply fan & 1,870 & TSD (DOE, 2014a) & 678 & TSD (DOE, 2014a) \\
\hline Furnace & Inducer fan & 650 & $\begin{array}{l}\text { Based on TSD (DOE, 2007); } \\
\text { NODA-TSD (DOE, 2014i) }\end{array}$ & 98 & $\begin{array}{l}\text { Based on TSD (DOE, 2007); } \\
\text { NODA-TSD (DOE, 2014i) }\end{array}$ \\
\hline Heat Pumps & Condenser & 1,000 & TSD (DOE, 2011c) & 560 & TSD (DOE, 2011c) \\
\hline RACs & $\begin{array}{l}\text { Condenser \& } \\
\text { Supply fan }\end{array}$ & 750 & TSD (DOE, 2011b) & 60 & $\begin{array}{l}\text { Motor efficiency increased from } \\
50 \% \text { to } 80 \% \text { TSD (DOE, 2011b) }\end{array}$ \\
\hline $\begin{array}{l}\text { Refrigerator/ } \\
\text { Freezers }\end{array}$ & Condenser & 3,000 & TSD (DOE, 2011d) & 27 & TSD (DOE, 2011d) \\
\hline
\end{tabular}

Table 7-2: Data Sources for Commercial Fan Operating Hours and UEC

\begin{tabular}{|c|c|c|c|c|c|}
\hline \multirow{2}{*}{$\begin{array}{l}\text { Commercial } \\
\text { Fan }\end{array}$} & \multirow{2}{*}{ Fan Use } & \multicolumn{2}{|c|}{ Annual Operating Hours } & \multicolumn{2}{|r|}{ Average UEC } \\
\hline & & Hours & Sources/Notes & kWh/yr. & Sources/Notes \\
\hline $\begin{array}{l}\text { Clean Air } \\
\text { Ventilation }\end{array}$ & $\begin{array}{l}\text { Supply \& } \\
\text { circulation }\end{array}$ & 6,700 & LCC/NIA (DOE, 2015b) & - & \\
\hline $\begin{array}{l}\text { Exhaust } \\
\text { Ventilation }\end{array}$ & Exhaust & 6,200 & LCC/NIA (DOE, 2015b) & - & \\
\hline PTAC & Indoor & 3,600 & $\begin{array}{l}\text { DOE estimates (via BTO } \\
\text { Motors Report, 2013) }\end{array}$ & 230 & TSD (DOE, 2012c) \\
\hline PTAC & Outdoor & 3,600 & $\begin{array}{l}\text { DOE estimates (via BTO } \\
\text { Motors Report, 2013) }\end{array}$ & 150 & TSD (DOE, 2012c) \\
\hline SPVAC & Indoor & 5,700 & $\begin{array}{l}\text { DOE estimates (via BTO } \\
\text { Motors Report, 2013) }\end{array}$ & 1400 & TSD (DOE, 2009a) \\
\hline SPVAC & Outdoor & 5,700 & $\begin{array}{l}\text { DOE estimates (via BTO } \\
\text { Motors Report, 2013) }\end{array}$ & 920 & TSD (DOE, 2009a) \\
\hline CUAC & Small - Indoor & 1,000 & Report (DOE-ADL, 1999) & 920 & TSD (DOE, 2012e) \\
\hline CUAC & Med - Indoor & 1,200 & Report (DOE-ADL, 1999) & 1800 & TSD (DOE, 2012e) \\
\hline CUAC & Lrg - Indoor & 1,500 & Report (DOE-ADL, 1999) & 4400 & TSD (DOE, 2012e) \\
\hline CUAC & Small - Outdoor & 1,000 & Report (DOE-ADL, 1999) & 920 & TSD (DOE, 2012e) \\
\hline CUAC & Med - Outdoor & 1,200 & Report (DOE-ADL, 1999) & 1800 & TSD (DOE, 2012e) \\
\hline CUAC & Lrg - Outdoor & 1,500 & Report (DOE-ADL, 1999) & 4400 & TSD (DOE, 2012e) \\
\hline Furnace & Draft & 442 & $\begin{array}{c}\text { Estimate based on Pre-Analysis } \\
\text { TSD (DOE, 2014b) }\end{array}$ & 100 & Calculated \\
\hline Boiler & Draft & 442 & $\begin{array}{c}\text { Estimate based on Pre-Analysis } \\
\text { TSD (DOE, 2014b) }\end{array}$ & 290 & Pre-analysis TSD (DOE, 2014b) \\
\hline
\end{tabular}




\begin{tabular}{|c|c|c|c|c|c|}
\hline \multirow{2}{*}{$\begin{array}{l}\text { Commercial } \\
\text { Fan }\end{array}$} & \multirow{2}{*}{ Fan Use } & \multicolumn{2}{|c|}{ Annual Operating Hours } & \multicolumn{2}{|r|}{ Average UEC } \\
\hline & & Hours & Sources/Notes & kWh/yr. & Sources/Notes \\
\hline Chiller & $\begin{array}{l}\text { Air-cooled } \\
\text { evaporator }\end{array}$ & 2,000 & Report (DOE-ADL, 1999) & 3500 & (BTO Motors Report, 2013) \\
\hline Cooling Tower & Outdoor & 2,400 & Report (DOE-ADL, 1999) & 20000 & (BTO Motors Report, 2013) \\
\hline CRE & Condenser & 6,600 & $\begin{array}{l}\text { DOE estimates (via BTO } \\
\text { Motors Report, 2013) }\end{array}$ & 1100 & TSD (DOE, 2011a) \\
\hline CRE & Evaporator & 6,600 & $\begin{array}{l}\text { DOE estimates (via BTO } \\
\text { Motors Report, 2013) }\end{array}$ & 300 & TSD (DOE, 2011a) \\
\hline BVM & Condenser & 8,760 & $\begin{array}{l}\text { DOE estimates (via BTO } \\
\text { Motors Report, 2013) }\end{array}$ & 1500 & TSD (DOE, 2009b) \\
\hline BVM & Evaporator & 8,760 & $\begin{array}{l}\text { DOE estimates (via BTO } \\
\text { Motors Report, 2013) }\end{array}$ & 490 & TSD (DOE, 2009b) \\
\hline WICF & Condenser & 4,400 & $\begin{array}{l}\text { DOE estimates (via BTO } \\
\text { Motors Report, 2013) }\end{array}$ & 1900 & TSD (DOE, 2010) \\
\hline WICF & Evaporator & 4,400 & $\begin{array}{l}\text { DOE estimates (via BTO } \\
\text { Motors Report, 2013) }\end{array}$ & 1900 & TSD (DOE, 2010) \\
\hline ACIM & Condenser & 3,700 & $\begin{array}{l}\text { DOE estimates (via BTO } \\
\text { Motors Report, 2013) }\end{array}$ & 550 & TSD (DOE, 2012a) \\
\hline
\end{tabular}

Table 7-3: Data Sources for Residential Pump Operating Hours and UEC

\begin{tabular}{|c|c|c|c|c|c|}
\hline \multirow{2}{*}{$\begin{array}{l}\text { Residential } \\
\text { Pump }\end{array}$} & \multirow{2}{*}{ Pump Use } & \multicolumn{2}{|c|}{ Annual Operating Hours } & \multicolumn{2}{|c|}{ Average UEC } \\
\hline & & Hours & Sources/Notes & kWh/yr. & Sources/Notes \\
\hline $\begin{array}{l}\text { Hydronic heating } \\
\text { (boilers) }\end{array}$ & Circulation & 2520 & $\begin{array}{l}\text { Presentation (ASRAC Pumps } \\
\text { Working Group, 2015) }\end{array}$ & 260 & Calculated \\
\hline $\begin{array}{l}\text { Potable water } \\
\text { pressure }\end{array}$ & Circulation & 5475 & $\begin{array}{l}\text { Presentation (ASRAC Pumps } \\
\text { Working Group, 2015) }\end{array}$ & 560 & Calculated \\
\hline Well pump & Well water & 700 & Report (Smyrna, 2014) & 500 & Calculated \\
\hline Dishwasher & $\begin{array}{l}\text { Circulation } \\
\text { and Drain }\end{array}$ & 215 & TSD (DOE, 2012d) & 110 & TSD (DOE, 2012d) \\
\hline Clothes Washer & Drain & 148 & TSD (DOE, 2012b) & 53 & TSD (DOE, 2012b) \\
\hline Pool pump & Circulation & 1400 & $\begin{array}{l}\text { Report (EPA, 2011); expert } \\
\text { input }\end{array}$ & 1300 & Calculated \\
\hline Geothermal HP & $\begin{array}{c}\text { Loop } \\
\text { circulation }\end{array}$ & 4400 & Report (ASHRAE, 2011) & 900 & Calculated \\
\hline
\end{tabular}

Table 7-4: Data Sources for Commercial Pump Operating Hours and UEC

\begin{tabular}{|c|c|c|c|c|c|}
\hline \multirow{2}{*}{$\begin{array}{l}\text { Commercial } \\
\text { Pump }\end{array}$} & \multirow{2}{*}{ Pump Use } & \multicolumn{2}{|c|}{ Annual Operating Hours } & \multicolumn{2}{|r|}{ Average UEC } \\
\hline & & Hours & Sources/Notes & kWh/yr. & Sources/Notes \\
\hline $\begin{array}{l}\text { Pumps - HVAC \& } \\
\text { Water Supply }\end{array}$ & $\begin{array}{l}\text { Circulation; } \\
\text { pressure }\end{array}$ & $1000-2400$ & NOPR TSD (DOE, 2014d) & 23,000 & NOPR TSD (DOE, 2014d) \\
\hline $\begin{array}{l}\text { Circulators - HVAC } \\
\text { \& Water Supply }\end{array}$ & Circulation & $2500-5500$ & $\begin{array}{c}\text { Based on Report (DOE-ADL, } \\
\text { 1999) and (ASRAC Pumps } \\
\text { Working Group, 2015) }\end{array}$ & 2,000 & $\begin{array}{l}\text { (ASRAC Pumps Working Group, } \\
\text { 2015) }\end{array}$ \\
\hline Pool Pumps & Circulation & 8,760 & Website (Spectra Light, 2015) & 18,000 & Calculated \\
\hline Well Pumps & $\begin{array}{c}\text { Well } \\
\text { pumping }\end{array}$ & $300-2000$ & NOPR TSD (DOE, 2014d) & 13,000 & NOPR TSD (DOE, 2014d) \\
\hline $\begin{array}{l}\text { Commercial Ice } \\
\text { Makers }\end{array}$ & Circulation & 3,700 & TSD (DOE, 2014h) & 180 & TSD (DOE, 2012a) \\
\hline $\begin{array}{l}\text { Commercial } \\
\text { Clothes Washers }\end{array}$ & Drain & 74 & $\begin{array}{c}\text { TSD (DOE, 2012b); Navigant } \\
\text { SME input }\end{array}$ & 53 & TSD (DOE, 2012b) \\
\hline
\end{tabular}




\section{Appendix E - Data Sources for Energy Savings Opportunities}

Table 8-1 - Residential Fan Motors and Controls

\begin{tabular}{lccccc}
\multicolumn{1}{c}{$\begin{array}{c}\text { Residential } \\
\text { Savings } \\
\text { Opportunity }\end{array}$} & Applications & $\begin{array}{c}\text { Est. Energy } \\
\text { Savings (\%) }\end{array}$ & $\begin{array}{c}\text { U.S. Primary } \\
\text { Technical Savings } \\
\text { Potential (Quads) }\end{array}$ & $\begin{array}{c}\text { Est. Purchase } \\
\text { Price Increase }\end{array}$ & Source \\
\hline $\begin{array}{l}\text { Brushless DC } \\
\text { motors or ECMs }\end{array}$ & $\begin{array}{c}\text { Residential } \\
\text { fans in } \\
\text { appliances }\end{array}$ & $10-64 \%$ & 0.5 & $\begin{array}{c}\text { Varies (22\% FFs, } \\
40 \% \text { ceiling) }\end{array}$ & (BTO Motors Report, 2013) \\
$\begin{array}{l}\text { Integrated smart } \\
\text { controls; } \\
\text { occupancy sensor }\end{array}$ & Ceiling fans & $10 \%$ & 0.01 & High (Haiku fan) & Report (BTO, 2012) \\
$\begin{array}{l}\text { Multi-staged } \\
\text { airflows }\end{array}$ & Furnace fans & $10 \%$ & 0.04 & $68 \%$ & TSD (DOE, 2014a) \\
\hline
\end{tabular}

Table 8-2 - Residential Fan Blade Design

\begin{tabular}{lccccc}
\hline \multicolumn{1}{c}{$\begin{array}{c}\text { Residential } \\
\text { Savings } \\
\text { Opportunity }\end{array}$} & Applications & $\begin{array}{c}\text { Est. Energy } \\
\text { Savings (\%) }\end{array}$ & $\begin{array}{c}\text { U.S. Primary } \\
\text { Technical Savings } \\
\text { Potential (Quads) }\end{array}$ & $\begin{array}{c}\text { Est. Purchase } \\
\text { Price Increase }\end{array}$ & Source \\
\hline $\begin{array}{l}\text { Aerodynamic } \\
\text { blade design; } \\
\text { reduce tip gaps }\end{array}$ & $\begin{array}{l}\text { Propeller fans } \\
\text { in appliances }\end{array}$ & $30 \%$ & 0.1 & $2-12 \%$ & Report (SAVE, 2001) \\
$\begin{array}{l}\text { Aerodynamic } \\
\text { blade design }\end{array}$ & Ceiling fans & $36 \%$ & 0.04 & 0 & Pre-Analysis (DOE, 2014f) \\
$\begin{array}{l}\text { Replace FC } \text { with } \\
\text { Bl or airfoil blades }\end{array}$ & Furnace fans & $5 \%$ & 0.02 & $10 \%$ & TSD (DOE, 2014a) \\
\hline
\end{tabular}

Table 8-3 - Residential Fan System

\begin{tabular}{lccccc}
\hline $\begin{array}{c}\text { Residential } \\
\text { Savings } \\
\text { Opportunity }\end{array}$ & Applications & $\begin{array}{c}\text { Est. Energy } \\
\text { Savings (\%) }\end{array}$ & $\begin{array}{c}\text { U.S. Primary } \\
\text { Technical Savings } \\
\text { Potential (Quads) }\end{array}$ & $\begin{array}{c}\text { Est. Purchase } \\
\text { Price Increase }\end{array}$ & Source \\
\hline $\begin{array}{l}\text { Aerodynamic } \\
\text { blade design; } \\
\text { reduce tip gaps }\end{array}$ & $\begin{array}{l}\text { Propeller fans } \\
\text { in appliances }\end{array}$ & $30 \%$ & 0.1 & $2-12 \%$ & Report (SAVE, 2001) \\
$\begin{array}{l}\text { Aerodynamic } \\
\text { blade design }\end{array}$ & Ceiling fans & $36 \%$ & 0.04 & 0 & Pre-Analysis (DOE, 2014f) \\
$\begin{array}{l}\text { Replace FC } \text { with } \\
\text { Bl or airfoil blades }\end{array}$ & Furnace fans & $5 \%$ & 0.02 & $10 \%$ & TSD (DOE, 2014a) \\
\hline
\end{tabular}

\section{Table 8-4 - Commercial Fan Motors and Controls}

\begin{tabular}{lccccc}
\hline $\begin{array}{c}\text { Commercial } \\
\text { Savings } \\
\text { Opportunity }\end{array}$ & Applications & $\begin{array}{r}\text { Est. Energy } \\
\text { Savings (\%) }\end{array}$ & $\begin{array}{c}\text { U.S. Primary } \\
\text { Technical Savings } \\
\text { Potential (Quads) }\end{array}$ & $\begin{array}{c}\text { Est. Purchase } \\
\text { Price Increase }\end{array}$ & Source \\
\hline $\begin{array}{l}\text { ECM or } \\
\text { permanent } \\
\text { magnet motors }\end{array}$ & $\begin{array}{c}\text { Outdoor fans - } \\
\text { Packaged AC units }\end{array}$ & $24 \%$ & 0.04 & (BTO Motors Report, 2013) \\
$\begin{array}{l}\text { ECM or } \\
\text { permanent } \\
\text { magnet motors }\end{array}$ & $\begin{array}{c}\text { Indoor fans - } \\
\text { Packaged AC (excl. } \\
\text { CUAC); draft fans }\end{array}$ & $24 \%$ & 0.01 & (BTO Motors Report, 2013) \\
\hline
\end{tabular}




\begin{tabular}{|c|c|c|c|c|c|}
\hline $\begin{array}{l}\text { Commercial } \\
\text { Savings } \\
\text { Opportunity }\end{array}$ & Applications & $\begin{array}{l}\text { Est. Energy } \\
\text { Savings (\%) }\end{array}$ & $\begin{array}{c}\text { U.S. Primary } \\
\text { Technical Savings } \\
\text { Potential (Quads) }\end{array}$ & $\begin{array}{l}\text { Est. Purchase } \\
\text { Price Increase }\end{array}$ & Source \\
\hline $\begin{array}{l}\text { ECM or } \\
\text { permanent } \\
\text { magnet motors }\end{array}$ & Exhaust Ventilation & $25 \%$ & 0.05 & & (BTO Motors Report, 2013) \\
\hline $\begin{array}{l}\text { ECM or } \\
\text { permanent } \\
\text { magnet motors }\end{array}$ & $\begin{array}{c}\text { Commercial } \\
\text { Refrigeration } \\
\text { (including ACIMS) }\end{array}$ & $60-70 \%$ & 0.1 & & (BTO Motors Report, 2013) \\
\hline VSDs & Clean-air ventilation & See VAVs & & & (BTO Motors Report, 2013) \\
\hline VSDs & $\begin{array}{l}\text { Indoor blower - } \\
\text { CUAC }\end{array}$ & See VAVs & & & (BTO Motors Report, 2013) \\
\hline VSDs & Cooling tower fans & $40 \%$ & 0.02 & & (BTO Motors Report, 2013) \\
\hline $\begin{array}{l}\text { Occupancy sensor } \\
\text { DCV }\end{array}$ & $\begin{array}{l}\text { Clean-air ventilation } \\
\text { (room fan coil units); } \\
\text { packaged AC units } \\
\text { (excluding CUACs) }\end{array}$ & $10-30 \%$ & 0.1 & & Report (PNNL, 2013a) \\
\hline $\begin{array}{l}\text { Replace indirect } \\
\text { drive with direct } \\
\text { drive }\end{array}$ & $\begin{array}{l}\text { Clean-air ventilation; } \\
\text { CUAC indoor } \\
\text { blowers; Cooling } \\
\text { towers }\end{array}$ & $5-15 \%$ & 0.08 & & Report (SAVE, 2001) \\
\hline $\begin{array}{l}\text { Higher efficiency } \\
\text { indirect belt } \\
\text { drives }\end{array}$ & $\begin{array}{c}\text { Clean-air ventilation } \\
\text { fans; CUAC indoor } \\
\text { blowers; Cooling } \\
\text { tower fans }\end{array}$ & $2-5 \%$ & 0.02 & & (DOE-AMO, 2012) \\
\hline
\end{tabular}

Table 8-5 - Commercial Fan Blade or Housing Design and Selection

\begin{tabular}{|c|c|c|c|c|c|}
\hline $\begin{array}{l}\text { Commercial } \\
\text { Savings } \\
\text { Opportunity }\end{array}$ & Applications & $\begin{array}{l}\text { Est. Energy } \\
\text { Savings (\%) }\end{array}$ & $\begin{array}{c}\text { U.S. Primary } \\
\text { Technical Savings } \\
\text { Potential (Quads) }\end{array}$ & $\begin{array}{l}\text { Est. Purchase } \\
\text { Price Increase }\end{array}$ & Source \\
\hline $\begin{array}{l}\text { Aerodynamic } \\
\text { blade design; } \\
\text { reduce tip gaps }\end{array}$ & $\begin{array}{c}\text { Propeller fans - HVAC } \\
\text { applications }\end{array}$ & $11 \%$ & 0.2 & $2-12 \%$ & Report (SAVE, 2001) \\
\hline $\begin{array}{l}\text { Aerodynamic } \\
\text { blade design; } \\
\text { reduce tip gaps }\end{array}$ & $\begin{array}{l}\text { Propeller fans - } \\
\text { appliances }\end{array}$ & $30 \%$ & 0.06 & $2-12 \%$ & Report (SAVE, 2001) \\
\hline $\begin{array}{l}\text { Housing design; } \\
\text { Aerodynamic } \\
\text { wheel/blade; } \\
\text { reduce tip gaps }\end{array}$ & $\begin{array}{l}\text { Centrifugal fans - } \\
\text { HVAC supply fans }\end{array}$ & $7 \%$ & 0.1 & $7-12 \%$ & Report (SAVE, 2001) \\
\hline $\begin{array}{l}\text { Install variable } \\
\text { pitch blades }\end{array}$ & $\begin{array}{l}\text { Larger axial fans - } \\
\text { Clean-air ventilation; } \\
\text { cooling towers }\end{array}$ & $40 \%$ & 0.1 & & Same as VSDs \\
\hline $\begin{array}{l}\text { Replace FC with } \\
\text { Bl or airfoil blades }\end{array}$ & $\begin{array}{l}\text { Centrifugal fans - } \\
\text { small HVAC supply } \\
\text { fans (Small CUAC, } \\
\text { SPVAC, PTAC) }\end{array}$ & $19 \%$ & 0.01 & & Estimated \\
\hline
\end{tabular}


Table 8-6 - Commercial Fan Systems

\begin{tabular}{|c|c|c|c|c|c|}
\hline $\begin{array}{l}\text { Commercial } \\
\text { Savings } \\
\text { Opportunity }\end{array}$ & Applications & $\begin{array}{l}\text { Est. Energy } \\
\text { Savings (\%) }\end{array}$ & $\begin{array}{c}\text { U.S. Primary } \\
\text { Technical Savings } \\
\text { Potential (Quads) }\end{array}$ & $\begin{array}{l}\text { Est. Purchase } \\
\text { Price Increase }\end{array}$ & Source \\
\hline $\begin{array}{l}\text { ECM or } \\
\text { permanent } \\
\text { magnet motors }\end{array}$ & $\begin{array}{c}\text { Outdoor fans - } \\
\text { Packaged AC units }\end{array}$ & $24 \%$ & 0.04 & & (BTO Motors Report, 2013) \\
\hline $\begin{array}{l}\text { ECM or } \\
\text { permanent } \\
\text { magnet motors }\end{array}$ & $\begin{array}{c}\text { Indoor fans - } \\
\text { Packaged AC units } \\
\text { (excluding CUAC); } \\
\text { draft fans }\end{array}$ & $24 \%$ & 0.01 & & (BTO Motors Report, 2013) \\
\hline $\begin{array}{l}\text { ECM or } \\
\text { permanent } \\
\text { magnet motors }\end{array}$ & Exhaust Ventilation & $25 \%$ & 0.05 & & (BTO Motors Report, 2013) \\
\hline $\begin{array}{l}\text { ECM or } \\
\text { permanent } \\
\text { magnet motors }\end{array}$ & $\begin{array}{c}\text { Commercial } \\
\text { Refrigeration } \\
\text { (including ACIMS) }\end{array}$ & $60-70 \%$ & 0.1 & & (BTO Motors Report, 2013) \\
\hline VSDs & Clean-air ventilation & See VAVs & & & (BTO Motors Report, 2013) \\
\hline VSDs & $\begin{array}{l}\text { Indoor blower - } \\
\text { CUAC }\end{array}$ & See VAVs & & & (BTO Motors Report, 2013) \\
\hline VSDs & Cooling tower fans & $40 \%$ & 0.02 & & (BTO Motors Report, 2013) \\
\hline $\begin{array}{l}\text { Occupancy sensor } \\
\text { DCV }\end{array}$ & $\begin{array}{c}\text { Clean-air ventilation } \\
\text { (room fan coil units); } \\
\text { packaged AC units } \\
\text { (excluding CUACs) }\end{array}$ & $10-30 \%$ & 0.1 & & Report (PNNL, 2013a) \\
\hline $\begin{array}{l}\text { Replace indirect } \\
\text { drive with direct } \\
\text { drive }\end{array}$ & $\begin{array}{l}\text { Clean-air ventilation } \\
\text { fans; CUAC indoor } \\
\text { blowers; Cooling } \\
\text { tower fans }\end{array}$ & $5-15 \%$ & 0.08 & & Report (SAVE, 2001) \\
\hline $\begin{array}{l}\text { Higher efficiency } \\
\text { indirect belt } \\
\text { drives }\end{array}$ & $\begin{array}{c}\text { Clean-air ventilation } \\
\text { fans; CUAC indoor } \\
\text { blowers; Cooling } \\
\text { tower fans }\end{array}$ & $2-5 \%$ & 0.02 & & (DOE-AMO, 2012) \\
\hline
\end{tabular}

Table 8-7 - Commercial Fan Maintenance

\begin{tabular}{|c|c|c|c|c|c|}
\hline $\begin{array}{l}\text { Commercial } \\
\text { Savings } \\
\text { Opportunity }\end{array}$ & Applications & $\begin{array}{l}\text { Est. Energy } \\
\text { Savings (\%) }\end{array}$ & $\begin{array}{c}\text { U.S. Primary } \\
\text { Technical Savings } \\
\text { Potential (Quads) }\end{array}$ & $\begin{array}{l}\text { Est. Purchase } \\
\text { Price Increase }\end{array}$ & Source \\
\hline $\begin{array}{l}\text { Ensure proper } \\
\text { maintenance (belt } \\
\text { drives, bearings, } \\
\text { motors) }\end{array}$ & $\begin{array}{l}\text { All HVAC-related } \\
\text { fan applications }\end{array}$ & $5-20 \%$ & 0.1 & & $\begin{array}{c}\text { Report (SAVE, 2001), } \\
\text { Guidebook (DOE-EERE, } \\
\text { 2003) }\end{array}$ \\
\hline
\end{tabular}

\section{Table 8-8 - Residential Pump Motors and Controls}

\begin{tabular}{lccccc}
\hline $\begin{array}{c}\text { Residential } \\
\text { Savings } \\
\text { Opportunity }\end{array}$ & Applications & $\begin{array}{c}\text { Est. Energy } \\
\text { Savings (\%) }\end{array}$ & $\begin{array}{c}\text { U.S. Primary } \\
\text { Technical Savings } \\
\text { Potential (Quads) }\end{array}$ & $\begin{array}{c}\text { Est. Purchase } \\
\text { Price Increase }\end{array}$ & Source \\
\hline ECMs & $\begin{array}{c}\text { All non- } \\
\text { appliance } \\
\text { circulators }\end{array}$ & $40 \%$ & 0.02 & $177 \%$ & (ASRAC Pumps Working Group, \\
ECMs & Dishwashers & $10 \%$ & 0.01 & - & 2015) \\
VSDs & Pool pumps & $82 \%$ & 0.06 & $275 \%$ & (BTO Motors Report, 2013) \\
\hline
\end{tabular}




\begin{tabular}{|c|c|c|c|c|c|}
\hline $\begin{array}{l}\text { Residential } \\
\text { Savings } \\
\text { Opportunity }\end{array}$ & Applications & $\begin{array}{l}\text { Est. Energy } \\
\text { Savings (\%) }\end{array}$ & $\begin{array}{c}\text { U.S. Primary } \\
\text { Technical Savings } \\
\text { Potential (Quads) }\end{array}$ & $\begin{array}{l}\text { Est. Purchase } \\
\text { Price Increase }\end{array}$ & Source \\
\hline $\begin{array}{l}\text { "Smart" controls; } \\
\text { auto-adapting } \\
\text { controls (uses } \\
\text { ECMs) }\end{array}$ & $\begin{array}{l}\text { Hydronic } \\
\text { heating }\end{array}$ & $70 \%$ & 0.02 & $50-250 \%$ & $\begin{array}{l}\text { Article (Environmental, 2010); } \\
\text { White Paper (Armstrong, 2015) }\end{array}$ \\
\hline $\begin{array}{l}\text { "Connected" } \\
\text { functionality; } \\
\text { ability to } \\
\text { interface with } \\
\text { home energy } \\
\text { management } \\
\text { device }\end{array}$ & Pool pumps & None & & & \\
\hline
\end{tabular}

\section{Table 8-9 - Residential Pump Design}

\begin{tabular}{|c|c|c|c|c|c|}
\hline $\begin{array}{l}\text { Residential } \\
\text { Savings } \\
\text { Opportunity }\end{array}$ & Applications & $\begin{array}{l}\text { Est. Energy } \\
\text { Savings (\%) }\end{array}$ & $\begin{array}{c}\text { U.S. Primary } \\
\text { Technical Savings } \\
\text { Potential (Quads) }\end{array}$ & $\begin{array}{l}\text { Est. Purchase } \\
\text { Price Increase }\end{array}$ & Source \\
\hline $\begin{array}{l}\text { Hydraulic } \\
\text { redesign }\end{array}$ & $\begin{array}{l}\text { Non-appliance } \\
\text { circulators; } \\
\text { pool pumps; } \\
\text { well pumps }\end{array}$ & $4 \%$ & 0.008 & $21 \%$ & $\begin{array}{l}\text { Used commercial data from } \\
\text { NOPR-TSD (DOE, 2014c) }\end{array}$ \\
\hline $\begin{array}{l}\text { Hydraulic } \\
\text { redesign }\end{array}$ & $\begin{array}{c}\text { Appliances } \\
\text { (DW and RCW) }\end{array}$ & $4 \%$ & 0.007 & & $\begin{array}{l}\text { Used commercial data from } \\
\text { NOPR-TSD (DOE, 2014c) }\end{array}$ \\
\hline
\end{tabular}

\section{Table 8-10 - Residential Pump Systems}

\begin{tabular}{llcccc}
\hline $\begin{array}{c}\text { Residential } \\
\text { Savings } \\
\text { Opportunity }\end{array}$ & Applications & $\begin{array}{c}\text { Est. Energy } \\
\text { Savings (\%) }\end{array}$ & $\begin{array}{c}\text { U.S. Primary } \\
\text { Technical Savings } \\
\text { Potential (Quads) }\end{array}$ & $\begin{array}{c}\text { Est. Purchase } \\
\text { Price Increase }\end{array}$ & Source \\
\hline $\begin{array}{l}\text { Better sizing } \\
\text { selection }\end{array}$ & $\begin{array}{c}\text { Non-appliance } \\
\text { circulators }\end{array}$ & $20 \%$ & 0.005 & $\begin{array}{c}\text { None (for new); } \\
\text { same as } \\
\text { replacement } \\
\text { (for retrofit) }\end{array}$ & $\begin{array}{c}\text { Used commercial data from } \\
\text { Article (EEP, 2014) }\end{array}$ \\
\hline
\end{tabular}

\section{Table 8-11: Commercial Pump Motors and Controls}

\begin{tabular}{|c|c|c|c|c|c|}
\hline $\begin{array}{l}\text { Commercial } \\
\text { Savings } \\
\text { Opportunity }\end{array}$ & Applications & $\begin{array}{l}\text { Est. Energy } \\
\text { Savings (\%) }\end{array}$ & $\begin{array}{c}\text { U.S. Primary } \\
\text { Technical Savings } \\
\text { Potential (Quads) }\end{array}$ & $\begin{array}{c}\text { Est. Purchase } \\
\text { Price } \\
\text { Increase }\end{array}$ & Source \\
\hline $\begin{array}{l}\text { High efficiency } \\
\text { NEMA Premium } \\
\text { Motor ( } 3 \text { phase } \\
\text { AC) }\end{array}$ & $\begin{array}{l}\text { Pumps for HVAC \& } \\
\text { Water Supply; Well } \\
\text { pumps }\end{array}$ & $3 \%$ & 0.02 & & (BTO Motors Report, 2013) \\
\hline ECMs & $\begin{array}{l}\text { Circulators for HVAC } \\
\text { \& Water Supply }\end{array}$ & $20 \%$ & 0.004 & $177 \%$ & $\begin{array}{l}\text { (ASRAC Pumps Working } \\
\text { Group, 2015) }\end{array}$ \\
\hline ECMs & $\begin{array}{l}\text { Commercial Ice } \\
\text { Makers }\end{array}$ & $71 \%$ & 0.002 & & (BTO Motors Report, 2013) \\
\hline VSDs & $\begin{array}{l}\text { Pumps for HVAC \& } \\
\text { Water Supply }\end{array}$ & & \multicolumn{2}{|c|}{ Please refer to Table 7-13 } & \\
\hline VSDs & Pool Pumps & $41 \%$ & 0.02 & $275 \%$ & $\begin{array}{l}\text { Adapted from Report (EPA, } \\
\text { 2011) }\end{array}$ \\
\hline
\end{tabular}




\begin{tabular}{|c|c|c|c|c|c|}
\hline $\begin{array}{l}\text { Commercial } \\
\text { Savings } \\
\text { Opportunity }\end{array}$ & Applications & $\begin{array}{l}\text { Est. Energy } \\
\text { Savings (\%) }\end{array}$ & $\begin{array}{c}\text { U.S. Primary } \\
\text { Technical Savings } \\
\text { Potential (Quads) }\end{array}$ & $\begin{array}{c}\text { Est. Purchase } \\
\text { Price } \\
\text { Increase }\end{array}$ & Source \\
\hline $\begin{array}{l}\text { "Smart" controls; } \\
\text { auto-adapting } \\
\text { controls (uses } \\
\text { ECMs) }\end{array}$ & $\begin{array}{l}\text { Circulators for HVAC } \\
\text { \& Water Supply }\end{array}$ & $70 \%$ & 0.01 & $50-250 \%$ & $\begin{array}{l}\text { Article (Environmental, } \\
\text { 2010); White Paper } \\
\text { (Armstrong, 2015) }\end{array}$ \\
\hline $\begin{array}{l}\text { "Connected" } \\
\text { functionality; } \\
\text { ability to } \\
\text { interface with } \\
\text { building energy } \\
\text { management } \\
\text { device }\end{array}$ & $\begin{array}{c}\text { Pumps and } \\
\text { circulators for HVAC } \\
\text { \& Water Supply; } \\
\text { Well pumps }\end{array}$ & None & - & & \\
\hline
\end{tabular}

Table 8-12: Commercial Pump Design

\begin{tabular}{|c|c|c|c|c|c|}
\hline $\begin{array}{l}\text { Commercial } \\
\text { Savings } \\
\text { Opportunity }\end{array}$ & Applications & $\begin{array}{l}\text { Est. Energy } \\
\text { Savings (\%) }\end{array}$ & $\begin{array}{c}\text { U.S. Primary } \\
\text { Technical Savings } \\
\text { Potential (Quads) }\end{array}$ & $\begin{array}{l}\text { Est. Purchase } \\
\text { Price Increase }\end{array}$ & Source \\
\hline $\begin{array}{l}\text { Hydraulic } \\
\text { redesign }\end{array}$ & $\begin{array}{l}\text { All non-appliance } \\
\text { pump applications }\end{array}$ & $4 \%$ & 0.03 & $21 \%$ & NOPR-TSD (DOE, 2014c) \\
\hline $\begin{array}{l}\text { Smoother pump } \\
\text { surfaces }\end{array}$ & $\begin{array}{c}\text { All non-appliance } \\
\text { pump applications } \\
\text { (excluding well } \\
\text { pumps) }\end{array}$ & $0.1 \%$ & 0.001 & & NOPR-TSD (DOE, 2014c) \\
\hline $\begin{array}{l}\text { Lower friction } \\
\text { bearings } \\
\text { (including } \\
\text { magnetic } \\
\text { bearings) }\end{array}$ & $\begin{array}{c}\text { Pumps - HVAC \& } \\
\text { Water Supply }\end{array}$ & $3.5 \%$ & 0.02 & High & $\begin{array}{l}\text { Presentation (McQuay, } \\
\text { 2015) }\end{array}$ \\
\hline Impeller trimming & $\begin{array}{c}\text { Pumps - HVAC \& } \\
\text { Water Supply }\end{array}$ & $5 \%$ & 0.01 & None & $\begin{array}{l}\text { Abstract (Savar, M. et al. } \\
\text { 2009) }\end{array}$ \\
\hline
\end{tabular}

Table 8-13 - Commercial Pump Systems

\begin{tabular}{|c|c|c|c|c|c|}
\hline $\begin{array}{l}\text { Commercial } \\
\text { Savings } \\
\text { Opportunity }\end{array}$ & Applications & $\begin{array}{l}\text { Est. Energy } \\
\text { Savings (\%) }\end{array}$ & $\begin{array}{c}\text { U.S. Primary } \\
\text { Technical Savings } \\
\text { Potential (Quads) }\end{array}$ & $\begin{array}{l}\text { Est. Purchase } \\
\text { Price Increase }\end{array}$ & Source \\
\hline $\begin{array}{l}\text { Variable flow } \\
\text { system (VSDs } \\
\text { required) }\end{array}$ & $\begin{array}{c}\text { Pumps and } \\
\text { circulators for HVAC } \\
\text { \& Water Supply }\end{array}$ & $40 \%$ & 0.13 & High & $\begin{array}{l}\text { White Paper (Armstrong, } \\
\text { 2015) }\end{array}$ \\
\hline $\begin{array}{l}\text { Better pump } \\
\text { sizing selection }\end{array}$ & $\begin{array}{l}\text { All non-appliance } \\
\text { pump applications }\end{array}$ & $20 \%$ & 0.08 & $\begin{array}{l}\text { None (for } \\
\text { new); same as } \\
\text { replacement } \\
\text { (for retrofit) }\end{array}$ & Article (EEP, 2014) \\
\hline $\begin{array}{l}\text { Better piping } \\
\text { configurations } \\
\text { (pipe size, } \\
\text { efficient fittings) }\end{array}$ & $\begin{array}{l}\text { All non-appliance } \\
\text { pump applications }\end{array}$ & $20 \%$ & 0.09 & $\begin{array}{l}\text { Depends on } \\
\text { length of piping } \\
\text { and piping } \\
\text { network }\end{array}$ & Fact sheet (WRF, 2015) \\
\hline $\begin{array}{l}\text { Pipe } \\
\text { linings/coatings }\end{array}$ & $\begin{array}{c}\text { Pumps and } \\
\text { circulators for HVAC } \\
\text { \& Water Supply }\end{array}$ & $15 \%$ & 0.04 & $\begin{array}{l}50 \% \text { less } \\
\text { expensive than } \\
\text { pipe } \\
\text { replacements } \\
\text { (Nu Flow) }\end{array}$ & $\begin{array}{l}\text { Estimated from Article (DOE- } \\
\text { Office of Industrial } \\
\text { Technologies, 2011); costs } \\
\text { from Webpage (Nu Flow, } \\
\text { 2015) }\end{array}$ \\
\hline
\end{tabular}




\section{Table 8-14 - Commercial Pump Maintenance}

\begin{tabular}{lccccc}
\hline $\begin{array}{c}\text { Commercial } \\
\begin{array}{c}\text { Savings } \\
\text { Opportunity }\end{array}\end{array}$ & Applications & $\begin{array}{r}\text { Est. Energy } \\
\text { Savings (\%) }\end{array}$ & $\begin{array}{c}\text { U.S. Primary } \\
\text { Technical Savings } \\
\text { Potential (Quads) }\end{array}$ & $\begin{array}{c}\text { Est. Purchase } \\
\text { Price Increase }\end{array}$ & Source \\
\hline $\begin{array}{l}\text { Correction of } \\
\text { common pumping } \\
\text { problems (e.g. } \\
\begin{array}{l}\text { leakage, valves, } \\
\text { cavitation, seals }\end{array}\end{array}$ & $\begin{array}{l}\text { All non-appliance } \\
\text { pump applications }\end{array}$ & $10 \%$ & 0.03 & None & Report (AEAT, 2001) \\
\hline
\end{tabular}




\section{Appendix F - Motor Technology Overview}

(Direct extraction from BTO Motors Report - please refer to that document for further details)

A variety of electric motor types are available for use in the residential and commercial sectors, employing a range of methods to convert electrical energy into mechanical energy. Choice of motor type is often determined by cost or the specific application or load; efficiency and energy savings potential are often secondary considerations.

This section describes existing motor technologies that are commonly found in residential or commercial applications and describes some of the advantages of using each technology. The section is generally organized by increasing technological complexity starting with a discussion of simple, low horsepower single-phase alternating current (AC) induction motors and universal motors. Residential and small commercial buildings are typically supplied with three-wire single phase power, making single-phase motors suitable for residential and low-horsepower commercial applications.

The discussion moves to three-phase AC induction motors. Three-phase power service is common in the commercial sector where large horsepower motors and drives are necessary. The section finishes with descriptions of more advanced motor-drive systems as well as recent innovations that could lead to reduced motor-driven system and component energy consumption. The discussion of each technology is not exhaustive, but characterizes the general operating principles of each device.

\subsection{Single-Phase AC Induction Motors}

Alternating current induction motors operate using the principle of electromagnetic induction to produce a motor torque. The stator and rotor make up the two primary motor components, as shown in Figure 2.1. The stator, or stationary portion of the motor, is formed by layers of steel laminations. The stator has a hollow core with slots for conductive material along its interior known as poles. This conductive material is typically composed of wound, insulated copper wire. The rotor, or rotating portion of the motor, is positioned inside the stator's hollow core and is separated from the stator by an air gap. The rotor is also composed of layered steel laminations that are attached to the motor shaft. Slots on the outer surface of the rotor also contain copper windings or, in the case of the squirrel cage induction motor, conductive bars of aluminum or copper that are joined by rings at their lengthwise ends (ADL, 1999). 


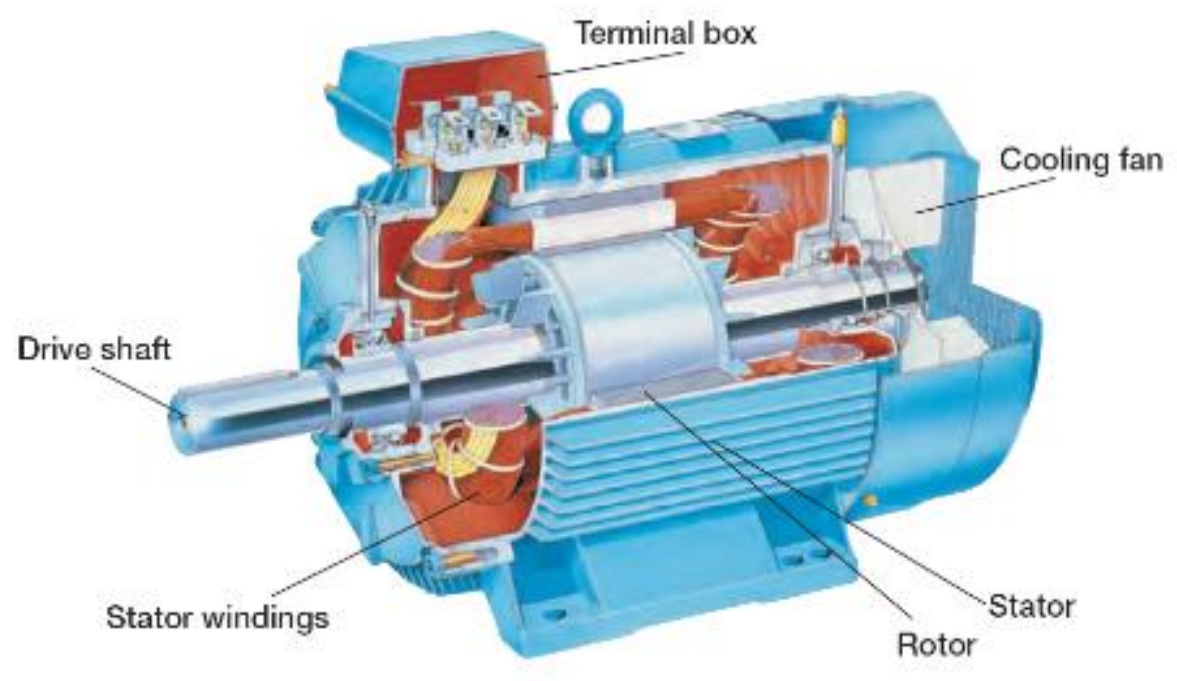

Figure 9-1 Squirrel Cage AC Induction Motor

Source: http://www.enggcyclopedia.com/2012/09/squirrel-cage-induction-motors/

When a single-phase induction motor is energized, a magnetic field is generated that rotates at a speed dependent on the number of magnetic poles and the electrical input frequency. The number of poles is controlled by the configuration of the windings in the stator. The movement of the stator's magnetic field in relation to the rotor induces a current in the rotor. The induced current in the rotor produces a magnetic field of polarity opposite that of the stator. The interaction of the two magnetic fields results in a torque that turns the rotor and the motor shaft.

Efficiency losses in the motor include resistive losses in the stator or rotor that are dissipated as heat. Hysteresis and eddy current losses in the stator's steel laminations occur due to the type and quality of the steel and the thickness of the laminations. Efficiency losses also result from friction in the bearings and shaft seals (NEMA, 2001).

In general, as motor horsepower increases, the efficiency of the motor at full load also increases. This is partially due to the difficulty in dissipating heat in smaller motors. Higher horsepower motors also operate close to peak efficiency for a wide range of loading conditions (NEMA, 2001). Low-horsepower motors with lighter loads can have wide ranges of efficiency, meaning that under-loading the motor can significantly impact performance.

If the rotor were to turn at speed synchronous to the rotating magnetic field of the stator, no torque would be generated. Instead, the rotor operates at a speed slightly slower than synchronous speed. The difference between actual and synchronous speed is called slip. As an example, a two-pole motor supplied by a $60 \mathrm{~Hz}$ power source would have a synchronous speed of 3,600 $\mathrm{rpm}^{212}$. Due to slip, the rotor would actually have an operating speed closer to 3,500 rpm. Hence, induction motors are often called asynchronous motors. This slight difference in speed between the stator magnetic field and rotor provides the torque necessary to sustain rotation.

\footnotetext{
${ }^{212}$ Motor synchronous speed: $\mathrm{RPM}=2 \times 60 \times(\mathrm{f} / \mathrm{n})$; where $\mathrm{f}=$ frequency, $\mathrm{n}=\#$ of poles
} 
Single-phase induction motors require additional components in order to start. If a single-phase motor without any additional components was energized by a single-phase source, a pulsating magnetic field, instead of a rotating field, would result. This pulsating field would generate counteracting torque that would cause the rotor to remain static. Instead, in addition to the primary winding, single-phase motors have either a copper coil wrapped around the stator poles or a secondary winding, often called an auxiliary or start winding, which provides a delay in current to part of the motor's poles. The resulting asymmetric magnetic field produces the starting torque, which initiates rotation of the rotor in the desired direction. Once rotating, torque can be sustained by the primary winding alone. The addition of an auxiliary winding causes single-phase motors to experience fluctuations in torque that impact their efficiency. While a single-phase induction motor may appear to operate smoothly due to the inertia of the motor's rotor for small loads, single-phase motors suffer up to a $10 \%$ loss in efficiency compared to their three-phase counterparts (ADL, 1999). Single-phase power is found most often in homes and is used in commercial buildings for fractional horsepower systems.

A single-phase induction motor is often classified by the mechanism used to generate the rotating magnetic field. Table 2.1 provides a summary of the single-phase induction motors covered in this section, their peak efficiencies, and the relative cost of the single-phase motors to one another (Fans \& Blowers Twin City).

Table 9-1 Summary of Single-Phase AC Induction Motor Characteristics

\begin{tabular}{|l|c|c|c|}
\hline \multicolumn{1}{|c|}{$\begin{array}{c}\text { Single-phase Induction } \\
\text { Motor Type }\end{array}$} & $\begin{array}{c}\text { Peak } \\
\text { Efficiency } \\
\text { Range }\end{array}$ & Starting Torque & Relative Cost \\
\hline Shaded-Pole & $20-40 \%$ & Medium & $\begin{array}{c}\text { Least expensive } \\
\$\end{array}$ \\
\hline $\begin{array}{l}\text { Resistance Start Induction } \\
\text { Run (RSIR) }\end{array}$ & $50-60 \%$ & High & $\$ \$$ \\
\hline $\begin{array}{l}\text { Capacitor Start Induction } \\
\text { Run (CSIR) }\end{array}$ & $50-60 \%$ & Low & $\$ \$$ \\
\hline $\begin{array}{l}\text { Permanent Split Capacitor } \\
\text { (PSC) }\end{array}$ & $50-70 \%$ & High & Most expensive \\
\hline $\begin{array}{l}\text { Capacitor Split Capacitor } \\
\text { Run (CSCR) }\end{array}$ & $50-70 \%$ & $\$ \$$ \\
\hline
\end{tabular}

The following sections provide a description of the most common single-phase induction motors found in residential and commercial applications. Three-phase AC induction motors are discussed in Section 2.3.

\subsubsection{Shaded-Pole Motor}

Shaded-pole motors have a main winding and an additional copper coil, or shading coil, wrapped around the stator poles. Current induced in the shading coil creates the phase lag needed to produce the rotating magnetic field. These motors provide low starting torques and are one of the least expensive, least efficient single-phase configurations. Shaded-pole motors are most often used in small, fractional horsepower systems. One common application is multi-speed household fans, where speed is controlled through a multi-tap winding that allow the motor to operate at 
multiple speeds. (Heinecke). Shaded-pole motors are increasingly being replaced by other more advanced motor technologies that are more efficient. In stand-alone residential refrigeration units that use shaded-pole motors to drive evaporator fans or compressors, shaded-pole motors were found to be only 15-30\% efficient (Blackburn, 2012). Shaded-pole motors also rotate only in one direction, a disadvantage for systems that need to run in reverse, such as heat pump compressors, and can only be reversed by physically flipping the stator to switch the motor poles.

\subsubsection{Resistance Start Induction Run}

The resistance start induction run (RSIR) motor incorporates an auxiliary winding at a 90-degree angle to the primary winding to impart the rotational energy needed to start the motor. An example schematic is provided in Figure 2.2. The auxiliary winding is usually composed of a higher gauge (smaller diameter) wire with a higher resistance than the primary stator winding. The higher resistance provides the time delay needed to generate the rotating magnetic field. Once started, the auxiliary winding is de-energized via a centrifugal switch. RSIR motors are only suitable for applications requiring low starting torque (GRUNDFOS, 2004). Typical applications of RSIR motors include compressor motors for home refrigerators and freezers or dehumidifiers (Tecumseh).

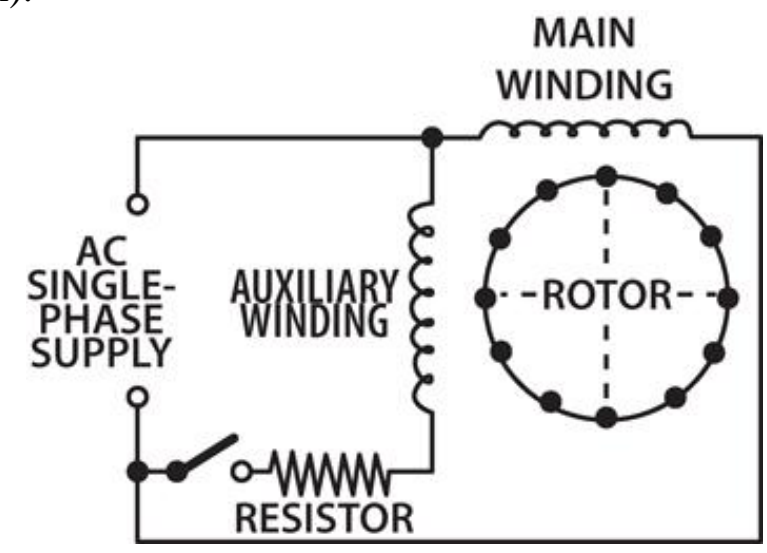

Figure 9-2 Resistance Start Induction Run Schematic

Source: http://www.pump-zone.com/topics/motors/ac-motors-part-3-single-phase-operation-0

\subsubsection{Capacitor Start Induction Run}

A capacitor start induction run (CSIR) motor also employs an auxiliary winding to impart the rotational energy needed to start the motor. The auxiliary winding is connected in series to a capacitor and switch. The capacitor delays the flow of current between the two windings and also helps provide a higher starting torque for applications with a high start load. Once the motor reaches speed, the switch connecting the auxiliary winding and capacitor to the primary winding opens and removes the auxiliary winding from the circuit (GRUNDFOS, 2004). CSIR motors are typically used in refrigeration compressors (GRUNDFOS, 2004). 


\subsubsection{Permanent Split Capacitor}

A permanent split capacitor (PSC) motor has a capacitor and auxiliary winding joined in series, but, unlike the CSIR, no switch separates the primary and auxiliary windings. Without the switch, the auxiliary winding remains energized throughout operation. PSCs are the current industry standard for HVAC applications and are gaining popularity in all residential appliances. An example schematic is provided in Figure 2.3.

PSCs can be designed to be more efficient at the application's rated load compared to CSIR motors. Many PSCs used in HVAC applications are designed with "speed taps" that allow the motor to operate at multiple speeds. These taps are connected at various points along the primary and auxiliary windings so that voltage, and hence speed, can be changed in set increments. While speed taps can make the PSC more versatile than other simpler motor types, the added functionality is not typically used for speed control. Rather it is a method for installers to adapt the system to installed conditions by selecting a motor speed that most closely matches the system load (Michael, 2009).

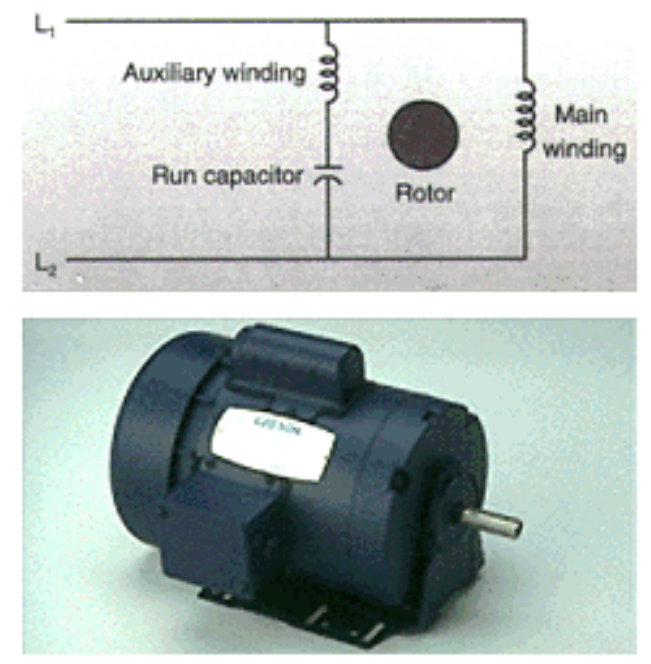

Figure 9-3 Permanent Split Capacitor Motor

Source: http://www.leeson.com/TechnicalInformation/sphase.html

\subsubsection{Capacitor Start Capacitor Run}

A capacitor start capacitor run (CSCR) motor has a run capacitor and auxiliary winding connected permanently in series, similar to that of a PSC. CSCR motors also have a start capacitor and switch (similar to that of a CSIR) connected in series with the start winding, to offer a high starting torque. An example schematic is provided in Figure 2.4.

The combination of the two configurations makes the CSCR more expensive than other singlephase motors, but also more efficient across the full range of operation. The start capacitor has a high capacitance and helps provide a high starting torque, while the run capacitor has a lower capacitance and helps smooth out any torque pulsations during operation. The sizing of the capacitors is optimized to match the expected starting loads and run loads (ADL, 1999). Due to 
their higher cost compared to simpler motor types, CSCR motors are typically only used in systems with large loads that require high starting torque.

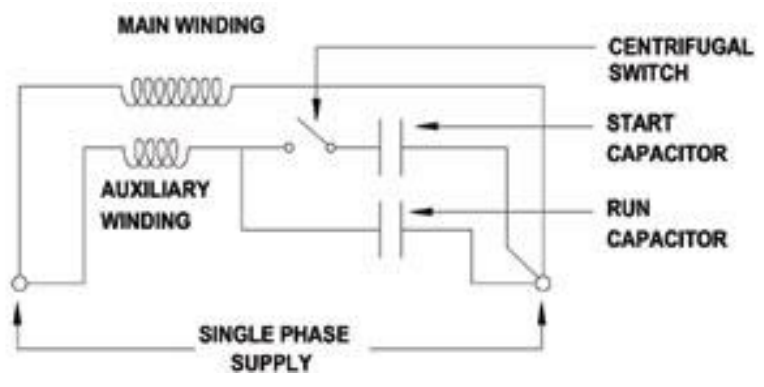

Figure 9-4 Capacitor Start Capacitor Run

Source: http://www.acpd.co.uk/cw-single-phase-motors.html

\subsection{Universal Motor}

Universal motors are also known as series-wound commutated motors. The windings of the stator are connected in series to the windings in the rotor, typically through a brush-type commutator that reverses the direction of current as the motor rotates to generate constant torque. Universal motors can operate with either AC or direct current (DC) electrical input because the same current that establishes the stator magnetic field also flows through the rotor. As the AC supply alternates, so will the current through the rotor.

The universal motor is commonly used in AC applications because it offers certain desirable features more common to DC motors. For example, universal motors can operate at much higher speeds than are typical of AC induction motors, which are limited by line frequency. Universal motors also provide a high starting torque and can have a more compact design than their induction counterparts. They are commonly used in applications requiring demanding highspeed, intermittent operation, such as vacuum cleaners, power tools, or food mixers. These devices often operate between 15,000 and 20,000 rpm, while basic AC induction motors generally cannot operate over 3,500 rpm (ADL, 1999).

A disadvantage to using universal motors is the limited lifespan of the brush or commutator. The mechanical commutation can also cause the potential for electromagnetic interference and sparking. Historically, universal motors offered an inexpensive way to achieve high-speed operation for small devices, despite these downsides. However, as high-frequency inverter drives (used with permanent magnet and induction motors) become more readily available, the market is transitioning away from universal motors (Hughes et al. 2013). 


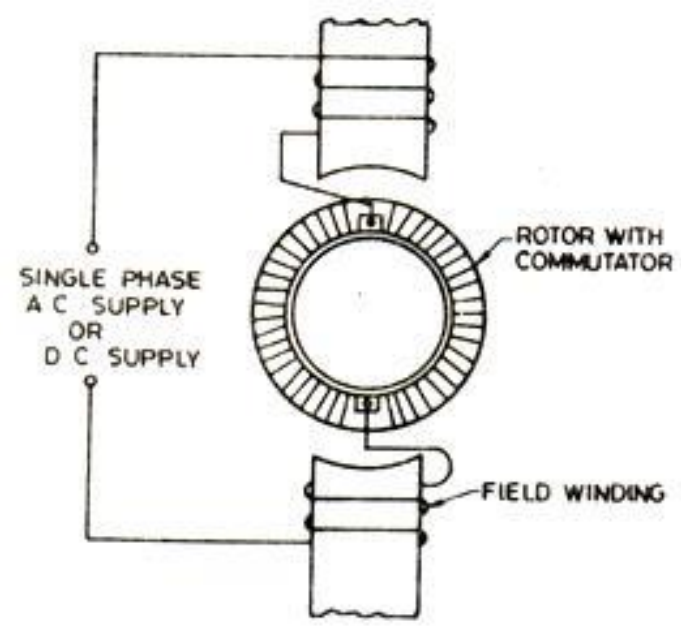

Figure 9-5 Universal (Series) Motor

Source: http://www.transtutors.com/homework-help/electrical-engineering/single-phase-ac-motors/universalmotor.aspx

\subsection{Three-phase AC induction motors}

Three-phase induction motors are similar in construction to single-phase induction motors, except that the stator contains three distinct windings per motor pole. This configuration eliminates the need for an auxiliary winding to provide the starting torque. The rotating speed of the motor is determined by the frequency of the power input and the number of poles in the stator; a larger number of poles will decrease the rotation speed. Three-phase induction motors require a three-phase power source, which is available in most commercial buildings where large loads are expected. The three-phase induction motor is generally considered reliable when compared to more advanced technologies due to its technological maturity and length of time in the marketplace.

Three-phase induction motors most commonly have an "open" configuration or a totally enclosed fan-cooled (TEFC) configuration. TEFC motors are designed with a fan attached to one end of the rotor and are covered by a sealed enclosure so that contaminants cannot enter. TEFC motors are common in the commercial and industrial sectors where the enclosure provides protection in applications such as pumps, fans, and blowers that are subject to harsh conditions. Because these applications have loads that are highly dependent on individual system design, three-phase induction motors are typically offered in two-, four-, or six-pole configurations for a variety of possible speeds. Three-phase induction motors generally operate with less than 5\% slip (NEMA, 2001).

The Energy Policy and Conservation Act (EPCA), as amended, established a minimum energy conservation standard for certain types of electric motors that became effective in 1997. In 2007, EPCA was amended by the Energy Independence and Security Act of 2007 (EISA) which both expanded the scope of motors covered by the regulation, and increased the minimum efficiency requirements, replacing them with the National Electrical Manufacturers Association (NEMA) Premium Efficiency levels. 
These minimum allowable electric motor full load efficiencies are provided for select horsepower in Table 9-2. Covered electric motors manufactured either as a component or standalone product after 2010 must meet or exceed these efficiency levels.

Table 9-2 Full-Load Efficiencies for General Purpose Electric Motors [Subtype I] (DOE, 2012f)

\begin{tabular}{|l|l|l|l|l|l|l|}
\hline \multirow{2}{*}{$\begin{array}{l}\text { Motor } \\
\text { Horsepower }\end{array}$} & \multicolumn{5}{|c|}{ Openinal Full Load Efficiency (\%) } \\
\cline { 2 - 7 } & \multicolumn{3}{|c|}{ (Number of Poles) } & \multicolumn{3}{c|}{ Enclosed Motors } \\
\cline { 2 - 7 } & 6 & 4 & 2 & 6 & 4 & 2 \\
\hline 1 & 82.5 & 85.5 & 77 & 82.5 & 85.5 & 77 \\
\hline 3 & 88.5 & 89.5 & 85.5 & 89.5 & 89.5 & 86.5 \\
\hline 5 & 89.5 & 89.5 & 86.5 & 89.5 & 89.5 & 88.5 \\
\hline 7.5 & 90.2 & 91 & 88.5 & 91 & 91.7 & 89.5 \\
\hline 10 & 91.7 & 91.7 & 89.5 & 91 & 91.7 & 90.2 \\
\hline 25 & 93 & 93.6 & 91.7 & 93 & 93.6 & 91.7 \\
\hline 50 & 94.1 & 94.5 & 93 & 94.1 & 94.5 & 93 \\
\hline 100 & 95 & 95.4 & 93.6 & 95 & 95.4 & 94.1 \\
\hline 125 & 95 & 95.4 & 94.1 & 95 & 95.4 & 95 \\
\hline 150 & 95.4 & 95.8 & 94.1 & 95.8 & 95.8 & 95 \\
\hline 200 & 95.4 & 95.8 & 95 & 95.8 & 96.2 & 95.4 \\
\hline & & & & & & \\
\hline
\end{tabular}

The electric motors covered under the regulation are general purpose, single-speed, polyphase, two, four, six, or eight pole induction motors of NEMA Design A, B, or C. The covered range of horsepower for NEMA Design B motors is 1 to 500 and 1 to 200 for Design A and C. Open dripproof (ODP), explosion proof, and TEFC configurations are all covered. The increase in efficiency between 1997 levels and 2010 is approximately 1-4\% depending on the motor's horsepower.

The efficiency of three-phase induction motors can be increased to meet or exceed the EPCA/NEMA Premium levels through optimization of rotor and stator design. The availability of die-cast copper rotors for squirrel cage induction motors has also enabled improvements in induction motor efficiency. Copper is more conductive than aluminum by approximately $70 \%$. Increased conductivity means fewer thermal losses in the rotor. Using a die-cast copper rotor also means less material is required to maintain the same power and efficiency as an aluminum rotor and thus the motor can be made smaller (Baldwin, 2012). With fewer thermal losses, additions like cooling fins at the end of the rotor can be eliminated and further decrease size. There are concerns that the increased weight of copper, as compared to aluminum, will require the motor to overcome higher inertia at start (Baldwin, 2012). However, studies have shown that since a copper rotor also allows for a shorter stack length (of steel laminations), the added weight is negated by the reduced rotor (Mechler, 2010). Generally, copper die-cast rotors are available for three-phase induction motors from 1 to $30 \mathrm{hp}$. 
Small electric motors are also covered by EPCA, as amended, but DOE has developed a separate energy conservation standard that will not go into effect until 2015. This standard covers single and polyphase motors, as well as CSIR motors ranging from $1 / 4$ to $3 \mathrm{hp}$.

\subsection{Advanced Motor Technologies and Controls}

As described above, single and three-phase AC induction motors are still frequently used in baseline residential and commercial products. However, many of the motor-driven products and equipment in these sectors could benefit from the use of more efficient motor technologies or from the use of variable frequency drives to optimize system energy consumption during partload operation. Sections 9.4.1 to 9.4.4 describe these technologies, first by addressing motor drives and controls and their associated advances and then by discussing the technologies that have developed as a result of these advances.

\subsubsection{Variable Frequency Drives}

Electronic speed control of electric motors has become increasingly common as the cost of solidstate power electronics decreases. Devices providing speed control have a variety of names, including:

- Inverter drives

- Adjustable speed drives

- Variable speed drive (VSDs)

- Variable frequency drives (VFDs)

- Vector control drives.

The name often varies with the type of motor paired with the device. For example, the term VFD is typically associated with three-phase AC induction motors. While variable speed control devices are not all identical, the primary principles of operation remain the same. This section of the report refers to variable frequency control devices generically as "VFDs" and provides a broad description of their features, efficiency, and application. Any notable differentiation in the construction or operation of a variable frequency control device is addressed in subsequent sections.

Variable loads occur frequently in the commercial and residential sectors. Three-phase induction motors are often paired with variable speed drives for use with fans, compressors, and pumps in commercial and industrial applications. Boiler-feed circulator pumps provide a common example of the benefits of using variable speed motor drives. In conventional designs with fixed-speed motors, pumps are oversized to ensure they can handle the maximum expected load or accommodate any future increase of system capacity. By using a variable frequency drive, motor speed can be adjusted to match the system's actual operating requirements. Due to affinity laws, for pumps, fans, and compressors, the relationship between speed and power is such that a $10 \%$ reduction in speed generally results in $30 \%$ reduction in power. Therefore, operating pumps, fans, or compressors at lower speeds for longer periods can lead to reduced total energy consumption. Operating at a lower, more continuous speed also eliminates the abrupt 
fluctuations in temperature or flow and other system losses associated with the on/off operation of conventional single-speed systems.

In a true constant load application, adding a VFD could actually decrease overall efficiency due to inefficiencies in the drive itself. Realistically, however, most systems in the residential and commercial sectors could benefit from a variable frequency drive. Systems rarely operate at their designed load due to engineered safety factors, deliberate oversizing by building engineers and operators, or environmental conditions. Figure 9-6 shows how variable speed drive efficiency decreases under part load. The greatest decrease in efficiency occurs at part-load conditions less than $25 \%$ of a drive's rated power output. Near-peak efficiency is achieved for part-load conditions above $25 \%$ of a drive's rated power output.

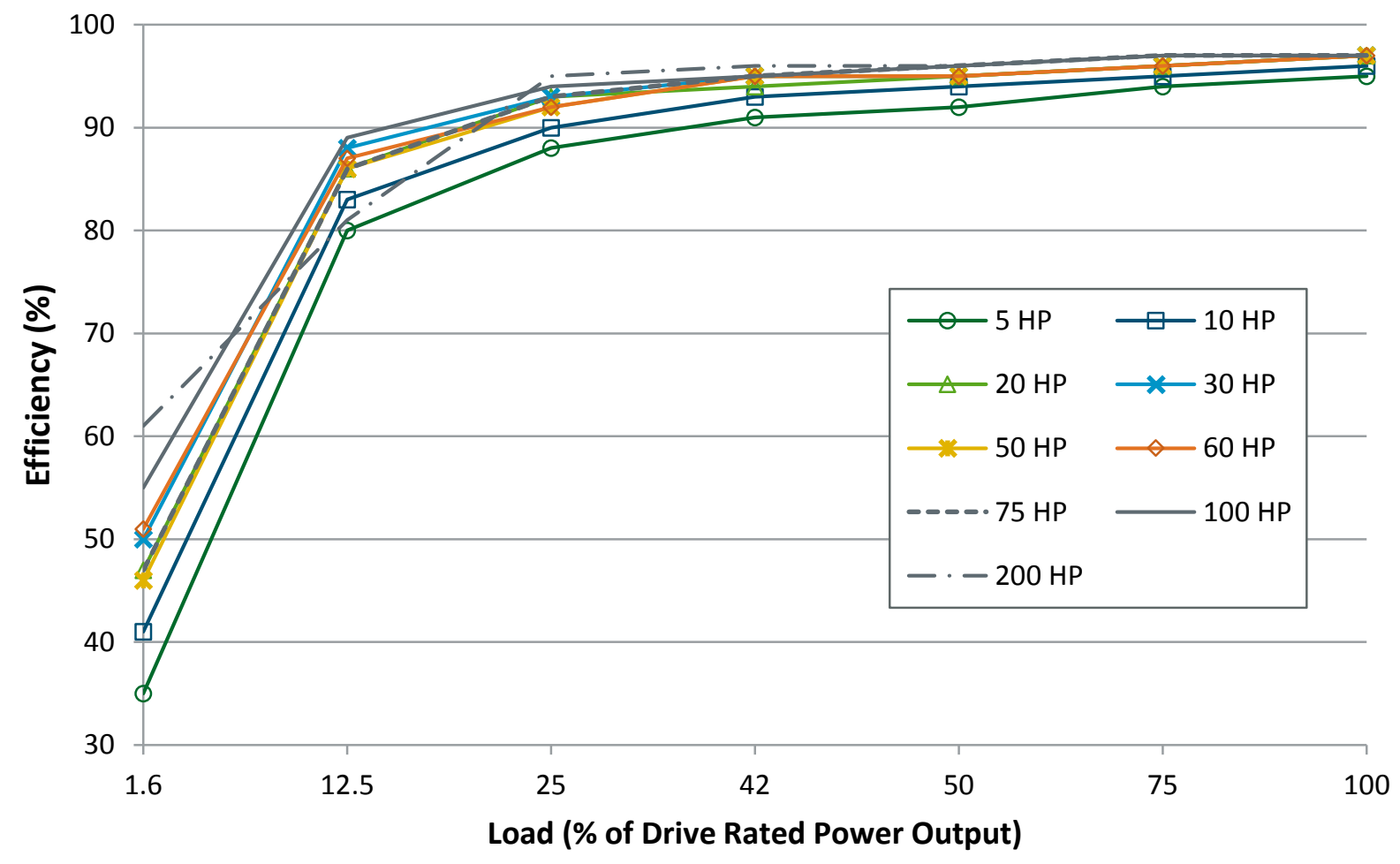

Figure 9-6 Variable Frequency Drive Efficiency at Part Load (DOE AMO, 2012)

A VFD enables the motor to operate at speeds other than the fixed-speed that is determined by the AC line frequency $(60 \mathrm{~Hz}$ in North America) and the number of motor poles. This is achieved by modifying the frequency and voltage input to the motor. VFDs consist of a rectifier to convert the AC line input to DC. A diode bridge or power transistor then modulates the DC output to simulate an AC-like waveform with the frequency and voltage (or current) desired for the motor application. The power transistors use pulse-width modulation (PWM) to create the output waveform by switching the DC supply ON and OFF. By changing the duration of the pulse, the VFD can approximate a sinusoidal waveform for smooth operation. During the ON phase of the pulsation, energy is stored in the motor windings as an inductance and is released during the OFF phase. This configuration ensures that uninterrupted current is supplied to the motor (ADL, 1999). 
The output power transistors used for switching in commercially available VFDs are typically silicon ( $\mathrm{Si}$ ) based insulated-gate bipolar transistors (IGBT) integrated with freewheeling diodes that reduce the impact of voltage fluctuations associated with PWM. While having rated efficiencies of 95-98\%, VFDs with IGBTs have disadvantages that include (Novak, 2009):

- The amount of heat generated by switching operations

- The resulting external cooling costs

- Harmonic current distortions in the simulated sinusoidal waveform.

Additionally, the VFD requires the motor windings to store inductance and may lead to insulation breakdown in the winding or put additional stress on the motor bearings (Wu, 2012).

Recent research suggests that using wide bandgap (WBG) semiconductors in place of conventional semiconductor materials, like silicon, in switches, could improve the performance and efficiency of variable speed drives. Wide bandgap semiconductors have a higher energy gap - the energy range in a solid where no electron states can exist-which allows them to operate at both higher temperatures and higher frequencies. Operation at higher temperatures eliminates the need for external cooling and addresses some issues related to heat generation (Neudeck, 2002). Higher switching frequencies may also result in quieter drives. Converting to WBG materials also has the potential to reduce the overall size of the VFD, which could be beneficial in space-constrained residential or commercial applications (Compound Semiconductor, 2012).

Two WBG materials have been identified for use in VFDs and include:

- $\quad$ Silicon carbide $(\mathrm{SiC})$

- Gallium nitride $(\mathrm{GaN})$.

SiC-based diodes were first used over a decade ago but have proven difficult to manufacture. $\mathrm{GaN}$ transistors may be easier and less costly to manufacture, but both $\mathrm{SiC}$ and $\mathrm{GaN}$ devices remain significantly more expensive than silicon-based IGBTs. Furthermore, the reliability of WBG materials is unknown. Since these devices have yet to operate over the lifetime of a product, little can be said about their long-term or fatigued performance (Compound Semiconductor, 2012). Nevertheless, studies indicate that significant reduction in switching losses could be achieved using WBG semiconductors. Semiconductor manufacturers continue to explore the technology (Palmour, 2006).

One company has shown that GaN high-electron mobility transistors (HEMTs) are more efficient than IGBTs when used in variable speed drives. The high PWM frequency available to GaN HEMTs can produce a smooth sinusoidal current with fewer harmonic disturbances that is more efficient than IGBT output. GaN HEMTs also eliminate the need for freewheeling diodes. This could prolong motor life by limiting inductances in the motor windings and wear on motor bearings (Wu, 2012).

The widespread adoption of VFDs has been limited in part by the additional cost of the components required to implement them. VFDs also require the design and implementation of control algorithms. Although more recent variable speed motor systems with integrated controls 
may reduce the complexity of implementing VFDs, many applications will require that system manufacturers have controls expertise to properly incorporate variable speed control into their equipment. Historically, this has been a barrier limiting the rapid adoption of variable speed motor technologies.

\subsubsection{Permanent-Magnet Motors}

Permanent magnet motors continue to gain popularity as a more efficient alternative to AC induction motors. This increase in popularity is largely due to a decrease in costs associated with electronic control, as discussed above. Instead of using conductive material in the rotor, permanent magnets are integrated into the rotor's laminations or fixed to the rotor's outer surface and do not need to be energized. The magnetic field established by the permanent magnets interacts with the field produced by windings in the stator to generate a torque. Permanent magnet motors are synchronous, meaning that no slip is required for the motor to operate. Rather, the phase of the stator windings is switched, or commutated, to align the stator's field with the magnetic poles of the rotor. To maintain this alignment and rotor rotation, commutation must be timed using feedback of the rotor's position.

Permanent magnet motors operate using principles similar to those of brushed DC motors, although a major difference is that the electronic commutation of permanent magnet motors eliminates the need for manual commutation classically provided by carbon brushes. Electronic commutation not only improves the efficiency of the motor but extends its life by eliminating the need to maintain or replace the brushes, which wear down over time. The similarity to brushed motor operation has lead permanent magnet motors to be synonymous with the name "brushless DC" (BLDC). The term permanent magnet motor can also refer to permanent magnet AC (PMAC) motors which are similar in configuration to squirrel cage induction motors but that have permanent magnet rotors that eliminate slip and rotate at synchronous speed. However, because they operate at synchronous speed, PMAC motors require a VFD to provide a start to rotation. The terms BLDC and PMAC are sometimes erroneously used interchangeably, as both types are have permanent magnet rotors and use AC line input power.

Electronic commutation of permanent magnet motors can be achieved using a rotary encoder, sensors, or "sensorless" configurations. A common technique to determine rotor position (in brushless DC permanent magnet motors) is to use three Hall-effect sensors (position sensors) embedded in the stator. When a rotor pole passes a sensor, the sensor's output voltage increases or decreases in response. The combined response of all three sensors in the stator is used to calculate their position relative to the rotor. Another commutation technique utilizes the inherent counter-electromotive force, or back EMF, of the motor to derive position. Back EMF is a voltage that results from motion of an electromagnetic field. The interaction between back EMF and applied voltage leads to a drop in overall voltage. Back EMF is dependent on the angular velocity of the rotor and increases proportionally with rotor speed. Thus, the back EMF can be estimated using known motor properties to provide a form of "sensorless" control. Benefits of "sensorless" control include reduced number of components and potentially reduced cost (Blackburn, 2012).

Despite their similarities, BLDC and PMAC motors contain subtle differences in their control schemes. BLDC motors have a more trapezoidal-shaped back EMF while PMAC motors have a 
sinusoidal back EMF. Factors contributing to this difference in shape include the geometry of the rotor, the distribution of windings in the stator, and the stator core geometry. Additionally, the shape of the back EMF produced by the motor should ideally match the shape of the waveform driving the motor. A square-wave commutation typically drives a BLDC motor, while a threephase sinusoidal commutation drives a PMAC type motor. Although the torque density provided by either type of motor and drive configuration is similar, there is some advantage to using a sinusoidally driven PMAC motor, as torque ripple is minimized (Colton, 2010). Other than its impact on efficiency, torque ripple can contribute to acoustic noise, which is undesirable in many residential and commercial applications.

Permanent magnet motors are typically more efficient than alternatives for a variety of reasons. Because permanent magnet motors do not require current to be induced in rotor windings, overall power consumption can be reduced compared to induction motors. The elimination of brushes for commutation also contributes to increased efficiency, reliability, and longevity as described above. Furthermore, because permanent magnet motors have either integrated controls or are paired with drives, they are ideal for use in applications with varied loads. Permanent magnet motors tend to have a more constant efficiency over a range of speeds instead of a high peak efficiency at a single speed.

The magnets used in permanent magnet motors are typically made of rare-earth metals, the most common being an alloy of neodymium, iron, and boron. Rare-earth based magnets can have a magnetic strength up to 2 times more powerful than more typical ferrite based magnets (Murphy). Rare-earth metals, while rare only in name, are difficult to mine and fabricate into components. They are also only found in limited quantities at a given site. Over $90 \%$ of the world's rare-earth metals are supplied by China. Small fluctuations in the Chinese supply, often due to environmental or geopolitical factors, can greatly impact the cost of these magnets and thus the cost of permanent magnet motors. To address issues associated with dependency on foreign materials, the US Department of Energy (DOE) has begun funding research into alternatives, including motor designs that utilize magnets of lesser strength, as well as motor designs that do not employ permanent magnets but offer efficiencies similar to that of permanent magnet motors (Witkin, 2012).

Permanent magnet motors can be more efficient than induction motors by up to 10 percentage points, especially during part-load operation (ADL, 1999). As discussed in previous sections, the design of an asynchronous AC induction motor is inherently less efficient than a permanent magnet motor due to motor slip. However, induction motors do not contain rare-earth metals and are thus both lower cost and more readily available. A number of equipment manufacturers use variable speed $\mathrm{AC}$ induction motors in their three-phase power equipment for the commercial sector.

\subsubsection{Electronically Commutated Motors (ECMs) with Integrated Controls}

The term electronically commutated motor (ECM) is another term commonly used for permanent magnet motors described above, but it has a more specific connotation. In general, ECMs refer to low horsepower BLDC motors that have integrated drives and controls and are commonly found in HVAC applications. This makes the ECM ideal for use in existing residential and commercial designs that require a compact and simple motor and control package. In HVAC airflow 
applications, for example, ECMs can be programmed to operate over a broad range of speeds and deliver constant airflow for a variety of external static pressures.

ECMs are often sought as more efficient replacements to PSC induction motors. As discussed in section 9.1.4, PSC motors are generally considered single-speed devices and manufacturers use speed taps so that installers can manually adjust the motor to meet changing system conditions. Even in a reduced-speed arrangement, PSCs consume more energy than ECMs. The range of efficiency for PSCs is very broad, for example 35-50\% in airflow applications, especially when operating at less than full load. ECMs can have a more narrow range of efficiency over different speeds, typically around $70 \%$ for motors that have fractional horsepower and above $80 \%$ for those at integral horsepower (Blackburn, 2012).

Although the cost of ECM technology continues to decrease as it is incorporated into more highefficiency products, ECMs remain more expensive than PSC motors. To address this, some manufacturers offer an intermediate device often called a "constant torque ECM." The constanttorque ECM is still a permanent magnet motor, but it is designed to provide constant torque as opposed to constant speed or airflow. Whereas ECMs can increase or decrease torque to provide desired speed or airflow, constant torque ECMs maintain torque as environmental factors change. Constant torque ECMs may be preferred to PSCs because their permanent magnet configuration makes them more efficient (Michael, 2009).

Constant torque motors may also be easier to integrate into existing products than standard ECMs. Because equipment manufacturers and installers are comfortable with the speed tap configuration of PSCs or lack the expertise to implement the control schemes necessary for optimal operation of ECMs, constant torque ECMs also employ a speed tap interface. Instead of providing reduced speed, the "speed taps" of the constant torque ECM correspond to various programmed levels of torque to meet the desired operating condition (Michael, 2009). The speed tap interface limits the range of operation compared to standard ECMs but still provides a lower cost, more-efficient alternative to PSCs.

\subsubsection{Switched-Reluctance Motors (SRMs)}

A mechanically commutated version of the switched reluctance motor (SRM) predates both DC electric motors and AC induction motors. However, issues associated with control, acoustic noise, and torque ripple made the motor unsuitable for many applications, especially those where quiet operation is important. With advances in variable frequency drives (as discussed in Section 9.4), digital signal processing, and other software-based control solutions, SRMs are again becoming a viable alternative to other motor types with peak efficiencies comparable to ECMs, up to $90 \%$ for integral horsepower devices (Teschler, 2008). Interest in SRMs has also increased as these motors do not rely on permanent magnets, and thus do not contain rare-earth metals.

The stator in a switched reluctance motor is configured much like a permanent magnet motor and has copper windings establishing the magnetic poles. The rotor consists of steel laminations with no windings or permanent magnets. The rotor laminations are cut in such a way that the steel protrusions act as magnetic poles; this configuration exploits the concept of "magnetic reluctance," in which magnetic flux will follow the path of least magnetic resistance in the presence of a magnetic field. When the stator windings are energized, the magnetic reluctance of 
the rotor in this geometrical configuration results in a force that aligns the rotor poles with those of the stator. The stator windings are energized in sequence to maintain rotation of the rotor via a switching action provided by a VFD. Like permanent magnet motors, position feedback is required to time the stator switching operations with that of the rotor. To sustain rotation, the number of poles in the stator and the number of poles in the rotor are mismatched. Typically, the number of poles in the stator is higher than in the rotor. This mismatch ensures the SRM will always have a starting torque equivalent to its operational torque (Jin-Woo Ahn, 2011).

Due to their simple design and use of readily available materials, SRMs can be easier to manufacture than AC induction motors or permanent magnet motors. This also means that the manufacturing processes and equipment that already exist can be leveraged to bring SRM production up to scale so that SRMs may become competitive with longstanding motor alternatives. Additionally, SRMs can be made smaller and more compact than AC induction motors. The robustness of SRMs make them ideal for high-temperature applications, where permanent magnets rotors run the risk of being demagnetized (Wai-Chuen Gan, 2008).

Historically, reliance on the rotor's magnetic reluctance has resulted in non-linear motor operation, preventing commercially available VFDs from being suitable for use with SRMs without modification. Lack of compatibility with commercial VFDs has been a major factor preventing the SRM from being widely implemented (Wai-Chuen Gan, 2008). A variety of companies and researchers have proposed solutions to this problem, and the decreasing cost of controls will also supplement SRM-tailored VFD availability. Other factors contributing to the unpopularity of SRMs include:

- High torque ripple

- The acoustic noise and vibration that result from the switching algorithms

- The geometrical configuration of the rotor.

Traditionally, SRMs were used in the transportation industry, because at high speeds, the motors retain torque longer than a permanent-magnet motor. At high speeds, permanent magnet motors must implement field weakening to prevent back EMF from interfering with motor input power (Teschler, 2008). For electric vehicles, SRMs can act as generators so that slowing rotation increases the stored energy in the magnetic field, which can then be used to supply another load.

Currently, manufacturers are investigating SRMs for use in appliances. SRMs and drive systems have been applied to vacuum cleaners, washing machines, and laboratory centrifuges. One manufacturer produces industrial-size SRMs for compressors and high-speed pumps as well as low-speed, high-torque applications like conveyors and extruders (Bartos, 2010). To address the issues of acoustic noise and torque ripple, start-up companies and universities have expressed interest in high rotor-pole technology, where the number of the poles in the rotor is greater than the number of poles in the stator. This reduces the angular travel of the rotor per excitation and addresses issues related to torque ripple (HEVT, LLC, 2013).

\subsection{Future Innovations in Motor Technology}

A number of innovations have occurred in the area of electric motors and variable speed drives, outside the increased interest in switched reluctance motors as mentioned in Section 9.4.4. 
Although manufacturers have only begun in the last decade to use permanent magnet and other high-efficiency motor drive combinations as standard components, the motivation to find ECM replacements has increased as a result of concerns about the availability and cost of rare-earth metals.

A range of projects at early-stage companies are investigating rare-earth replacements or alternative motor configurations that retain the efficiency of permanent magnet motors without the cost or constraints of rare-earths. The DOE's Advanced Research Projects Agency-Energy (ARPA-E) Rare Earth Alternatives in Critical Technologies (REACT) initiative has spurred research in rare-earth alternatives. One possible option is to substitute neodymium with a more abundant and less expensive rare-earth metal, cerium (Witkin, 2012). Much of the research associated with rare-earths has been for application in electric vehicles, or industrial integral horsepower motors, but not for home appliances or commercial buildings. However, some companies are exploring the economics of producing these alternatives at the size and scale required for residential or commercial implementation ${ }^{213}$.

Other innovations include changes in rotor and stator geometry that result in increased magnetic field strength and more efficient torque output (Jones, 2011). Patents on various technologies claim it is possible to use lower-strength magnetic materials (ferrite) in combination with unique air-gap and winding configurations to boost the magnetic properties of the lower-strength material. Like SRMs, these motors use only steel laminations in the rotor, and employ windings and magnetic material in the stator (Flynn et al.)

Finally, motor manufacturers continue to research and develop lower-cost manufacturing techniques so that motors of all types and variable speed drives can be produced as cheaply as possible. For many of the motor alternatives discussed above to be cost competitive, they must be simple to manufacture, even if the material composition is inherently less expensive.

${ }^{213}$ Phone interview with CEO at motor technology startup. 


\section{References Cited in Appendices}

\section{Table 10-1: References used in the Appendices A through E}

\section{References: Appendices A-E}

Appliance magazine, 2013. "2012 Full-Year Appliance Industry Shipment Statistics \& Year-in-Review," Appliance Magazine, March 2013.

APSP, 2013. "Industry Statistics," The Association of Pool \& Spa Professionals. 2013.

http://apsp.org/resources/research/industry-statistics.aspx

ASHRAE, 2011. "Less Pumping means Cooler Ground Loops," ASHRAE Journal, 2011.

https://www.ashrae.org/File\%20Library/docLib/Journal\%20Documents/2011\%20July/026-035_kavanaugh.pdf

ASRAC Pumps Working Group, 2015. DOE. “ASRAC Pumps Working Group Scope” - Slides from Commercial/Industrial Pumps Working Group. Accessed Feb 2015. http://www.regulations.gov/\#!documentDetail;D=EERE-2013-BT-NOC-0039-0037

BTO Motors Report, 2013. "Energy Savings Potential and Opportunities for High-Efficiency Electric Motors in Residential and Commercial Equipment," prepared by Navigant Consulting Inc. for BTO, December 2013.

http://www1.eere.energy.gov/library/viewdetails.aspx?productid=6746\&page $=2$

DOE, 2007. Technical Support Document: Energy Efficiency Program for Consumer Products: Energy Conservation Standards for Residential Furnaces and Boilers. September 2007

DOE, 2009a. Technical Support Document Impacts on the Nation of the Energy Independence and Security Act of 2007. March 2009 SPVU

DOE, 2009b. Final Rule Technical Support Document: Energy Efficiency Standards for Commercial and Industrial Equipment: Refrigerated Bottled or Canned Beverage Vending Machines. August 2009

DOE, 2010. Preliminary Technical Support Document: Energy Conservation Program for Certain Commercial and Industrial Equipment: Walk-in Coolers and Walk-in Freezers. April 2010

DOE, 2011a. Preliminary Technical Support Document: Energy Conservation Program for Certain Commercial and Industrial Equipment: Commercial Refrigeration Equipment. March 2011

DOE, 2011b. Technical Support Document: Energy Efficiency Program for Consumer Products and Commercial and Industrial Equipment: Residential Clothes Dryers and Room Air Conditioners. April 2011

DOE, 2011c. Technical Support Document: Energy Efficiency Program for Consumer Products: Residential Central Air Conditioners, Heat Pumps, and Furnaces. June 2011

DOE, 2011d. Technical Support Document: Energy Efficiency Program for Consumer Products: Residential Refrigerators, Refrigerator-Freezers, and Freezers. August 2011

DOE, 2012a. Preliminary Analysis Technical Support Document: Energy Efficiency Standards for Automatic Commercial Ice Makers. January 2012

DOE, 2012b. Technical Support Document: Energy Efficiency Program for Consumer Products and Commercial and Industrial Equipment: Residential Clothes Washers. April 2012

DOE, 2012c. Technical Support Document: Packaged Terminal Air Conditioners and Heat Pumps Energy Conservation Standard Final Rule. April 2012

DOE, 2012d. Technical Support Document: Energy Efficiency Program for Consumer Products and Commercial and Industrial Equipment: Residential Dishwashers. May 2012

DOE, 2012e. Technical Support Document: Energy Efficiency Program for Consumer Products and Commercial and Industrial Equipment: Commercial Heating, Air Conditioning, and Water Heating Equipment. July 2012

DOE, 2013. Energy Conservation Standards Rulemaking Framework Document for Ceiling Fans and Ceiling Fan Light Kits. March 2013 


\section{References: Appendices A-E}

DOE, 2014a. Technical Support Document: Energy Efficiency Program for Consumer Products and Commercial and Industrial Equipment: Residential Furnace Fans. June 2014

DOE, 2014b. Preliminary Analysis Technical Support Document: Commercial Packaged Boilers. November 2014. http://www.regulations.gov/\#!docketDetail;D=EERE-2013-BT-STD-0030

DOE, 2014c. NOPR - Technical Support Document: Energy Efficiency Standards for Commercial and Industrial Equipment: Commercial and Industrial Pumps. October 2014. http://www.regulations.gov/\#!docketDetail;D=EERE-2011-BT-STD-0031

DOE, 2014d. National Impact Analysis and Life Cycle Cost Analysis - Rulemaking for Commercial and Industrial Pumps. March 2015. http://www.regulations.gov/\#!docketDetail;D=EERE-2011-BT-STD-0031

DOE, 2014e. Technical Support Document: Energy Efficiency Program for Consumer Products and Commercial and Industrial Equipment: Commercial Clothes Washers. December 2014.

DOE, 2014f. Preliminary Analysis - Technical Support Document: Energy Efficiency Program for Consumer Products and Commercial and Industrial Equipment: Ceiling Fans. September 2014

DOE, 2014g. Preliminary Analysis - Technical Support Document: Energy Efficiency Program for Consumer Products and Commercial and Industrial Equipment: Residential Dehumidifiers. May 2014.

DOE, 2014h. Technical Support Document: Energy Efficiency Program for Consumer Products and Commercial and Industrial Equipment: Automatic Commercial Ice Makers. December 2014.

DOE, 2014i. NODA Technical Support Document: Energy Efficiency Program for Consumer Products: Energy Conservation Standards for Residential Boilers. February 2014.

DOE, 2015a. Technical Support Document: Energy Efficiency Standards for Commercial and Industrial Equipment: Commercial Warm Air Furnaces. January 2015

DOE, 2015b. National Impact Analysis and Life Cycle Cost Analysis - Rulemaking for Commercial and Industrial Fans and Blowers. Accessed Feb 2015. http://www1.eere.energy.gov/buildings/appliance_standards/rulemaking.aspx/ruleid/25.

DOE-ADL 1999. "Opportunities for Energy Savings in Residential and Commercial Sectors with high-Efficiency Electric Motors." Prepared by Arthur D. Little, Inc. for DOE, 1999. http://www.totalenergycompany.com/pdf/Motor_Efficiency_DOE1999.pdf.

EPA, 2011. "Pool and Sump Pumps; Residential Market and Industry Scoping Report," ENERGY STAR. April 2011.

EPA, 2013. "ENERGY STAR Unit Shipment and Market Penetration Report Calendar Year 2013 Summary," EPA. 2013. https://www.energystar.gov/ia/partners/downloads/unit_shipment_data/2013_USD_Summary_Report.pdf?e464-9585

Nav Research 2013. "Geothermal Heat Pumps," Navigant Research. 3Q 2013.

http://www.navigantresearch.com/research/geothermal-heat-pumps

PG\&E, 2004a. "Analysis of Standards Options for Whole House Fans," PG\&E. April 2004.

http://www.energy.ca.gov/appliances/2003rulemaking/documents/case_studies/CASE_Whole_House_Fans.pdf

PG\&E, 2004b. "Analysis of Standards Options for Residential Exhaust Fans," PG\&E. April 2004.

http://www.energy.ca.gov/appliances/archive/2004rulemaking/documents/case_studies/CASE_Res_Exhaust_Fans.pdf

RASS, 2009. "Residential Appliance Saturation Study," California Energy Commission. 2009.

SEIA, 2015. "Solar Heating and Cooling: Economics and Growth," Solar Energy Industries Association. Accessed 2014.

http://www.seia.org/research-resources/solar-heating-cooling-economics-growth

Smyrna, 2014. "Appliance Usage Calculator," Smyrna, Delaware. Accessed 2014.

http://www.smyrna.delaware.gov/DocumentCenter/Home/View/1284

Spectra Light, 2015. Website accessed March 2015. http://www.spectralightuv.com/eco-pool-pump.html

USCB, 2008. "American Housing Survey for the United States: 2007," USCB. September 2008.

http://www.census.gov/prod/2008pubs/h150-07.pdf 
Table 10-2: References used in Appendix F

\section{References: Appendix F}

ADL, 1999. Arthur D. Little, Inc. (ADL). 1999. "Opportunities for Energy Savings in the Residential and Commercial Sectors with High-Efficiency Electric Motors." December 1, 1999.

Baldwin, 2012. "Industry could take a shine to Copper-Rotor Motors," Machine Design. September 6, 2012. Retrieved from http://machinedesign.com/news/industry-could-take-shine-copper-rotor-motors

Bartos, Frank J. 2010. "Resurgence for SR Motors, Drives?" Control Engineering. March 01, 2010. Retrieved from http://m.controleng.com/index.php?id=2819\&tx_ttnews\%5Btt_news\%5D

Blackburn, Herschel. 2012. "Refrigeration Motors and Motor Efficiencies." Appliance Design. January 1, 2012. Retrieved from http://www.appliancedesign.com/articles/92844-refrigeration-motors-and-motor-efficiencies

Colton, Shane W. 2010. "Design and Prototyping Methods for brushless Motors and Motor Control." Massachusetts Institute of Technology, Department of Mechanical Engineering. May 7, 2010. Retrieved from http://web.mit.edu/scolton/www/SCThG.pdf

Compound Semiconductor. 2012. "SiC and GaN Electronics: Where, When and How Big?" July 27, 2012. Retrieved from http://www.compoundsemiconductor.net/csc/features-details/19735293/SiC-and-GaN-electronics:-Where,-when-and-howbig.html

Fans \& Blowers Twin City. "Fan Engineering Single-Phase AC Induction Squirrel Cage Motors." Retrieved from http://www.tcf.com/docs/fan-engineering-letters/single-phase-ac-induction-squirrel-cage-motors---fe1100.pdf?Status=Master

Flynn, C Joseph et al. "Evaluating Parallel Path Magnetic Technology Motors and Conventional Motors by Their Performance Curves." Retrieved from http://www.qmpower.com/UserFiles/ File/White_Paper_Variable_Speed_Motor_Applications.pdf

GRUNDFOS Management A/S. 2004. "Grundfos Motor Book." 2004. Retrieved from http://us.grundfos.com/content/dam/Global\%20Site/Industries\%20\%26\%20solutions/waterutility/pdf/motorbook.pdf

Heinecke, Kevin. "Single-phase Electric Motors: Characteristics \& Applications." LEESON Electric Corporation. Retrieved from http://www.leeson.com/Technicallnformation/sphase.html

HEVT, LLC. 2013. Cleantech Open Presentation. Retrieved from http://www.cleantech.com/wpcontent/uploads/2013/03/HEVT-Presentation.pdf

Hughes, Austin et al. 2013 “Electric Motors and Drives, Fourth Edition.” Waltham, MA: Elsevier 2013. Print.

Jin-Woo Ahn. 2011. "Switched Reluctance Motor, Torque Control." Prof. Moulay Tahar Lamchich (Ed.), ISBN: 978-953-307428-3, InTech, Retrieved from http://cdn.intechopen.com/pdfs/13717/InTech-Switched_reluctance_motor.pdf

Jones, Dan. 2011. "HVAC Moves Toward Higher Efficiency ECMs.” Appliance Design. June 30, 2011. Retrieved from http://www.appliancedesign.com/articles/92754-hvac-moves-toward-higher-efficiency-ecm-motors?v=preview

Mechler, 2010. "Manufacturing and Cost Analysis for Aluminum and Copper Die Cast Induction Motors for GM's Powertrain and R\&D Divisions," Massachusetts Institute of Technology. September 2010.

Michael, Brian. 2009. “Comparing Motor Technologies." November 23, 2009. Retrieved from

http://www.achrnews.com/articles/comparing-motor-technologies-1

Murphy, Jim. "Understanding AC induction, permanent magnet and servo motor technologies: operation, capabilities and caveats." LEESON Electric Corp., Grafton, Wis. Retrieved from

http://www.cmafh.com/WebsiteCatalogs/VendorVideos/TechnicalDropDown/Electrical/Understanding\%20Electric\%20Motor s.pdf

National Electrical Manufacturers Association (NEMA). 2001. NEMA Standards Publication MG 10-2001, "Energy management Guide For Selection and Use of Fixed Frequency medium AC Squirrel-Cage Polyphase Induction Motors." 2001. Retrieved from http://www.conae.gob.mx/work/sites/CONAE/resources/LocalContent/2391/1/images/MG10.pdf

Neudeck, Philip G. et al. 2002. "High-Temperature Electronics - A Role for Wide Bandgap Semiconductors?" Proceedings of the IEEE Vol. 90, No. 6, 1065-1076. June 2002. 


\section{References: Appendix F}

Novak, Peter. 2009. “The Basics of Variable-Frequency Drives.” Electrical Construction \& Maintenance (EC\&M). May 1, 2009. Retrieved from http://ecmweb.com/power-quality/basics-variable-frequency-drives

Palmour, John W. 2006. "Energy Efficient Wide Bandgap Devices." IEEE 2006. Retrieved from: http://www.cree.com/ /media/Files/Cree/RF/Papers\%20and\%20Articles/Energy_Efficient_Wide_Bandgap_Devices.pdf

Tecumseh. "Compressor Motor and Component Information." Retrieved from http://www.hvacrinfo.com/Tecumseh_bulletins/compressor.pdf

Teschler, Leland. 2008. "The Switch to Switched Reluctance." Machine Design. December 12, 2008. Retrieved from http://machinedesign.com/article/the-switch-to-switched-reluctance-1211

Wai-Chuen Gan et al. 2008. "Application of Linear Switched Reluctance Motors to Precision Position Control." Asian Power Electronics Journal, Vol. 2, No. 1, April 2008. Retrieved from http://repository.lib.polyu.edu.hk/jspui/bitstream/10397/1578/1/APEJ_2_1_31-36.pdf

Witkin, Jim. 2012. "A Push to Make Motors With Fewer Rare Earths." New York Times. April 20, 2012. Retrieved from http://www.nytimes.com/2012/04/22/automobiles/a-push-to-make-motors-with-fewer-rare-

earths.html?_r=5\&pagewanted=all\& 
